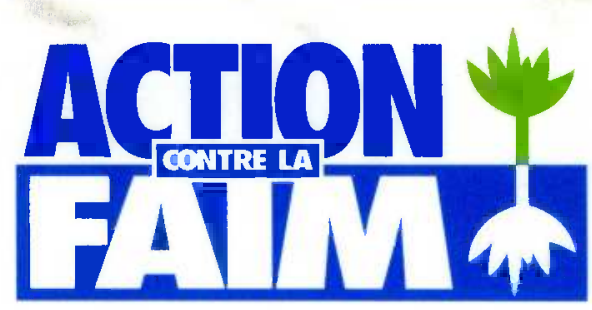

NUTRITION, HEALTH AND FOOD SECURITY ASSESSMENT

for the

HAZARAJAT, AFGHANISTAN

Action contre la faim

Final Report

Oct.1998

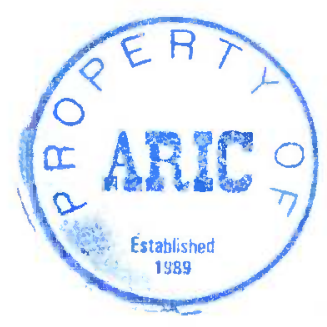

Lisa Zarrabi

Iesha Singh

Nutrition Department

Food Security Department 


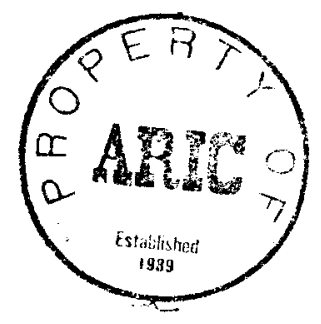

NUTRITION, HEALTH AND FOOD SECURITY ASSESSMENT

for the

HAZARAJAT, AFGHANISTAN

Action contre la faim

Final Report

Oct.1998 
The study could not have been carried out without the contributions of Ahmad, Farid, Ismail, Latif and Najib who were essential in providing the link between ourselves and the community about whom and with whom we wished to learn. They all worked hard under conditions not always amenable and often tiring.

A further huge thanks must go to Ben Hell (Country Director for Afghanistan and Agronomist), together with Christel Braconnot (Nurse/Nutritionist), and Monique Lhussier (Medical CoOrdinator). Their technical support, later backed-up by that of Barnaby Peacock (Food Security), and Claudine Prudhon (Nutrition), in Paris, as well as Frances Mason (Nutrition/Food Security), in London, was essential to the report.

Lastly, the study could not have been undertaken without the logistical support of Herve Bertois, who facilitated our passage through the Hazarajat - and our foodstocks! 
Part I: Resume of Main Study Findings

- Nutrition and Health

- Food Security

- Cause and Effect Diagrams

- Summary According to Zone

\section{Part II: Introduction}

- Objectives (Nutrition and Health; Food Security; the Link)

- Report Layout

Part III: Materials and Methods

- Zone Selection

- Timetable

- Nutrition and Health

- Food Security

\section{Part IV: Macro to Micro Context}

- The Natural Environment (Geo-Topography; Climatology)

- Ecological Zones Identified and Assessed

- Historical Background (Formation, Consolidation and 'Development' of the Afghan State, Soviet Occupation and the Jihaad, To Date: Political Fragmentation, the Taliban and the Future)

- Development in Perspective - Development in Crisis (Demographic Growth, Population Movements, Family Size, Food Production and Dependencies, Education, Health, Financial Management)

- Political Economy (Trade, Power and Internationalism; The State, Development and Autonomy; Community Patterns of Organisation, Identity and Social Control) ${ }^{1}$

- Expressions of Socio-Cultural Norms and Vahues (Intra-Community Support Mechanisms, Important Festivals Reaffirming Community Cohesion) ${ }^{2}$

- Seven Household Types

\section{Part V: Nutrition Situation and Health}

- Production/Consumption Possibilities (By Zone; By Household Type) 45

- Vulnerability Thresholds by Zone

- Diets

\section{Part VI: Nutrition and Health Technical Section}

- Introduction

- Results

- Health

- Health Facilities Available

- Education

\footnotetext{
${ }^{1}$ For a fuller analysis of these subjects, please refer to Appendix Il.

${ }^{2}$ For a more detailed analysis of gender issues, please refer to Appendix III.
} 
Part VII: Food Security Technical Section

- Introduction

- Agricultural Systems (Ecological and Demographic Constraints; Land Ownership Constraints; Agricultural Patterns; Agricultural Tools)

- Water Sources and Irrigation Systems for Agricultural Purposes

- Livestock and Poultry Systems (Ecological Constraints; Land Ownership Constraints; Management and Production Patterns)

- Fuel Collection and Consumption

- Labour Calendars

Part VIII: Conclusions and Recommendations

- Nutrition and Health

- Food Security

Part IX: Appendices

- For Part III

- For Part IV

- For Part VI

- For Part VII 


\section{A. NUTRITION AND HEALTH:}

$\begin{array}{ll}\text { Date: } & \text { June/July } 1998 \\ \text { Target population: } & \text { Children aged 0-59 months }(\leq 110 \mathrm{~cm}) \\ \text { Methodology: } & \text { Screening } \\ \text { Sample size } & 969 \text { children }\end{array}$

\section{Context:}

The blockade imposed by the Talêban in the Hazarajat area has now been in force for over a year, putting pressure on the supply routes of the Hazarajat, with the potential of causing a worsening food security problem. Trade now takes place through smuggling and prices have, as a result, increased dramatically. In addition, there are harsh climatic conditions and a lack of health facilities to contend with.

Action contre la faim decided to conduct a nutrition, vaccination and mortality survey in the Central Highland Region - the Hazarajat. In addition, information was gathered on the general living conditions of people, including health services available, most common diseases and causes of death (amongst women and children) and diet. This information was gathered in order to determine the needs, in terms of health services and nutrition, by assessing the health and nutritional status of the under 5 years population.

The assessment was based on the collection of anthropometric measurements of approximately 970 children (aged 0-5 years) over a one month period.

Although a previous survey was carried out in the Bamiyan area prior to this survey, the Upper Valley region was not included. In view of this, Bamiyan Upper Valley was included in this survey.

\section{Results:}

Table 1: Overall acute malnutrition prevalence in children aged 6-59 months, the Hazarajat, June/July 1998

\begin{tabular}{lccc}
\hline MALNUTRITION & SEVERE (<-3SD) & MODERATE (<-2 and >-3SD) & GLOBAL (<-2SD) \\
\hline Z-Score & $\mathbf{0 . 3 \%}$ & $\mathbf{4 . 7 \%}$ & $\mathbf{5 . 0 \%}$ \\
$95 \%$ Confidence Interval $(0.1-1.1 \%)$ & $(3.6-5.7 \%)$ & $(3.7-6.8 \%)$ \\
& & & \\
\% of the median & $\mathbf{0 . 1 \%}$ & $\mathbf{2 . 7 \%}$ & $\mathbf{2 . 8 \%}$ \\
$95 \%$ Confidence Interval $(-0.0-1.3 \%)$ & $(1.8-2.9 \%)$ & $(1.8-4.2 \%)$ \\
\hline
\end{tabular}

\footnotetext{
${ }^{3}$ See Appendices for Part III: Appendix I for definition of nutritional status.
} 
Table 2: Overall acute malnutrition prevalence in children 0-5 months, the Hazarajat, June/July 1998

\begin{tabular}{lccc} 
MALNUTRITION & SEVERE (<-3SD) & MODERATE (<-2 and >-3SD) & GLOBAL (<-2SD) \\
\hline Z-Score & $\mathbf{0 . 0 \%}$ & $\mathbf{1 . 3 \%}$ & $\mathbf{1 . 3 \%}$ \\
$95 \%$ Confidence Interval $(-0.3-6.0 \%)$ & $(0.1-2.2 \%)$ & $(0.2-8.2 \%)$
\end{tabular}

95\% Confidence Interval $(-0.3-6.0 \%)$

$(0.1-2.2 \%)$

$(0.2-8.2 \%)$

Although the overall results show no real reason for concern in the area, certain areas such as Malestan, do need nutritional attention, since with failed crops and Taleban restrictions, coping
mechanisms are not reaching the needs.

In terms of health care Ajarestan and Nawor are priority. Despite a comparatively good diet, morbidity and mortality are of concern in Ajarestan, particularly concerning mother and child health. In Nawor, vaccinations are the only form of health care in operation and again focus needs to be placed on mother and child health care, both pre and post natal.

Of the total number of $<5$ years old children of families included in the mortality survey (1039), the calculated mortality rate was 0.64 over 10,000 children per day, which is acceptable ${ }^{5}$.

\section{Major recommendations:}

- to set up health facilities were possible, focusing on Mother and Child Health (MCH)

- to concentrate on public awareness of the importance of pre and post natal care, including the involvement of local birth attendants

- to implement a health education programme in order to make the public aware of health matters, including nutrition and vaccinations

- to encourage ongoing and implement where needed, EPI, so that there is a better and more effective coverage of the targeted diseases

- to try and avoid future wasting/stunting in the $<5$ years population by having a monitoring/response system in place, at key points, such as clinics, particularly in the Malestan area, including regular surveys

- to implement a nutritional and health programme in Malestan, working with other organisations present

- to find out through future surveys, why, in most areas, acute malnutrition is greater in boys than in girls aged 6-29 months

- to increase the level micro-nutrient intake by encouraging vegetable growth in kitchen gardens, providing nutrition education and distributing micro-nutrients to mothers and children, from any health structures that may be operational

- to set up a co-ordination body for all agencies involved within each area, so that with collaboration, more efficient and effective programmes may be functional

\section{B. FOOD SECURITY:}

In general, food security issues revolved around both short-term, conjectural circumstances (the blockade of the Hazarajat, followed by Talêban capture), and longer-tern, structural constraints (relating to systems of agriculture and animal husbandry - infrastructure, management techniques and so on), both of which may well decline even further given current events. As a result, any response

\footnotetext{
${ }_{5}^{4}$ See Appendices for Part III: Appendix I for definition of nutritional status. ${ }^{5}$ This is a global figure. For more detail of each region, see Results chapter, or each village, see Appendices for Part
VI: Appendix I.
} 
may well need to be premised on activities covering both short-term needs together with those accenting the mitigation (and where possible, the prevention), of more entrenched vulnerabilities. Recommendations are outlined in the Causal-Effect Charts that follow, together with a Table summarising the zones to be prioritised. For a more detailed breakdown, looking at Household Types and community participation, please see Part VIII: Conclusions and Recommendations.

\section{CAUSE-EFFECT ANALYSIS OF CHRONIC MALNUTRITION} IN THE HAZÂRADJAT, AFGHANISTAN

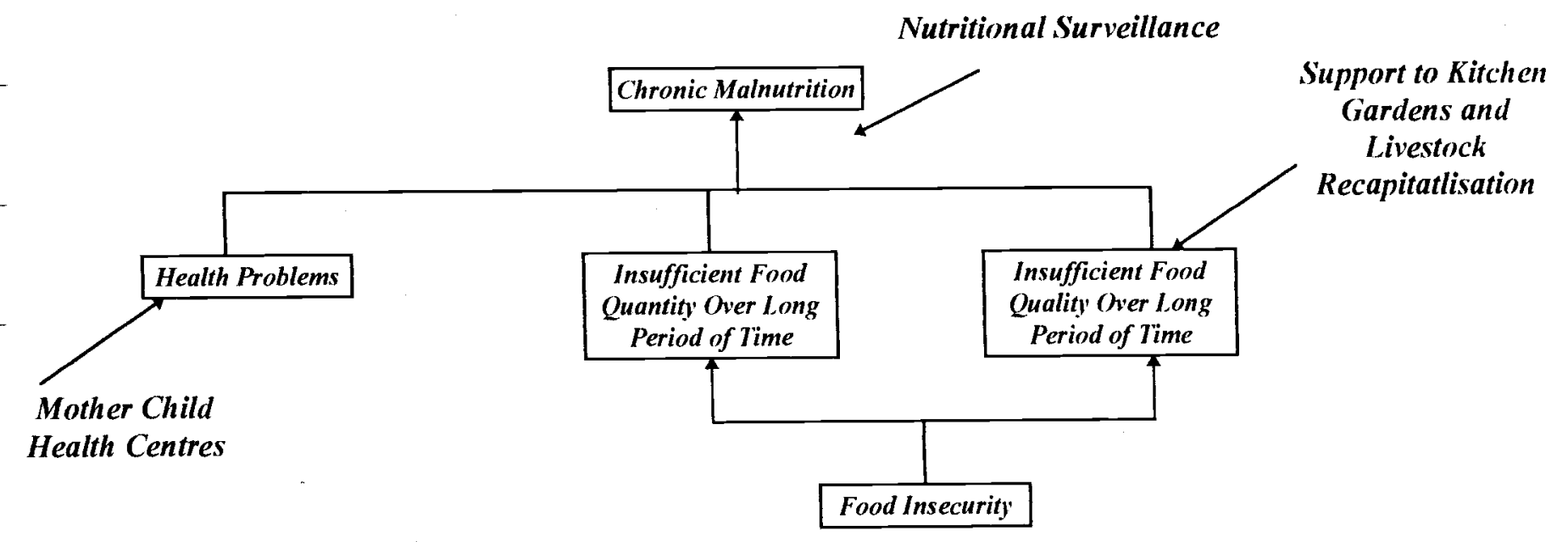

\section{CAUSE-EFFECT ANALYSIS OF HEALTH PROBLEMS \\ IN THE HAZÂRADJAT, AFGHANISTAN}

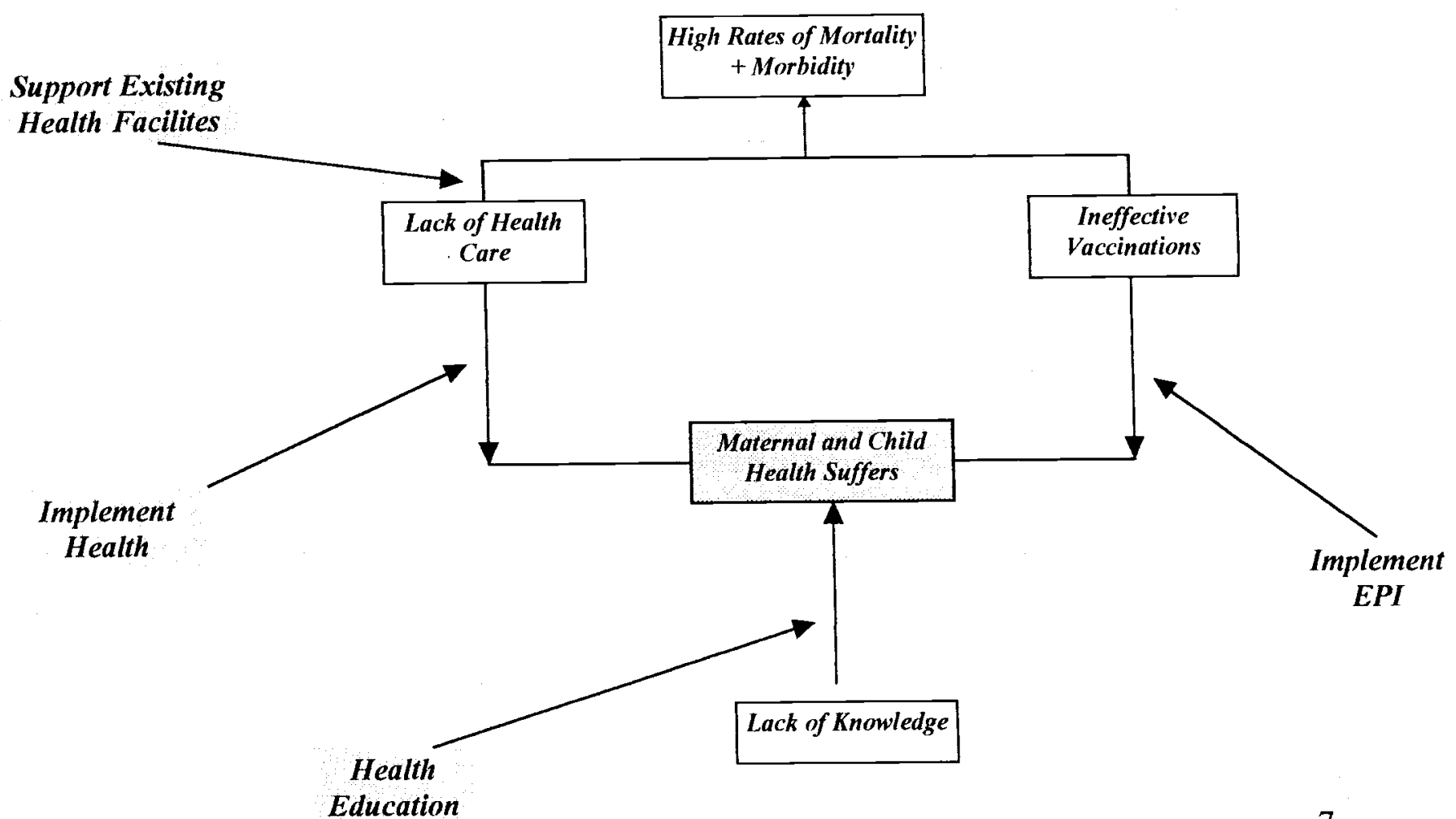

Education 


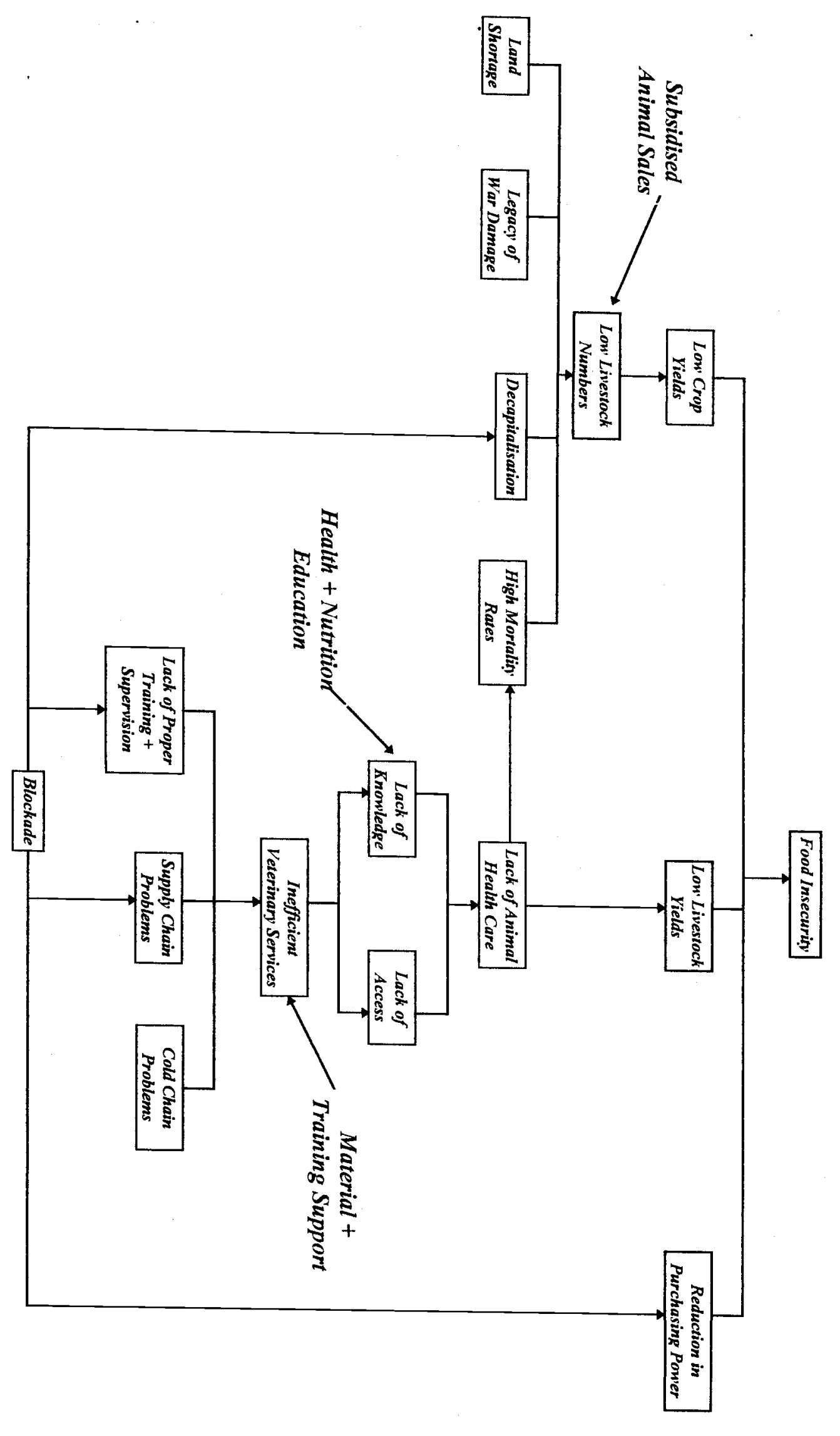




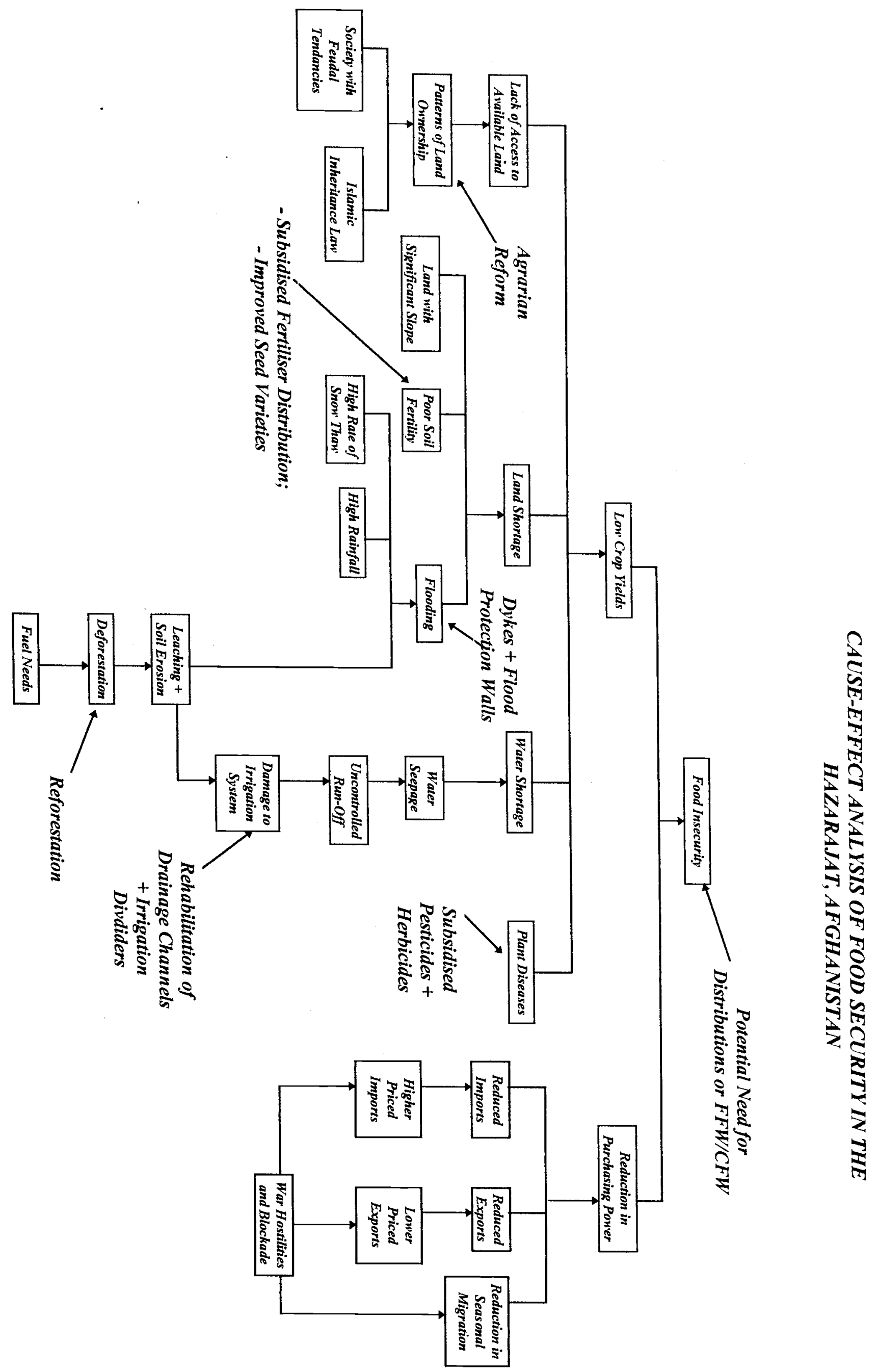




\section{SUMMARY ACCORDING TO ZONE:}

Table 3: Summary According to Zone (only marked where considered a priority - that is, involving needs not yet covered):

\begin{tabular}{|c|c|c|c|c|c|c|}
\hline \multirow{2}{*}{ Recommended Actions } & \multirow[t]{2}{*}{ Ajarestan } & \multicolumn{2}{|c|}{ Bamiyan } & \multirow[t]{2}{*}{ Jaghoori } & \multirow[t]{2}{*}{ Malestan } & \multirow[t]{2}{*}{ Nawor } \\
\hline & & Lower Valley & Upper Valley & & & \\
\hline $\begin{array}{l}\text { Regular nutritional surveys } \\
\text { for evaluation }+ \text { further } \\
\text { research on diets by } \\
\text { household type, gender } \\
\text { differential etc. }\end{array}$ & $\checkmark$ & $\checkmark$ & $\checkmark$ & $\checkmark$ & $\checkmark$ & $\checkmark$ \\
\hline $\begin{array}{l}\text { Mother \& child health care } \\
\text { centres with EPI, pre-\& post- } \\
\text { natal care, nutritional } \\
\text { supplements, } \\
\text { education. }\end{array}$ & $\checkmark$ & $\begin{array}{l}\text { Ibn Sena, } \\
\text { Shuhada }+ \\
\checkmark\end{array}$ & $\checkmark$ & Shuhada & $\begin{array}{c}\mathrm{SCA}+ \\
\checkmark\end{array}$ & $\checkmark$ \\
\hline $\begin{array}{l}\text { Distribution of subsidised } \\
\text { fertiliser, herbicides \& } \\
\text { pesticides. }\end{array}$ & & & Solidarités & & $\begin{array}{c}\text { GRSP + } \\
\checkmark \\
\end{array}$ & $\checkmark$ \\
\hline $\begin{array}{l}\text { Construction / rehabilitation } \\
\text { of flood protection walls. }\end{array}$ & $\checkmark$ & & $\begin{array}{c}\text { DHSA + } \\
\text { Solidarités }\end{array}$ & & $\checkmark$ & \\
\hline $\begin{array}{l}\text { Construction /. rehabilitation } \\
\text { of irrigation networks. }\end{array}$ & $\checkmark$ & & Solidarités & & $\checkmark$ & $\checkmark$ \\
\hline Support to kareze cleaning & & & & $\checkmark$ & & \\
\hline $\begin{array}{l}\text { Support to construction of } \\
\text { veterinary clinics } \begin{array}{r}\text { with } \\
\text { immunisation and health } \\
\text { education. }\end{array}\end{array}$ & $\checkmark$ & & Solidarités & & $\begin{array}{c}\text { Shuhada } \\
+ \\
\checkmark \\
\end{array}$ & $\begin{array}{c}\text { Shuhada } \\
+ \\
\\
\end{array}$ \\
\hline $\begin{array}{l}\text { Seed multiplication and } \\
\text { distribution of improved seed } \\
\text { varieties. }\end{array}$ & & & Solidarités & & $\checkmark$ & $\checkmark$ \\
\hline Support to kitchen gardens. & & & 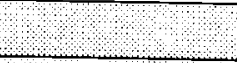 & & $\checkmark$ & $\checkmark$ \\
\hline Subsidised sale of animals. & & & & $\checkmark$ & $\checkmark$ & \\
\hline Reforestation. & $\checkmark$ & $\checkmark$ & $\checkmark$ & $\checkmark$ & $\checkmark$ & $\checkmark$ \\
\hline $\begin{array}{l}\text { Further research on income- } \\
\text { generating projects. }\end{array}$ & & & HABITAT & & $\checkmark$ & $\checkmark$ \\
\hline District co-ordination bodies. & $\begin{array}{l}\text { No NGOs } \\
\text { or UN. }\end{array}$ & $\begin{array}{l}\text { Participation } \\
\text { in existing. }\end{array}$ & $\begin{array}{l}\text { Participation } \\
\text { in existing. }\end{array}$ & $\checkmark$ & $\checkmark$ & $\checkmark$ \\
\hline
\end{tabular}

All in all, Bamiyan Upper Valley (although due to be covered by a combination of Solidarités, DHSA and HABITAT for food security), Malestan and Nawor would appear priority zones for intervention - given ecological
constraints, population densities and problems encountered. 


\section{A. OBJECTIVES:}

\section{Nutrition:}

- To assess the current nutritional status of the under five years old children (they being one of the best indicators of the nutritional status of the population as a whole, since they are amongst the most vulnerable);

- To assess existing health structures and make recommendations based on information gathered from the community, regarding health needs.

\section{Food Security:}

- To assess the causes of food insecurity and their effects in specifically selected districts of the Hazarajat, such that proposals might be made as to timely and appropriate interventions, whether short-term relief or longer-term rehabilitation/developmental activities, depending upon the situation;

- To establish an information baseline together with certain key indicators that might permit regular and periodic follow-up of the food security situation, including early warning indicators, stress indicators and result indicators such as levels of malnutrition (acute or chronic). Following from this, was to be the invitation to other NGOs and UN bodies to partake in a training session on nutrition and food security survey techniques.

\section{Food Security, Nutrition and Health:}

Crucial to the surveys undertaken, was the integration between nutrition, health and food security concerns such that the totality of needs and vulnerabilities might be better understood and a response better planned. In this, any acute malnutrition potentially leading to death, was seen as resulting from an inadequate dietary intake and disease, themselves the result of household food insecurity, inadequate maternal and child care and an unhealthy environment, where the latter in turn, is caused by the larger socio-political and economic context. The following framework drawn up by UNICEF envisages this well. 


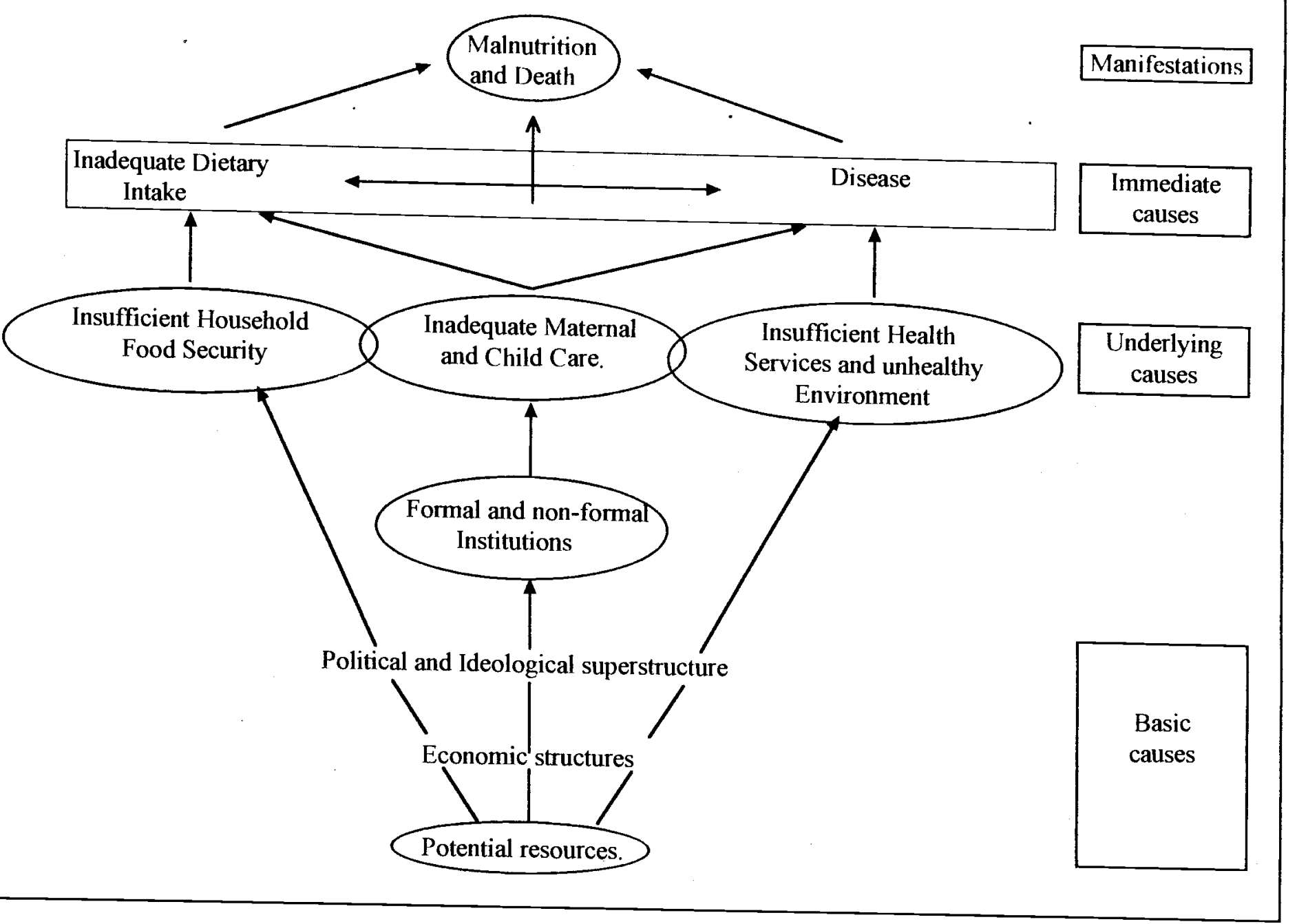

Source: Young, H. \& Jaspars, S.; 1995; Nutrition Matters: People, Food and Famine; Intermediate Technology.

The surveys were to be done in parallel and in two phases, such that after an initial global analysis, the identification of household types and levels of vulnerability in terms of food security, a subsequent nutritional screening and health questionnaire be undertaken of selected groups of household types (including the most vulnerable), so as to better assess and substantiate the linkage between the two. However, this was not achieved due to insecurity in the region and subsequent evacuation. Neither, and for the same reasons, was a significant part of the nutritional training and all of the food security training undertaken. Nor was a reliable quantitative estimate of the number of beneficiaries for food security proposals able to be obtained. This also means that the food security surveys cannot be taken as statistically representative of the population.

The situation is such that today, a return in the immediate future cannot be envisaged and these two aspects of the exploratory mission thus abandoned - perhaps for another team at a later date.

\section{B. REPORT LAYOUT:}

As the report stands then, an initial section details the methodology used by both the food security and nutrition teams within the Hazarajat, with some mention of both positive and negative features. The report then goes on to assess the general context moving from the macro to the micro and situating the Hazarajat within the context of Afghanistan as a whole. This section has been 
divided into several sections spanning geography, through history, to the political economy and norms and values of today. Ecological zones are identified, followed later by the delineating of household types. A fifth section attempts to assess potential causes of malnutrition as found in issues relating to food security: The subsequent two sections deal with the more technical issues of nutrition and health, in one part, and food security in another. The report then finishes with the conclusions and recommendations drawn from the study - and the various annexes. 


\section{A. ZONE SELECTION:}

The decision as to where the surveys should be undertaken was based on information obtained from Kabul, claims by WFP that over 167,000 people were facing starvation, and a mini-exploratory
mission.

Although Bamiyan is an area where a large number of NGOs and UN agencies working in the Hazarajat had programmes, it was decided that a nutritional cluster sampling survey be undertaken, complimented by a food security assessment, due to the dearth of reliable and comparable data in terms of malnutrition and conflicting reports about the latter. The other zones, Ajarestan, Jaghoori, Malestan and Nawor were selected for reasons of accessibility and difficulty, and in the case of Ajarestan and Nawor, the lack of any other NGO or UN presence. It was also hoped that Shahrestan might be included in the surveys, but this proved logistically impractical.

\section{B. TIMETABLE:}

The surveys were to be undertaken over a period of three months so that a relatively good grip of a complex situation could be obtained and lead to relevant and effective interventions when and where necessary. Approximately two weeks were spent in Bamiyan province, followed by one month of mobility in the south, where approximately 3-5 days were spent in each ecological zone identified.

On the basis of a first analysis, allowing the identification of household types, the teams were due to return to the south to further concretise the link between food security and nutrition, looking at production possibilities as against consumption needs, looking at the quality and quantity of diets and any health problems manifest. Approximately 100 households of each of the selected types were to be surveyed and the specific malnutrition indicators to be compared to that obtained through the previous more global, aggregated analysis. This second return to the field was also to have furnished more concrete numbers of beneficiaries for recommendations made in the area of food security. It was to take perhaps another two weeks.

\section{NUTRITION AND HEALTH:}

Type of survey and sample size:

\section{Screening ${ }^{6}$}

A general screening survey was conducted on 969 children ( 75 babies aged $0-5$ months and 894 children aged 6-59 months), excluding errors. The area covered within the Central Highland Region included Ajarestan, Bamiyan Upper Valley, Jaghoori, Malestan and Nawor.

\footnotetext{
${ }^{6}$ For detail of information collected, see Appendices Part III, Appendix 1.
} 
The villages screened were chosen by taking a different road daily and covering as many villages as possible- in a day. Villages up to a 2 hours radius by car from the central bazaar of each area had the likelihood of being included ${ }^{7}$.

Once a village was chosen, the head of the village was called and asked to gather all families with children under 5 years of age, to attend with the mother and vaccination cards (if any), at the mombar ${ }^{8}$. Children were measured in family groups, so that all children, aged 0-59 months within one family (sharing the same mother and father ${ }^{9}$ ), were weighed and measured whilst the mother was interviewed on their vaccination status and mortality within the family, of this target group (0-59 months), over the past 30 days ${ }^{10}$. Although all families with children under the age of five were asked to attend, it has to be assumed that not all did. Vaccination and mortality rates were calculated on the number of children under five years of age in the families being screened. Therefore, all children in the families present, aged five years or under, were accounted for, whether at the screening or not. It cannot be said that all families attended each screening, though the majority of villages produced the number of children expected, assuming that $17 \%^{11}$ of the population is made up of children under five years of age. Additional information, relating to the way of life, diet and health issues was collected through a series of group interviews ${ }^{12}$.

\section{Health and nutrition:}

At each village, discussions were held in small groups, whereby a general picture of the daily life of the population was established ${ }^{13}$. The information collected included:

- At the village level: the name of the village; the population; number of houses; nearest clinic; nearest school; internally displaced people; female headed households

- At the household level: availability of latrines; water source; frequency of fetching water; quantity fetched

- Diseases: most common diseases amongst adults and children; taboos and traditional medicine; vaccinations and frequency

- Maternal and child health: conditions for birth; availability of traditional birth attendants; cost of any health care; death rates and causes

- Breast feeding: length of; age of weaning; weaning foods; cessation during pregnancy

- Diet: pre/post blockade; price of food; nearest bazaar; frequency of travel

\footnotetext{
${ }^{7}$ See Appendices Part III: Appendix II for a list of all villages involved, by region and Appendix III for maps of regions.

${ }^{8}$ A mombar is the equivalent of a village hall, where meetings and functions are held. Almost every village has one and it is usually located in the centre.

${ }^{9}$ Under Islamic Law, men are allowed up to four wives. Some of the women interviewed shared their husband with another woman. A family was considered as being the children shared by one man and woman. If the husband had more than one wife and they were present, they were counted as another separate family

${ }^{10}$ An example of a data collection sheet can be found in Appendices Part III: Appendix IV.

${ }_{11}^{11}$ The percentage assumed for Kabul and Bamian surveys, according to population data.

${ }^{12}$ See Health and Diet sections.

${ }^{13}$ See Appendices Part III: Appendix V for a description of each village by region.
} 


\section{Health structure assessment}

Each area was investigated and information gathered - on health structures. This included the services available, any problems and the potential usefulness of the structure.

\section{Vaccination survey}

Information was obtained by asking the vaccination status of each child (aged 9 months or over), regarding measles. This method was chosen as measles is normally the last vaccine given in the measles, then he would be fully covered for taken that if the child had been vaccinated against included in this survey, since, for the vaccine to ber diseases. Only children 9 months or over were immunity that he has acquired from materna be effective, the child needs to be rid of his natural child was vaccinated before the age of 9 antibodies and this normally takes 9 months. If the maternal antibodies he carries would inhibit anys, he was not included in the calculations as the immunised.

\section{Mortality survey}

The crude mortality rate of all children aged 0-59 months was determined. Each family was asked the number of children they had in this age range (whether present at the screening or not and sharing the same mother and father). Although all children of the families screened were accounted for, it cannot be assumed that every household in the village was present at the screening. The mother was then asked if a child in this age range had deceased in the 30 days preceding the survey. If a child had died, the mother was asked the cause of death and the symptoms, in order to double
check the cause.

\section{Team composition:}

One team of four people completed the survey in 4 weeks. The team consisted of 2 measurers, 1 registrar and 1 interviewer. All were supervisors from Action Contre la Faim feeding centres and were very able to carry out the survey competently. One member was a doctor and was able to help with identification of diseases by considering the symptoms described.

\section{FOOD SECURITY:}

\section{In General:}

The food security surveys essentially attempted to look at systems of agriculture and animal husbandry as affected by the larger politico-economic environment - taking the distortionary effects of the blockade around the south of the Hazarajat as one such essential aspect. Two people were involved: one female expatriate and one male agronomist of Afghan origin. 
The study was divided according to two levels:

- A macro level assessment: which entailed obtaining a general picture of Afghanistan as a whole and systematically moving from the global through the national to the regional, where activity was eventually to be focused. It involved research from existing information archives and secondary sources (some of which are cited in footnotes), as well as semi-directive interviews with key persons/informants from any existing government officials (usually the Governor of a district), NGOs (such as Solidarités), and UN bodies (including HABITAT, WFP);

- A micro level assessment: which entailed focusing on particular communities within the area to be studied and entailed semi-directive interviews with key persons/informants from the community, together with more general Participatory Rural Appraisal exercises.

The results of this first level permitted movement to the second with discussions between the various groups contributing to the identification of the more vulnerable areas according to zone.

At the second level, then, villages initially tended to be chosen as far away as possible from the nearest commercial centre, the main market of the district, usually at a distance of 2 hours by car, with a final survey being done mid-way between the furthest village and the centre point.

Several attempts were made to undertake both food security and nutritional surveys in the same villages, but this proved detrimental to the former due to its more qualitative character and the propensity of a small, but nonetheless significant, number of villagers to give inconsistent and often incredible, information.

The initial first stage, qualitative surveys tended to open with a social/community and resource mapping, usually with male only groups (although it did prove possible in a small number of instances to have parallel women-only groups as well). From here, discussions tended to branch out into two main directions:

- Transects, looking more specifically at agricultural and animal husbandry systems;

- Proportional piling matrices looking at sources of food income before the blockade and at present.

Semi-directive, individual interviews tended to be integrated within these, usually followed by observation of the participant's home and surroundings. This said, semi-directive interviews were, in a number of cases, allowed to overshadow the use of PRA tools due to the breadth of the subjects to be covered and limited time.

Had the second stage of surveys been completed, these would have been done on the basis of a questionnaire in order to validate and strengthen points raised during the above qualitative survey and to identify beneficiary numbers.

\section{Comments:}

The eventual emphasis on semi-directive techniques was to the detriment of useful PRA exercises such as the labour calendar. In this, the surveys might have been better structured. While the 24-hour clock was initially employed, the gains from it were minimal compared to the time necessary and it was, therefore, abandoned. However, the advantage of those PRA techniques employed were:

- Increased participation by community members in a relaxed atmosphere that tried to make as little distinction as possible between the literate outsider and the often illiterate insider; 
- Where women and children were involved, there was often a real sense of achievement and pride once pictures of sheep, the local Mosque or WFP lorries had been drawn - with or without the help of the facilitator: leaving the drawings behind possibly reinforced this;

- The flexibility of the tools allowed a series of themes to be tackled within a given time period and without either engendering boredom or detracting too much from time that could have been spent elsewhere (usually in the fields) Participants tended to find the semi-directive interviews, where not accompanied by PRA,
somewhat monotonous.

Furthermore, interviews were most common with men since the barrier of language and the presence of a male inhibited contact with females. 


\section{Part IV: Macro to Micro Context situating the Ilazarajat \\ within the Context of $\mathbf{A}$ fghanistan as a whole}

\section{A. The Natural Environment:}

\section{Geo-Topography:}

With a land area of some 652,000 sq. $\mathrm{km}$ (about the size of France), Afghanistan is situated at the cross-roads of central Asia, locked in by the newly created States of Uzbekistan, Tajikistan and Turkmenistan to the north, Iran in the west, Pakistan in the south and east, and China in the extreme north-east. The landscape is dominated by rugged mountains - most notably the Hindu Kush, the western-most extension of the Karakoram and the Himalayas - juxtaposed against arid plains which effectively become deserts in the south-west ${ }^{14}$.

The result is that cultivable land surface only numbers 7.6 million lectares, or $12 \%$ of the land surface. Permanent pastures and meadows suitable for livestock, on the other hand, have been estimated to cover about $84 \%$ of the country.

Of the 7.6 million hectares of arable land, approximately 1.4 million hectares, or $18 \%$, are rainfed, and 5.2 million hectares, or $68 \%$, irrigated - although due to the scarcity of water not all land can be cultivated ${ }^{15}$ :

Much of the country's water is derived from a network of four main rivers, the Kunduz, Kabul, Helmand and Herat, which in turn feed into open canals leading to the fields. Somewhat paradoxically, excesses of water during the spring thaw sometimes cause floods and landslides. In other areas, reliance tends to be upon underground channels or kareze, that bring water down from nearby hills to land in the plains.

The central provinces increasingly referred to as the Hazarajat essentially coincide with the central Hindu Kush mountain massif, so setting much of the area physically apart. Encirclement by the major road system, Kabul-Mazar-Herat-Kandahar-Ghazni-Kabul, reinforces this relative isolation.

The Hazarajat as a whole is estimated to have around 90,000 hectares of irrigated land - by river, reservoir, spring or kareze - and 50,000 hectares of rainfed land ${ }^{16}$. Flooding caused by the swelling of rivers and the bursting of their banks is a common feature particularly in Malestan and to a somewhat lesser extent, Bamiyan - although other areas such as Ajarestan, are not immune to the phenomenon. Throughout much of the region, destruction of natural forest (essentially poplar, willow and Judas tree), has also reduced the infiltration of rainfall, leading to flash flooding - again most visible in the areas of Malestan and Bamiyan. Such flooding also increases the risks of waterborne diseases, such as diarrhoea and cholera, which subsequently affect manpower levels and work capacities - and potentially, any level of malnutrition.

\footnotetext{
${ }_{14}^{14}$ Economist Intelligence Unit, 1998; Afghanistan Country Profile 1997; EIU, p. 67.

${ }^{15}$ Christensen, A.; 1995; Aiding Afghanistan: the Background and Prospects for Reconstruction in a Fragnemed Society; NIAS Reports $\mathrm{N}^{\circ} 26 ;$ p. 28.

${ }^{16}$ FAO/WFP; 1997; Crop and Food Supply Assessment Mission to Afghanistan; FAO/WFP; p. 11
} 
Erosion of land and subsidence, soil leaching and the deposit of mud and stones on land are thus uncultivable, particulanty damage to irigation systems and fields. This makes the land reducing food production possibilities.

\section{Climatology:}

The prevalence of mountainous ranges means that temperatures across Afghanistan bound from one extreme to the other, with lows of $-50^{\circ} \mathrm{C}$ and highs of $53^{\circ} \mathrm{C}$ having been recorded across the country. Average anmual rainfall is about $180 \mathrm{~mm}$, although precipitation rates of between 400 $1,000 \mathrm{~mm}$ have been estimated for the nortl and north-eastern areas ${ }^{17}$

Rain across the Hazarajat appears to be heaviest between the end of April to inid-July, while snows begin in October and may last 6-7 months. The heaviest period of snowfall tends to be around December to February time, and can result in up to 2 metres of snow, sometimes significantly more due to windstorms as in Nawor. For at least 4 montlıs at this time, any water is likely to freeze

The length of winter-time means that any growing season is inherently shortened relative to elsewhere in the country, so requiring greater adaptability and sturdiness of plants, which may otherwise be vulnerable to damage caused by early cold. This was found to be a particular problem in Nawor, in the Upper Valley of Bamiyan and to a relatively lesser extent, Malestan. The cold also results in greater fuel requirements, so affecting rates of deforestation and affects mobility, so affecting access to markets and any existing education or health structures

In certain areas travel over the passes that connect the multitude of valleys - some being as high as $4000 \mathrm{~m}$ or more - can be severely impeded (if not completely inhibited). While minimising community interaction and activity, this also has inplications for the intervention of any external
agency with regard to:

- Service provision - whether in-house or outreach: level, accessibility and staffing
requirements;

- Logistics and supply lines - stocks and so on.

\section{B. THE ECOLOGICAL ZONES IDENTIFIED AND ASSESSED:}

1. Ajarestan District (located within Uruzgan province): at an altitude of 2,800 to 3,000 metres, Ajarestan is nestled in a relatively fertile valley straddling about $80 \mathrm{~km}$ from east to west, and bordered by mountainous ranges, affording important pastureland. This means that relatively larger numbers of livestock may be sustained and allows for more manure to be used on the land as opposed to for fuel purposes only. Water derived inainly from the river and sources of snowmelt, tends to be in abundance - although there are some problems of flooding in Spring. Temperatures tend to be higher in spring/summer as a result of the lower altitude. Conditions, then, are such that a wider variety of crops is possible - including maize and rice, in addition to the usual wheat and barley - as well as fruit trees - apricot, sour cherry and apple among them;

\footnotetext{
${ }^{17}$ Economist Intelligence Unit; 1998; Afghanistan Comniry Profile; EIU; p. 67
} 
2. Bamiyan Lower Valley (part of the district of Bamiyan, located within Bamiyan province): concentrated around the main roads, or arteries, leading to Mazar-i Sharif and Kabul, this is in fact made up of a series of inter-connecting valleys. The land is relatively fertile and the climate warmer, while water. tends to be obtained from river and spring sources. From the north of the Baba mountain, the rivers of Amirdam and Balkhab flow, while from the south, flows the river of Helmand. In general, water flow appears sufficient in volume but may also cause floods during the spring/summer period so affecting the land cultivable and crop yields. Nevertheless, a greater variety of crops may be found compared to Bamiyan Upper Valley - including fruit sucl as apple and apricot, and vegetables such as onion, aubergine, leak, spinacl and tomato in particular;

3. Bamiyan Upper Valley (part of the district of Bamiyan, located within Bamiyan province): situated at a higher altitude and so more prone to climatic vagaries - particularly cold - Bamiyan Upper Valley tends to have less fertile land and a shorter growing period. Agricultural land is also confined to narrow valleys and mountain slopes, and is also subject to problems of flooding in spring/summer. The zone also experiences greater problems of water shortage compared to Bamiyan Lower Valley - either due to insufficient irrigation systems or water loss due to seepage and/or sand absorption. A more limited variety of crops prevails, based on barley, wheat, potato, lentil, faba bean, turnip and carrot, together with alfalfa and vetch;

4. Jaghoori District (located within Ghazni province): stretches across a wide expanse of undulating land, where much of the land has been terraced. Temperatures are higher allowing for a relatively longer growing season. However, pastureland and meadow are relatively limited, so also limiting livestock numbers and manure for fuel and fertiliser. Water is obtained through karezes, which are increasingly in need of cleaning to improve serviceability due to a drop in the underground water table. Crops tend to be quite diverse, including the staple cereals of wheat and barley as well as carrots turnips, but also including chick pea, okra, tomatoes, cabbage, marrow, apricots, mulberry and almond;

5. Malestan District (located within Ghazni province): spreads in many directions, encompassing both relatively wide plains which gradually span out in hills and then mountains. A fair number of meadows are in evidence so facilitating cattle grazing (given that smaller livestock tend to be taken into the mountains). Temperatures appear to be mid-way between those of high elevation Nawor and low elevation Ajarestan. The district is subject to severe flooding problems in spring, in particular, and less so, in summer, resulting in large tracts of land being deposited with mud and stones and therefore, left uncultivated due to a lack of manpower and the risk of repeated flooding. Loss of land cover due to deforestation and the collection of bushes for fuel is evident so exacerbating this;

6. Nawor High Plateau (part of the district of Nawor, located within Ghazni province): situated at an average altitude of 3,250 metres, the plateau of Nawor is semi-arid stretching across an immense area, and also fringed by mountains. Small open plains of cultivable land may be found many of them treeless. Cold (which may plunge to $-32^{\circ} \mathrm{C}$ ), and the short growing season have severely limited the diversity of crops that may be found, these being mainly wheat, barley, lentil, some potato, carrot and turnip. The plateau and its surroundings, however, provide significant pastureland, such that while the land is relatively unsuitable for cultivation, it lends itself to sustaining important numbers of livestock. Manure for fertiliser and for fuel, then, are less of a problem than elsewhere. There also exists a large lake but for the moment, its water resources remain essentially untapped. 


\section{Historical BaCkground:}

\section{Formation, Consolidation and 'Development' of the Afghan State:}

The geographic configuration of Afghanistan is such that trade through it has been of continual importance, with the famed Silk Route, for instance, passing through the northern areas (including Bamiyan), and connecting the country to China. In the same way, however, the land area it represents has been regularly subject to invasion, whether from the Persians, Alexander the Great's Macedonians, Bhuddist Khushans, Ghengis Khan or - several centuries later - the Soviets. Thus, until the mid-eighteenth century, Afghanistan remained part of one or both of the two large empires then regionally predominant: Sfavid Persia and Moghul India. It was only as these empires began to weaken that the establishment of an Afghan confederation began to materialise under the direction of Ahmad Shah, a Durrani Pashtun. By the 1800s, the kingdom of Kabul came into being.

At around the same time, foreign interest in the new fledgling State was renewed, this time by Tsarist Russia and British India. The period between 1839 to 1879 was to witness two AngloAfghan wars, culminating in the Treaty of Gandanak which gave the British control over Afghanistan's foreign policy and ceded certain border areas to British India. An attempt was made to install a client ruler in the form of one Amir Abdur Rahman.

The logic governing the activities of Amir Abdur Rahman was twofold:

- State expansion, which led on the one hand to the incorporation of the Hazarajat into the Afghan state, and on the other hand, to the demarcation of the Durand Line defining the boundary between India and Afghanistan - and cutting right through areas inhabited by the Pashtun tribes;

- Modernisation, as equated with positive social progress and the eventual capacity to govern independent of any foreign power.

In 1919, accession to the throne by Amir Amanullah was followed by a declaration of independence from the British empire - and the third Anglo-Afghan war. The outcome was a reduction of British influence, formalised in the Treaty of Rawalpindi - and an ensuing commitment by Amir Amanullah to something of an isolationist policy relative to foreign interests. At the same time, the king, under pressure from groups such as the 'Young Afghans' (styled along similar lines to the Ottoman Empire's 'Young Turks') - with this pressure being later reinforced by the influence of Kamal Ataturk in Turkey and Reza Shah in Iran - revived the emphasis on 'western' modernisation which, in the Afghan context, entailed:

- The creation of educational opportunities for women, followed by compulsory education for both girls and boys;

- The introduction of a Family Code banning child marriage and placing restrictions on the expenses associated with marriage;

- An edict allowing women to discard the veil and stipulating the wearing of western dress for both men and women;

- The introduction of a new constitution abolishing slavery and granting equality to all Afghan citizens followed later by the abolition of hereditary titles;

- An overhaul of the tax system (principally pertaining to land and livestock), with tax collection becoming monetised (as opposed to in-kind);

- The increasing recognition of private property and the sale of crown lands;

- The establishment of a few military-oriented small-scale industries in Kabul;

- Improvements to some of the roads. 
Such modernisation was inevitably premised on the ability of the state to tax its subjects and so finance its development - hence, reorganisation of the tax system. However, control over the Afghan territory, and therefore, influence over the State's subjects - those in the Hazarajat included - tended to fade out towards ill-defined borders. The jurisdiction of the Afghan State was never definitively defined, but tended to ebb and flow according to the vagaries of differing allegiances. As a result, State revenue was subject to continual fluctuation - and also proved inadequate to cover the costs incurred so eventually leading to cuts being made in army salaries (one form of saving), and the relaxation of foreign trade restrictions (to stimulate external capital injection).

By 1929, however, these policies had triggered the King's overthrow - probably determined by increasing demoralisation within the army and growing discontent at government implication in the private domain. Attacks on established practices and customary social organisation cut to the heart of the conglomeration of Afghan societies - whether by interfering in the relationship between men and women and so eroding both tribal and Islamic authority, or by encroaching upon feudalistic relationships, hierarchies and dependencies. The King's policies were subsequently abolished.

His eventual successor (after a brief Tajik intervention), Pashtun General Mohammed Nadir Shah, then went on to make concessions to these traditionalist forces while nonetheless adhering to the policy of modernisation by making something of a distinction between the private and the public domains. Such policies were continued by his successor, Amir Zahir Shall:

- On the one hand, then, the Islamic clergy, or Ulema, were given a stronger role in legal matters, with the Hanafi Shari'a of Sunni Islam established as the official religion (to the detriment of the Ja'afri system of Hazara Shi'a Islam), while the rural elite were given the power to veto changes in taxation through parliament (so reducing the capacity of the State to finance any modernisation);

- On the other hand, efforts were made to promote trade, with the establishment of joint stock companies, the country's first bank, Bank-i Milli, and the extension of credits for cotton cultivation and the textile and sugar industries. Time was also devoted to rebuilding the army and the State bureaucracy with British support. As part of this general expansion, the conscription of non-Pashtun ethnic groups into the army (including the Hazaras), together with employment in the civil service, gained importance - and some resentment.

In 1947, the independence of India and the newly-created Pakistan brought to the fore questions concerning the validity of the Durand Line, such that support was given by the Afghan government to the demands for self-determination by some of the Pashtuns in Pakistan's North West Frontier Province. Afghanistan also voted against the entry of Pakistan to the United Nations - the only country to do so. The result in 1950, was the closure of the Pakistani border to Afghanistan, later followed by skirmishes. Having previously been dependent on trade with British India and its successor after decolonisation, the Afghan government began to look towards the Soviet Union. Continued support under Prime Minister Mohammed Daoud, to secessionist movements across the border and contingent refusal by the United States to provide financial assistance, only served to intensify these links ${ }^{18}$. Thus, in 1956, one year after Pakistan joined the Baghdad Pact and SEATO (two American-oriented treaties for defence and trade), and trapped within the Cold War logic, Soviet military and economic aid to Afghanistan was able to be officially launched.

\footnotetext{
${ }^{18}$ For the Americans, Pakistan provided a mountainous platform ideal for monitoring events in Soviet Central Asia and so in keeping with Cold War rivalries
} 
This essentially involved low interest loans for the purchase of Soviet capital equipment, as well as equipment and training of the Afghan army. Concomitantly, pro-Soviet political groups were nurtured within an increasingly dissatisfied Kabul-based intelligentsia - frustrated by growing nepotism within the establishment which restricted avenues for social mobility and the absorption of
new graduates ${ }^{19}$

\section{Soviet Occupation and the 'Jihaad':}

Politically-oriented groups at this time, tended to be of three colours: ethno-nationalist, Islamic and Communist - each riven by fissure according to ethnic group, Sunni/Shi'ite differences and urban/rural followings. Of the Communist groups that emerged, Khalq (the Masses), and Parcham (the Banner), were historically the most significant - the former being largely composed of rural Pashtun speakers, the latter of Kabul-based Dari speakers. The two were ostensibly united within the Soviet-encouraged People's Democratic Party of Afghanistan. However, this coalition was fraught with difficulties and tensions due to deep-seated rivalry between the two groups, based on personality (Nur Mohammed Taraki and Hafizullah Amin of Khalq against Barbrak Karmal of Parcham), tactics and linguistic division.

Nevertheless, in the 1965 elections to the Loya Jirga, or parliament, both managed to gain a small number of seats, although the majority of these going members of the rural elite and the Ulema. This said, final power still remained with the royal family partly due to the lack of appeal of such a legalrational system to the Afghan population - a population which tended to see legitimacy rather as being embodied in the traditional presence of the monarch.

With Soviet financial backing, meanwhile, a number of five year plans were able to be adopted. These initially focused on basic infrastructure (roads and power plants), together with investments in mining and, to a lesser extent, manufacturing (textiles and construction), and then gradually shifted to supporting the productive capacity of small farmers and improving irrigation. By 1967, exploitation of natural gas reserves (estimated at 100 to 150 billion cubic metres), was begun - with exports at prices below those of world markets being oriented towards the Soviet Union. To further development, an Industrial Development Bank was also established, although despite the legal and financial mechanisms created to stimulate private enterprise, the public sector remained dominant ${ }^{20}$.

At the same time, attempts were made by the Prime Minister Musa Shafiq to rationalise Afghanistan's relationship with the Soviet Union through seeking more strictly to limit the activities of communists, to enlist foreign aid from other sources and to settle the border disputes with Iran and Pakistan. This in turn, provoked a Republican-oriented coup d'Etat to oust Amir Zahir Shah. It was led by previous Prime Minister Mohammed Daoud with support from Parchami sympathisers in the Air Force and Tank Brigade (rifled by exclusion from prevailing patronage networks and with a history of closer links to the Soviet Union).

Once in power, however, Daoud then set about removing the Parchamis from positions of power, opening the country up to business interests from States other than the Soviet Union - including Iran, Saudi Arabia and Iran, all of which were regarded with mistrust by Soviet officials. Rapprochement with Pakistan and a campaign to strengthen Afghanistan's position in the non-aligned Movement also
took place.

\footnotetext{
${ }^{19}$ Christensen, A.; 1995; Aiding Afghanistan: the Background and Prospects for Reconstruction in a Fragmented
Society; NIAS Report, N $^{\circ} 26 ;$ p. 24 .

${ }^{20}$ Christensen, A.; 1995; Aiding Afghanistan: the Background and Prospects for Reconstruction in a Fragmented
Society; NIAS Report, N $^{\circ}$ 26; p. 33 .
} 
In parallel, and no doubt in part response, the forging of links between Khalq, Parcham and the military grew stronger, such that by April 1978 the scene was set for a Communist coup led by the PDPA - and the restoration of good relations with the Soviet Union. However, beset by increasing tensions between the now dominant Khalq vis-à-vis Parcham, another coup d'Etat orchestrated by Prime Minister Amin some 17 months later, led to the accession of the latter group - and triggered a civil war. In December 1979, invoking their Treaty of Friendship with Afghanistan, the Soviets invaded to establish a client State ostensibly headed by Babrak Kamal and the Parchams, but with Soviet advisers essentially controlling all government departments and the media ${ }^{21}$.

The Soviet occupation proved tortuous and demanding for virtually all parties. The ideology espoused never gained from mass support and rather than unifying the country under one umbrella, the Soviets remained at continual loggerheads with the different communities. Managing to control only a few key towns and the capital (in a manner somewhat reminiscent of the first Afghan monarchs), they were subject to a guerrilla war that lasted until their withdrawal almost ten years later.

This guerrilla war was spearheaded by a number of militia groups, the colours of which were impregnated by Islam: Islam proved to be the cohesive and motivating factor in challenging what came to be seen as an affront to the Muslim Ummah, or community, by kafir, or unbelievers. In this, the struggle for liberation became portrayed as a total war: a Jihaad, or Holy War that, by its very definition, involved all. That Islam gained such importance was in part also due to the prompting of Pakistan, the country to where all the Sunni Muslims had repaired - the Shi'ites finding refuge across the Iranian border. The linchpin of Pakistani policy, was to substitute nationalism with an Islamism which would, for historical reasons, be easier to manipulate, and so avoid any government that might take an autonomous political line antagonistic to Pakistani interests - including the maintenance of its territorial integrity, particularly the border Pashtun areas ${ }^{22}$. Pakistan then, embroiled in the Cold War logic, and supported by the American $\mathrm{CIA}^{23}$, channelled the bulk of assistance it received to the Islamist parties (those parties over which it might have the most influence in the long-run), in particular to the Hezb-i Islami of Gulbaddin Hekmatyar. Support to Hekmatyar was essentially premised on his ethnic identity (being Pashtun and thus, a Pashtun dependent on Pakistani goodwill), although he was never a particularly good strategist compared to Masood, military commander of Rabbani's Jamiat-i Islami (and Tajik).

In terms of the economy, meanwhile, the subsections of the economy that received most attention, were those from whose development trade with the Soviet Union benefited - such as natural gas and other minerals. Beyond this, the Soviets, embroiled in war, had little time, few resources and insufficient control to implement large-scale economic programmes - such as farm collectivisation, agricultural co-operatives and large-scale manufacturing industries. This said, something of a double economy arose: that of 'official' routes oriented towards the Soviet Union, and that of 'unofficial' tracks leading towards Pakistan and Iran.

\footnotetext{
${ }^{21}$ Economist Intelligence Unit; 1998; Afghanistan Couniry profile; EIU; p. 54.

${ }^{22}$ Barry, M.; 1996/97; Afghanistan: les Séminaristes de la Guerre; Politique Internationale (Hiver).

${ }^{23}$ It might be mentioned that a multiplicity of influences exists in UN-foreign policy making, such that there is rarely a mastermind behind the steps taken. Partly as a result of this, the CIA quickly and regularly delegated important decision-making to Pakistan, often neglecting the fact that Pakistan might have interests that did not necessarily coincide with those of either Washington or the Afghan people. Maley, W. (ed); 1998; Fundamenlalism reborn? Afghanistan and the Talêban; Hurst \& Co.
} 
Towards the end of the 1980s, with Perestroika and Glasnost making their impact on the Soviet Union, and with the latter's internal problems overwhelming any external commitments, attempts at reconciliation and negotiation were increasingly made between the Afghan government led by one Najibullah and the Mujahideen forces (forces of the Jihaad). By February 1989, Soviet withdrawal was completed and an Afghan Interim Government established - still under Najibullah but incorporating the seven main Peshawar-based parties (to the exclusion of the Hazara party, the Hezb-i Wadhat, formed in the same year in Iran).

By 1992, however, and following the inability of the government to function with any coherence and the effects of a temporary closure of the border with Pakistan (due to the distortionary effects posed by trade with Afghanistan) as well as an effective halt to any remaining Soviet financial assistance, Mujahideen forces began to close in on Kabul - so forcing the resignation of Najibullah. However, inter-factional fighting among the Mujahideen was such that, in the same year, Hekmatyar and his Hezb-i Islami fighters were expelled from the capital, and a Tajik-led government (including two Hazara representatives to the cabinet) was installed under Burhanuddin Rabbani of the Jamiat-i Islami. An Islamic State based on Sunni Hanafi Law was then declared.

Incessant inter-factional fighting among the Mujahideen, intensified by the dissipation of the 'national' army along the same lines - gradually meant that the ideological dimension of the conflict against the Soviets and targeting State tenure, increasingly eroded in parallel with the gaining importance of non-Pashtun Sunni politico-ethnic considerations. Controversy over the re-election of Rabbani only served to fuel this, with fighting between Hezb-i Islami and Jamiat intensifying. Thus, in a bid to divert attention away from the governing body, Rabbani adopted something of a divide and rule policy - that worked particularly to the detriment of the Hazaras, with several military offensives against Hezb-i Wadhat military bases and Hazara residential areas in Kabul taking place. Iran, meanwhile, although wracked by dilemma, nonetheless supported the official Tajik
government.

\section{To Date: Political Fragmentation, the Talêban and the Future:}

By 1994, a new force, the Talêban, Islamic students most of whom were educated in Pakistan, descended upon the scene. Interestingly enough, just as Pakistan declared its intention to re-open trade routes to Central Asia (and the oil and gas reserves awaiting exploitation), the Talêban emerged to free the first convoy to ply the route from ambush by Mujahideen brigands. Hekmatyar was obviously proving something of a disappointment.

Given Hazara persecution, their advent caused Mazari, leader of the Hezb-i Wadhat, to forge links with them - only to be betrayed and assassinated in March 1995 - a momentous event for the Hazaras who, under Mazari's successor, Khalili subsequently managed to take control over much of the Hazarajat and establish something of an autonomous enclave in the heart of Afghanistan - the command centre of which was established in Bamiyan. This also lead to the expulsion of large numbers of Tajiks from the area - with small numbers only returning towards the end of 1997, after the re-establishment of friendly relations with Massoud and Rabbani and the strengthening of the Northern Alliance.

In September 1996, the Talêban, meanwhile, motivated by disgust at the in-fighting and secure in a sense of moral-religious duty/authority, overran Kabul then held under the newly 'reconciled' Hezb-i Islami and Jamiat-i Islami. In this, they were supported both logistically and financially by 
the Pakistani government and its Inter-Services Intelligence Agency (and through them, the US) ${ }^{24}$, as well as by Pashtun business communities in Pakistan. Since then, the history of Afghanistan has been that of a coalition of forces, the Northern Alliance, struggling against the Talêban but still wracked by internal divisions, temporary defections, lack of co-ordination and incoherence. While the Talêban managed to make significant advances initially, their fortunes ebbed and flowed with the misfortunes striking the cohesion of the Alliance. In Summer 1997, in response to the massacre of thousands of Talêban by Hazaras in Mazar-i Sharif (after penetration of the town was facilitated by temporary defection within the Northern Alliance), and no doubt as a means of starving out the Hazara people, an economic blockade was imposed on all southern areas of the Hazarajat coming into contact with Talêban territory.

In a final drive to sweep across the country, the Talêban captured Mazar-i Sharif in August 1998, massacring 300 Hazaras and 10 Iranian diplomats - no doubt also to further their revenge for the thousands of Talêban killed there, and due to the role the Iranians have played in supporting the opposition to the Talêban ${ }^{25}$. This was followed by the capture of Bamiyan one month later.

The international community has been slow to respond (given also the expulsion of NGOs from Kabul - after non-compliance with ministerial directives - and then elsewhere in the country due to insecurity), although American support to Pakistan and by implication to the Talêban, has wavered, particularly due to the former's recent nuclear test and the latter's harbouring of reputed international terrorist, Osama Bin Laden - which triggered American strikes on Afghanistan at the end of August. Although the Talêban - in control of some $90 \%$ of the country - have offered to tackle drug production in the country and despite international business interests in a pipeline linking Pakistan to the vast oil and gas resources in Central Asia, international recognition does not appear forthcoming (and by implication, access to IMF funds, for instance). Indeed, the reverse appears all the more possible, with gaining links between Iran and the rest of the world. At the same time, Iran has since threatened war (although it might not wish to jeopardise its growing acceptance in the world with carrying this threat out), while the role of Russia, given its current and deepening economic crisis, is unclear $^{26}$.

As things currently stand, neither are the Talêban the great monolithic machine usually portrayed, being riven by political differences, a number of which are based on personalities and tribal leadership. Indeed, the movement also includes drug barons and former communist army officers, such that policies implemented differ from region to region (based on the decisions of regional shuras, or assemblies of mullahs), and tend to be somewhat fragmentary. Obviously, it is not known how events may develop. To date, the various Talêban administrations (including that of Kandahar, where the Talêban have been present since 1994), have not been able to turn their minds to rebuilding the areas under their jurisdiction, having neither the necessary training and personnel, nor the resources for this. While able to secure a degree of stability and permit economic activity to be revived, they have been able to do little to encourage it - whether through investment policies or

\footnotetext{
${ }^{24}$ « That Pakistan has been so supportive, together with the US, was shown by the unwavering direction combined with speed and mobility usually characteristic of the Talêban - and at variance with the Jihaad era of warfare, which tended to be a conflict of hit-and-run skirmishes, organisationally fragmented and seldom, if ever, fought to conclusion. This can only have been due to an efficient communications and command and control network. It might also been mentioned that policy in the US tended to be influenced by the thought that the Talêban might: clean up drugs, serve as a bulwark against Russian and Iranian interests, restore order to all of Afghanistan as they had done in Kandahar and elsewhere in the South, get rid of terrorist training camps, and provide a US ally, Pakistan, with an overland link to the immense profits to be made from trade with the new Central Asian Republics »: cf. Maley, W: 1998; Fundamentalism Reborn? Afghanistan and the Taleban; Hurst \& Co.

${ }^{25}$ This was evident in the Iranian-funded hospital in Bamiyan, together with the later establishment of an Iranian Consulate and deliveries of arms and weapons.

${ }^{26}$ For more detail on the international scene, please refer to Appendix II, Trade, Power and Internationalism
} 
otherwise. Theirs has been something of a Jihaad within the Muslim community, conditioned and propelled by politico-military-religious considerations. Should they be unable to change this, and become involved in a sustainable reconstruction process, a new outlet for their energies would be required. Previously, they functioned within the logic of the-State of Afghanistan, aiming only at the capture of the reins of the Afghan State. It is not known what the future may hold - but it would be fair to mention that Iran, worried about the security of its own borders, has amassed significant numbers of troops there.

Were international agencies to return to Afghanistan, they would no doubt be affected by this with the opportunity cost for the Taliban being quite favourable in this respect, since NGOs and the UN agencies provide basic welfare services and so endear the population to them, whilst also freeing resources for other commitments - including any continuing war effort. This said, the Hazarajat, being somewhat looked down upon, would probably not be a priority area for the Talêban - so having implications for future working possibilities there ${ }^{27}$

\section{DeVelopment in PERSPECTIVE - DeVElopMent IN CRISIS:}

\section{Demographic Growth:}

The last population census was conducted in Afglianistan in 1979, but could not be completed due to turmoil following the change in government. However, the resident population in Afghanistan is currently estimated to be anywhere between 16.6 and 20.1 million $^{28}$. Resistance to the Soviet occupation led to a highly militarised society, and is thought to have claimed the lives of more than 1 million Afghans. It also caused a significant exodus from the countryside to the towns, particularly Kabul. Moreover, at the peak of the unrest in the early 1990s, an estimated $30 \%$ of the population had fled the country, or were internally displaced, although since 1992, about 3 million of the 6 million expatriate Afghans have returned ${ }^{29}$. Much of the population suffers from disabilities, widowhood, orphanage and unemployment.

Afghanistan is divided into provinces, such as Bamiyan and Ghazni, which are further subdivided into districts, or Woloswalis, and then Alaqadaris, or smaller districts. The Hazarajat has often been divided along various lines into several provinces, recently extending into Bamiyan, Ghazni, Wardak, Ghowr and parts of Uruzgan provinces.

According to the WFP, there are perhaps 1.2 million people in the Hazarajat (although the entire population is often put at a figure of 4-5 million, with many being dispersed throughout the country). However, again, since the outbreak of intern factional fighting and particularly since the Talêban gained control of Kabul, Mazar and Pol-i Komri, there were increasing influxes of Hazaras to lands or communities once left behind, or to the only place considered relatively 'safe'. In 1990, population densities of up to 20 per sq. $\mathrm{km}$ were registered in Nawor and Ajarestan, of 21-40 per sq. km in Malestan and Bamiyan, and of 41-60 per sq. $\mathrm{km}$ in Jaghoori ${ }^{30}$. However, it may be that these figures are quite high, although whatever the situation, they may well have increased since them due to recent turmoil and population movements.

\footnotetext{
${ }^{27}$ For a timeline marking important dates, please refer to Appendix I, of Part IV.

${ }^{28}$ Economist Intelligence Unit; 1998; Afghanistan Conmtry Profile; EIU; p. 1.

${ }^{29} \mathrm{FAO} / \mathrm{WFP} ; 1997$; Crop and Food Supply Assessment Mission to Afghamistan; FAO/WFP; $\mathrm{p} .3$ ${ }^{30}$ UNIDATA; 1992; Afghanistan: Ghazni Province: A Socio-Economic Profile and Afghamistan: Bamiyan
Province: A Socio-Economic Profile; UNDP/OPS \& UNOCA.
} 
The vast majority of the population in the Hazarajat is involved in agricultural activities. However, the inability of the Hazarajat to feed its population has meant that both temporary and permanent migration have long been an important feature. From Bamiyan, temporary migrants have tended to search for work in Pol-i Komri, Mazar-i Sharif, Kabul and Iran and Pakistan. In this, they tend to go for 6 months leaving after the harvest has been reaped and returning at the beginning of the next growing season. Most villages appear to have had around $5-10 \%$ of their population following this pattern prior to the blockade. From Jaghoori, Malestan and Nawor, young men have tended to migrate in greater numbers and usually for a longer period - perhaps one to three years. All usually found work as farmhands, tailors, builders, waiters and so on, as a result of which they were able to send money to relatives (usually done through passing merchants), or return laden with goods - most notably, rice, tea, ghee and clothes.

Conversely, Hazarajat tended to be subject to the seasonal movements of the nomadic population, the Koutchis. Prior to Soviet Occupation, these were visible throughout the Hazarajat, having also been given Hazara land at the turn of the century to facilitate their sedentarisation (which in turn, was to help both 'modernise' communities by giving them access to important education and health facilities, as well as to 'pashtunise' the country). Today, a number of Koutchis still spend the growing season in Ajarestan, from where they go to Trinkut, the centre of Uruzgan province for six months, due to the higher temperatures. They move together in families or groups around the same time (depending on the size of the households). In Ajarestan itself, the families, where manpower is available, will separate: to nearby pastures with larger livestock, to cultivated land, to mountains with smaller livestock. During this time, male children will attend the Madresseh.

In addition to this temporary migration, the Hazarajat has also traditionally been subject to a permanent exodus of families in search of a better life. While a small number prefer to move within the area, a larger number tend to have opted either for one of the larger towns in Afghanistan, or for neighbouring Iran and Pakistan. Upper Bamiyan, Malestan and Nawor appear to have been particularly affected by this trend.

The effects of inter-factional fighting since 1992, has tended to enhance migratory movements particularly those that are incoming into the Hazarajat, although whether these are temporary or become permanent, only time will tell.

\section{Family Size:}

Among the sedentary population, an average family size of 8 persons could be discerned, although if 'mouths to feed' were generally taken into account, this tended to rise to at least 10 . Figures were even higher for the nomadic populations, although due to the short time spent in the area, a well-grounded estimate is not possible.

\section{Food Production and Dependencies:}

Afghanistan is essentially an agrarian society, the productivity and traditions of which vary with the country's topography and climate. Nevertheless, wheat tends to form the staple food and primary crop throughout the country. The sector, however, has not always been a privileged one and over the years, has suffered much damage due to the war. 
While much of the seed in use in Afghanistan tends to be of local origin, low-yielding and susceptible to disease ${ }^{31}$, high-yielding varieties of wheat and rice were introduced together with the use of chemical fertiliser from the late 1960s onwards. From 1968 to 1978, the production of wheat increased by around $13 \%$, from $2,354,000$ tons to $2,652,000$ tons, and by the mid-1970s, the country had reached self-sufficiency in food-grains ${ }^{32}$. The northern provinces were a particular surplus

However, the effects of the Jihaad against Soviet occupation resulted in a decrease in output, the Soviet army adopting a scorched-earth policy to undermine the Mujahideen and the Mujahideen retaliating by sabotaging economic installations and infrastructure. The government estimated that foodgrain output fell by $30 \%$ between 1978 and 1986. By the end of the 1980s, Afghanistan as a whole had moved to dependency on imports, initially from the former Soviet Union, currently from Pakistan and Iran. Inıports are mainly in the form of wheat flour, although lower quality rice is also imported from Pakistan - in exchange for exports of small quantities of domestic high grade rice ${ }^{33}$. Food imports for 1988 accounted for US $\$ 150,000,000$ or $16.7 \%$ of total imports ${ }^{34}$.

Since then, there has also been an increase in the area under poppy cultivation, reducing the irrigated wheat area ${ }^{35}$. According to the UNDP, this had jumped from 6,000 hectares in the late 1970 s to 57,000 hectares by the early $1990 \mathrm{~s}$, generating 3,200 tons of opium and making Afghanistan by the far the world's largest producer of the raw material for heroin. Deteriorating economic circumstances and the absence of official sanction encouraged farmers, and later returning refugees, to grow poppy as a cash crop ${ }^{36}$.

The livestock population, meanwhile - estimated in the late 1970s at 6.5 million karakul sheep, 15 million ordinary sheep, 3.7 million cattle, 3.2 million goats and 500,000 horses - has also been hard hit by the war, with numbers falling quite substantially. According to a 1988 survey, cattle numbers were down by $55 \%$, and sheep and goats by $65 \%$, while the number of draught oxen, essential for ploughing for most farmers, had declined by $30 \%{ }^{37}$. These animals, besides providing meat, dairy products, fibre and power for local use, also produced raw materials for chief exports (to European markets in particular): carpets and karakul lambskin. In 1990, carpets accounted for US $\$ 44,000,000$ or $18.7 \%$ of total exports, and wool and karakul skins US $\$ 13,000,000$ or $5.5 \%{ }^{38}$.

The Hazarajat has traditionally been a food deficit region, relying significantly on imports of wheat flour, tea, sugar, ghee, fuel, fertiliser, soap and so on. Bamiyan province, given its proximity to the more northern towns of Mazar-i Sharif and Pol-i Komri, relies for the main part on imports passing through these areas coming from the new Central Asian republics, Russia and Iran. Ajarestan, Jaghoori, Malestan and Nawor meanwhile, have depended more upon goods passing through Ghazni, often transiting through Kabul and originating (since the withdrawal of the Soviets) from Pakistan.

\footnotetext{
${ }^{31}$ FAO/WFP; 1997; Crop and Food Supply Assessment Mission to Afghanistan; FAO/WFP; p. 5. ${ }^{32}$ Christensen, A.; 1995; Aiding Afghanistan: the Background and Prospects for Reconstruction in a Fragmented
Society; NIAS Reports, N $^{\circ}$ 26; p. 28 .

${ }_{34}^{33}$ FAO/WFP; 1997; Crop and Food Suply Assessment Mission to Afghanistan; FAO/WFP; p. 1

${ }_{35}^{34}$ Economist Intelligence Unit; 1998; Afghanistan Country Profile I997; EIU; p. 21.

${ }^{35}$ FAO/WFP; 1997; Crop and Food Suply Assessment Mission to Afghanistan; FAO/WFp; p. 4

${ }^{36}$ Economist Intelligence Unit; 1998; Afghanistan Country Profile 1997; EIU; p. 71

${ }^{37}$ Economist Intelligence Unit; 1998; Afghanistan Country Profile 1997; EIU; p. 71

${ }^{38}$ Economist Intelligence Unit; 1998; Afghanistan Country Profile 1997; EIU; p. 21
} 
Exports of livestock, animal hide, gilims and namad (rugs and felt - particularly from Jaghoori), potato (particularly from Bamiyan), poplar and croute (dried curd), on the other hand, have always tended more towards the south and understandably, have been a principal source of revenue (whether on a small or large scale) for huge numbers of families, permitting them to buy much needed supplies of the basic staple commodity, wheat ${ }^{39}$. In the case of both imports and exports, significant losses and damage to goods are encountered due to poor roads and bridges.

Export of manpower, or remittance labour, on the other hand, has tended to pass in both directions - although oriented more towards the north in Bamiyan, and more towards the south elsewhere.

The eruption of inter-factional fighting among Mujahideen members and the ensuing fragmentation of authority has meant that checkpoints along the main arteries feeding into and out of the Hazarajat, have proliferated in number over the past few years. Contingent upon this, has been the arbitrary levying of taxes by local commanders on people and goods passing through their 'fiefdom'. Members of the Northern Alliance and the Talebban are said to charge anything from US \$1 to US \$5 on average, while those under the influence of the Hezb-i Wadhat and actually within the Hazarajat demand considerably less and have considerably fewer checkpoints. However, together, these have been an important factor affecting the profitability and prices of goods as well as the size of remittances (whether brought in-cash or in-kind).

In the north, and affecting Bamiyan province to a greater degree, the closure of the border with Uzbekistan (particularly around Hairaton), has had a major impact on supplies through Mazar-i Sharif, and thus, on prices at that end.

In mid-1997, when the Talêban imposed an economic blockade on the Hazarajat from the south, effectively following the then front-line, the mountainous enclave, particularly the southern areas, became deprived of one of its principal markets and export/import points: Ghazni.

The blockade has involved:

- Greater checks on people travelling between the Hazarajat and Ghazni in addition to more stringent controls on those trying to cross international borders, such that temporary migration to Pakistan and Iran has been slowed down to a trickle, with perhaps only one quarter or even one fifth of previous numbers managing to migrate (Ajarestan being an exception, where numbers appear to have increased). Reports of Hazaras being captured and imprisoned for several months by the Talêban are common. The blockade has also meant that fewer merchants carrying remittance money to relatives are passing the front-line, while those wishing to collect money sent to banks in Pakistan by their relatives abroad are also facing greater problems (since aggravated by the closure of Pakistani banks to foreign withdrawals following capital flight after the recent nuclear test);

- A reduction in both the volume of exports and concurrently, in the amount of money being offered, and due to pressing needs, being accepted for these. Thus, potato exports from Bamiyan, for instance, have witnessed a $50 \%$ reduction in volume. Concurrently, poplar beams have been subject to a $60 \%$ reduction in their value, potatoes $50 \%$, and livestock such as cattle, at least $30 \%$. It is the Talêban and the zones under their control, who are reaping the economic gains from this - through both cheaper goods and in some instances, through greater demand for their own products to substitute those no longer forthcoming. The result within the Hazarajat, meanwhile, has been a sharp reduction in the purchasing power of all

\footnotetext{
39 In 1990, Jaghoori was also reputed to export iron products, farm tools and stone quarry. UNIDATA; 1992 Afghanistan: Socio-Economic Profile of Ghazni Province; UNDP.
} 
those families reliant upon monetary exchange to meet their energy needs. While one sheep previously bought one $100 \mathrm{~kg}$ sack of wheat flour, today, three sheep are required to buy the same amount. Similarly, where 1 ser $(7 \mathrm{~kg})$ of almonds previously bought 3 sers $(21 \mathrm{~kg})$ of wheat, today, the same volume will only purchase 1 ser of wheat. Moreover, traders are increasingly offering banknote in small denominations, which are causing problems of exchange;

- A general ban on food and medical imports destined for the Hazarajat. For this reason, piles of food can be seen at the Talêban checkpoint out of Ghazni - sacks of wheat flour in particular. In part compensation, a smuggling racket has been established whereby wheat flour, tea, vegetables and fruit are all brought by donkey across the mountains at night to Qiork - the market that was also thrown together on the other side in response ${ }^{40}$. It is essentially Pashtun traders as well as certain Talêban military personnel who have been profiting from this thriving commerce. Apparently, the volume of goods arriving is similar to that which would be expected over the winter period; however, the needs over winter are considerably less for most families given relatively low activity levels and that they would have just profited from the harvest a few months before. It is during the hunger-gap/growing season, once stocks start to become depleted, that people are most vulnerable. The result is that while some goods are reaching the Hazarajat, the prices at which they are being sold, are exorbitant. A $100 \mathrm{~kg}$ sack of wheat flour, for instance, leaves Ghazni priced at US $\$ 20$, arrives at Qiork at one and a half times the price (at US \$30), and arrives in Malestan priced at US \$49. Eighteen months ago, that same sack would have cost US \$8 - indicating a sixfold increase. This is shown in the diagram below (prices for Nawor proved difficult to obtain):

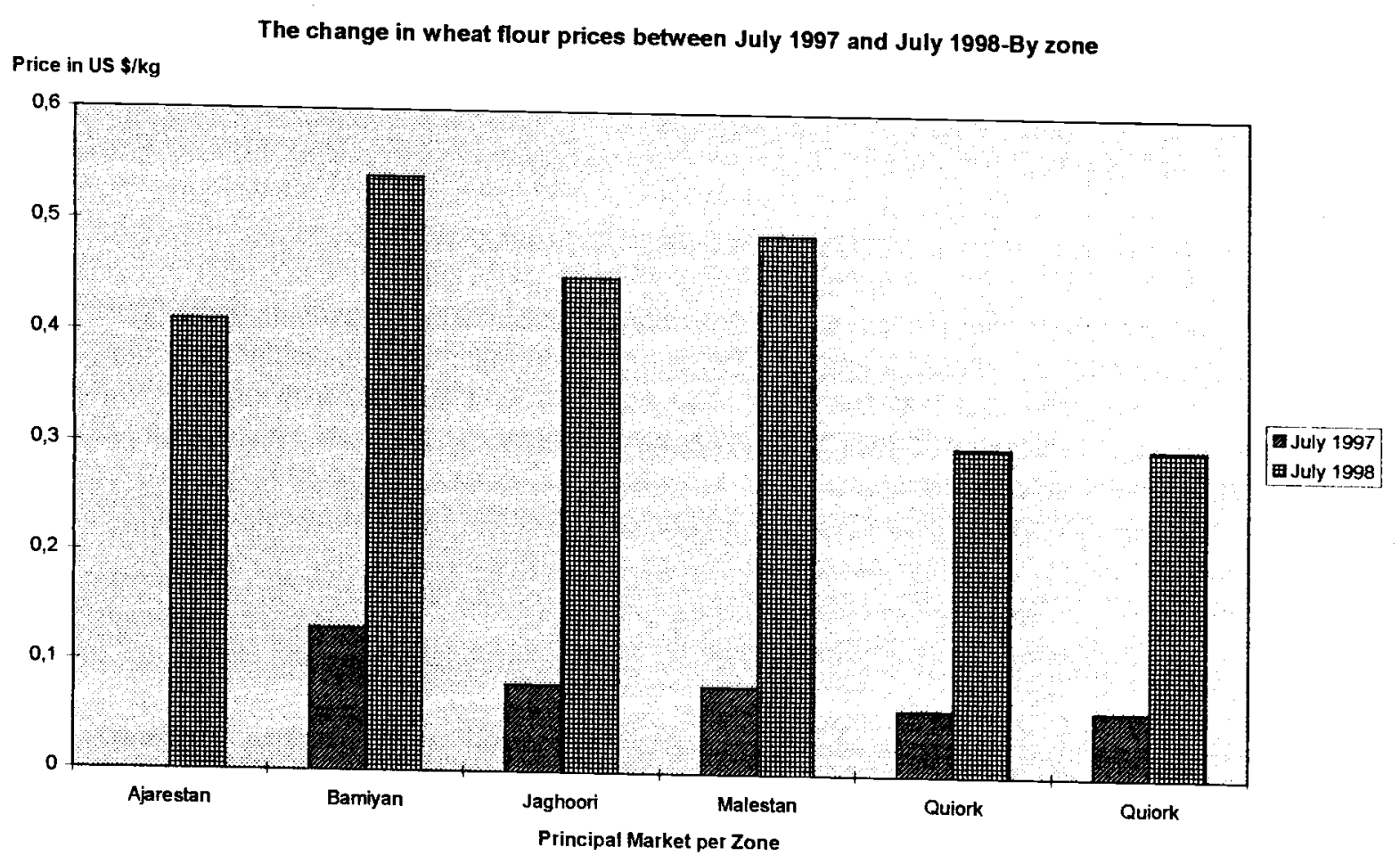

\footnotetext{
${ }^{40}$ Prior to the blockade, Qiork essentially served as a military base for the Mujahiddeen during the Soviet
occupation, and subsequently for Hezb-i Wahdat.
} 
The situation in Ajarestan presents something of an aberration: while within the Hazarajat, it is a Pashtun enclave with strong links to the Talêban. As such, it is witnessing increased demand for certain of its export products, among them poplar beams and potatoes - both by at least $30 \%$. Poplar beams have also been subject to an important price increase - in theory, due both to the reduction in supply from the Hazarajat in general ${ }^{41}$. At the same time, however, livestock exports from Ajarestan (for the resident population) have diminished since road closure through Hezb-i Wahdat held areas has meant a diversion along the road to Kandahar that is too long and hazardous for their transportation alive - in addition to being costly and so reducing profitability ${ }^{42}$. It has, however, been affected by the increase in wheat prices due to transportation problems.

The Talêban have effectively been using hunger as a weapon, as a means to subdue and weaken the civilian, non-combatant communities of the Hazarajat by attacking their very means of subsistence. As such, the blockade should be in direct violation of both International Human Rights and International Humanitarian Law:

- Article 6 of the International Covenant on Civil and Political Rights, for instance, stipulates that: 'every human being has an inherent right to life. No one shall be arbitrarily deprived of his life';

- Article 14 of Additional Protocol II to the Geneva Conventions, meanwhile, declares that: 'starvation of civilians as a method of combat is prohibited. It is therefore prohibited to attack, destroy, remove or render useless, for that purpose, objects indispensable to the survival of the civilian population, such as foodstuffs, crops, livestock, drinking water installations and supplies and irrigation works'.

This said, however:

- The Talêban neither claim adherence to such international norms nor recognise their applicability - however much - paradoxically - they crave international recognition;

- The international community due to the predominance of a sovereign-State system combined with the existence of vested interests, has no coercive mechanism by which to internationally enforce such legal provisions.

It is not known what the current situation is; whether with the capture of Bamiyan food supplies are being released or whether the blockade has been intensified as part of a strategy to subdue the population.

\section{Education:}

Education facilities throughout Afghanistan have tended to be somewhat limited - featuring Madresseh (religious schools) and primary schools in particular, both of which have been most prevalent in urban areas - particularly that of Kabul. By 1971, only about $4 \%$ of students attended high schools, with the number of males far outweighing those of females - but both again being concentrated in Kabul as opposed to in outlying regions. By $1979,90 \%$ of the population was still illiterate. The advent of the Talêban has led to the implementation of strict constraints on girls attending schools and other higher educational structures.

\footnotetext{
${ }^{41}$ Potatoes are also being supplied through Pakistan, which means that the effect on potato prices has not been so dramatic.

${ }^{42}$ This route involves travel through Kandahar and then on to Ghazni, adding some $480 \mathrm{~km}$ onto what would normally be a journey of $120 \mathrm{~km}$ and taking around 2 days of travel.
} 
Within the Hazarajat (a traditionally marginal area), Madresseh were found to be quite prevalent, with both-boys and girls attending. Ostensibly non-religious schools (including male-only boarding schools), were also found to exist, being shared between several villages at a time. In Pashtun Ajarestan, however, only Madresseh were noted, although there were facilities for private tuition. Fees were charged according to ability and essentially went towards payment of teacher salaries. There was one university, that of Bamiyan.

\section{Health:}

Across the country by 1978 , there were 64 hospitals, 157 basic health centres and 132 sub-health centres. Most of these were in the larger towns, with only $25 \%$ of the country's population estimated to be covered by some form of health service delivery ${ }^{43}$. Much of all this has been damaged or totally destroyed by the war, with a large share of qualified medical personnel killed during the war or having fled the country. Within Talêban areas, women were banned from working and female patients from being treated by male doctors.

Ajarestan was found to be devoid of any health structure, although 20 years previously, a hospital did exist but was destroyed during the anti-Soviet resistance. Elsewhere, one hospital was to be found in Bamiyan (under the aegis of the Iranian government and the Iranian Red Crescent), and another in Jaghoori (supported by Shuhada). Throughout the area (Ajarestan excepted), clinics were also in evidence - although in Nawor, only vaccination facilities were available. Also important, was traditional medicine - particularly in Ajarestan - with herbs being brought from the mountains (mostly by women - again except in Ajarestan), and sinall plants often being grown in the vicinity of the household. In Malestan and Bamiyan, at least, it was noticed that small amounts of poppies were grown for medicinal purposes.

\section{Financial Management:}

Within Talêban-held areas, the Afghani is used as the main currency; however, most banks have collapsed and the relevant ministries appear somewhat limited in capacity.

In former Northern Alliance areas, the Hazarajat included, a new currency, known as the Dostumi (or alternatively as the Jumbashi), was established as the medium of exchange following the expulsion of the Jamiat from Kabul. Tapping into a previous agreement that had been conducted between Kabul and Moscow when both had communist governments and subsequently reactivated under the Jamiat when it held sway in $\mathrm{Kabul}^{44}$, this involved the airlifting of large quantities of Dostumi printed in Russia to the north of Afghanistan ${ }^{45}$. At this point the money was divided among the principal Northern Alliance leaders, Dostum, Masood and Khalili, and presumably used to pay troops and encourage the allegiance of rival faction leaders and commanders ${ }^{46}$. This then, reinforced external dependency - on a country that itself only recently fell into deep economic recession.

\footnotetext{
${ }^{43}$ Christensen A.; 1995; Aiding Afghanistan: the Background and Prospects for Reconstruction in a Fragmented
Society; NIAS Reports, $\mathrm{N}^{\circ} 26 ;$ p. 34 .

${ }^{44}$ The notes were essentially the same as the Afghanis that were also printed in Russia, their main distinguishing feature being in the lettering and the numbering, whereby any note having a registration number more than 35 was a Dostumi - all other being Afghanis

${ }^{45}$ It is not known whether the printing of Afghanis was discontinued after Talêban take-over and what medium of exchange was prevalent in Talêban-held areas.

${ }^{46}$ It is not known how access to hard currency came about allowing the groups to purchase arms for the war effort unless these were effectively 'donations' from Uzbekistan, Iran, Russia, India and so on
} 
Given, however, that each administration's overriding priorities were of a military nature and that any amount of Dostumi could be ordered without the existence of a guarantor, public finance management would appear to have become something of a meaningless concept. Price evolution and inflation. Indeed, money-changers appear to be the only providers of financial services.

The Hazarajat further suffered from the partition of the area into two monetary zones, each one predicated upon the direction of trade flows and the money in use at the relevant trade centres. Thus, while Bamiyan used Dostumi, Nawor, Malestan, Jaghoori and Ajarestan all used Afghanis - one result of which must have been to complicate flows of goods and people through the area

\section{E. Political Economy:}

The history of the territorial entity known as Afghanistan has been perhaps most marked by three phenomena - most of which have provoked an outward orientation that has exacerbated internal fragmentation. An understanding of these phenomena should permit a better understanding of the country's situation today since the Afghan State has traditionally had to contend with all of these none of which look set to disappear in the immediate future (for a more in-depth analysis, please refer to Appendix II):

\section{Geopolitics:}

Being situated at the cross-roads of Central Asia and being landlocked, Afghanistan has traditionally been vulnerable to external influence, coveted as a trade route on the one hand (to the Central Asian states in particular), and dependent on transit rights through neighbouring countries on the other.

The inability of the State to finance its drive for modernisation domestically, such that recourse has constantly been sought from foreign sources who, in turn, have tended to be motivated by quite different considerations:

Historically, the weakness of the Afghanistan State entity was compounded during the Jihaad against Soviet occupation, which effectively gave vent to the micro-societies making up Afghanistan. At that time, tax collection in most outlying regions, the Hazarajat included, was essentially rendered defunct and in the formal sense, remains so today. The result has been dependence on Russia, followed today by significant dependence on Pakistan, the United States and Saudi Arabia. In this, the distance between the ruling Talêban and that of the societies ruled, has grown, with the Talêban, whose repressive policies have grown, essentially acting with little, if any, reference to the Afghan population. Indeed, no mechanisms of accountability have yet been established between the two: instead, the gulf between ruling and ruled has tended to grow - and with it, so too may civil unrest.

The existence of a plethora of micro social structures and competing identities, where these have in certain instances, nurtured centripetal forces tugging and pushing towards groups of similar ethnic, religious or other affiliation elsewhere:

At one level, towers Islam as an immensely important factor in Afghan society, both legitimising and uniting resistance to the Soviets, and causing arms to be stretched towards other Islamic societies - from Saudi Arabia to Iran. At the same time, religion has also provided a factor of fissure. In this, most of the Afghan population is Sunni (hence, the links with countries like Pakistan and Saudi Arabia), with only the Hazaras being Shi'a (hence, the links with Iran). The distinction is 
based on allegiance to one or other group succeeding the Prophet Mohammed, but has also meant that Shi'as tend not to be recognised by Sunnis, so leading to considerable tension.

At another level, are the ethnic groups (and within these, tribal associations), making-up Afghanistan. Of the most important groups, are perhaps the Pashtuns, who make-up the overwhelming majority of the Taliban and are Sunni, the Tajiks (also Sunni, with links to their confreres in Tajikistan) and the Hazara. The Pashtuns (groups of whom may also be found in neighbouring Pakistan), have tended to predominate throughout Afghan history, to the exclusion of other ethnic groups - manifest today in the significant hostilities witnessed between themselves on the one hand, and the Tajiks, Hazaras and so on, on the other hand. However, friction between nonPashtun groups has also served to impede coalition-building and cohesion.

At a third level, exists that of what remains of feudal Afghanistan, which has conditioned a series of relationships between landholders and landless in the rural areas, based on systems of employment and rent, patronage and clientelism. This too, has caused a fragmentation of authority structures within Afghanistan, reinforcing those present at other levels - and still to some extent, unresolved today.

\section{The Effect on Land Distribution in the Hazarajat:}

While the Hazarajat may no longer be overtly feudal, feudalistic relationships can still be discerned, although having been subject to the ravages of war and the changes that this has brought about.

Across the six zones surveyed by Action contre la faim, significant inequalities were revealed particularly in Ajarestan, Malestan and Nawor. Here the tendency appeared to be for a sprinkling of large landowners in each village (often just 1-3), with anything from 10 to 50 jeribs (2-10 hectares), followed by a cohort of small landholders and landless labourers. In some villages, in fact, this group of small landholders did not even exist - there being only the landlord and the tenant. It may well be that through the practice of mortgaging ${ }^{47}$, land has been increasingly transferred from the small to the large landholders due to increasing bankruptcy due to increasing difficulties in obtaining access to food.

These same landlords also owned the mountains and the grasslands, although landless labourers were usually allowed to graze their animals on this land, with the landlord having priority.

In Lower and Upper Bamiyan, as well as in Jaghoori, on the other hand, small landholders, in addition to a number of landless labourers (often IDPs), appear to predominate. In the same way, pastureland may be common property rather than private, with the livestock of different villages sharing the same pasture.

In all cases, demographic pressure and Islamic inheritance law had resulted in increasing land fragmentation - particularly visible in Upper Bamiyan.

\footnotetext{
${ }^{47}$ A mortgage involves a loan for which the borrower, instead of paying interest, transfers the right to cultivate a
piece of land to the creditor, whilst still retaining the title to the land.
} 


\section{F. EXPRESSIONS OF SOCIO-CULTURAL NORMS AND VALUES:}

Intra-Community Support Mechanisms:

While people are aware of their membership of more inclusive social entities, it is their local qawm, based on patrilineal kinship, in the village of locality where they live which constitutes the framework that defines their main identity and allegiance - so very much colouring community systems of inter-aid. Across the board, however, current circumstances have been such as to put increasing pressure on coping mechanisms relying on these, to the extent that they are being increasingly weakened: the already vulnerable, then, are set to become even more so.

Table 4: religious obligations and different other practices

\begin{tabular}{|c|c|c|}
\hline MECHANISMS & EXPRESSION & COMMENTS \\
\hline \multicolumn{3}{|c|}{ Religious Obligations } \\
\hline Zakaat & $\begin{array}{l}\text { A yearly tax levied on one-fifth of a } \\
\text { family's total surplus and usually } \\
\text { redistributed by the religious } \\
\text { establishment among the poor - } \\
\text { Female-Headed Households, the } \\
\text { Disabled and the Elderly included }\end{array}$ & $\begin{array}{l}\text { - forms one of the five pillars of } \\
\text { adherence to Islam; } \\
\text { - in Ajarestan, this was formally } \\
\text { collected by the Governor, whereas } \\
\text { elsewhere throughout the Hazarajat, no } \\
\text { institutionalised mechanism appeared to } \\
\text { exist. }\end{array}$ \\
\hline Oshra & $\begin{array}{l}\text { A tax levied on land and livestock and } \\
\text { given to the Mullah (or religious } \\
\text { establishment) to distribute. }\end{array}$ & $\begin{array}{l}\text { - in Ajarestan, this was also formally } \\
\text { collected by the Governor }\end{array}$ \\
\hline Nasr & $\begin{array}{l}\text { Gift given to the families of martyrs - } \\
\text { usually meat }\end{array}$ & - tends to be informal \\
\hline Sadaqa & $\begin{array}{l}\text { A one-off gift or donation to poorer } \\
\text { members within society - including } \\
\text { rice, bushes for fuel, milk and } \\
\text { yoghurt, and so on. }\end{array}$ & - tends to be informal. \\
\hline \multicolumn{3}{|c|}{ Practices not explicitly Religious } \\
\hline $\begin{array}{l}\text { Growing } \\
\text { Season }\end{array}$ & $\begin{array}{l}\text { - A collective effort is made by all } \\
\text { landholders, whether formally or } \\
\text { informally organised, to clean and } \\
\text { repair the irrigation network; } \\
\text { - Oxen are often lent to poorer } \\
\text { villagers free of charge; } \\
\text { - Help is given to villagers with } \\
\text { insufficient manpower in } \\
\text { harvesting their crops. }\end{array}$ & $\begin{array}{l}\text { - These are especially evident among the } \\
\text { poorer villages - usually those situated } \\
\text { in zones at high altitudes like Upper } \\
\text { Bamiyan and Nawor - although not } \\
\text { absent elsewhere. }\end{array}$ \\
\hline Loans & $\begin{array}{l}\text { Perhaps in accordance with the } \\
\text { Qu'ranic injunction against usury, } \\
\text { no interest will be charged within } \\
\text { the village (however, loans taken } \\
\text { out externally may be subject to } \\
\text { interest rates of } 40-100 \% \text { or more, } \\
\text { over a one year period) }\end{array}$ & $\begin{array}{l}\text { - In-kind and cash; } \\
\text { - These may take place among relatives, } \\
\text { neighbours, friends, but in a large } \\
\text { number of cases, in fact, interest is } \\
\text { charged - the amount being dependent } \\
\text { on the relationship of the borrower to } \\
\text { the lender and the risk associated with } \\
\text { the loan. }\end{array}$ \\
\hline
\end{tabular}


Table 5: Important Festivals Reaffirming Community Cohesion:

\begin{tabular}{|c|c|c|}
\hline $\begin{array}{l}\text { IMPORTANT } \\
\text { FESTIVALS }\end{array}$ & SYMBOLISM & SOCIAL EXPRESSION \\
\hline Weddings & $\begin{array}{l}\text { Alliance between two } \\
\text { families and their } \\
\text { tribes (see Appendix } \\
\text { III of Part IV for more } \\
\text { detail) }\end{array}$ & $\begin{array}{l}\text { - All villagers asked to share in a meal of rice with meat } \\
\text { from a calf or sheep specially slaughtered for the } \\
\text { occasion; among the poorer families soup may be } \\
\text { more common together with some wild vegetables; } \\
\text { - Outside Taliban-held areas singing and dancing will } \\
\text { usually take place: men and women separately. Where } \\
\text { possible, men may hold their festivities outside with } \\
\text { perhaps one person going to the front of an audience } \\
\text { and dancing to their applause; money may be thrown } \\
\text { for the poorer village boys to collect. Women } \\
\text { meanwhile, will tend to be constrained to the private } \\
\text { sphere, inside the house, also with one woman or } \\
\text { young girl being chosen to dance before the rest. }\end{array}$ \\
\hline Deaths & & $\begin{array}{l}\text { On the third day of mourning food and sadaqa, a one- } \\
\text { off form of alms-giving (often cash particularly where } \\
\text { children have been left behind) are prepared by those } \\
\text { villagers able to do so and given to the bereaved family } \\
\text { together with words of condolence from non-intimates; } \\
\text { - In Afghanistan, a cult of martyrdom was evident } \\
\text { among both Shi'as (already integral to their way of life) } \\
\text { and Sunnis during the Jihaad against Soviet occupation } \\
\text { with flags placed over the gravestones; nasr may be } \\
\text { offered to such families. }\end{array}$ \\
\hline $\begin{array}{l}1^{\text {ST }} \text { Eid, Eid al- } \\
\text { Fitr }- \text { in } 1997, \text { in } \\
\text { January }{ }^{48}\end{array}$ & $\begin{array}{l}\text { Religious festival for } \\
\text { both sunni and Shi'a; } \\
\text { ends period r of } \\
\text { Ramadan or fasting } \\
\text { (one of five pillars of } \\
\text { Islam). }\end{array}$ & $\begin{array}{l}\text { - A Mauludi in Taliban-sunni areas and a Mullah in } \\
\text { Hazara-Shi'a areas will usually preside; } \\
\text { - Money is collected among the more wealthy and } \\
\text { distributed among the village; } \\
\text { - Rice and wild vegetables may be prepared together } \\
\text { with mutton again by the more wealthy families, and } \\
\text { distributed among their relatives and the poor. }\end{array}$ \\
\hline $\begin{array}{l}2^{\mathrm{ND}} \text { Eid: } \\
\text { Qurbani - in } \\
1997 \text {, in March } \\
\text { (usually } 2 \text { months } \\
10 \text { days after } 1 \mathrm{st} \\
\text { Eid). }\end{array}$ & $\begin{array}{l}\text { Associated } \\
\text { pilgrimage to } \text { wecca } \\
\text { and } \\
\text { (Abraham and the } \\
\text { sheep), as a form of } \\
\text { repentance. }\end{array}$ & $\begin{array}{l}\text { The more wealthy families provide food (usually meat) } \\
\text { which will be distributed to the villagers through } \\
\text { village elders; }\end{array}$ \\
\hline Hyroth $^{48}$ & $\begin{array}{l}\text { Religious festival to } \\
\text { celebrate the return of } \\
\text { a family member } \\
\text { absent for some time - } \\
\text { important in a society } \\
\text { where temporary } \\
\text { migration features } \\
\text { strongly. }\end{array}$ & - Distribution of food. \\
\hline
\end{tabular}

\footnotetext{
${ }^{48}$ The dates of each of these religious festivals varies, being dependent, in Sunni areas, on the Arabic lunar calendar based on a 28-day month, and in the Shi'a areas, on the solar calendar (introduced into Hazarajat one year ago).
} 


\begin{tabular}{|c|c|c|}
\hline $\begin{array}{l}\text { Maharam - in } \\
1997, \text { in April }\end{array}$ & $\begin{array}{l}\text { A Shi'a festival } \\
\text { commemorating the } \\
\text { assassination of Ali } \\
\text { and lasting } 10 \text { days - } \\
\text { the } 10^{17 \mathrm{H}} \text { day being } \\
\text { known as Ashora, the } \\
\text { day on which Ali's } \\
\text { sons, Hussein and } \\
\text { Hassan were killed. }\end{array}$ & $\begin{array}{l}\text { - Communal prayers will be said in the mosque (women } \\
\text { and men separately) and a discourse relating religion to } \\
\text { current affairs often given; } \\
\text { - Crying over the murder will also occur; } \\
\text { - Wheat seed and sometimes meat may be collected } \\
\text { from the } 2-3 \text { wealthier families on a rotation basis: } \\
\text { halwa a sweet made from flour, water, sugar and } \\
\text { almonds may also be included where possible: this will } \\
\text { be distributed to villagers through the mosque. }\end{array}$ \\
\hline
\end{tabular}

\section{G. SEVEN HOUSEHOLD TYPES:}

Identified during the course of the Food Security surveys, these effectively correspond to feudal divisions, with an additional strata of vulnerable households having been inserted to take into account the impact of the blockade around the Hazarajat. However, given that the surveys were qualitative in character, it is not known to what extent, statistically, these household types hold true.

\section{A: Large Landholders or Owner-Occupiers:}

These have been classified as any landholder having 6 jeribs or more - an equivalent to 1.2 hectares. Across those surveyed, an average of 8.3 jeribs ( 1.66 hectares), was noticed, in accordance with an average family size of 13 persons. These families were often found to have members abroad in other countries (although remittances may now be significantly diminished), or working in nonagricultural occupations. They often hire landless labourers to assist them in working the land. They also appear to have a fair amount of livestock - in the region of: at least one ox if not a pair of oxen, at least one cow if not more, 1-2 donkeys, and often 4 or more sheep and/or goats as well as around 4 chickens.

It should be noted, however, that in Nawor the amount of land is usually higher than elsewhere due to the use of dryland, or rainfed, cultivation. In both Nawor and Ajarestan, meanwhile, the number of livestock also tends to be higher due to a more favourable ecological environment for this.

As a rule, most such large landholders currently have access to both manure and chemical fertiliser, if only for key crops such as wheat, barley and potato. However, this they may have been obtained by borrowing money or mortgaging a part of their land - given in particular the reduction in remittance labour possibilities. Nevertheless, should the need arise, they still have relatively significant decapitalisation possibilities - including a (usually) full range of agricultural tools (and often the means with which to furnish any necessary wood for their fabrication), as well as gilims, bicycles, watches, sewing machines - not to mention a relatively large house. However, it is not known how production needs may come into conflict with any marriage costs that require covering. These same people are also responsible for providing for community festivals.

\section{B: Small Landholders or Owner-Occupiers Currently Having Access to Chemical Fertiliser:}

These tend to have an average of 2.4 jeribs, or 0.48 hectares, corresponding to an average family size of 12 persons. However, most families also tend to be significantly reliant on remittance or wage labour, and/or access to a cash crop - such as potatoes in Bamiyan Lower Valley, apricots and almonds in Jaghoori, or poplar in Malestan. They may hire labourers to help them work their land. All would appear to have their own tools with which to work the land, although they may not all 
have the material required to make the tools, instead depending upon the market. In terms of animal traction, these families often had one ox, sharing with their neighbour to make up a pair. Where they did not have any animal traction power they tended to hire a pair of oxen, usually for a fixed sum of money which appears to vary according to financial status. Other livestock usually included one cow, one donkey and perhaps two sheep/goats as well as one/two chickens.

In Jaghoori, however, the number of cattle was significantly less due to ecological constraints and the impact of the war. As a result, oxen were often substituted either by manpower or by donkeys. The Koutchis also represent a slightly different case, given that the basis of their wealth lies with the number of livestock possessed rather than any land - whether semi-sedentary or otherwise. Semisedentary Koutchis all seem to have a pair of oxen, and like the non-sedentary, will have perhaps five or more camels, two or more cows and 100 or more sheep/goats - particularly among the more wealthy.

In order to purchase chemical fertiliser, loans often proved to be the intermediate stage prior to harvest time when the lender could be repaid - usually in wheat or another crop, if not in cash. The interest on these loans tends to vary, often being interest-free for the first 2-3 months, and then ranging between $40 \%$ in Malestan to $100 \%$ in Bamiyan Upper Valley. In some instances, prioritisation has taken place with fertiliser being used only for wheat, the staple cereal throughout the Hazarajat, or for a designated part of a selected crop. This was most notable in Bamiyan Upper Valley and Nawor High Plateau.

In order to fend off food insecurity generated by the blockade, these households have also taken to increasing their wild food intake and a greater dependency on their own food production - as the diagrams below illustrate.

Food income sources for Household Type B over Spring/Summer 1997

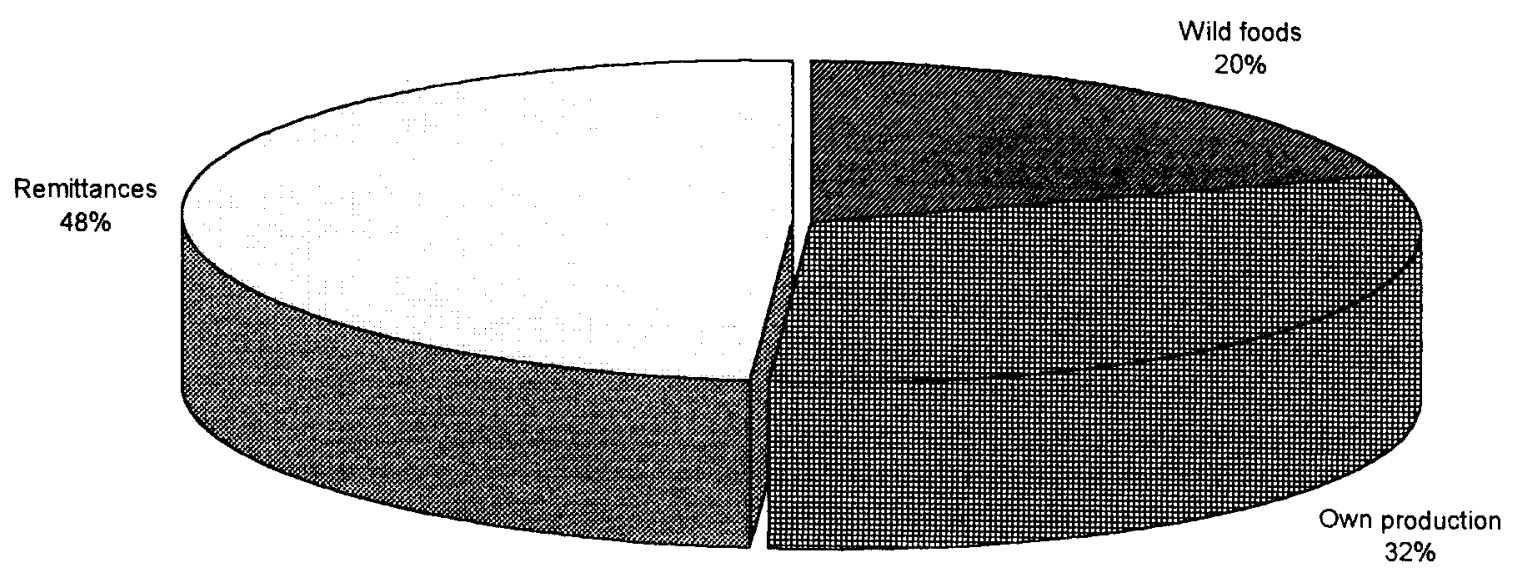




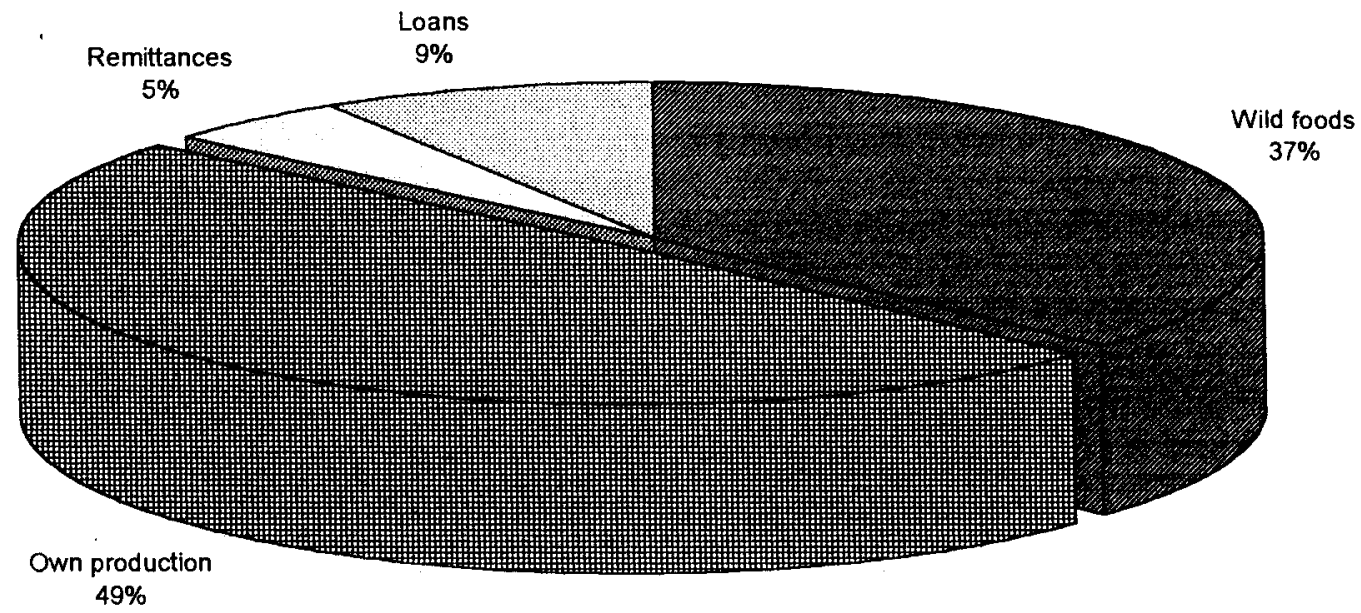

Whatever the case, these families appeared to have sufficient capital assets to survive in the immediate term without depleting stocks and crossing the threshold towards decapitalisation (on the assumption that conditions remain the same - no looting or pillaging causing damage to assets and/or destitution). Again, however, it is not known to what extent debt might be engendered due to marriage and the expenses that go with it. These families may also be those involved in providing for community festivals.

\section{Small Landholders or Owner-Occupiers No Longer or Never Having Access to Chemical Fertiliser:}

In this category were found those with an average of 1.9 jeribs, or 0.38 hectares, for a family of approximately 9 persons. These families tend to have a small number of livestock. A few, particularly in Lower and Upper Bamiyan, have one ox which again they will share with their neighbours to make up a pair (although a much smaller number might have a pair). All tend to have one cow, one donkey and perhaps three sheep/goats as well as one/two chickens. Some also have recourse to small amounts of cash crops and/or have previously gained from remittance money. Others - particularly those with 1 jerib ( 0.2 hectares) or less, may engage in work as labourers (whether daily or resident for the duration of the growing period), for larger landholders whether in their own village or elsewhere in the Hazarajat. In this case, their land tends to be left with a relative, who then obtains $1 / 5$ of any yield. For the relatively large numbers of Female, Disabled and Elderly-Headed Households that fell into this category, and lacked sufficient manpower, a labourer was hired - gaining 1/5 of any yield, and therefore reducing the yield for the relevant family.

At another level, these families also appear to have been significantly hit by the blockade in that where once chemical fertiliser was purchased, today none have been able to afford this, immediate needs being too great to invest in the future. Moreover, not all families within the category were found to have the full range of tools, animal traction or manpower (at peak periods) to work their fields. Indeed, these same households may have increasing problems in replacing their tools as a result of the costs imposed - particularly in Nawor where wood for their fabrication is relatively less. 
As a result, increasing reliance on community assistance and cohesion might be noted: the lending of tools, the lending of oxen or the collective reaping of fields at harvest time. This not only draws upon mechanisms of social exchange, but through the collective experience and activity, reinforces it. However, it does mean that such families may have to 'wait their turn', which could affect the
quality of their yields.

Among the Tajik returnees in Bamiyan Lower Valley, a dearth of tools and traction animals is particularly visible, especially in villages that are not ethnically mixed and thus, contain no long-time resident Hazaras with whom to share. In the extreme cases, particularly among with those Female, Disabled or Elderly -Headed Households suffering from manpower shortages, land has been left
uncultivated.

Within the group as a whole, particularly in Bamiyan Upper Valley and Malestan, are also significant numbers of farmers who are unable to keep the seed rate necessary for the next season, due not only to an inferior seed quality, but also due to inadequate yields relative to consumption requirements. Some, in Nawor, have also changed their cropping practices, mixing barley with
alfalfa, for instance.

Across the board, large numbers appear to have contracted a fair amount of debt - usually more than $\$ 50$ US - mostly borrowed as food (the interest on these loans tends to vary, often being interest-free for the first 2-3 months, and then ranging between $40 \%$ in Malestan to $100 \%$ in Bamiyan Upper Valley), or through the mortgaging of their land in order to purchase food. A further number have also had to decapitalise over the last two years in order to survive - either through selling more livestock than would be considered standard practice, or in the worst case scenario by selling their land - something which most are loathe to do. This has particularly been the case for those with medical costs to cover, and may well be the result of marriage debt as well. Members of this household type have also increased their intake of wild foods in order to ward off food insecurity as well as having had recourse to external assistance (usually that of WFP) - as shown in the diagrams below:

Food income sources for Household Type C over Spring/Summer 1997

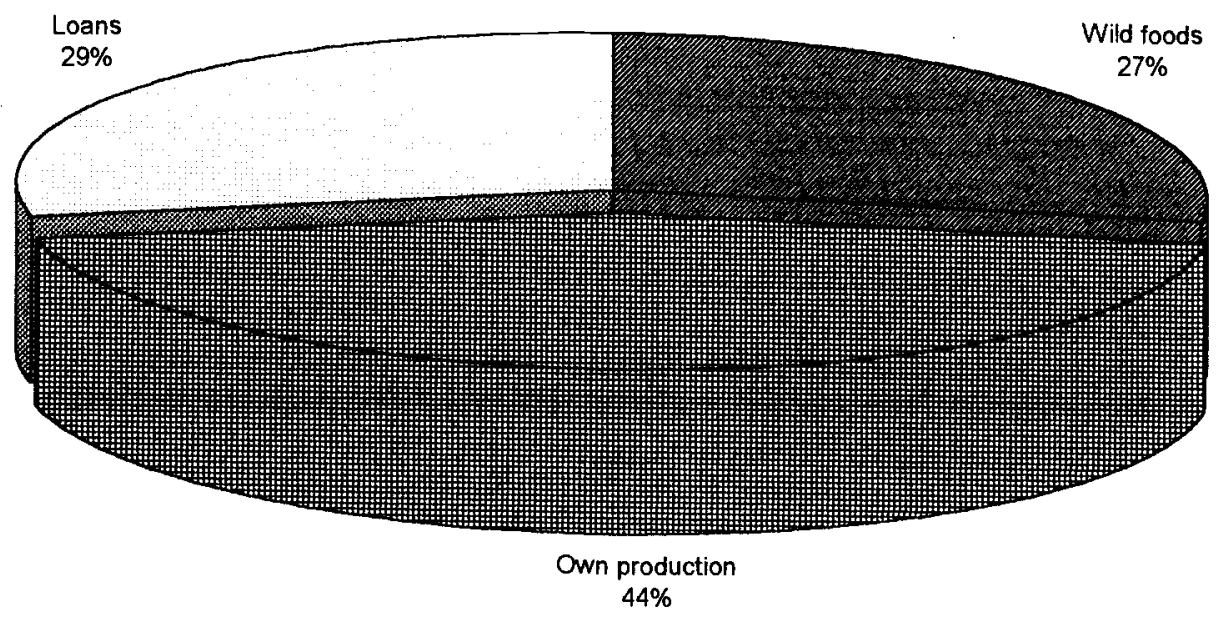




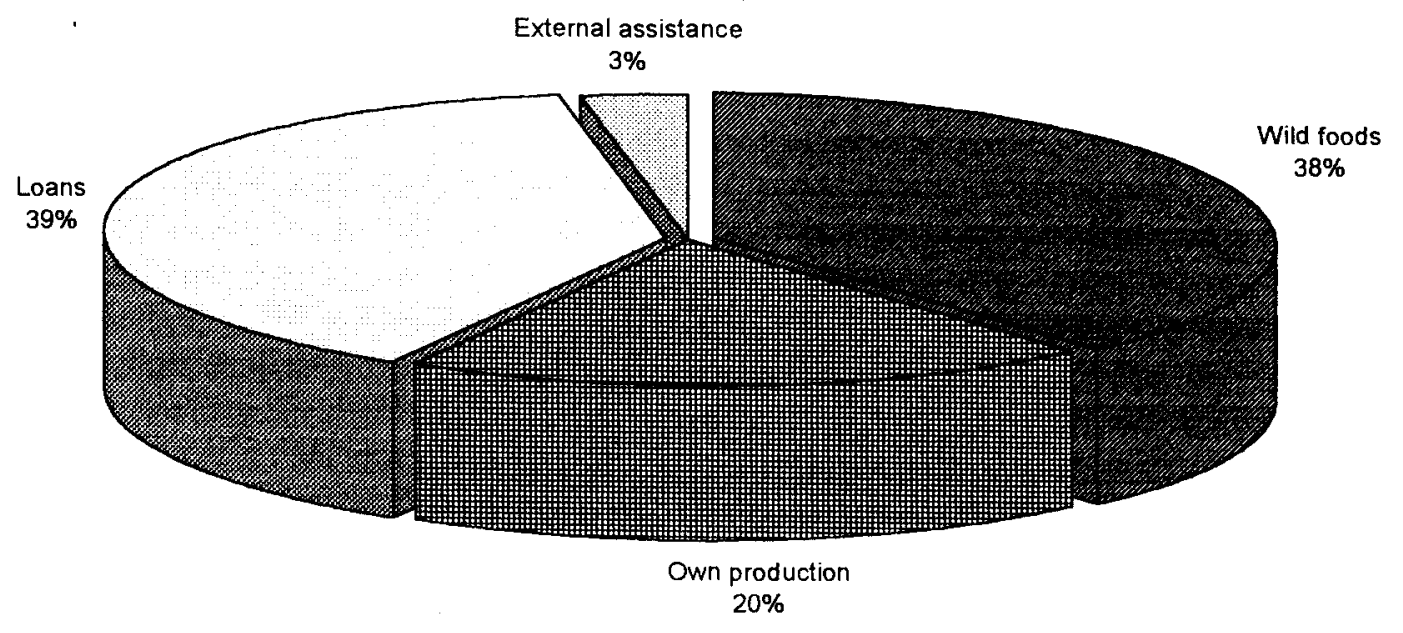

D. Yeoman: Landless Labourer Working and Living on the Land of the Landholder but who Supplies the Seeds, the Fertiliser and the Animal Traction Himself:

These tend to be share-croppers receiving half or two-fifths of the yield. Such labourers have greater decapitalisation possibilities in times of need compared to those groups below, although they usually lack their own houses, living in that of the landlord. They tend to have a full range of tools as well as a fair amount of livestock, including the pre-requisite pair of oxen to work the land, as well as other cattle, sheep and goats. However, the sample size was so small that it would be difficult to make any generalisations beyond this. No households of this type were encountered in either Bamiyan Upper Valley or Jaghoori.

Should these households be forced into decapitalisation of livestock due to a bad harvest, or marriage costs for instance, they might then be relegated to the status of a serf.

\section{E. Serf: Landless Labourer Working and Living on the Land of the Landholder Where the Latter Supplies the Seeds, the Fertiliser and the Animal Traction:}

These tend to be share-croppers receiving $1 / 5$ of the yield (alone or in conjunction with any other labourer). They have even fewer decapitalisation possibilities, being all the more dependent on the landlord: living in the landlord's house, using the landlord's equipment - although they may have a few livestock (but generally, no traction animals). A number of Internally Displaced Persons fall into this category - Hazaras who have fled other areas due to persecution and the war hostilities, but have no land or family to which to return. Debt levels also tend to be high and are no doubt aggravated by marriage expenses and so on. 


\section{F. Landless Labourers: Obtaining Casual Work:}

While some of these appear to possess their own houses, others appear more dependent on the largess of community members. The majority of landless labourers tend to be Internally Displaced Persons, displaced either for reasons of poverty and 'hunger', or due to the war. Where recent arrivals, they tend not to have any livestock, although the more established may have at least one cow. Many of the landless labourers engage in work on farmland, receiving 1/4 of any yield. Others work as guards for the village pasturelands (particularly relevant in Malestan and Jaghoori due to ecological limits on the amount of land available for these), as shoemakers, as porters in the nearest market (particularly in Bamiyan Lower and Upper Valleys), as collectors of grass, small shrubs and bushes from the mountains and so on. Their wives may also be employed in collecting grass for sale beyond any needed for livestock. Still others - particularly small Female, Disabled or ElderlyHeaded Households may also be in regular receipt of, or involved in seeking, community assistance - whether wheat, rice, or dhour, for instance, as part of a family's zakaat, sadaqa or so on. Throughout the Hazarajat, significant numbers have also been in receipt of aid from WFP. Debt levels also tend to be very high - with interest rates ranging from $40 \%$ in Malestan to $100 \%$ in Bamiyan Upper Valley over a one year period. Marriage expenses and so on, would only aggravate

\section{G. Unemployed:}

These families tend to have no livestock, and to be the most endetted. They also tend to be relatively small in size (perhaps 4 or 5 persons). Often they may be newly arrived Internally Displaced Persons lacking family or land, or Female, Disabled or Elderly Households - either lacking sufficient manpower to work and/or constrained, particularly in Ajarestan, from working due to the norms and values governing the gender division of labour outside the household sphere. As such, these families are essentially dependent on mechanisms of community and external assistance. 


\section{A. Production/Consumption Possibilities:}

\section{By Zone:}

In terms of zones, ecological and financial constraints appeared more considerable in Bamiyan Upper Valley, Malestan and Nawor, whether subject to land shortage, flooding, water shortage or crop disease, for instance. Ajarestan, Bamiyan Lower Valley and Jaghoori, on the other hand, being at lower altitudes and having better market access, were found to have both better crop yields and diversity, together with other income-generating possibilities permitting indirect access to consumption possibilities. In accordance with this, it was found that long-term chronic malnutrition was less prevalent in Ajarestan and Jaghoori (the data for Bamiyan Upper and Lower Valleys not being comparable due to differences in methodology), compared to Malestan and Nawor.

Acute malnutrition, meanwhile, precipitated by sudden changes in the immediate, was not found to be a problem as such throughout the Hazarajat, although it may be assumed that should any problems arise due specifically to the blockade and the concomitant weakening of coping mechanisms, for instance, these too, may afflict Malestan and Nawor (as well as Bamiyan Upper Valley) to a greater extent than elsewhere, due to the greater vulnerability of these zones to a reduction in purchasing power as imposed on pre-existing structural problems.

\section{By Household Type:}

In an attempt to better understand the constraints faced by household type, the divergence between production and consumption possibilities was assessed, taking land as a baseline and then assessing the contribution of animal husbandry to these. This was done by calculating the number of kilocalories required per family per annum and then offsetting this against productive capacity. The following assumptions were made:

- That all cereals and tubers grown were for family consumption, so excluding family expenditure on millers, mullahs, blacksmiths and so on;

- Unless otherwise stated, that all newly born calves, lambs and kids would be sold at approximately 1-2 years of age (with a corresponding weight of $42-56 \mathrm{~kg}$ for calves and 14-21 kg for lambs and kids), with prices being based on those obtained for Bamiyan (an average of US $\$ 32.9$ for calves and US $\$ 14.1$ for lambs and kids).

The following was found:

- taking only their land into consideration, families of household type $A$ tended to have a deficit of around $15 \%$ (with variation among them), although once livestock as saleable assets were taken into account (exchanging the livestock for wheat in the marketplace), this deficit became a small surplus of around $0.43 \%$;

- on the basis of their land producing capacities, families of household type B meanwhile, tended to be in deficit by $48.0 \%$, with this being reduced to $35.7 \%$ once livestock were taken into account - although there was quite significant variation among households;

- families of household type $C$ tended to have an average deficit of $71.1 \%$ according to their land production possibilities only; once livestock were considered, this diminished to $62.1 \%$; 
- due to the paucity of families of household types $D$ and $E$, it was not considered possible to calculate production/consumption possibilities for these;

- families of household type $F$ : for those that worked on the land, and those that worked in the bazaar as porters (mainly applicable to the Bamiyan Lower Valley cave population), a deficit was always in evidence;

- families of household type $G$, obviously being landless and without employment, were found to have a $100 \%$ deficit

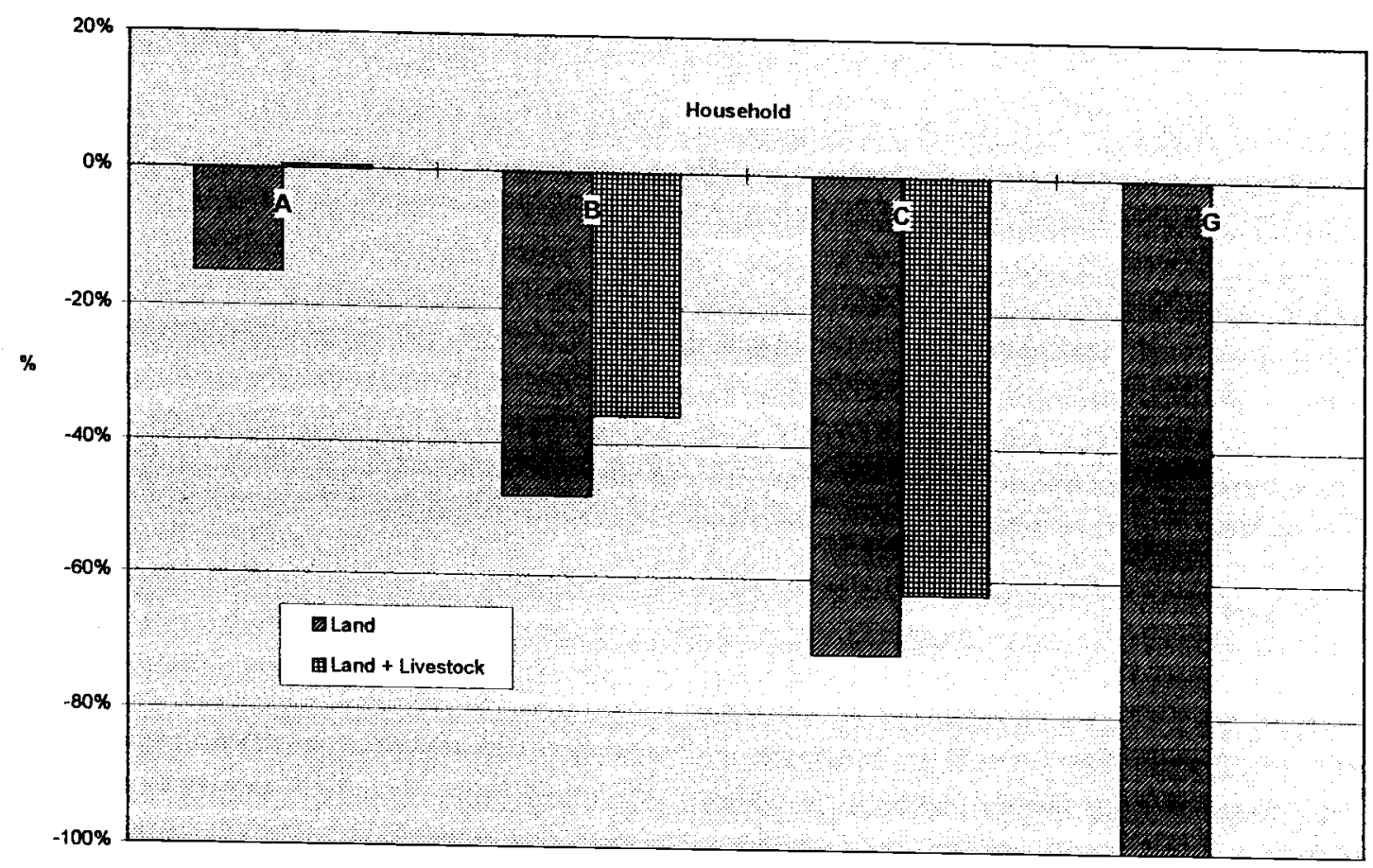

On the basis of land only, all household types (where applicable) were found to be in debt, with livestock only managing to make a significant change among families of household type $\mathrm{A}$, among families in Nawor and Upper Bamiyan, among the Koutchis and among relatively small families. The changes were obviously greater for households of type $A$, and then in decreasing succession, for households of type B and C. In Jaghoori, any changes were relatively negligible, due to the higher proportion of sheep and goats held, as opposed to cattle, and the lower prices for these. Sale of livestock to meet consumption needs was particularly prevalent among household types B and C often leading to decapitalisation in the latter case.

However, in Ajarestan, Jaghoori and Lower Bamiyan, deficits were also offset by sales of fruit, potatoes and poplar - particularly among households $A, B, C$ and D, although in significantly lesser evidence for other households (IDPs not included). Households A, B and C were also more likely to have access to kitchen gardens and some, to remittances, particularly in southern Hazarajat, although here too, numbers have dwindled since the blockade.

Thus, one might hypothesise that of those with land, household $\mathrm{C}$ might be most vulnerable to problems of both acute and chronic malnutrition, although it was not possible to validate this. Similarly for household types E, F and G. 


\section{B. VULNERABILITY THRESHOLDS BY ZONE:}

In order to obtain an indication of self-sufficiency requirements, and by implication, of vulnerability threshold levels, ideal amounts of land only, then land and livestock and lastly, cash were calculated according to zone. In this, the following assumptions were made:

- an average family size of 8 - taking into account what seems to be family size, as opposed to 'mouths to feed', which varies immensely but nevertheless tends to be larger;

- an average kilocalorie requirement of 1,900 kcal per person, so allowing for an age structure that reveals a greater number of young children than adults;

- standard irrigated wheat yields based on access to manure only (except in the case of Jaghoori, where the yield with chemical fertiliser only is used), which seems more probable given actual and potential livestock numbers and practices of prioritisation of manure and fertiliser according to crop importance;

- a basic land requirement of 2 jeribs ( 0.4 hectares) plus as many sheep (given the preference for holding and selling these, together with their general availability across all six zones), as would be necessary to sell (at current prices) in order to make up the remaining calories in wheat;

- wheat prices according to district for the cash only column, but being otherwise based on prices for Bamiyan at US $\$ 0.54 / \mathrm{kg}$;

- livestock prices based on those for Bamiyan in August 1998;

This gave an average requirement of $5,548,000 \mathrm{kcal}$ (equivalent to $1681.21 \mathrm{~kg}$ of wheat-grain at $3,300 \mathrm{kcal}$ per $\mathrm{kg}$ or $1585.14 \mathrm{~kg}$ of wheat flour at $3,500 \mathrm{kcal}$ per $\mathrm{kg}$ ) per year.

\begin{tabular}{|c|c|c|c|}
\hline Zone & Land Only & Land and Livestock & Cash Only \$US \\
\hline Ajarestan & $\begin{array}{l}6.86 \text { jeribs (or } \\
1.37 \text { hectares) }\end{array}$ & 2 jeribs $(0.4$ hectares $)+33$ sheep & 649.91 \\
\hline Bamiyan Lower Valley & $\begin{array}{l}6.00 \text { jeribs (or } \\
1.20 \text { hectares) }\end{array}$ & 2 jeribs $(0.4$ hectares $)+35$ sheep & 855.98 \\
\hline Bamiyan Upper Valley & $\begin{array}{l}8.01 \text { jeribs (or } \\
1.60 \text { hectares) }\end{array}$ & 2 jeribs $(0.4$ hectares $)+46$ sheep & 855.98 \\
\hline Jaghoori & $\begin{array}{l}6.40 \text { jeribs (or } \\
1.28 \text { hectares) }\end{array}$ & 2 jeribs $(0.4$ hectares $)+35$ sheep & 713.31 \\
\hline Malestan & $\begin{array}{l}5.80 \text { jeribs (or } \\
1.16 \text { hectares) }\end{array}$ & 2 jeribs $(0.4$ hectares $)+36$ sheep & 776.72 \\
\hline Nawor High Plateau & $\begin{array}{l}5.60 \text { jeribs (or } \\
1.12 \text { hectares) }\end{array}$ & $\begin{array}{c}2 \text { jeribs }(0.4 \text { hectares })+33 \text { sheep (at } \\
\text { Jaghoori wheat prices due to } \\
\text { proximity) }\end{array}$ & $\begin{array}{l}713.31 \text { (at } \\
\text { Jaghoori wheat } \\
\text { prices due to } \\
\text { proximity) }\end{array}$ \\
\hline
\end{tabular}

The table reveals an average requirement of 6.40 jeribs $(1.29$ hectares $)$ per family across the zones, with a large variation of 5.60 jeribs (1.12 hectares) for Nawor and 8.01 jeribs (1.60 hectares) for Bamiyan Upper Valley, due to land quality and access to manure over a sustained period of time. Only Household Type A manages to meet this requirement. Interestingly, Malestan and Nawor were found to require less land than other zones, the implication being then, that an increase in crop yields relative to a given land area, would be most beneficial here - particularly when taking into account the structural constraints to which both are subject.

With a baseline of 2 jeribs, most households today would require between 33-46 sheep, the variation being due to the diversity in land quality and the change in wheat prices, with those in 
Bamiyan being the highest at US $\$ 0.54 / \mathrm{kg}$ compared to US $\$ 0.41 / \mathrm{kg}$ in Ajarestan - a Pashtun area less subject to the effects of the blockade vis-à-vis wheat flour imports. Whatever the case, such a number of sheep is obviously out of the reach of virtually all household types - the Koutchis excepted.

Those having to supplement their food income through the sale of livestock - as opposed to its consumption - have obviously been significantly affected by the current blockade, with prices having suffered a reduction and therefore, livestock having to be sold, having concomitantly risen. This would affect in particular, household types B, C, D, E and F, with household type A being more prone to livestock consumption relative to the others, and household type $G$ tending to have few, if any, livestock to sell. Nevertheless, access to dairy products for some 3 to 6 months of the year, depending on whether sheep, goats or cows are held, also plays an important role in reducing sale requirements to fulfil energy needs, as does possession of poultry and consumption and/or sale, of eggs.

The cash only group, corresponding to household type $G$, reveals an average requirement of, across a range of $\$ 649.91$ for Ajarestan to $\$ 855.98$ for Bamiyan Upper and Lower Valleys. Since Ajarestan is effectively Talêban held area, and thus, has relatively privileged access to wheat flour with greater supplies but higher transportation costs due to road closures - prices in Ajarestan are less $^{49}$. In Bamiyan, with average salaries for a porter at 65,000 Dos (or US\$ 0.87), this would currently require approximately 984 working days, or 2.7 years.

The cash only group tends to be the most vulnerable group, having no capital assets of any stable food value, but being rather subject to any vagaries in prices - particularly given that wages tend to be seasonal and may not follow inflationary trends. In terms of zones, Upper Bamiyan would appear the most susceptible to food insecurity and any malnutrition, acute or chronic, that might arise from this.

\section{DIETS:}

\section{Dairy products:}

The milk obtained from camels (in the case of the Koutchis), cows, sheep and goats all tends to be mixed. Of this, around $15 \%$ is boiled and used for immediate consumption, while the rest is turned into yoghurt, and from yoghurt, butter, and croute, or dried curd, are made with dhour, or buttermilk, being left behind

Yoghurt is made by boiling the milk and adding yeast, and is consumed immediately. To obtain butter, the yoghurt is placed in a sheepskin container and shaken for one or more hours. The butter that forms tends to be kept in a pot made from mud and eaten over the winter. The buttermilk that is left behind tends to be consumed immediately - containing important amounts of lactose, water and amino acids. Croute may also be stored in wicker baskets made from willow and kept for the winter period, if not sold.

During the Spring/Summer period, any surplus milk or yoghurt tends to be shared among those villagers lacking cows, goats or sheep. In this way, nothing is wasted and all benefit - both rich and poor.

\footnotetext{
${ }^{49}$ Indeed, it is perhaps for this reason that wheatflour is often seen being transported across from Ajarestan (by both
Pashtuns and bearded Hazaras) to Malestan, by donkey.
} 
In Ajarestan where livestock is plenty and the standard of living appears to be significantly higher, meat tends to be eaten on a regular basis. In Nawor, the likelihood of eating meat is also increased, but as elsewhere in the Hazarajat, livestock tend rather to be sold in order to purchase wheat or other'staple foods - barley or potatoes, for instance. At present, meat is something of a luxury for the majority of families, given the effects of the blockade on livestock prices. Only household types A and B, together with the Koutchis, showed any discernible tendency to consume their livestock and/or purchase meat - although households of type $C$ may also do this, but significantly less regularly.

Where meat is consumed, the blood needs first to be drained out of the body of the animal (making the meat halaal, according to Qu' ranic injunctions). Some amount may be stored - fresh or sundried - particularly in winter, while the rest will be distributed within the village (undertaken most notably by the Koutchis as well as by households A and B), or sold then and there, as need dictates. The same process will be gone through with any diseased animal where considered possible, with any infected parts of the carcass being buried under the soil.

Ghee may also be made from the fat of the animals, by boiling the fat - the cooled down product effectively being the ghee.

Throughout the Hazarajat neither the milk nor the meat from donkeys are used, with this being considered dirty and haraam - against Qu'ranic stipulations and shameful. When the donkey dies, the carcass is either given to any dogs or buried.

Poultry:

In Bamiyan Upper Valley and Malestan, the trend seems to be for eggs to be sold on the market, particularly among household types C, D, E, F and G, so as to buy threads, matches, shampoo and so on. Elsewhere, they tended to be consumed within the family.

\section{Wild food:}

Different wild vegetables tend to be found throughout the Hazarajat, their use sometimes varying in accordance with season and location. Thus, bouldaghour and kharf are eaten by humans, particularly small children, throughout Bamiyan during spring, after which time, only livestock tend to consume them. 


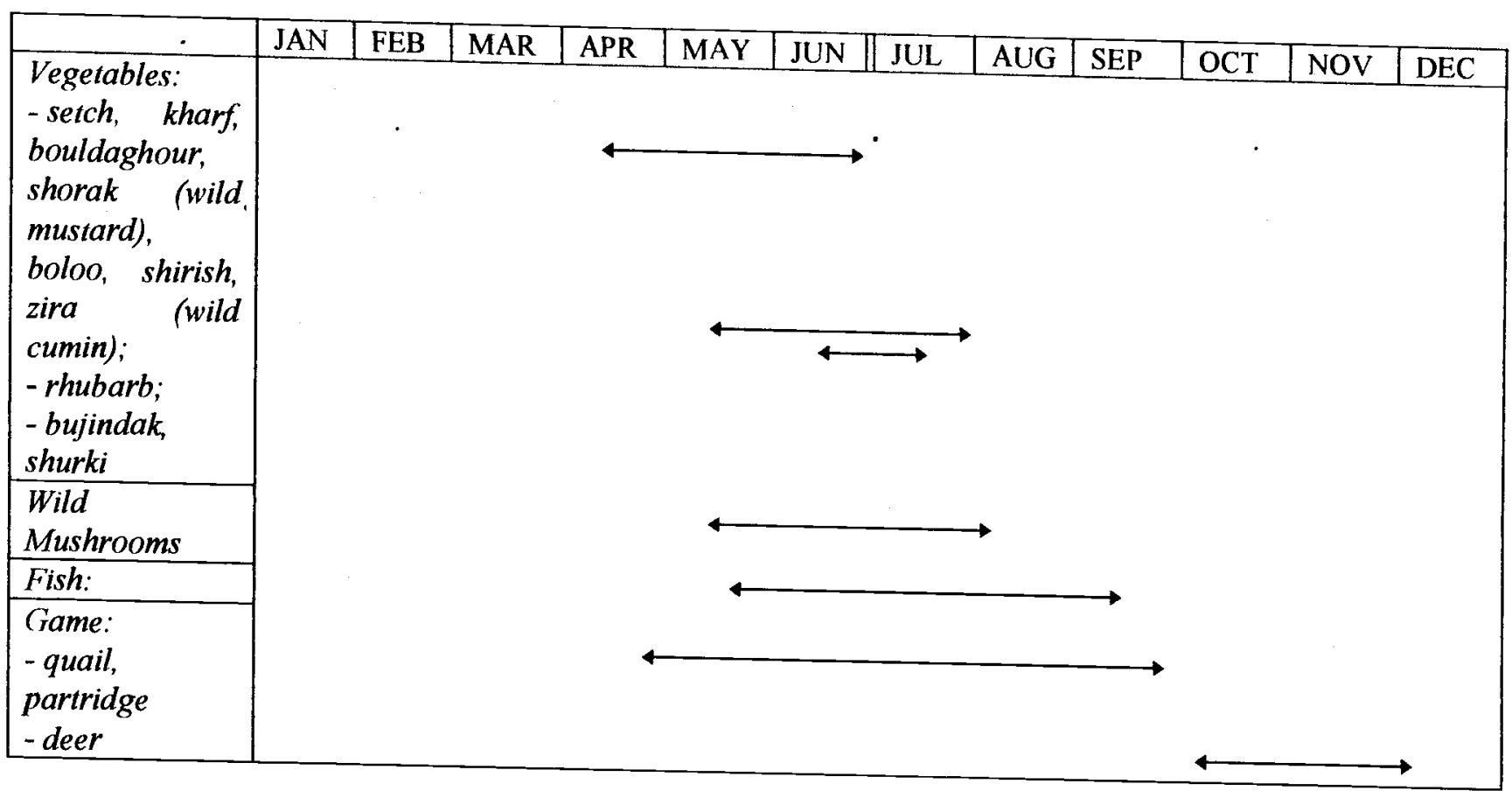

It tends to be women and small children who are involved in their collection. Most wild vegetables will be cooked and eaten fresh - either with yoghurt or perhaps encased in pastry and boiled where possible. A proportion will also be sun-dried for winter use

Rhubarb tends to be most prevalent in Bamiyan Lower Valley, Malestan and Jaghoori - perhaps due to the exigencies of altitude. As from August (up to which time it may be eaten fresh), its value will be more as a fuel, by which time it may have dried somewhat.

Mushrooms, meanwhile, were most evident in Malestan around willow trees or in the mountains perhaps due to the humidity and problems of flooding.

Fish (possibly trout?) are to be found in most rivers, and tend to be caught by small children - by corralling them into baskets, by using a hook and line or a net. In Bamiyan Upper Valley and Jaghoori they are fewer in number and smaller (perhaps 10-12 cm), while in Ajarestan in particular, and then Malestan they are both greater in number and larger (perhaps upwards from $40 \mathrm{~cm}$ ).

Quail and partridge were particularly visible in Nawor and Jaghoori, where they are caught using in net. In the case of the latter, a caged partridge was sometimes used as bait. Deer, although once prominent in other areas, were only mentioned in Nawor, and hunted using guns.

\section{Daily Diet:}

The areas assessed had varying amounts of food available. Ajarestan and Bamiyan had a reasonably good supply. Jaghoori was plentiful, with an abundance of fruits and vegetables, as well as meat being available. Malestan, particularly in the Shineday area, was pitiful in terms of food availability, as there really was not much available for purchase. Nawor had limited resources, though plenty of trade passed through daily and at a price, most things could be bought. 
The following is a summary of the different types of food eaten on average, in one day. It is a list of the food-available to eat most days. For example, at dinner, rice and potatoes may be listed. This does not necessarily mean that both rice and potatoes are eaten at one meal - it is usually a case of either potatoes or rice. Therefore, people may eat all, some, or a combination of what is listed daily. Greens can be leafy vegetables, clover and alfalfa, as well as grass-like plants and pulses which were formerly animal feed.

Coping mechanisms have been adopted whereby the collection and consumption of wild foods and the adoption of animal feed into the daily diet has become the norm. Families still consume three meals per day, though some claimed that the quantity, as well as the quality of the meal had decreased.

Vetch, formerly used as animal feed, is now also used as human food. The seed is somewhat bitter and once harvested, is put in a sack and left to soak in water for a week, to swell. It is then left to dry in the sun, milled and the flour used to make bread, with wheat flour.

Alfalfa also is now eaten (in certain areas it has always been part of the diet), where formerly it was used as animal feed. It is picked in early Spring when still young and is boiled with a small amount of wheat flour.

Lathyrus, known locally as 'Kalool' is being consumed in Malestan and Nawor. Before the blockade, it was being eaten in small amounts, but now it is being eaten more often, since supplies are limited and wheat flour is hard to come by. Kalool has to be soaked and then boiled and the water discarded and then boiled again, before it is ready for human consumption.

Meat no longer features in people's daily diet (Ajarestan excepted) and is normally only consumed at religious festivals such as Ashoora and Moharam and during Ramasan. It cannot therefore be considered as nutritionally significant, since it is eaten once in a period of some time.

The figures of malnutrition quoted are in Z-Score ${ }^{50}$. A second, more detailed assessment was planned in the areas considered as vulnerable and within households of concern, such as certain female headed households and internally displaced families, in order to carry out a household food basket monitoring survey. However, this had to be abandoned due to a deteriorating security situation within the area.

\section{Ajarestan:}

In terms of diet, this area has not been affected by the blockade as yet. This is a Taleban controlled area and although the blockade is not imposed on them directly, traders are suffering because of a lack of traffic across to the restricted areas. Livestock trade, for example, was a very important and profitable venture, traders not having far to go in order to sell. Since the restrictions, traders have to travel a greater distance with their livestock to other areas in the country, losing much time and money. Although people complained of a huge increase in prices, their diets had not changed particularly since the blockade.

- BREAKFAST: tea; bread; sugar; butter

- LUNCH: tea; bread; meat; yoghurt; doughe ${ }^{51}$; eggs

- DINNER: tea; greens; meat; potatoes; rice

- MEAT: daily

\footnotetext{
${ }^{50}$ Figures for each individual village as well as region can be found in Appendices for Part VI: Appendix I

${ }^{51}$ This is a dairy drink made of fermented buttermilk and salt, which is sometimes diluted with water, depending on the consistency of the buttermilk and the wealth of the family
} 
Most families own livestock in this area and eat meat daily. Portions of meat are not very big, but nonetheless it is eaten every day. Butter is eaten within the family and not just sold as it can be in other areas. The ability to buy sugar is still evident. People complained of the price of sugar, but it was obviously still within a reachable price range. Greens eaten usually are leafy vegetables, which have always been eaten. Eggs are eaten and sold.

Milk is used for drinking, making yoghurt, making butter from yoghurt and doughe from the liquid left behind once butter is made. Croute is made from drying doughe and can provide dairy
intakes in the winter.

Breast feeding and weaning last for a longer period here, compared to other regions. This seems to be more a matter of traditional practices and may be that Pashtuns traditionally have longer periods of breast feeding than the Hazaras. Breast feeding starts immediately after birth and usually continues for between 2-3 years. If the mother becomes pregnant during breast feeding, she decides whether to continue breast feeding or not, depending on the development of the child being fed. It is very much a personal decision and 'rules' do not apply here. Mothers were very conscious of the benefits and importance of breast feeding, though echos of the 'Western World' were found, in that dried milk was used as a weaning food. Weaning normally starts at 1 year of age and foods used include butter, reconstituted dried milk and the normal daily family meals.

Though only 2 villages and one group of nomads (Koutchis) were surveyed in the region, no severe acute malnutrition and 3.3\% moderate malnutrition was found in the area. However, global stunting affected $51.6 \%$ of the population, including $17.6 \%$ severe stunting. Although more acute malnutrition was found amongst village children, the nomads suffered the most in terms of chronic malnutrition. A global figure of $68.4 \%$ including $42.1 \%$ severe stunting was found amongst the nomads. Despite what appeared to be an adequate diet, a third of the children who were stunted, were wasted too. This may well be a result of disease, considering the void in health care. Interestingly, the nomads were said to be wealthier than villagers and those interviewed certainly seemed to be, according to their possessions, including in some cases, shops in Pakistan. Genetics or the lack of health care available may also contribute to these figures. Illiteracy however, is high in this area, particularly amongst the nomads, so the age given for the children may be more inaccurate than the average.

\section{Bamiyan:}

This area has always had to trade in order to get food supplies in. With the imposition of the blockade, supplies and therefore prices have been greatly affected, particularly as goods have to be smuggled. The diet, before and after the blockade has not changed particularly in quality. However, quantities were very different before the blockade, when food was much more affordable and therefore more was bought. Wild rhubarb could be seen growing on the foothills, throughout most areas.

\section{BEFORE THE BLOCKADE}

- BREAKFAST: tea/boiled water; bread

- LUNCH: tea; bread; barley

- DINNER: tea; bread; doughe; potatoes; oil

- MEAT: often 


\section{AFTER THE BLOCKADE}

- BREAKFAST: tea/boiled water; bread

- LUNCH: tea; bread; barley

- DINNER: tea; bread; doughe; potatoes; oil

- MEAT: $1 / 30$, or when an animal dies

Tea is an every day item, though there were some families who claimed it to be a luxury and said that they drank boiled water in its place. Sugar has not been accessible, because of its price since the blockade. Lentils, particularly in the winter, are cooked with rice. Meat is now a rarity, eaten when an animal dies or during religious festivals. In this case, the animal is shared amongst neighbours. When meat is available, the fat is used to make ghee, which is made by boiling the fat, until it separates. Potatoes feature largely in the daily diet of the region throughout the year. Wild rhubarb can be collected from the mountain side and is eaten fresh, when available (June - August).

An internally displaced family, who may be landless labourers or unemployed, could be expected to eat bread (made of broad bean flour), barley and boiled water for every meal in the winter, with potatoes and doughe as a variation in the summer. The doughe is normally given as a donation, by better off friends and neighbours. A porridge of flour and barley is also sometimes consumed in the summer. This same family, before being displaced, living say in Kabul, would normally be consuming bread, tea and sugar for breakfast, with beans, potatoes or rice for lunch and dinner, with the possibility of doughe in the summer.

Cow, sheep or goat's milk is used to make butter, by first producing yoghurt, which has been made using a yeast culture, part of which is then churned, producing butter and doughe as a byproduct. Croute is then made by drying doughe and storing it for future use.

There is a taboo on eating fish here, as it is said that brown marks appear on the skin if fish is consumed. However, it seems that there is little fish in the river.

Breast feeding starts immediately after birth and continues until the age of 11/2-2 years. Upon finding out that she is pregnant again, the mother continues to breast feed throughout the pregnancy. Weaning starts at around 6 months and foods used include boiled water, bread, milk, oil, raisins, yoghurt, butter and porridge.

$4.7 \%$ moderate acute malnutrition was found in this area, no severe cases were found. There was much stunting here, affecting $69.9 \%$ globally, including $36.3 \%$, who were severely stunted. It must be considered that these people in particular, are of Mongol origin and may therefore be prone to a shorter height genetically.

\section{Jaghoori:}

Jaghoori is an area with plenty of food resources, home grown and imported from other areas. At the time of the survey, it was the height of the fruit and vegetable season. Although the markets were brimming with food, the quality of the claimed daily food intakes was not very impressive.

\section{BEFORE THE BLOCKADE}

- BREAKFAST: tea; bread; sugar

- LUNCH: tea; bread; potato soup; sugar

- DINNER: tea; bread; potatoes; beans; meat; candy

- MEAT: $15 / 30$ 


\section{AFTER THE BLOCKADE}

- BREAKFAST: tea; barley bread

- LUNCH: tea; bread; doughe; greens

- DINNER: tea; bread; potato soup; doughe

- MEAT: $1 / 365$

The diet before the blockade was of fairly good quality, with plenty of carbohydrates and proteins available daily. Meat was consumed every other day, whereas now it is a rarity. Sugar and sweets were available and consumed daily by most households. Now they are a luxury. The diet now is very basic, though greens and doughe are consumed daily.

As set down by tradition, breast feeding commences 3 days after birth and the child is fed with oil or butter in the meantime. Breast feeding continues for 2 years, though some mothers reported $11 / 2-31 / 2$ years duration. In Jowdari, there was a differentiation between the sexes, where boys were breast fed for 2 years and girls for 11/2 years. Interestingly, the results showed no boys as being malnourished and $3.85 \%$ of girls moderately malnourished. However, these are the figures for children aged 6-59 months, in the 6-29 months age range, there is no acute malnutrition in either of the sexes. Upon finding out they are pregnant, some mothers stop breast feeding immediately, some 2 months after finding out and some do not stop breast feeding. Weaning starts from 6-8 months and foods given include butter, milk, yoghurt and bread.

Global acute malnutrition was $3.3 \%$, including $0.9 \%$ severe. Stunting was evident in $47.9 \%$ of the population globally, including $15.5 \%$ severe stunting.

Khwajali and Sabz Choob villages, two particularly poor looking villages, showed the highest rates of chronic malnutrition in the area, with $63.6 \%$ and $78.6 \%$ global stunting, including $30.3 \%$ and $42.9 \%$ severe stunting, respectively.

\section{Malestan:}

At the time of the survey, Malestan was seen to be a particularly disadvantaged area, with very little food available. The 'centre', Shineday bazaar, comprised of many closed shops, due to the effects of the blockade, limiting goods and increasing prices. Wild mushrooms could be seen in some areas. Clover is used as food for human consumption and animal feed. It is eaten fresh, but may also be boiled with wheat flour and eaten with doughe. Vetch is also now eaten as food and not just used for animal feed as before.

\section{BEFORE THE BLOCKADE}

- BREAKFAST: tea; bread; sugar; milk

- LUNCH: rice; potatoes; yoghurt

- DINNER: rice; yoghurt; Croute $^{52}$ soup; meat

- MEAT: $2 / 7$

\footnotetext{
${ }^{52}$ Croute is dried doughe, which is available for use all year round, due to its dehydrated state
} 


\section{AFTER THE BLOCKADE}

- BREAKFAST: tea; barley bread

- LUNCH: tea; barley bread; greens; oil; yoghurt

- DINNER: tea; bread; rice; beans; potato soup

- MEAT: 2-10/365

Since the blockade, diet is limited in choice and quantity. WFP distributed food here 10 days prior to our visit, but it was said not to have reached the people who needed it. $35 \mathrm{Kg}$ of wheat flour were distributed per household. Yoghurt is not always available and the poorer families tend to sell any they have made. What was formerly animal feed is now being used for regular human consumption. Kalool is now consumed as there is not much else available. Most of the villages within this region had resorted to using this plant. Sabzak, a very poor looking village, reported 20 deaths of children due to oedema, following the eating of a green they do not normally eat. However, no cases of oedema, nutritional or otherwise, were seen during the survey.

A landless labourer without tools or livestock, may collect wild mushrooms and cook them with milk or meat (if available), as a curry. The family would normally consume bread and tea for breakfast, doughe, tea and bread for lunch and perhaps a small amount of yoghurt with bread and tea for dinner.

Breast feeding starts immediately after birth here, with the exception of Kharzar and Wali villages, where breast feeding commences 3 days after birth. In the meantime the child is fed with oil or butter. Children are breast fed up until the age of 11/2-2 years, but in Qol Adam there is a differentiation between the sexes, where boys are breast fed up until the age of 2 years and girls $11 / 2$ years. This could be one reason for the difference of an additional $10 \%$ of acute moderate malnutrition evident in girls aged 6-29 months in this village. Weaning starts at 6 months, with the exception of Dahan Boom, where weaning is from 3-5 months, reflected in the acute malnutrition rate of $16.7 \%$, the highest in the region. Weaning foods include, the top of the milk, butter, sugar, doughe, yoghurt, bread, oil and wheat in the form of a porridge and rice.

\section{Nawor:}

$\mathrm{Du} \mathrm{Abi}$, the centre of Nawor, has much trade passing through on a daily basis. A fair amount of varied food was available to those who could afford it.

\section{BEFORE THE BLOCKADE}

- BREAKFAST: tea; bread; butter; milk

- LUNCH: tea; bread; doughe; oil; meat

- DINNER: rice; Croute; potato soup

- MEAT: $1-5 / 30$

\section{AFTER THE BLOCKADE}

- BREAKFAST: tea; bread

- LUNCH: tea; bread; doughe; potatoes; oil; Croute

- DINNER: tea; bread; doughe; potatoes; oil; Croute; potato soup

- MEAT: 1/365 - when animal dies 
Meat was eaten once a week before the blockade, but now it is rarely eaten. Poorer people eat vetch and alfalfa, picking them before harvest time. Alfalfa has always been consumed in this area, but vetch has been adopted since the blockade. Those without livestock would have tea and bread for all three meals, with perhaps wild vegetables at lunch. Those with livestock, may have doughe at lunch and rice at dinner, in addition. Peas may also be consumed fresh, or dried and ground to a flour from which bread or soup is made.

Breast feeding starts immediately after birth, though some do not start until 2 days after birth. In this case, the baby is fed a sugar solution and buttermilk. Children are breastfed up until the age of 2-21/2 years and if the mother becomes pregnant again during this time she normally stops breast feeding immediately. However, in Khawat they continued breast feeding until the new baby was born. Weaning starts at 5-6 months, though in Qarge Balah, weaning started at around 1 year. Weaning foods include cow's milk, porridge (made with wheat flour and oil), doughe, yoghurt, bread and sugared tea. 


\section{Part VI: Nutrition and Health Technical Section}

\section{A. INTRODUCTION:}

Five regions of the Hazarajat were studied. These were Ajarestan, Bamiyan (Upper Valley), Jaghoori, Malestan and Nawor.

Prior to our visit, relief, in the form of food aid was distributed by the World Food Programme (WFP) in various regions of the Hazarajat. This was in the form of a sack of wheat flour $(35 \mathrm{Kg}$, though some reported more) per family.

This area of geographical isolation, has had a worsening situation since the introduction of the blockade imposed by the Talêban, affecting the whole area, stopping food supplies and population movements. People mainly live off their own agricultural activities and are used to suffering shortages regularly over the years (with particularly hard Hunger Gaps) by importing the missing food items. The blockade, imposed over a year ago, has hindered food exchanges with the rest of the country, causing huge increases in price and limiting goods. As a result of insufficient crop production, some men migrate for work in the winter, relieving the family of one more mouth to feed, whilst bringing in an additional income.

Health services vary from region to region ${ }^{53}$. Although in some areas health structures may be available, some have been paralysed or have had to reduce activities due to the difficulty of getting supplies as a result of the blockade.

In Ajarestan, there are absolutely no medical facilities available.

In Bamiyan city a range of health facilities exist, run by the Ministry of Public Health, some of which are supported by Non-Governmental Organisations (NGO). The facilities include an hospital and five basic health centres.

Jaghoori is equipped with one hospital and eight clinics, supported by the Shuheyda organisation.

Malestan has three clinics, only one of which (Swedish Committee) is able to function properly at present.

Nawor has a vaccination point within what was formerly the clinic. No other health facilities exist.

Action contre la faim conducted an anthropometric survey in the Hazarajat funded by ECHO. This was to evaluate the nutritional status of the $<5$ years population after reports of alarming food situations throughout the winter. The data collected during this survey may serve as a reference for further studies, since no other data is available at this point in time. Information on the number of $<5$ years deaths and vaccination status were also collected.

Within each region, the existence of an Expanded Programme on Immunisation (EPI) was investigated. Such programmes are aimed at reducing morbidity and therefore mortality in children under the age of five. Diseases covered by standard EPI are tuberculosis, tetanus, diphtheria,

\footnotetext{
${ }^{53}$ See Health section.
} 
whooping cough, poliomyelitis and measles. The World Health Organisation (WHO) recommends
targeting children under one year old.

In addition, a diet survey was carried out, whereby discussions were held with small groups of members of the community - women, mixed groups and men (depending on the area and who was
available), concerning their daily diet.

An assessment of the health structures available in each region was conducted, in order to identify existing structures and determine the needs for health facilities. To complement this, discussion groups were held in each village, concerning health and hygiene matters.

\section{B. RESULTS:}

969 children (894 6-59 months and 75 0-5 months) were surveyed and the data was analysed using the Epinut/Epi-info version 5.0 and 6.0 software from CDC Epicentre - WHO. The anthropometric indices were calculated using the Epinut software from Epicentre. Global results will be presented as 'the Hazarajat', along with results of each region surveyed ${ }^{54}$. Children aged $0-5$ months will be presented separately. Figures in the 0-5 months category cannot be considered as statistically significant at the village level, since no children in some villages and no more than seven children in larger villages, were found and surveyed.

\section{Description of the sample population:}

Table 6: Distribution by age and sex, The Hazarajat, June July 1998

\begin{tabular}{ccccc|ccc}
\hline AGE & \multicolumn{2}{c}{ BOYS } & \multicolumn{2}{c|}{ GIRLS } & \multicolumn{2}{c}{ TOTAL } & SEX RATIO \\
in months & $\mathrm{Nbr}$ & $\%$ & $\mathrm{Nbr}$ & $\%$ & $\mathrm{Nbr}$ & $\%$ & \\
\hline $06-17$ & 101 & $51.5 \%$ & 95 & $48.5 \%$ & 196 & $21.9 \%$ & 1.06 \\
$18-29$ & 122 & $53.3 \%$ & 107 & $46.7 \%$ & 229 & $25.6 \%$ & 1.14 \\
$30-41$ & 113 & $53.6 \%$ & 98 & $46.4 \%$ & 211 & $23.6 \%$ & 1.15 \\
$42-53$ & 84 & $47.5 \%$ & 93 & $52.5 \%$ & 177 & $19.8 \%$ & 0.90 \\
$54-59$ & 35 & $43.2 \%$ & 46 & $56.8 \%$ & 81 & $9.1 \%$ & 0.76 \\
\hline TOTAL & $\mathbf{4 5 5}$ & $\mathbf{5 0 . 9} \%$ & $\mathbf{4 3 9}$ & $\mathbf{4 9 . 1} \%$ & $\mathbf{8 9 4}$ & $\mathbf{1 0 0 . 0} \%$ & $\mathbf{1 . 0 4}$ \\
\hline
\end{tabular}

The sex ratio of the sample is $\mathbf{1 . 0 4}$ which shows that the survey has represented the population as a whole quite well. The fact however, does need to be taken into consideration, that there is little evidence to show the exact age of each child. Therefore, the age categories should only be considered as indicators and not as hard facts.

\footnotetext{
${ }^{54}$ Detailed results can be found in Appendices for Part VI: Appendix II.
} 
Table 7: Distribution by age and sex, Ajarestan, July 1998

\begin{tabular}{ccccc|ccc}
\hline AGE & \multicolumn{2}{c}{ BOYS } & \multicolumn{2}{c|}{ GIRLS } & \multicolumn{2}{c}{ TOTAL } & SEX RATIO \\
in months & Nbr & $\%$ & Nbr & $\%$ & Nbr & $\%$ & \\
\hline $06-17$ & 7 & $35.0 \%$ & 13 & $48.5 \%$ & 20 & $22.0 \%$ & 0.54 \\
$18-29$ & 11 & $57.9 \%$ & 8 & $46.7 \%$ & 19 & $20.9 \%$ & 1.38 \\
$30-41$ & 11 & $40.7 \%$ & 16 & $46.4 \%$ & 27 & $29.7 \%$ & 0.69 \\
$42-53$ & 7 & $35.0 \%$ & 13 & $52.5 \%$ & 20 & $22.0 \%$ & 0.54 \\
$54-59$ & 2 & $40.0 \%$ & 3 & $56.8 \%$ & 5 & $5.5 \%$ & 0.67 \\
\hline TOTAL & $\mathbf{3 8}$ & $\mathbf{4 1 . 8} \%$ & $\mathbf{5 3}$ & $\mathbf{5 8 . 2} \%$ & $\mathbf{9 1}$ & $\mathbf{1 0 0 . 0} \%$ & $\mathbf{1 . 0 4}$ \\
\hline
\end{tabular}

The sex ratio 0.72 shows an under representation of boys within this area. However, it has to be remembered that only 2 villages and a group of nomads were surveyed in this area, owing to logistical and security problems. Therefore, the resulting ratio may not be a good representation of the area as a whole. The same can be said of the various age brackets being under or over represented. Although the diet in this area was comparably good than other regions, health facilities were non-existent and there therefore were many health problems, which could also be a reason for under representation in the 18-29 and 54-59 months categories, caused by sickness or death. Again, inaccurate ages must be considered when interpreting the data, particularly since mothers generally did not attend the screenings and fathers had to be relied upon, to estimate ages.

Table 8: Distribution by age and sex, Bamiyan, June 1998

\begin{tabular}{ccccc|ccc}
\hline AGE & \multicolumn{2}{c}{ BOYS } & \multicolumn{2}{c}{ GIRLS } & \multicolumn{2}{c}{ TOTAL } & SEX RATIO \\
in months & Nbr & \% & Nbr & $\%$ & Nbr & $\%$ & \\
\hline $06-17$ & 19 & $45.2 \%$ & 23 & $54.8 \%$ & 42 & $21.8 \%$ & 0.83 \\
$18-29$ & 31 & $53.4 \%$ & 27 & $46.6 \%$ & 58 & $30.1 \%$ & 1.15 \\
$30-41$ & 17 & $48.6 \%$ & 18 & $51.4 \%$ & 35 & $18.1 \%$ & 0.94 \\
$42-53$ & 15 & $41.7 \%$ & 21 & $58.3 \%$ & 36 & $18.7 \%$ & 0.71 \\
$54-59$ & 11 & $50.0 \%$ & 11 & $50.0 \%$ & 22 & $11.4 \%$ & 1.00 \\
\hline TOTAL & $\mathbf{9 3}$ & $\mathbf{4 8 . 2} \%$ & $\mathbf{1 0 0}$ & $\mathbf{5 1 . 8} \%$ & $\mathbf{1 9 3}$ & $\mathbf{1 0 0 . 0} \%$ & $\mathbf{0 . 9 3}$ \\
\hline
\end{tabular}

The sex ratio of 0.93 shows a reasonable representation of the population. There is a slight under representation in the age category 30-41 months and a slight over representation in the age group 1829 . This is more than likely due to inaccurate birth dates being given.

Table 9: Distribution by age and sex, Jaghoori, July 1998

\begin{tabular}{ccccc|ccc}
\hline AGE & \multicolumn{2}{c}{ BOYS } & \multicolumn{2}{c}{ GIRLS } & \multicolumn{2}{c}{ TOTAL } & SEX RATIO \\
in months & Nbr & \% & Nbr & $\%$ & Nbr & $\%$ & \\
\hline $06-17$ & 33 & $68.8 \%$ & 15 & $31.3 \%$ & 48 & $22.5 \%$ & 2.20 \\
$18-29$ & 24 & $48.0 \%$ & 26 & $52.0 \%$ & 50 & $23.5 \%$ & 0.92 \\
$30-41$ & 29 & $55.8 \%$ & 23 & $44.2 \%$ & 52 & $24.4 \%$ & 1.26 \\
$42-53$ & 20 & $47.6 \%$ & 22 & $52.4 \%$ & 42 & $19.7 \%$ & 0.91 \\
$54-59$ & 10 & $47.6 \%$ & 11 & $52.4 \%$ & 21 & $9.9 \%$ & 0.91 \\
\hline TOTAL & $\mathbf{1 1 6}$ & $\mathbf{5 4 . 5} \%$ & $\mathbf{9 7}$ & $\mathbf{4 5 . 5} \%$ & $\mathbf{2 1 3}$ & $\mathbf{1 0 0 . 0} \%$ & $\mathbf{1 . 2 0}$ \\
\hline
\end{tabular}

There was a slight over representation of boys within this sample, with the sex ratio being 1.2 . Age ranges are represented in a fairly typical distribution. There is quite good vaccination coverage in this area as a whole and therefore many of the population had vaccination cards with a date of 
birth on them. These were used along with the mother's word to determine a more accurate age estimate. However, as was found, the date of birth on some vaccination cards was sometimes very unlikely, therefore the age of each child still has to be considered as an estimate

Table 10: Distribution by age and sex, Malestan, July 1998

\begin{tabular}{ccccc|ccc}
\hline AGE & \multicolumn{2}{c}{ BOYS } & \multicolumn{2}{c|}{ GIRLS } & \multicolumn{2}{c}{ TOTAL } & SEX RATIO \\
in months & Nbr & $\%$ & Nbr & $\%$ & Nbr & $\%$ & \\
\hline $06-17$ & 27 & $48.2 \%$ & 29 & $51.8 \%$ & 56 & $21.9 \%$ & 0.93 \\
$18-29$ & 37 & $57.8 \%$ & 27 & $42.2 \%$ & 64 & $25.6 \%$ & 1.37 \\
$30-41$ & 30 & $52.6 \%$ & 27 & $47.4 \%$ & 57 & $23.6 \%$ & 1.11 \\
$42-53$ & 25 & $46.3 \%$ & 29 & $53.7 \%$ & 54 & $19.8 \%$ & 0.86 \\
$54-59$ & 10 & $40.0 \%$ & 15 & $60.0 \%$ & 25 & $9.1 \%$ & 0.67 \\
\hline TOTAL & $\mathbf{1 2 9}$ & $\mathbf{5 0 . 4} \%$ & $\mathbf{1 2 7}$ & $\mathbf{4 9 . 6 \%}$ & $\mathbf{2 5 6}$ & $\mathbf{1 0 0 . 0} \%$ & $\mathbf{1 . 0 2}$ \\
\hline
\end{tabular}

The sex ratio of this sample was 1.02, showing a good representation of the population. There was a slight over representation in the $42-53$ months category, which may be due to inaccuracies in the process of estimation of age.

Table 11: Distribution by age and sex, Nawor, July 1998

\begin{tabular}{ccccc|ccc}
\hline AGE & \multicolumn{2}{c}{ BOYS } & \multicolumn{2}{c|}{ GIRLS } & \multicolumn{2}{c}{ TOTAL } & SEX RATIO \\
in months & Nbr & $\%$ & Nbr & $\%$ & Nbr & $\%$ & \\
\hline $06-17$ & 15 & $50.0 \%$ & 15 & $50.0 \%$ & 30 & $21.9 \%$ & 1.00 \\
$18-29$ & 19 & $50.0 \%$ & 19 & $50.0 \%$ & 38 & $25.6 \%$ & 1.00 \\
$30-41$ & 26 & $65.0 \%$ & 14 & $35.0 \%$ & 40 & $23.6 \%$ & 1.86 \\
$42-53$ & 17 & $68.0 \%$ & 8 & $32.0 \%$ & 25 & $19.8 \%$ & 2.13 \\
$54-59$ & 2 & $25.0 \%$ & 6 & $\mathbf{7 5 . 0} \%$ & 8 & $9.1 \%$ & 0.33 \\
\hline TOTAL & $\mathbf{7 9}$ & $\mathbf{5 6 . 0} \%$ & $\mathbf{6 2}$ & $\mathbf{4 4 . 0} \%$ & $\mathbf{1 4 1}$ & $\mathbf{1 0 0 . 0} \%$ & $\mathbf{1 . 2 7}$ \\
\hline
\end{tabular}

There was a slight over representation of boys within this survey, the sex ratio being 1.27 . There was slight under representation in the youngest (6-17 months) and oldest (54-59 months) categories, which may be due to inaccurate age estimations.

\section{Nutritional status:} follows:

The global acute malnutrition rates expressed as Z-Score and percentage of the median are as

Table 12: Overall acute malnutrition prevalence in children aged 0-5 months, the Hazarajat, June/July 1998

\begin{tabular}{lccc}
\hline MALNUTRITION & SEVERE (<-3SD) & MODERATE (<-2 and >-3SD) & GLOBAL (<-2SD) \\
\hline Z-Score & $\mathbf{0 . 0} \%$ & $\mathbf{1 . 3} \%$ & $\mathbf{1 . 3} \%$ \\
$95 \%$ Confidence Interval & $(-0.3-6.0 \%)$ & $(0.1-2.2 \%)$ & $(0.2-8.2 \%)$ \\
\hline
\end{tabular}

According to the Z-score interpretation 0 cases of severely malnourished children were found in the survey population. 1 was moderately malnourished. 
Table 13: Overall acute malnutrition prevalence in children aged 6-59 months, the Hazarajat, June/July 1998

\begin{tabular}{|c|c|c|c|}
\hline MALNUTRITION & SEVERE (<-3SD) & MODERATE $(<-2$ and $>-3 S D)$ & GLOBAL (<-2SD) \\
\hline Z-Score & $0.3 \%$ & $4.7 \%$ & $5.0 \%$ \\
\hline $95 \%$ Confidence Interva & $a l(0.1-1.1 \%)$ & $(3.6-5.7 \%)$ & $(3.7-6.8 \%)$ \\
\hline $\begin{array}{l}\% \text { of the median } \\
95 \% \text { Confidence Intervo }\end{array}$ & $\begin{array}{c}\mathbf{0 . 1} \% \\
\text { al }(-0.0-1.3 \%)\end{array}$ & $\begin{array}{c}2.7 \% \\
(1.8-2.9 \%)\end{array}$ & $\begin{array}{c}2.8 \% \\
(1.8-4.2 \%)\end{array}$ \\
\hline
\end{tabular}

According to the Z-score interpretation 3 cases of severely malnourished children were found in the survey population, all of whom were marasmic. 42 were moderately malnourished. With the percentage of the median calculations, 1 child was severely malnourished and 24 moderately.

There were no children aged 0-5 months surveyed in Ajarestan. This could be due to a high death rate, since there is no medical support in the area, of any sort. This is only a consideration, as this fact was not reflected in the mortality survey. However, a limited number of children were surveyed here.

Table 14: Overall acute malnutrition prevalence in children 6-59 months, Ajarestan, July 1998

\begin{tabular}{lccc}
\hline MALNUTRITION & SEVERE (<-3SD) & MODERATE (<-2 and >-3SD) & GLOBAL (<-2SD) \\
\hline Z-Score & $\mathbf{0 . 0} \%$ & $\mathbf{3 . 3} \%$ & $\mathbf{3 . 3} \%$ \\
$95 \%$ Confidence Interval $(-0.2-5.0 \%)$ & $(0.5-5.1 \%)$ & $(0.7-10.1 \%)$ \\
& & $\mathbf{0 . 0} \%$ & $\mathbf{0 . 0} \%$ \\
\% of the median & $\mathbf{0 . 0} \%$ & $(0.0-0.0 \%)$ & $(-0.2-5.0 \%)$ \\
95\% Confidence Interval $(-0.2-5.0 \%)$ &
\end{tabular}

According to the Z-score interpretation 3 children were found to be moderately malnourished. With the percentage of the median calculations all children were normal.

Table 15: Overall acute malnutrition prevalence in children aged 0-5 months, Bamiyan, June 1998

\begin{tabular}{lccc}
\hline MALNUTRITION & SEVERE (<-3SD) & MODERATE (<-2 and >-3SD) & GLOBAL (<-2SD) \\
\hline Z-Score & $\mathbf{0 . 0} \%$ & $\mathbf{1 . 3} \%$ & $\mathbf{1 . 3 \%}$ \\
$95 \%$ Confidence Interval & $(-0.9-19.7 \%)$ & $(0.5-7.2 \%)$ & $(0.4-26.9 \%)$ \\
\hline
\end{tabular}

According to the Z-score interpretation 0 cases of severely malnourished children were found in the survey population. 1 was moderately malnourished.

Table 16: Overall acute malnutrition prevalence in children 6-59 months, Bamiyan, June 1998

\begin{tabular}{lccc}
\hline MALNUTRITION & SEVERE (<-3SD) & MODERATE (<-2 and >-3SD) & GLOBAL (<-2SD) \\
\hline Z-Score & $\mathbf{0 . 0} \%$ & $\mathbf{4 . 7} \%$ & $\mathbf{4 . 7 \%}$ \\
$95 \%$ Confidence Interval & $(-0.1-2.4 \%)$ & $(2.1-6.6 \%)$ & $(2.2-9.0 \%)$ \\
& & & $\mathbf{2 . 6} \%$ \\
\% of the median & $\mathbf{0 . 0} \%$ & $(0.8-3.9 \%)$ & $(0.9-6.3 \%)$ \\
$95 \%$ Confidence Interval & $(-0.1-2.4 \%)$ &
\end{tabular}


According to the Z-score interpretation 9 children were found to be moderately malnourished With the percentage of the median calculations, 5 were moderately malnourished.

Table 17: Overall acute malnutrition prevalence in children aged 0-5 months, Jaghoori, July 1998

\begin{tabular}{lccc} 
MALNUTRITION & SEVERE (<-3SD) & MODERATE (<-2 and >-3SD) & GLOBAL (<-2SD) \\
\hline Z-Score & $\mathbf{0 . 0 \%}$ & $\mathbf{0 . 0} \%$ & $\mathbf{0 . 0} \%$ \\
$95 \%$ Confidence Interval $(-0.1-22.5 \%)$ & $(0.0-0.0 \%)$ & $(-0.1-22.5 \%)$ \\
\hline
\end{tabular}

According to the Z-score interpretation there were no cases of severely or moderately malnourished children in the survey population.

Table 18: Overall acute malnutrition prevalence in children 6-59 months, Jaghoori, July 1998

\begin{tabular}{lccc}
\hline MALNUTRITION & SEVERE (<-3SD) & MODERATE (<-2 and >-3SD) & GLOBAL (<-2SD) \\
\hline Z-Score & $\mathbf{0 . 9} \%$ & $\mathbf{2 . 4} \%$ & $\mathbf{3 . 3} \%$ \\
$95 \%$ Confidence Interval & $(0.1-3.7 \%)$ & $(1.3-3.3 \%)$ & $(1.4-7.0 \%)$ \\
& & & \\
\% of the median & $\mathbf{0 . 0} \%$ & $\mathbf{2 . 3} \%$ & $\mathbf{2 . 3} \%$ \\
$95 \%$ Confidence Interval & $(-0.1-2.2 \%)$ & $(0.7-3.5 \%)$ & $(0.8-5.7 \%)$ \\
\hline
\end{tabular}

According to the Z-score interpretation 2 cases of severely malnourished children were found in the survey population, all of whom were marasmic. 5 were moderately malnourished. With the percentage of the median calculations, 5 were moderately malnourished.

Table 19: Overall acute malnutrition prevalence in children aged 0-5 months, Malestan, July 1998

\begin{tabular}{lccc} 
MALNUTRITION & SEVERE (<-3SD) & MODERATE (<-2 and >-3SD) & GLOBAL (<-2SD) \\
\hline Z-Score & $\mathbf{0 . 0 \%}$ & $\mathbf{0 . 0} \%$ & $\mathbf{0 . 0} \%$ \\
$95 \%$ Confidence Interval & $(-0.8-16.3 \%)$ & $(0.0-0.0 \%)$ & $(-0.8-16.3 \%)$ \\
\hline
\end{tabular}

According to the Z-score interpretation there were no cases of severely or moderately malnourished children in the survey population.

Table 20: Overall acute malnutrition prevalence in children 6-59 months, Malestan, July I998

\begin{tabular}{lccc} 
MALNUTRITION & SEVERE (<-3SD) & MODERATE (<-2 and >-3SD) & GLOBAL (<-2SD) \\
\hline Z-Score & $\mathbf{0 . 4} \%$ & $\mathbf{8 . 6 \%}$ & $\mathbf{9 . 0 \%}$ \\
$95 \%$ Confidence Interval & $(-0.1-2.5 \%)$ & $(5.7-10.9 \%)$ & $(5.8-13.4 \%)$ \\
& & & \\
\% of the median & $\mathbf{0 . 4} \%$ & $\mathbf{5 . 1} \%$ & $\mathbf{5 . 5} \%$ \\
$95 \%$ Confidence Interval $(-0.1-2.5 \%)$ & $(3.0-6.8 \%)$ & $(3.1-9.3 \%)$ \\
\hline
\end{tabular}

According to the Z-Score interpretation there was 1 case of a severely malnourished child in the survey population, who was marasmic. 22 were moderately malnourished. With the percentage of the median calculations, 1 child was severely malnourished and 13 moderately. 
Table 21: Overall acute malnutrition prevalence in children aged 0-5 months, Nawor, July 1998

\begin{tabular}{lccc}
\hline MALNUTRITION & SEVERE (<-3SD) & MODERATE (<-2 and >-3SD) & GLOBAL (<-2SD) \\
\hline Z-Score & $\mathbf{0 . 0} \%$ & $\mathbf{0 . 0} \%$ & $\mathbf{0 . 0} \%$ \\
$95 \%$ Confidence Interval $\cdot(-1.2-27.8 \%)$ & $(0.0-0.0 \%)$ & $(-1.2-27.8 \%)$ \\
\hline
\end{tabular}

According to the Z-score interpretation there were no cases of severely or moderately malnourished children in the survey population.

Tabl 22: Overall acute malnutrition prevalence in children 6-59 months, Nawor, July 1998

\begin{tabular}{lccc} 
MALNUTRITION & SEVERE (<-3SD) & MODERATE (<-2 and >-3SD) & GLOBAL (<-2SD) \\
\hline Z-Score & $\mathbf{0 . 0} \%$ & $\mathbf{2 . 1} \%$ & $\mathbf{2 . 1} \%$ \\
$95 \%$ Confidence Interval & $(-0.2-3.3 \%)$ & $(0.3-3.3 \%)$ & $(0.5-6.6 \%)$ \\
& & & \\
\% of the median & $\mathbf{0 . 0} \%$ & $\mathbf{0 . 7} \%$ & $\mathbf{0 . 7} \%$ \\
$95 \%$ Confidence Interval $(-0.2-3.3 \%)$ & $(-0.1-1.2 \%)$ & $(-0.1-4.5 \%)$ \\
\hline
\end{tabular}

According to the Z-Score interpretation 3 children were moderately malnourished. With the percentage of the median calculations, 1 child was moderately malnourished.

\section{Weight-for-height index distribution ${ }^{55}$ :}

Distribution of weight-for-height index, children aged 6-59 months, Hazarajat, June/July 1998

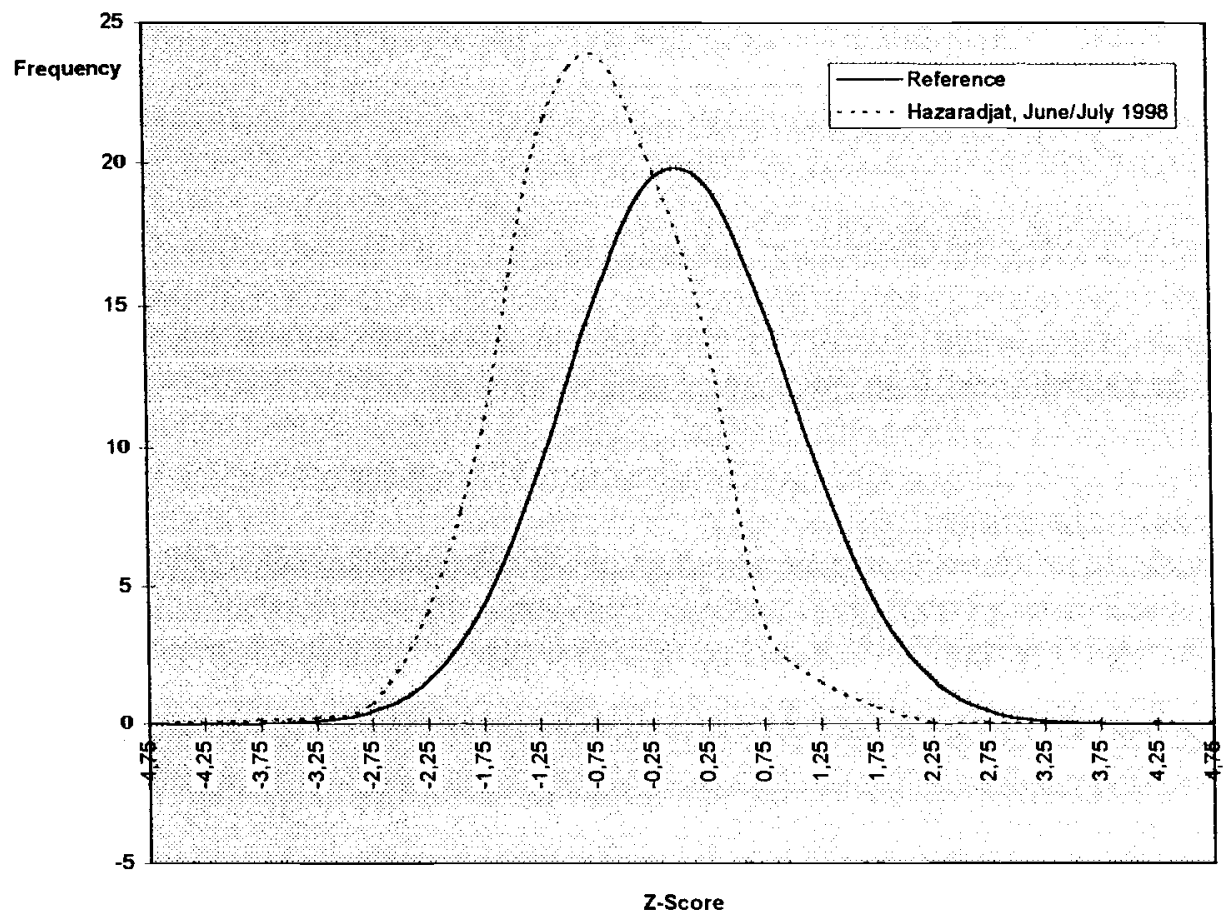

The distribution of weight-for-height expressed as a Z-Score, compared with the reference population, shows a shift to the left. This indicates that children to the left, not overlapping the

${ }^{55}$ See Appendices for Part VI: Appendix II for curves by region. 
curve, have a low weight in proportion to their height. The curve has a much higher peak indicating a larger number of children having a medium weight in proportion to their height.

Distribution of weight-for-height index, children aged ()-5 months, Hazarajat, June July I998

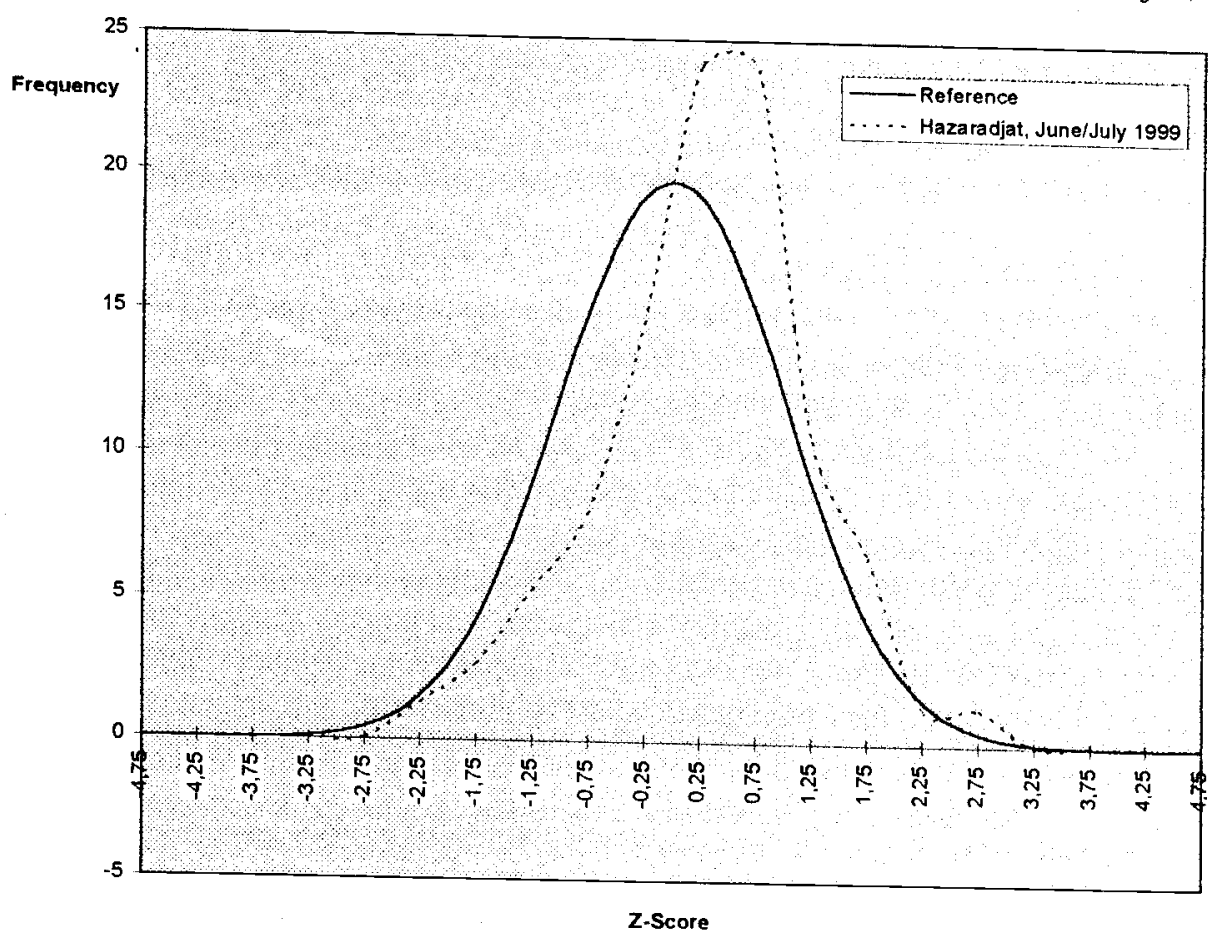

The distribution of weight-for-height expressed as a Z-Score, compared with the reference population, shows a shift to the right. This indicates that children to the right, not overlapping the curve, have a higher weight in proportion to their height. The curve has a much higher peak indicating a larger number of children having a medium weight in proportion to their height.

\section{Weight-for-height index versus oedema:}

No cases of oedema were found in any of the regions surveyed, indicating no cases of kwashiorkor or marasmic kwashiorkor within the survey population.

\section{Acute malnutrition versus age group:}

Table 23: WHZ and oedema distribution versus age, the Hazarajat, June/July 1998

\begin{tabular}{cccccccccc}
\hline AGE & TOTAL & \multicolumn{2}{c}{$\mathbf{X}<-\mathbf{- 3 S T D}$} & $\mathbf{- 3 ~ S T D} \leq \mathbf{X}<-\mathbf{2} \mathbf{S T D}$ & $\mathbf{- 2} \mathbf{S T D} \leq \mathbf{X}$ & \multicolumn{2}{c}{ OEDEMA } \\
in months & $\mathrm{Nbr}$ & $\mathrm{Nbr}$ & $\mathbf{\%}$ & $\mathrm{Nbr}$ & $\%$ & $\mathrm{Nbr}$ & $\%$ & Nbr & $\%$ \\
\hline $06-17$ & 196 & 2 & $1.0 \%$ & 12 & $6.1 \%$ & 182 & $92.9 \%$ & 0 & $0.0 \%$ \\
$18-29$ & 229 & 1 & $0.4 \%$ & 19 & $\mathbf{8 . 3} \%$ & 209 & $91.3 \%$ & 0 & $0.0 \%$ \\
$30-41$ & 211 & 0 & $0.0 \%$ & 5 & $2.4 \%$ & 206 & $97.6 \%$ & 0 & $0.0 \%$ \\
$42-53$ & 177 & 0 & $0.0 \%$ & 4 & $2.3 \%$ & 173 & $97.7 \%$ & 0 & $0.0 \%$ \\
$54-59$ & 81 & 0 & $0.0 \%$ & 2 & $2.5 \%$ & 79 & $97.5 \%$ & 0 & $0.0 \%$ \\
\hline TOTAL & $\mathbf{8 9 4}$ & $\mathbf{3}$ & $\mathbf{0 . 3} \%$ & $\mathbf{4 2}$ & $\mathbf{4 . 7} \%$ & $\mathbf{8 4 9}$ & $\mathbf{9 5 . 0} \%$ & $\mathbf{0}$ & $\mathbf{0 . 0} \%$ \\
\hline
\end{tabular}

A comparison can be made statistically, between children aged 6-29 months and those over 29 months. This shows that the malnutrition rates for the younger group are higher. The relative risk is 
3.41 (CI 1.75-6.65), which means that the risk of being malnourished is magnified by 3.41 for children less than 30 months (Chi square $=14.91 \mathrm{p}<0.0001$ ).

Table 24: Acute malnutrition rates for children aged 6-29 months, the Hazarajat, June/July I998

\begin{tabular}{lcc}
\hline MALNUTRITION & SEVERE (<-3SD) & GLOBAL (<-2SD) \\
\hline Z-Score & $\mathbf{0 . 7 \%}$ & $\mathbf{8 . 0 \%}$ \\
$95 \%$ Confidence Interval & $(0.1-2.2 \%)$ & $(5.6-11.2 \%)$ \\
& & \\
\% of the median & $\mathbf{0 . 2} \%$ & $\mathbf{4 . 9} \%$ \\
$95 \%$ Confidence Interval & $(-0.0-1.5 \%)$ & $(3.1-7.6 \%)$ \\
\hline
\end{tabular}

Table 25: WHZ and oedema distribution versus age, Ajarestan, July 1998

\begin{tabular}{|c|c|c|c|c|c|c|c|c|c|}
\hline \multirow{2}{*}{$\begin{array}{c}\mathbf{A G E} \\
\text { in months }\end{array}$} & \multirow{2}{*}{$\begin{array}{c}\text { TOTAL } \\
\text { Nbr }\end{array}$} & \multicolumn{2}{|c|}{$X<-3 S T D$} & \multicolumn{2}{|c|}{-3 STD $\leq X<-2$ STD } & \multicolumn{2}{|c|}{-2 STD $\leq X$} & \multicolumn{2}{|c|}{ OEDEMA } \\
\hline & & $\mathrm{Nbr}$ & $\%$ & $\mathrm{Nbr}$ & $\%$ & $\mathrm{Nbr}$ & $\%$ & $\mathrm{Nbr}$ & $\%$ \\
\hline $06-17$ & 20 & 0 & $0.0 \%$ & 1 & $5.0 \%$ & 19 & $95.0 \%$ & 0 & $0.0 \%$ \\
\hline $18-29$ & 19 & 0 & $0.0 \%$ & 2 & $10.5 \%$ & 17 & $89.5 \%$ & 0 & $0.0 \%$ \\
\hline $30-41$ & 27 & 0 & $0.0 \%$ & 0 & $0.0 \%$ & 27 & $100.0 \%$ & 0 & $0.0 \%$ \\
\hline $42-53$ & 20 & 0 & $0.0 \%$ & 0 & $0.0 \%$ & 20 & $100.0 \%$ & 0 & $0.0 \%$ \\
\hline $54-59$ & 5 & 0 & $0.0 \%$ & 0 & $0.0 \%$ & 5 & $100.0 \%$ & 0 & $0.0 \%$ \\
\hline TOTAL & 91 & $\mathbf{0}$ & $0.0 \%$ & 3 & $3.3 \%$ & 88 & $96.7 \%$ & $\mathbf{0}$ & $0.0 \%$ \\
\hline
\end{tabular}

A comparison can be made statistically, between children aged 6-29 months and those over 29 months. This shows that the malnutrition rates for the younger group are higher. The relative risk is 2.79 (CI $0.26-29.66$ ), which means that the risk of being malnourished is magnified by 2.79 for children less than 30 months (Chi square $=0.79 \mathrm{p}<0.374$ ).

Table 26: Acute malnutrition rates for children aged 6-29 months, Ajarestan, July 1998

\begin{tabular}{lcc}
\hline MALNUTRITION & SEVERE (<-3SD) & GLOBAL (<-2SD) \\
\hline Z-Score & $\mathbf{0 . 0} \%$ & $\mathbf{7 . 7} \%$ \\
$95 \%$ Confidence Interval & $(-0.5-11.0 \%)$ & $(1.7-22.1 \%)$ \\
& & $\mathbf{0 . 0} \%$ \\
\% of the median & $\mathbf{0 . 0} \%$ & $(-0.5-11.0 \%)$ \\
$95 \%$ Confidence Interval & $(-0.5-11.0 \%)$ &
\end{tabular}

Table 27: WHZ and oedema distribution versus age, Bamiyan, June 1998

\begin{tabular}{|c|c|c|c|c|c|c|c|c|c|}
\hline \multirow{2}{*}{$\begin{array}{c}\text { AGE } \\
\text { in months }\end{array}$} & \multirow{2}{*}{$\begin{array}{c}\text { TOTAL } \\
\text { Nbr }\end{array}$} & \multicolumn{2}{|c|}{$X<-3 S T D$} & \multicolumn{2}{|c|}{-3 STD $\leq X<-2$ STD } & \multicolumn{2}{|c|}{-2 STD $\leq X$} & \multicolumn{2}{|c|}{ OEDEMA } \\
\hline & & $\mathrm{Nbr}$ & $\%$ & $\mathrm{Nbr}$ & $\%$ & $\mathrm{Nbr}$ & $\%$ & $\mathrm{Nbr}$ & $\%$ \\
\hline $06-17$ & 42 & 0 & $0.0 \%$ & 3 & $7.1 \%$ & 39 & $92.9 \%$ & 0 & $0.0 \%$ \\
\hline $18-29$ & 58 & 0 & $0.0 \%$ & 5 & $8.6 \%$ & 53 & $91.4 \%$ & 0 & $0.0 \%$ \\
\hline $30-41$ & 35 & 0 & $0.0 \%$ & 0 & $0.0 \%$ & 35 & $100.0 \%$ & 0 & $0.0 \%$ \\
\hline $42-53$ & 36 & 0 & $0.0 \%$ & 1 & $2.8 \%$ & 35 & $97.2 \%$ & 0 & $0.0 \%$ \\
\hline $54-59$ & 22 & 0 & $0.0 \%$ & 0 & $0.0 \%$ & 22 & $100.0 \%$ & 0 & $0.0 \%$ \\
\hline TOTAL & 193 & $\mathbf{0}$ & $0.0 \%$ & 9 & $4.7 \%$ & 184 & $95.3 \%$ & $\mathbf{0}$ & $0.0 \%$ \\
\hline
\end{tabular}


A comparison can be made statistically, between children aged 6-29 months and those over 29 months. This shows that the malnutrition rates for the younger group are higher. The relative risk is 7.44 (CI $0.86-57.49$ ), which means that the risk of being malnourished is magnified by 7.44 for children less than 30 months (Chi square $=5.2 \mathrm{p}<0.023$ ).

Table 28: Acute malnutrition rates for children aged 6-29 months, Bamiyan, June 1998

\begin{tabular}{lcc}
\hline MALNUTRITION & SEVERE (<-3SD) & GLOBAL (<-2SD) \\
\hline Z-Score & $\mathbf{0 . 0} \%$ & $\mathbf{8 . 0} \%$ \\
$95 \%$ Confidence Interval & $(-0.2-4.6 \%)$ & $(3.7-15.7 \%)$
\end{tabular}

$\%$ of the median

95\% Confidence Interval

$0.0 \%$

$(-0.2-4.6 \%)$

$5.0 \%$

$(1.7-11.9 \%)$

Table 29: WHZ and oedema distribution versus age, Jaghoori, July 1998

\begin{tabular}{|c|c|c|c|c|c|c|c|c|c|}
\hline \multirow{2}{*}{$\begin{array}{c}\text { AGE } \\
\text { in months }\end{array}$} & \multirow{2}{*}{$\begin{array}{c}\text { TOTAL } \\
\text { Nbr }\end{array}$} & \multicolumn{2}{|c|}{$X<-3$ STD } & \multicolumn{2}{|c|}{-3 STD $\leq X<-2$ STD } & \multicolumn{2}{|c|}{-2 STD $\leq X$} & \multicolumn{2}{|c|}{ OEDEMA } \\
\hline & & $\mathrm{Nbr}$ & $\%$ & $\mathrm{Nbr}$ & $\%$ & $\mathrm{Nbr}$ & $\%$ & $\mathrm{Nbr}$ & $\%$ \\
\hline $06-17$ & 48 & 1 & $2.1 \%$ & 1 & $2.1 \%$ & 46 & $95.8 \%$ & 0 & $0.0 \%$ \\
\hline $18-29$ & 50 & 1 & $2.0 \%$ & 3 & $6.0 \%$ & 46 & $92.0 \%$ & 0 & $0.0 \%$ \\
\hline $30-41$ & 52 & 0 & $0.0 \%$ & 1 & $1.9 \%$ & 51 & $98.1 \%$ & 0 & $0.0 \%$ \\
\hline $42-53$ & 42 & 0 & $0.0 \%$ & 0 & $0.0 \%$ & 42 & $100.0 \%$ & 0 & $0.0 \%$ \\
\hline $54-59$ & 21 & 0 & $0.0 \%$ & 0 & $0.0 \%$ & 21 & $100.0 \%$ & 0 & $0.0 \%$ \\
\hline TOTAL & 213 & 2 & $0.9 \%$ & 5 & $2.3 \%$ & 206 & $96.7 \%$ & 0 & $0.0 \%$ \\
\hline
\end{tabular}

A comparison can be made statistically, between children aged 6-29 months and those over 29 months. This shows that the malnutrition rates for the younger group are higher. The relative risk is 7.04 (CI 0.86-57.49), which means that the risk of being malnourished is magnified by 7.04 for children less than 30 months (Chi square $=4.59 \mathrm{p}<0.032$ ).

Table 30: Acute malnutrition rates for children aged 6-29 months, Jaghoori, July 1998

\begin{tabular}{lcc}
\hline MALNUTRITION & SEVERE (<-3SD) & GLOBAL (<-2SD) \\
\hline Z-Score & $\mathbf{2 . 0} \%$ & $\mathbf{6 . 1} \%$ \\
$95 \%$ Confidence Interval & $(0.2-7.9 \%)$ & $(2.4-13.5 \%)$ \\
& & \\
$\%$ of the median & $\mathbf{0 . 0} \%$ & $\mathbf{5 . 1} \%$ \\
$95 \%$ Confidence Interval & $(-0.2-4.6 \%)$ & $(1.8-12.2 \%)$ \\
\hline
\end{tabular}

Table 31: WHZ and oedema distribution versus age, Malestan, July 1998

\begin{tabular}{|c|c|c|c|c|c|c|c|c|c|}
\hline \multirow{2}{*}{$\begin{array}{c}\text { AGE } \\
\text { in months }\end{array}$} & \multirow{2}{*}{$\begin{array}{c}\text { TOTAL } \\
\text { Nbr }\end{array}$} & \multicolumn{2}{|c|}{$X<-3$ STD } & \multicolumn{2}{|c|}{-3 STD $\leq X<-2$ STD } & \multicolumn{2}{|c|}{-2 STD $\leq X$} & \multicolumn{2}{|c|}{ OEDEMA } \\
\hline & & $\mathrm{Nbr}$ & $\%$ & $\mathrm{Nbr}$ & $\%$ & $\mathrm{Nbr}$ & $\%$ & $\mathrm{Nbr}$ & $\%$ \\
\hline $06-17$ & 56 & 1 & $1.8 \%$ & 6 & $10.7 \%$ & 49 & $87.5 \%$ & 0 & $0.0 \%$ \\
\hline $18-29$ & 64 & 0 & $0.0 \%$ & 8 & $12.5 \%$ & 56 & $87.5 \%$ & 0 & $0.0 \%$ \\
\hline $30-41$ & 57 & 0 & $0.0 \%$ & 3 & $5.3 \%$ & 54 & $94.7 \%$ & 0 & $0.0 \%$ \\
\hline $42-53$ & 54 & 0 & $0.0 \%$ & 3 & $5.6 \%$ & 51 & $94.4 \%$ & 0 & $0.0 \%$ \\
\hline $54-59$ & 25 & 0 & $0.0 \%$ & 2 & $8.0 \%$ & 23 & $92.0 \%$ & 0 & $0.0 \%$ \\
\hline TOTAL & 256 & 1 & $0.4 \%$ & 22 & $8.6 \%$ & 233 & $91.0 \%$ & $\mathbf{0}$ & $0.0 \%$ \\
\hline
\end{tabular}


A comparison can be made statistically, between children aged 6-29 months and those over 29 months. This shows that the malnutrition rates for the younger group are higher. The relative risk is 2.13 (CI 0.93-4.84), which means that the risk of being malnourished is magnified by 2.13 for children less than 30 months $($ Chi square $=3.41 \mathrm{p}<0.065)$.

Table 32: Acute malnutrition rates for children aged 6-29 months, Malestan, July 1998

\begin{tabular}{lcc}
\hline MALNUTRITION & SEVERE (<-3SD) & GLOBAL (<-2SD) \\
\hline Z-Score & $\mathbf{0 . 8} \%$ & $\mathbf{1 2 . 5} \%$ \\
$95 \%$ Confidence Interval & $(-0.1-5.2 \%)$ & $(7.3-20.2 \%)$ \\
& & \\
\% of the median & $\mathbf{0 . 8} \%$ & $\mathbf{9 . 2} \%$ \\
$95 \%$ Confidence Interval & $(-0.1-5.2 \%)$ & $(4.8-16.3 \%)$ \\
\hline
\end{tabular}

Table 33: WHZ and oedema distribution versus age, Nawor, July 1998

\begin{tabular}{cccccccccc}
\hline AGE & TOTAL & \multicolumn{2}{c}{$\mathbf{X}<-\mathbf{- 3 S T D}$} & \multicolumn{2}{c}{$\mathbf{3}$ STD $\leq \mathbf{X}<-\mathbf{2}$ STD } & \multicolumn{2}{c}{$\mathbf{- 2}$ STD $\leq \mathbf{X}$} & \multicolumn{2}{c}{ OEDEMA } \\
in months & $\mathrm{Nbr}$ & $\mathrm{Nbr}$ & $\mathbf{\%}$ & $\mathrm{Nbr}$ & $\%$ & $\mathrm{Nbr}$ & $\mathbf{\%}$ & $\mathrm{Nbr}$ & $\%$ \\
\hline $06-17$ & 30 & 0 & $0.0 \%$ & 1 & $3.3 \%$ & 29 & $96.7 \%$ & 0 & $0.0 \%$ \\
$18-29$ & 38 & 0 & $0.0 \%$ & 1 & $2.6 \%$ & 37 & $97.4 \%$ & 0 & $0.0 \%$ \\
$30-41$ & 40 & 0 & $0.0 \%$ & 1 & $2.5 \%$ & 39 & $97.5 \%$ & 0 & $0.0 \%$ \\
$42-53$ & 25 & 0 & $0.0 \%$ & 0 & $0.0 \%$ & 25 & $100.0 \%$ & 0 & $0.0 \%$ \\
$54-59$ & 8 & 0 & $0.0 \%$ & 0 & $0.0 \%$ & 8 & $100.0 \%$ & 0 & $0.0 \%$ \\
\hline TOTAL & $\mathbf{1 4 1}$ & $\mathbf{0}$ & $\mathbf{0 . 0} \%$ & $\mathbf{3}$ & $\mathbf{2 . 1} \%$ & $\mathbf{1 3 8}$ & $\mathbf{9 7 . 9} \%$ & $\mathbf{0}$ & $\mathbf{0 . 0} \%$ \\
\hline
\end{tabular}

A comparison can be made statistically, between children aged 6-29 months and those over 29 months. This shows that the malnutrition rates for the younger group are higher. The relative risk is 2.15 (CI $0.20-23.14$ ), which means that the risk of being malnourished is magnified by 2.15 for children less than 30 months (Chi square $=0.42 \mathrm{p}<0.518$ ).

Table 34: Acute malnutrition rates for children aged 6-29 months, Nawor, July 1998

\begin{tabular}{lcc}
\hline MALNUTRITION & SEVERE (<-3SD) & GLOBAL (<-2SD) \\
\hline Z-Score & $\mathbf{0 . 0} \%$ & $\mathbf{2 . 9} \%$ \\
$95 \%$ Confidence Interval & $(-0.3-6.6 \%)$ & $(0.3-11.2 \%)$ \\
& & \\
\% of the median & $\mathbf{0 . 0} \%$ & $\mathbf{0 . 0} \%$ \\
$95 \%$ Confidence Interval & $(-0.3-6.6 \%)$ & $(-0.3-6.6 \%)$ \\
Acute malnutrition versus sex & $\mathbf{5 6}$ & \\
\hline
\end{tabular}

The distribution of global acute malnutrition (weight-for-height index expressed as a Z-Score) between males and females does not reflect a difference in the $0-5$ months age group.

\footnotetext{
${ }^{56}$ For details per region, see Appendices for Part VI: Appendix III.
} 
$\frac{\text { Table 35: Acute malnutrition versus sex, 0-5 months, the Hazarajat, June/July } 1998}{\text { AGE }}$

\begin{tabular}{|c|c|c|c|c|c|}
\hline \multirow{2}{*}{$\begin{array}{c}\mathbf{A G E} \\
\text { in months }\end{array}$} & \multicolumn{2}{|c|}{ WH $Z<-2 S D$} & \multicolumn{2}{|c|}{ WHZ $\geq-2$ SD } & \multirow{2}{*}{$\begin{array}{c}\text { TOTAL } \\
\mathrm{Nbr}\end{array}$} \\
\hline & $\mathrm{Nbr}$ & $\%$ & $\mathrm{Nbr}$ & $\%$ & \\
\hline Males & 1 & $2.8 \%$ & $35^{\circ}$ & $97.2 \%$ & 36 \\
\hline Females & 0 & $0.0 \%$ & 39 & $100.0 \%$ & 39 \\
\hline TOTAL & 1 & $1.3 \%$ & 74 & $98.7 \%$ & 75 \\
\hline
\end{tabular}

The distribution of global acute malnutrition (weight-for-height index expressed as a Z-Score) between males and females does not reflect a difference in the 6-59 months age group.

Table 36: Acute malnutrition versus sex, 6-59 months, the Hazarajat, June July 1998

\begin{tabular}{|c|c|c|c|c|c|}
\hline \multirow{2}{*}{$\begin{array}{c}\text { AGE } \\
\text { in months }\end{array}$} & \multicolumn{2}{|c|}{ WHZ $<-2$ SD } & \multicolumn{2}{|c|}{$W H Z \geq-2 S D$} & \multirow{2}{*}{$\begin{array}{c}\text { TOTAL } \\
\text { Nbr }\end{array}$} \\
\hline & $\mathrm{Nbr}$ & $\%$ & $\mathrm{Nbr}$ & $\%$ & \\
\hline Males & 28 & $6.2 \%$ & 427 & $93.8 \%$ & 455 \\
\hline Females & 17 & $3.9 \%$ & 422 & $96.1 \%$ & 439 \\
\hline TOTAL & 45 & $5.0 \%$ & 849 & $95.0 \%$ & 894 \\
\hline
\end{tabular}

A difference was seen in moderate acute malnutrition between the sexes, when the sample was divided between the age groups 6-29 months and 30-59 months.

\begin{tabular}{ccccc}
\hline $\begin{array}{c}\text { REGION } \\
\text { in months }\end{array}$ & \multicolumn{2}{c}{ WHZ<-2SD (6-29 months) } & \multicolumn{2}{c}{ WHZ<-2SD (30-59 months) } \\
Global & $9.0 \%$ & $6.9 \%$ & $6.2 \%$ & Females \\
Ajarestan & $\mathbf{1 6 . 7 \%}$ & $\mathbf{0 . 0} \%$ & $0.0 \%$ & $0.0 \%$ \\
Bamian & $\mathbf{1 2 . 0 \%}$ & $\mathbf{4 . 0 \%}$ & $0.0 \%$ & $2.0 \%$ \\
Jaghoori & $5.3 \%$ & $7.3 \%$ & $0.0 \%$ & $1.8 \%$ \\
Malestan & $10.9 \%$ & $14.3 \%$ & $\mathbf{1 0 . 8} \%$ & $\mathbf{1 . 4} \%$ \\
Nawor & $2.9 \%$ & $2.9 \%$ & $2.2 \%$ & $0.0 \%$ \\
\hline
\end{tabular}

Although there was no significant difference between the sexes in the age groups 6-29 months and 30-59 months, globally, some dramatic differences were noted in certain regions. In Ajarestan, $16.7 \%$ of boys in the younger age category were acutely malnourished, whilst no girls suffered. In Bamiyan, $12.0 \%$ of boys compared to $4.0 \%$ of girls had acute moderate malnutrition in the $6-29$ months age range. Malestan showed $10.8 \%$ of boys and $1.4 \%$ of girls presenting moderate acute malnutrition in the 30-59 months age range. No explanation can be given for this phenomenon.

\section{Stunting:}

Stunting is expressed as a Z-Score, with 'stunting' showing the global figures including severe stunting. 


\section{Global:}

\section{Z-Score}

95\% Confidence Interval

\section{Ajarestan:}

\section{Z-Score}

95\% Confidence Interval

Bamiyan:

Z-Score

95\% Confidence Interval

Jaghoori:

Z-Score

95\% Confidence Interval

Malestan:

Z-Score

95\% Confidence Interval

Nawor:

Z-Score

95\% Confidence Interval
$28.7 \%$

(25.8-31.9\%)

$17.6 \%$

$(10.7-27.3 \%)$

$36.3 \%$

(29.6-43.5\%)

$15.5 \%$

(11.0-21.2\%)

$34.8 \%$

$(29.0-41.0 \%)$

$34.8 \%$

$(27.1-43.3 \%)$
$61.6 \%$

(58.3-64.8\%)

$51.6 \%$

(41.1-62.2\%)

$69.9 \%$

(62.9-76.2\%)

$47.9 \%$

(41.1-54.8\%)

$67.2 \%$

$(61.0-72.9 \%)$

$67.4 \%$

$(59.0-74.9 \%)$

There was a considerable amount of stunting evident within the sample, both moderate and severe. These figures seem rather alarming, but one has to consider that ages given are not necessarily accurate and that the Hazaras are of Mongol descent and may be genetically short. The harsh weather conditions and over-planting of crops have led to soil erosion, which must, in the long term, effect the quality and quantity of food produced.

These figures reflect ecological constraints and accessibility to markets. Ajarestan and Jaghoori, at comparatively low altitudes, have a wider variety of crops, including fruits and vegetables and have lower levels of chronic malnutrition, including lower levels of severe stunting. Jaghoori, with the lowest levels of stunting has more people with land ownership and greater production possibilities $^{57}$. Large markets within the vicinity and therefore lower prices allow better purchasing power.

\section{Height-for-age index distribution ${ }^{58}$}

The distribution curve of the height-for-age index expressed as a Z-Score (HAZ) shows a very different distribution from the normal reference population and is shifted to the left. Stunting may be due to a long term inadequate diet, but again, it must be taken into account, that the Hazaras are of Mongol descent and may be prone to a shorter height genetically.

\footnotetext{
${ }^{57}$ See Food Security section.

${ }^{58}$ For curves per region see Appendices for Part VI: Appendix IV.
} 


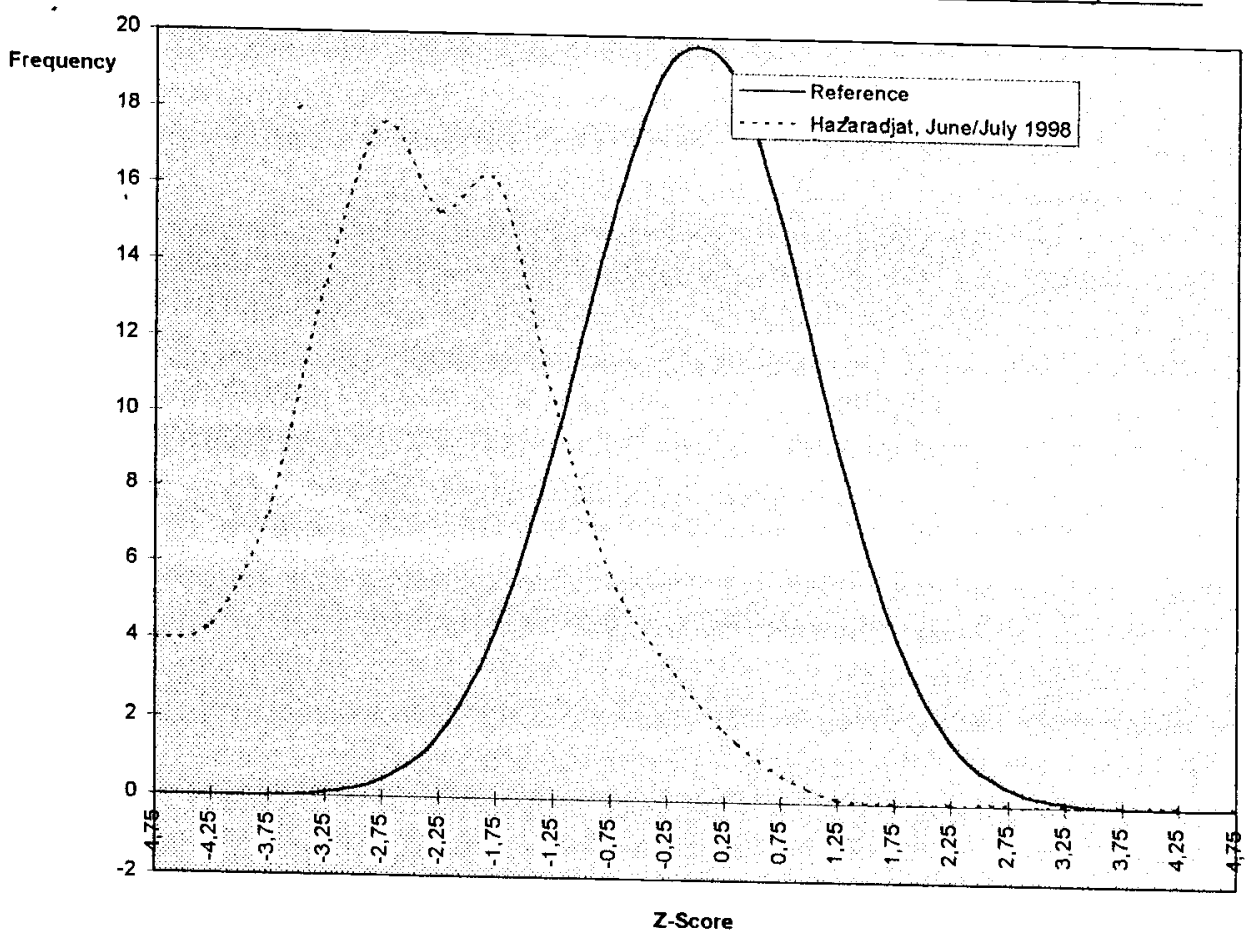

The curve shows much stunting and is badly affected by the poor reliability of the ages given by the mother, which can be due to a lack of attention put on dates of birth, but also the high level of illiteracy, particularly among women.

\section{Stunting versus wasting} index.

Using the Z-Score expression, the height-for-age index can be compared to the weight-for-height

Table 38: Stunting versus wasting, the Hazarajat, June/July 1998

\begin{tabular}{cccc|c}
\hline $\begin{array}{c}\text { AGE } \\
\text { in months }\end{array}$ & $\begin{array}{c}\text { HAZ }<- \text { 3SD } \\
\text { Severe stunting }\end{array}$ & $\begin{array}{c}- \text { 3SD } \leq \text { HAZ }<- \text { 2SD } \\
\text { Moderate stunting }\end{array}$ & $\begin{array}{c}\text { HAZ } \geq- \text { 2SD } \\
\text { Normal height }\end{array}$ & TOTAL \\
\hline $\begin{array}{c}\text { WHZ }<\text { - 3SD } \\
\text { Severe wasting }\end{array}$ & 0 & 0 & 3 & $\mathbf{3}$ \\
$\begin{array}{c}\text { - 3SD } \leq \text { WHZ }<- \text { 2SD } \\
\text { Moderate wasting } \\
\text { HAZ } \geq \text { - 2SD } \\
\text { Normal weight }\end{array}$ & 11 & 21 & 10 & $(0.3 \%)$ \\
$\mathbf{4 2}$ \\
TOTAL & 246 & 273 & 330 & $\begin{array}{c}(4.7 \%) \\
\mathbf{8 4 9}\end{array}$ \\
\hline
\end{tabular}

Amongst the children who have a normal weight for their height $61.1 \%$ are stunted, which may be due to a poor nutritional history, a poor estimation of age, or the fact that the Hazaras are of Mongol descent and may be prone to a shorter height average genetically, than the reference population. $76.2 \%$ of wasted children were also stunted. This could be an indication of a poor diet (see diet section) over a long period of time, resulting in growth retardation, which may have become worse in the weeks preceding the survey, causing wasting. The survey was carried out during the Hunger Gap of this region. $36.9 \%$ of the children were neither stunted nor wasted. 


\section{Stunting versus wasting by region ${ }^{59}$}

\section{$\underline{\text { Ajarestan }}$}

Amongst the children who have a normal weight for their height $52.3 \%$ were stunted. $33.3 \%$ of wasted children were also stunted. $47.7 \%$ of the children were neither stunted nor wasted.

\section{Bamivan}

Amongst the children who have a normal weight for their height $68.5 \%$ are stunted. $100 \%$ of wasted children were also stunted. $30.1 \%$ of the children were neither stunted nor wasted.

\section{Jaghoori}

Amongst the children who have a normal weight for their height $48.1 \%$ are stunted. $60.0 \%$ of wasted children were also stunted. $50.2 \%$ of the children were neither stunted nor wasted.

\section{Malestan}

Amongst the children who have a normal weight for their height $66.5 \%$ are stunted. $77.3 \%$ of wasted children were also stunted. $30.5 \%$ of the children were neither stunted nor wasted.

\section{Nawor}

Amongst the children who have a normal weight for their height $67.4 \%$ are stunted. $66.6 \%$ of wasted children were also stunted. $31.9 \%$ of the children were neither stunted nor wasted.

\section{Mid Upper Arm Circumference}

The MUAC distribution versus the height amongst the target population is reflected below. The following are the cut off points used:

- $75 \mathrm{~cm}$ as an average height for a child aged 1 year

- $90 \mathrm{~cm}$ as an average height for a child aged 3 years

- $110 \mathrm{~cm}$ as an average height for a child aged 5 years

Table 39: MUAC versus height, the Hazarajat, June/July 1998

\begin{tabular}{ccccccc|c}
\hline MUAC (in mm) & \multicolumn{2}{c|}{ MUAC $<\mathbf{1 1 0}$} & \multicolumn{2}{c|}{$\mathbf{1 1 0} \leq$ MUAC $<\mathbf{1 2 0}$} & \multicolumn{2}{c}{$\mathbf{1 2 0} \leq$ MUAC } & TOTAL \\
HEIGHT (in cm) & Nbr & $\%$ & Nbr & $\%$ & Nbr & $\%$ & Nbr \\
\hline H $<\mathbf{7 5}$ & 21 & $8.4 \%$ & 57 & $22.7 \%$ & 173 & $68.9 \%$ & $\mathbf{2 5 1}$ \\
$\mathbf{7 5} \leq \mathbf{H}<\mathbf{9 0}$ & 4 & $0.9 \%$ & 15 & $3.5 \%$ & 410 & $95.6 \%$ & $\mathbf{4 2 9}$ \\
$\mathbf{9 0} \leq$ H $\leq \mathbf{1 1 0}$ & 0 & $0.0 \%$ & 1 & $0.5 \%$ & 213 & $99.5 \%$ & $\mathbf{2 1 4}$ \\
\hline TOTAL & $\mathbf{2 5}$ & $\mathbf{2 . 8} \%$ & $\mathbf{7 3}$ & $\mathbf{8 . 2} \%$ & $\mathbf{7 9 6}$ & $\mathbf{8 9 . 0} \%$ & $\mathbf{8 9 4}$ \\
\hline
\end{tabular}

The average MUAC value of these 894 children is $135 \mathrm{~mm}$, with a standard deviation of 12.2 .

\footnotetext{
${ }^{59}$ For results per region, see Appendices for Part VI: Appendix V.
} 


\begin{tabular}{ccccccc|c}
\multicolumn{7}{l}{ Table 40: MUAC versus height, children $\geq 75 \mathrm{~cm}$ and $\leq 110 \mathrm{~cm}$, Ajarestan, July 1998} \\
\hline MUAC (in mm) & MUAC $<\mathbf{1 1 0}$ & $\mathbf{1 1 0} \leq$ MUAC $<\mathbf{1 2 0}$ & $\mathbf{1 2 0} \leq$ MUAC & TOTAL \\
HEIGHT (in cm) & $\mathrm{Nbr}$ & $\%$ & $\mathrm{Nbr}$ & $\%$ & $\mathrm{Nbr}$ & $\%$ & Nbr \\
\hline H $<\mathbf{7 5}$ & 0 & $0.0 \%$ & 3 & $\mathbf{1 4 . 3 \%}$ & 18 & $\mathbf{8 5 . 7} \%$ & $\mathbf{2 1}$ \\
$\mathbf{7 5} \leq$ H $<\mathbf{9 0}$ & 0 & $0.0 \%$ & 1 & $2.2 \%$ & 44 & $97.8 \%$ & $\mathbf{4 5}$ \\
$\mathbf{9 0} \leq$ H $\leq \mathbf{1 1 0}$ & 0 & $0.0 \%$ & 0 & $0.0 \%$ & 25 & $100.0 \%$ & $\mathbf{2 5}$ \\
\hline TOTAL & $\mathbf{0}$ & $\mathbf{0 . 0} \%$ & $\mathbf{4}$ & $\mathbf{4 . 4} \%$ & $\mathbf{8 7}$ & $\mathbf{9 5 . 6} \%$ & $\mathbf{9 1}$ \\
\hline
\end{tabular}

The average MUAC value of these 91 children is $137 \mathrm{~mm}$, with a standard deviation of 10.6 .

Table 41: MUAC versus height, Bamiyan, June 1998

\begin{tabular}{|c|c|c|c|c|c|c|c|}
\hline \multirow{2}{*}{$\begin{array}{l}\text { MUAC (in mm) } \\
\text { HEIGHT (in cm) }\end{array}$} & \multicolumn{2}{|c|}{ MUAC $<110$} & \multicolumn{2}{|c|}{$110 \leq$ MUAC $<120$} & \multicolumn{2}{|c|}{$120 \leq$ MUAC } & \multirow{2}{*}{$\begin{array}{c}\text { TOTAL } \\
\text { Nbr }\end{array}$} \\
\hline & $\mathrm{Nbr}$ & $\%$ & $\mathrm{Nbr}$ & $\%$ & $\mathrm{Nbr}$ & $\%$ & \\
\hline $\mathbf{H}<\mathbf{7 5}$ & 4 & $6.5 \%$ & 18 & $29.0 \%$ & 40 & $64.5 \%$ & 62 \\
\hline $75 \leq H<90$ & 0 & $0.0 \%$ & 1 & $1.2 \%$ & 84 & $98.8 \%$ & 85 \\
\hline $90 \leq H \leq 110$ & 0 & $0.0 \%$ & 0 & $0.0 \%$ & 46 & $100.0 \%$ & 46 \\
\hline TOTAL & 4 & $2.1 \%$ & 19 & $9.8 \%$ & 170 & $88.1 \%$ & 193 \\
\hline
\end{tabular}

The average MUAC value of these 193 children is $134 \mathrm{~mm}$, with a standard deviation of 12.1 .

Table 42: MUAC versus height, Jaghoori, July 1998

\begin{tabular}{ccccccc|c}
\hline MUAC (in mm) & \multicolumn{2}{c}{ MUAC $<\mathbf{1 1 0}$} & \multicolumn{1}{c|}{$\mathbf{1 1 0} \leq$ MUAC $<\mathbf{1 2 0}$} & \multicolumn{1}{c|}{$\mathbf{2 0} \leq$ MUAC } & TOTAL \\
HEIGHT (in cm) & Nbr & $\%$ & Nbr & $\%$ & Nbr & $\%$ & Nbr \\
\hline H $<\mathbf{7 5}$ & 2 & $4.3 \%$ & 7 & $14.8 \%$ & 38 & $80.9 \%$ & $\mathbf{4 7}$ \\
$\mathbf{7 5} \leq \mathbf{H}<\mathbf{9 0}$ & 1 & $0.9 \%$ & 1 & $0.9 \%$ & 110 & $98.2 \%$ & $\mathbf{1 1 2}$ \\
$\mathbf{9 0} \leq \mathbf{H} \leq \mathbf{1 1 0}$ & 0 & $0.0 \%$ & 0 & $0.0 \%$ & 54 & $100.0 \%$ & $\mathbf{5 4}$ \\
\hline TOTAL & $\mathbf{3}$ & $\mathbf{1 . 4} \%$ & $\mathbf{8}$ & $\mathbf{3 . 8} \%$ & $\mathbf{2 0 2}$ & $\mathbf{9 4 . 8} \%$ & $\mathbf{2 1 3}$ \\
\hline
\end{tabular}

The average MUAC value of these 213 children is $138 \mathrm{~mm}$, with a standard deviation of 11.0 .

Table 43: MUAC versus height, Malestan, July 1998

\begin{tabular}{ccccccc|c}
\hline MUAC (in mm) & \multicolumn{2}{c}{ MUAC $<\mathbf{1 1 0}$} & \multicolumn{2}{c|}{$\mathbf{1 1 0} \leq$ MUAC $<\mathbf{1 2 0}$} & \multicolumn{2}{c|}{$\mathbf{1 2 0} \leq$ MUAC } & TOTAL \\
HEIGHT (in cm) & Nbr & $\%$ & Nbr & $\%$ & Nbr & $\%$ & Nbr \\
\hline H $<\mathbf{7 5}$ & 12 & $15.4 \%$ & 14 & $17.9 \%$ & 52 & $66.7 \%$ & $\mathbf{7 8}$ \\
$\mathbf{7 5} \leq \mathbf{H}<\mathbf{9 0}$ & 3 & $2.5 \%$ & 8 & $6.8 \%$ & 107 & $90.7 \%$ & $\mathbf{1 1 8}$ \\
$\mathbf{9 0} \leq \mathbf{H} \leq \mathbf{1 1 0}$ & 0 & $0.0 \%$ & 0 & $0.0 \%$ & 60 & $100.0 \%$ & $\mathbf{6 0}$ \\
\hline TOTAL & $\mathbf{1 5}$ & $\mathbf{5 . 9} \%$ & $\mathbf{2 2}$ & $\mathbf{8 . 6} \%$ & $\mathbf{2 1 9}$ & $\mathbf{8 5 . 5} \%$ & $\mathbf{2 5 6}$ \\
\hline
\end{tabular}

The average MUAC value of these 256 children is $133 \mathrm{~mm}$, with a standard deviation of 13.1 . 
Table 44: MUAC versus height, Nawor, July 1998

\begin{tabular}{ccccccc|c}
\hline MUAC $($ in mm) & \multicolumn{2}{c|}{ MUAC $<\mathbf{1 1 0}$} & \multicolumn{1}{c|}{$\mathbf{1 1 0} \leq$ MUAC $<\mathbf{1 2 0}$} & \multicolumn{2}{c|}{$\mathbf{1 2 0} \leq$ MUAC } & TOTAL \\
HEIGHT (in cm) & Nbr & $\%$ & Nbr & $\%$ & Nbr & $\%$ & Nbr \\
\hline H $<75$ & 3 & $7.0 \%$ & 15 & $34.9 \%$ & 25 & $58.1 \%$ & $\mathbf{4 3}$ \\
$\mathbf{7 5} \leq \mathbf{H}<\mathbf{9 0}$ & 0 & $0.0 \%$ & 4 & $5.8 \%$ & 65 & $94.2 \%$ & $\mathbf{6 9}$ \\
$\mathbf{9 0} \leq$ H $\leq \mathbf{1 1 0}$ & 0 & $0.0 \%$ & 1 & $3.4 \%$ & 28 & $96.6 \%$ & $\mathbf{2 9}$ \\
\hline TOTAL & $\mathbf{3}$ & $\mathbf{2 . 1} \%$ & $\mathbf{2 0}$ & $\mathbf{1 4 . 2} \%$ & $\mathbf{1 1 8}$ & $\mathbf{8 3 . 7} \%$ & $\mathbf{1 4 1}$ \\
\hline
\end{tabular}

The average MUAC value of these 141 children is $133 \mathrm{~mm}$, with a standard deviation of 12.3 .

\section{WHZ versus MUAC}

Table 45: Distribution of WHZ versus $M U A C$ in children with a height of $\geq 75 \mathrm{~cm}$, the Hazarajat, June/July, 1998

\begin{tabular}{ccccc|c}
\hline MUAC (in mm) & \multicolumn{2}{c}{ MUAC $<\mathbf{1 2 0}$} & \multicolumn{2}{c|}{$\mathbf{1 2 0} \leq$ MUAC } & TOTAL \\
& Nbr & $\%$ & Nbr & $\%$ & Nbr \\
\hline WHZ $<-$ 2SD & 9 & $32.1 \%$ & 11 & $1.8 \%$ & $\mathbf{2 0}$ \\
WHZ $\geq$ - 2SD & 19 & $67.9 \%$ & 604 & $98.2 \%$ & $\mathbf{6 2 3}$ \\
\hline TOTAL & $\mathbf{2 8}$ & $\mathbf{4 . 4} \%$ & $\mathbf{6 1 5}$ & $\mathbf{9 5 . 6 \%}$ & $\mathbf{6 4 3}$ \\
\hline
\end{tabular}

Amongst the children $\geq 75 \mathrm{~cm}, 1$ case is suffering from severe acute malnutrition, combining a risk of mortality with wasting. None of the children who have a normal weight for their height in ZScore, have a high risk of mortality with a MUAC $<110 \mathrm{~mm} .1 .8 \%$ of the children with a low risk of mortality were found to be malnourished according to their weight-for-height index. This may mean that although these children have wasted somewhat, they have not reached the stage of catabolising muscle tissue to cover their basic metabolic needs.

\section{Vaccination status:}

A total of 816 children aged 9-59 months were included in this survey. Full vaccination status was assessed by considering the measles vaccination only. Since this is normally the last in the series of vaccinations to be administered, it can be assumed that the child has benefited from receiving a full course of vaccinations. It must be stressed that this is only an assumption.

Each child was recorded as either having the vaccine or not. Those considered as having had the vaccine, either had the date of vaccination recorded from the card, or were included according to the mother's word. A dose was only considered valid if it was administered at or above 9 months of age.

\footnotetext{
${ }^{60}$ For distribution per region, see Appendices for Part VI: Appendix VI.
} 


\begin{tabular}{|c|c|c|c|c|c|c|}
\hline \multirow{2}{*}{$\begin{array}{c}\text { REGION } \\
\text { (and number eligible) }\end{array}$} & \multicolumn{2}{|c|}{ CARD } & \multicolumn{2}{|c|}{ MOTHER'S WORD } & \multicolumn{2}{|c|}{ TOTAL } \\
\hline & $\mathrm{Nbr}$ & $\%$ & $\mathrm{Nbr}$ & $\%$ & $\mathrm{Nbr}$ & $\%$ \\
\hline $\begin{array}{c}\text { Ajarestan } \\
(86)\end{array}$ & 0 & $0.0 \%$ & 14 & $16.0 \%$ & 14 & $16.0 \%$ \\
\hline $\begin{array}{c}\text { Bamiyań } \\
(178)\end{array}$ & 43 & $24.0 \%$ & 30 & $17.0 \%$ & 73 & $41.0 \%$ \\
\hline $\begin{array}{l}\text { Jaghoori } \\
\text { (195) }\end{array}$ & 7 & $4.0 \%$ & 32 & $16.0 \%$ & 39 & $20.0 \%$ \\
\hline $\begin{array}{l}\text { Malestan } \\
\quad(240)\end{array}$ & 5 & $2.0 \%$ & 5 & $2.0 \%$ & 10 & $4.0 \%$ \\
\hline $\begin{array}{c}\text { Nawor } \\
(131) \\
\end{array}$ & 18 & $14.0 \%$ & 9 & $7.0 \%$ & 27 & $21.0 \%$ \\
\hline $\begin{array}{c}\text { TOTAL } \\
\text { the Hazarajat }(830)\end{array}$ & 73 & $9.0 \%$ & 90 & $11.0 \%$ & 163 & $20.0 \%$ \\
\hline
\end{tabular}

According to the vaccination cards, only $9 \%$ were vaccinated throughout the Hazarajat region. Bamiyan was the best covered with $24 \%$, followed by Nawor at $14 \%$. Both areas have an EPI implemented, though in Nawor this is somewhat limited. According to the mother's word, $11 \%$ of children have been vaccinated against measles, with Ajarestan, Bamiyan and Jaghoori claiming 16$17 \%$. Overall, $20 \%$ of children are covered against measles according to vaccination cards or their mother's word. Bamiyan is the best covered area combined, with $41 \%$ according to vaccination card and mother's word. These figures must be considered with some scepticism since vaccination knowledge is not of a very good standard in these areas. In addition, dates recorded on the actual card are not always reliable. One child was found to have been vaccinated before he was born!

\section{Source of immunisation}

In the areas where there was some sort of immunisation programme, mobile teams mostly carried out the vaccinations ${ }^{61}$. In Ajarestan, where there is absolutely no health facility available, immunisations have not taken place for at least 4 years. In Bamiyan, there is an EPI run by various organisations in conjunction with the Ministry of Public Health ${ }^{62}$. Jaghoori has at least one hospital and $8 \mathrm{MCHs}$, all of whom carry out vaccinations when they are available. Since the blockade, all health facilities have suffered, since a regular supply of vaccinations just is not possible. Although Malestan has around 3 health facilities, none are able to function properly as vaccination points. The Swedish Committee, at Miradina, has managed to secure a year's supply of drugs in to the area. Nawor now has a vaccination point in what was the clinic

\footnotetext{
${ }^{61}$ See Health section for more detail.

${ }^{62}$ For more detail, see Action Contre la Faim: Vaccination coverage survey, Bamiyan, Afghanistan, June 1998
} 


\section{Calculation of the mortality rate}

The Hazarajat, June/July 1998

Total number of reported deaths amongst $<5$ years: $n=2$

Total number $<5$ years alive at time of survey: $\quad \mathrm{N}=1039$

$\mathrm{CMR}$ of $<5$ years $=\quad 2 /[((2+1039)+1039) / 2)]=0.002$

Mortality Rate $=\quad(0.002 \times 10,000) / 30=\mathbf{0 . 6 4}$

From the total number of children $<5$ years old in the survey, the Mortality Rate was 0.64 over 10,000 children per day, which is considered to be acceptable.

\section{$\underline{\text { Jaghoori, July } 1998}$}

Total number of reported deaths amongst $<5$ years: $n=1$

Total number $<5$ years alive at time of survey: $\quad \mathrm{N}=244$

$\mathrm{CMR}$ of $<5$ years $=$

$$
1 /[((1+244)+244) / 2)]=0.004
$$

Mortality Rate $=$

$$
(0.004 \times 10,000) / 30=1.36
$$

From the total number of children $<5$ years old in the survey, the Mortality Rate was $\mathbf{1 . 3 6}$ over 10,000 children per day, which is considered to be just below alert level.

\section{Nawor, July 1998}

Total number of reported deaths amongst $<5$ years: $n=1$

Total number $<5$ years alive at time of survey: $\quad \mathrm{N}=170$
CMR of $<5$ years $=$$$
1 /[((1+170)+170) / 2)]=0.006
$$
Mortality Rate $=$
$(0.006 \times 10,000) / 30=1.96$

From the total number of children $<5$ years old in the survey, the Mortality Rate was $\mathbf{1 . 9 6}$ over 10,000 children per day, which is considered to be more than alert level and less than emergency level.

No deaths were found in Ajarestan, Bamiyan and Malestan, in the population surveyed during the preceding 30 days. 


\section{Cause of death}

One cause of death, in Jaghoori, was unknown, but the child died soon after birth. The other, in Nawor, was of a child, 9. months old, who died of pneumonia. For two months prior to death, the child suffered from vomiting and diarrhoea.

\section{HEALTH:}

The following are information derived from group discussions at each village. Any figures given are estimates without any statistical backing and should therefore be treated as so.

With a history of limited food resources, micro-nutrient deficiencies are likely. The accumulative effects this could have on women, consequently being passed on to their babies, may be one reason why there is so much maternal and infant mortality. An increased risk in matemal deaths for example, may be due to iron deficiency, leading to anaemia. An anaemic mother is more likely to bleed severely and die during delivery, than one who is not anaemic. Babies born to anaemic mothers are likely to be of low birth weight (found mostly in Ajarestan) and may become ill or even die during early childhood. The great amount of tea consumed in Afghanistan could effect the amount of iron being absorbed by the body. Anaemia was not identified in any of the areas bar Malestan, though the women in Ajarestan were not seen and therefore it cannot be said that anaemia is a problem in the area.

Goitre is a problem seen in most areas. The lack of iodine, causing goitre, could also be one reason why there are still births and low birth weight babies. No cretinism was seen in any of the villages. For goitre to be a severe problem in a community, more than $10 \%$ of people having visible goitre signs need to be seen. Although in none of the villages such a level was seen, the community claimed that high levels were apparent in certain areas (see below).

With the obligatory covering of women and their limited access to the outside world, particularly in Ajarestan, a lack of vitamin D is more than likely. Low birth babies are born with low levels of vitamin $\mathrm{D}$ and if their mother is also lacking in vitamin $\mathrm{D}$, they will get little through being breastfed. White skin is very important in Afghanistan and women wrap their children very well, in order to protect them from the sun. Skin diseases were common throughout the regions of the Hazarajat, particularly amongst children.

Rheumatism and arthritis were found in adults, particularly in the Malestan, Nawor and Bamiyan Upper Valley area. This could effect people's lives, as far as productivity is concerned. Indeed many complained of aches and pains and the restrictions caused by them, could in effect, damage the well being of the family as a whole.

Seasonal diseases, such as diarrhoea and ARIs contribute to high rates of morbidity and mortality.

\begin{tabular}{|c|c|c|c|c|c|c|c|c|c|c|c|c|}
\hline DISEASE & $\mathrm{J}$ & $F$ & $\mathrm{M}$ & $\mathrm{A}$ & $\mathrm{M}$ & $\mathrm{J}$ & $\mathrm{J}$ & $\mathrm{A}$ & $\mathrm{S}$ & $\mathrm{O}$ & $\mathrm{N}$ & $\mathrm{D}$ \\
\hline ARIs & 4 & 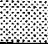 & 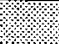 & 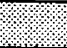 & & & & & & ? & & \\
\hline $\begin{array}{l}\text { Rheumatoid } \\
\text { Arthritis }\end{array}$ & & (s) & & & & & & & & & & \\
\hline Diarrhoea & & & & & & & ? & 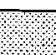 & 18 & 8 & & \\
\hline Cholera & & & & & & & & & & & & \\
\hline
\end{tabular}


Access to water, during the period of the survey, was no problem, with most people living close to a river, stream or spring. In winter time, it is a problem, when lots of sources are frozen.

Lathyrism is becoming a problem in Malestan and Nawor. It is a neurological disease often resulting in weakness and paralysis of the legs, caused by eating the pea-like seeds of the leguminous plant Lathyrus sativus. This plant, formerly animal feed, is increasingly becoming a common addition to the diet of the community.

\section{Ajarestan}

There are absolutely no health facilities available here, bar a chemist in the bazaar. Vaccinations do not exist here anymore. The last time there was any immunisation in the area was 4 years ago. Infections are a big problem, particularly in relation to dental problems. There is no dentist and people tend to treat each other, resulting in infections. 5 people died in a village of 180 people, last year.

Most common diseases include, in adults, ARIs, paralysis, cholera - 20 people died last year in one village, TB, malaria, hepatitis. In children, diseases include, dysentery, diarrhoea, vomiting, fever, ARIs, particularly pneumonia, meningitis, measles, malnutrition and skin diseases.

Goitre seemed to be a minimal problem. However, amongst the nomads, it was thought to be as much as $20 \%$. Night blindness was a problem for about $10 \%$ of the villagers, particularly men, whilst nomads found it a problem for up to $30 \%$ of the population.

Traditional medicine seemed to be relied upon heavily here, though mainly for minor complaints. The use of seeds, herbs and plants was common amongst both villagers and nomads alike. The most common illnesses treated were coughs, diarrhoea and fevers.

Babies are born straight on to some dust put onto the ground especially. Not surprisingly, there are many deaths due to tetanus, particularly in babies. $10-20 \%$ of mothers die in child birth, due to haemorrhaging. There seems to be a phenomenal number of low birth weight (LBW) babies here. Around $50 \%$ of babies are said to die at or soon after birth, the main causes being tetanus, 'floppiness' and LBW. Women are renowned for having LBW/premature babies in this area.

Although anaemia was not mentioned as a problem, it could be a reason for so much haemorrhaging in women during childbirth. No women attended the screenings and therefore were not examined for anaemia.

About half of the houses have access to latrines, which have to be shared with many others. Water is collected by the men from springs and rivers up to 3 times daily. An average of 6 buckets are used per family, which is around 17 litres per person, per day.

\section{Bamiyan}

Vaccinations are widely covered in this area ${ }^{63}$, where health structures and mobile teams carry out an Extended Programme on Immunisation (EPI).

\footnotetext{
${ }^{63}$ For more detail, see Action Contre la Faim: Vaccination coverage survey, Bamiyan, Afghanistan, June 1998.
} 
Diseases amongst adults include diarrhoea, blindness, arthritis, ARIs and cholera. In children, they include, diarrhoea, vomiting, ARIs and measles - though measles have reduced dramatically since vaccinations started. There is a little goitre and some night blindness evident in the population.

Babies are born onto cloths placed on to the ground. Not much tetanus is seen amongst the surveyed population in this area, but a good immunisation programme is in operation here.

All the villagers have access to a latrine, where they could be sharing with up to 15 other people, which often means 2 families sharing.

Water is collected from streams which run through the villages, as needed, with an average of 20 litres being used per person per day.

\section{Jaghoori}

Vaccinations were carried out in about half of the villages visited, the hospital, clinics and mobile teams being the facilitators.

The most common diseases amongst adults were typhoid, arthritis, diarrhoea, ARIs, rheumatism, dysentery. Amongst children they included, ARIs, particularly pneumonia, fever, diarrhoea, dysentery, malnutrition, TB, typhoid, impetigo, measles and coughs.

Goitre was thought to affect up to $10 \%$ of people, whilst night blindness, up to $5 \%$.

Traditional birth attendants, as a general rule are not used, though those who can afford to, use the trained midwife at Sang-e-Masha. Birthing takes place equally, on the ground or on to a cloth on the ground. About $10 \%$ of children are thought to die in child birth.

Traditional medicine is not generally practised here, though for diarrhoea, a grass-like plant is boiled with some water and the juice consumed, whilst the pulp is put on the head of the patient.

There were latrines available for over half of the population. Water was collected from rivers and wells as needed, with an average of 25 litres per person per day, being used.

\section{Malestan}

Only 2 out of the 9 villages visited were vaccinated, but only with polio.

Traditional medicine is not practised in this area, with the exception of Qoshnak, which borders and has good relations with Ajarestan, where the practice is very much in use. Pharmacies are heavily relied upon for cures. Prescriptions are obtained from one of the clinics and when affordable, drugs are bought. Some drugs are administered without a prescription.

Main diseases include, for adults, typhoid, malaria, ARIs - particularly pneumonia, urinary tract infections (UTI), liver diseases, sciatica, rheumatism, cholera, paralysis and TB. In children, diseases include, ARIs - particularly pneumonia, diarrhoea, whooping cough, worm infestation, fungal skin diseases, vomiting, cholera and paralysis. The paralysis is thought to be caused by eating Kalool, which people are now forced to eat.

Although not many cases were observed, goitre is said to be a big problem here. Night blindness seems to affect between $5-50 \%$ of the population. Three children were seen in the area with enlarged 
heads, perhaps showing signs of rickets, though of course other reasons are possible. No other signs of rickets were observed.

There is one TBA in the area who charges. Babies are born straight on to the ground or onto a sheet on the ground. Around $15-25 \%$ of babies are thought to die of tetanus, out of around $30 \%$ of children who die in or soon after child birth. Up to $30 \%$ of women die of haemorrhaging, after giving birth. Some anaemia, particularly in young women, was seen here.

There is a need for latrines, as not many villages had any. Water is collected from rivers that run through the villages, with an average of 15 litres of water being used per person per day.

\section{Nawor}

Vaccinations seem to cover most areas visited, however, they are only in the form of polio and vitamin A drops.

There is not much traditional medicine practised here, though a cure for diarrhoea, a re-hydrating solution made of a grass-like plant, is quite popular.

Diseases most common in adults include, paralysis, cholera, ARIs, rheumatoid arthritis, diarrhoea and UTIs. In children, ARIs, diarrhoea, measles, pneumonia, malnutrition, vomiting, whooping cough (there were 10 cases reported in Qarge Bayee, a village with a population of around 100 people) are common.

Goitre was said not to exist in any of the villages, bar Khawat, where up to $30 \%$ were estimated as having a problem. Night blindness affected up to $30 \%$ of the population.

Deaths were estimated at between $15-35 \%$ for women during childbirth, with $40-75 \%$ being due to haemorrhaging, up to $20 \%$ from tetanus and the remainder being due to a loss of consciousness, having a green tongue with convulsions and not being able to pass the placenta. Deaths were likely for about $30-50 \%$ of babies born, due to LBW/premature birth $(25 \%)$, up to $50 \%$ due to tetanus and $25 \%$ due to septicaemia, blue lips and foaming at the mouth.

About half of the villages visited had latrines for about half of the households, but there certainly was a need for more latrines, as there was much defecation around. Water was collected daily, by the women, from streams and springs, though some did have access to wells, with an average of 23 litres of water being used per person per day.

\section{Health FaCilities AVAIlable:}

A second visit was planned to Malestan and Nawor, in order to get more information on diseases. It was planned to study record books, if any, in the health structures, so that estimates could be made of the extent of prevalence of various diseases and conditions.

\section{Ajarestan}

There were no health facilities available in this region. 


\section{Bamiyan}

The Ministry of Public Health (MoPH) facilitates a number of health facilities in Bamiyan, some of which are supported by various aid agencies. The central hospital, situated in Bamiyan city, is supported by the Iranian government. There is a vaccination point recently opened. Malnutrition is treated with the distribution of BP5, based on a diagnosis of appearance.

Five other health centres exist within the area. Ibn Sena clinic offers MCH, OPD, EPI and health education. Malnutrition is diagnosed by MUAC measurements, but no records are kept. Fulladi clinic is supported by ICRC. OPD and EPI activities operate here. Area, a clinic run by the MoPH, also operates OPD and EPI. Another MoPH run clinic, Shaydan, has an OPD which charges of 10,000 Dostumis. EPI was planned and was due to start within weeks. Sar-e Asyab clinic, a recently opened clinic supported by HABITAT, runs an OPD and provides health education. A fee of 10,000 Dostumis is charged for consultation.

\section{Jaghoori}

\section{Shuhada Hospital}

This is a central hospital situated in the centre of Jaghoori. In addition to the hospital, Shuhada also runs $8 \mathrm{MCHs}$ in the Jaghoori area. Before Shuhada took over the hospital, there were no charges. The hospital was run by Mercy Corps International and FAO. It was found that this encouraged much abuse and so a charge was introduced. At present, a subsidised charge of 5,000 Afghanis is in force. Drugs have to be bought from the hospital or a prescription has to be taken to the bazaar. The latter is now certainly the case, as the hospital has not had drugs delivered in a long time due to the blockade enforced by the Talêban and is now out of stock. The MCHs charge a consultation fee, but do not dispense drugs.

At the MCHs, midwives are trained. The course lasts 3 months and equipment is given to the midwife who practices in a designated area. 4 courses are run simultaneously and each class trains 10 people. Since most of the people trained are illiterate, basic primary school education is taught for 3 months prior to joining the midwifery course.

The hospital is a 70 bed structure, though only 45 are functional at present. Since the blockade, there have not been available, the resources required for the hospital to run to its full capacity. As a result, staff have also had to be cut down. In and out patient departments (I/OPD) are functioning here. The OPD operates vaccinations, a laboratory, radiology and an emergency unit. It is open from 8.00 a.m. to 2.00 p.m. and at present around 35 people are treated daily. The IPD runs a general operating theatre and gynaecology and obstetrics. Conditions treated in the operating theatre include appendicitis, Caesarean sections, hysterectomy and peritonitis, though usually any condition that can be dealt with is treated.

This is a very nicely structured hospital with great potential - all it needs are resources. It seems that prior to the blockade, the hospital was functioning to its full capacity. At present, although many different departments operate, they are working with the bare minimum. The operating theatres, for instance, are very short of anaesthesia, so that any operations that can, are done under spinal anaesthesia. 
Malnutrition is treated here, detected by clinical signs such as anaemia, emaciation and loss of hair colour: It is mostly seen in children, the aged and women. Most cases are disease related, particularly TB and diarrhoea induced. Patients are treated for the cause, therefore a child malnourished by a bout of diarrhoea, is treated for the diarrhoea. A health education programme is in force to help the mother understand the causes of malnutrition and how to avoid it.

Vaccinations are pretty much at a stand still as a result of a shortage since the blockade. Some vaccines do get smuggled over the Front Line, but they are mainly polio and vitamin A drops. Prior to the blockade all vaccines were available apart from BCG. A cold chain is available on site.

TB is a big problem in the area. A TB treatment centre was set up last year at the LEPCO (leprosy) Shefah clinic in Chew Bibi. Types of TB found are lymph adonatitis, bone and spinal. Most are pulmonary, with very few extra pulmonary cases. Diagnosis is made by a sputum test. Negative results are kept under observation for 21 days and given cortrimoxazole. Up to 3 more sputum tests are then carried out again and if the symptoms persist, standard treatment is given. Many cases of resistance to drugs are found. Positive tests, around $90 \%$, get a complete course of treatment. Cases are most common in women. One theory is that women spend so much time together in close proximity.

\section{LEPCO (Anghoori)}

This is a leprosy clinic which now deals with as many other medical problems as it can. There no longer is much of a leprosy problem, so the clinic has taken on other health problems, including TB. There are medical personnel here and drugs are available, though limited since the blockade.

\section{Ali Abad Hospital (Anghoori)}

This was formerly an MSF hospital which closed in 1991. It stands as it was left - a structure with medical equipment The personnel are all still within the community but now have jobs elsewhere, since there is no-one to pay them a salary.

Anghoori is a Talêban controlled area close to Jaghoori. There does seem to be reasonably good access to the area. From the centre of Jaghoori, an estimated journey of around $21 / 2$ hours by car, via mountainous roads is necessary. The team travelled for 2 hours on this road to carry out surveys, but unfortunately did not reach the hospital. Although the structure itself was not visited, an interview took place with a doctor who formerly worked at the hospital.

In effect, this is a structure ready for operation, with its trained staff still living in the town, but not in use. 


\section{Malestan}

\section{Swedish Committee - Meradina Clinic}

This is an impressive clinic, graded C1/1st. Degree (has a doctor). The Austrian Committee was in charge of this clinic as part of their Rural Development Programme and Technical Training Centre. Primary health care was then founded 6 years ago and the Swedish Committee took over 4 years ago. The clinic was free of charge up until a month ago when a consultation fee of 500 Afghanis was enforced. $40 \%$ of the cost of drugs is covered by the patient. There were no drugs at the clinic for a year, because of the blockade, but a supply, which should last a year, was delivered recently, having being granted permission for passage.

In addition to a doctor, there is a fully trained midwife (as well as a private midwife in the town). Services include a laboratory (carrying out routine checks such as stool, urine and blood), a dental section, $\mathrm{MCH}$, OPD, dressings and Health Education. The clinic works at full capacity and is unable to cope with the demand. Those who are able, physically and financially, are referred to clinics in Ghazni and Jaghoori.

The MCH department is operated by the midwife and deals with children aged 0-5 years and their mothers. She detects and records malnutrition using weight for height cards which indicate the level of malnutrition on the card using colour coded 'danger zones' and show the child's progress. MUAC, head circumference, height and weight are measured and used with the Welcome chart, indicating the level of malnutrition. Originally, this programme was complimented by supplementary feeding, but now the resources are not available for this. The midwife claimed that $50 \%+$ of the children seen were malnourished. $60-70 \%$ of these are said to have oedema and therefore Kwashiorkor. For Marasmus cases, children $<60 \%$ are treated as severely malnourished. Advice on feeding, along with porridge demonstrations is given, including the use of plant proteins. Mothers are also said to look malnourished. Malnutrition has become a greater problem since the blockade and the clinic claims to see a lot more cases now than before.

Health Education is given at the clinic, by the midwife, every morning between 8.00-9.00 AM, when much of the patients have arrived and are waiting for treatment. Subjects covered include dehydration (including the preparation of home made ORS), hygiene (personal and environmental), nutrition (including weaning foods), vaccinations (the benefits and importance), TB (signs, symptoms, protection against).

Problems dealt with at the clinic include pregnancies, abortions, hypertension in women, UTIs, heart and respiratory problems, anaemia, goitre and seasonal problems such as ARIs in the winter and diarrhoea, typhoid, dysentery, along with sporadic cases of malaria in the summer. TB is one of the biggest problems here and patients are referred to the LEPCO/Bughra clinic, $20 \mathrm{~km}$ away, for treatment.

There is a cold chain here and vaccinations are carried out when there is a supply of vaccines. These are limited at present, due to the blockade enforced by the Taleban. Two supplies have arrived since the blockade, though both have been in drop form - polio. Previously mobile teams operated the area, but now sentinel sites are set up for 2 days. Vaccinations are free of charge. 


\section{$\underline{\text { Du Abi Clinic }}$}

This was formerly an $\mathrm{MCH}$, but now operates as a vaccination point only. Ibn Sena supplied this clinic under a 5 year contract, but has been unable to supply drugs, ending the contract after 3 years in Spring 1998. The Talêban blockade was the reason for the cessation in the supply. lbn Sena does still support the vaccination programme, however. Vaccines are supplied quarterly, normally, but now it is a case of when they can. Standard EPI coverage is in operation. There is a cold chain on site, consisting of cool boxes, carrying boxes and refrigerators.

Regions within close proximity of the clinic come to the clinic on a 3 month rotational system. A mobile team visits out of reach areas, again on a rotational systems. Campaigns, under WHO are carried out as well as routine vaccinations.

Prior to the blockade, the clinic operated an OPD and $\mathrm{MCH}$. There are 2 vaccinators at the centre and each one vaccinates 200 people per month. Children $<2$ years and mothers aged 15-45 are the target group, though children up to the age of 5 years are vaccinated during campaigns.

\section{E. EDUCATION:}

Most villages had Qu'ranic schools ${ }^{64}$ run by the community in the mombar. These were for boys and girls, and depending on the region, were in operation throughout the least productive times, such as winter, though in larger villages in Bamiyan Upper Valley, Nawor and Jaghoori, they were in operation for most of the year. Teachers were generally supported by the community, regardless of whether a family's own child was attending or not. This did depend on the capacity of the family, being able to make a donation.

Schools other than Qu'ranic, operated in major bazaar towns within each area. Those in more isolated regions had schools in the past, which over the years, due to war and the lack of resources, have closed down. Those who can afford to, send children to boarding type schools. Though most schools are 'free', a contribution normally has to be made towards the teacher's salary, though, according to the region, this depends on the family and those who could not afford to contribute, where not obliged to. Schools were generally shared amongst villages and were available for boys and girls.

There were no schools in Ajarestan, though private 'tuition' could be found in the bazaar. Villages had Qu'ranic schools operating. The nomads had no access to schools.

Bamian had schools for boys and girls. There was a girls school in Kamati and a boys in Syalayac. Nawal also had schools for boys and girls.

Jaghoori had a large central school for boys and girls at Sang-e-Masha. The same was available at Hediat.

Malestan had a school in Miradina, Shineday and Abo Ali Sina.

\footnotetext{
${ }^{64}$ See Appendices for Part III: Appendix V for individual details.
} 
In Nawor, the shopping centre of Du Abi, has a 'scientific' school, providing basic education for boys and girls, though at different schools. Schooling is 'free', though a contribution has to be made towards the teacher's salary. A boarding school is also available, about 7 hours walk from the centre, at Ab Dini. There was an additional school in. Nawor, supported by the Pakistani Mujaheedin, but it closed down five years ago, when support was withdrawn. 


\section{A. INTRODUCTION:}

The following section attempts to look at systems of agriculture and animal husbandry, by assessing the different constraints and possibilities to which both are subject, short- and long-tern. In as far as possible, these are looked at with a view to understanding divergence across zones as well as across household types, together with any external interventions in that domain - both actual and potential. Conclusions and recommendations are, however, principally drawn up in the final chapter of the report.

\section{B. AGRICULTURAL SYSTEMS:}

\section{Ecological and Demographic Constraints:}

Across the Hazarajat, land cultivation takes place right into the foot of the mountains due to demographic pressures. In 1990, these were most heavy in Jaghoori and Bamiyan Lower Valley, and least in Ajarestan (possibly due in part to the Hazara exodus when the Talêban arrived), and Nawor. Most of the land is irrigated with the notable exception of Nawor and to a lesser extent, Malestan and Bamiyan Upper Valley (Fooladi and Dokani in particular), where rainfed land has also been brought into cultivation. ${ }^{65}$ The land also varies widely from flat to sloped (with concomitant problems of leaching), particularly in Bamiyan Upper Valley, Malestan and Jaghoori (where terracing is widespread). Bamiyan Upper Valley in particular suffers from the more extreme consequences of the north/south-facing factor, where the narrowness of the valleys and the height of the mountains combine to reduce the yields to be had from such crop production. In general, the soil is of the sandy loam type and relatively less amenable to water retention, although alluvial soil can also be found, as in Malestan.

Malestan in particular, Bamiyan Lower and Upper Valleys and Ajarestan, all suffer from problems of flooding triggering regular crop destruction and rendering fairly large tracts of land uncultivable through the deposit of mud and stones - something which those families lacking manpower and/or financial resources, have been unable to overcome.

The climate is such that the growing period is relatively short, generally starting around the end of March and coming to an end at the beginning to mid October - although zones at lower altitudes with higher temperatures, like Jaghoori and Ajarestan may experience a growing period that begins slightly earlier (1-2 weeks perhaps). For this reason, the type of crops grown are considerably less diverse than in Ajarestan, Bamiyan Lower Valley, Jaghoori and Malestan.

\footnotetext{
${ }^{65}$ Ajarestan is estimated to have around 25,000 jeribs (or 5, 000 hectares) of land under cultivation.
} 


\begin{tabular}{|c|c|c|}
\hline Zone & Main Crops Cultivated & Cash Crops \\
\hline Ajarestan & $\begin{array}{l}\text { wheat, barley, maize, rice (east of Sanga), } \\
\text { potato, lentil, chick pea, kidney bean, broad } \\
\text { bean, clover, lathyrus, vetch, alfalfa, onion, } \\
\text { leak, garlic, cucumber, aubergine, okra, } \\
\text { tomato, turnip, carrot, almond, plum, apricot } \\
\text { and mulberry (east of Sanga inainly), apple, } \\
\text { watermelon, tobacco }\end{array}$ & $\begin{array}{l}\text { potato, maize, lentil, } \\
\text { clover, laterus, tobacco }\end{array}$ \\
\hline $\begin{array}{l}\text { Bamiyan Lower } \\
\text { Valley }\end{array}$ & $\begin{array}{l}\text { wheat, barley, potato, turnip, carrot, alfalfa, } \\
\text { broad bean, onion, spinach, tomato, marrow, } \\
\text { cucumber, cabbage, broccoli, leak, radish, } \\
\text { cauliflower, turnip, apricot, apple, sour cherry, } \\
\text { almond, walnut }\end{array}$ & $\begin{array}{l}\text { potato, apricot, apple, } \\
\text { sour cherry, almond, } \\
\text { walnut }\end{array}$ \\
\hline $\begin{array}{l}\text { Bamiyan Upper } \\
\text { Valley }\end{array}$ & $\begin{array}{l}\text { wheat, barley, potato, turnip, carrot, lentil, } \\
\text { alfalfa, pea, broad bean, vetch, lathyrus }\end{array}$ & $\begin{array}{l}\text { potato, vetch, pea, } \\
\text { tobacco }\end{array}$ \\
\hline Jaghoori & $\begin{array}{l}\text { wheat, barley, maize, onion, vetch, pea, } \\
\text { lathyrus, broad bean, alfalfa, radish, turnip, } \\
\text { carrot, chick pea, aubergine, marrow, } \\
\text { cucumber, leak, spinach, cabbage, cauliflower, } \\
\text { okra, apple, apricot, mulberry, plum, sour } \\
\text { clerry, almond, tobacco }\end{array}$ & $\begin{array}{l}\text { apricot, mulberry, sour } \\
\text { cherry, almond }\end{array}$ \\
\hline Malestan & $\begin{array}{l}\text { wheat, barley, turnip, carrot, vetch, lathyrus, } \\
\text { clover, tomato, onion, apple, apricot }\end{array}$ & vetch, clover \\
\hline Nawor & $\begin{array}{l}\text { wheat, barley, potato, lentil, pea, vetch, } \\
\text { lathyrus, alfalfa, turnip, carrot }\end{array}$ & vetch, pea \\
\hline
\end{tabular}

Land Ownership Constraints:

In Ajarestan, Malestan and Nawor High Plateau, the tendency seems to be for a small number of large landholders in each village, with anything from 10-50 jeribs (2-10 hectares), as well as a number of small landholders (although these may not always exist), and landless labourers - some working and living on the land of the landholder, others simply providing daily labour (often IDPs). The distribution of land ownership in these zones is relatively quite inegalitarian - with no land reform being foreseeable in the immediate future.

In Bamiyan Upper and Lower Valleys, as well as in Jaghoori, on the other hand, small landholders appear to be the norm having anything between $0.5-2$ jeribs (0.1-0.4 hectares) of cultivable land, together with a number of landless labourers - often IDPs.

All zones suffer from the continual division of the land according to which all males receive equal shares from their father and females one half of this (but tending to go to the husband). This has led to increasing fragmentation and smaller plots of land across the generations - something already quite precarious in Upper and Lower Bamiyan and, although less so, in Jaghoori. It also represents a source of vulnerability to food insecurity across all zones, for household type $C$ and then $B$, both of which already hold below the requisite 6 or so jeribs for self-sufficiency. 
Small amounts of government land also exist in Bamiyan Upper and Lower Valleys as well as in Ajarestan (about 3, 000 jeribs or 600 hectares of dryland and 650 jeribs or 130 hectares, of irrigated). These tend to be rented for a relatively small sum of wheat or money $(0.5$ sers of wheat in Ajarestan per jerib - $3.25 \mathrm{~kg}$ per 0.2 hectare), although they are reputed to lack fertility in comparison to other land areas.

\section{Coping Mechanisms:}

Common throughout the Hazarajat, has been the mortgaging of land for a determined period by landholders in order to provide for immediate consumption needs. In some instances, the mortgagee cultivates the land for the mortgage holder and receives one-fifth of the yield, in other instances, usually prior to expropriation, the land lies fallow with the mortgagee lacking the means to cultivate the land and the mortgage-holder having no need due to other income sources. This has been particularly the case of household type $\mathrm{C}$, although $\mathrm{B}$ has been afflicted to some extent as well. The importance of this cannot be overstated, given the effects of the blockade on cereal, fertiliser and other prices, as well as the continuing need to meet other obligations - whether medical, marriage or religious (although in the latter instance, the household may well find themselves recipient rather than donor).With an increasing number of households set to default on mortgage repayment, it is likely that increasing numbers of destitute families will be witnessed, some resorting to work as landless labourers, others leaving their home areas. However, under current conditions, too much competition in the labour market might force down wages, with an inability to migrate aggravating this. Problems of hunger and malnutrition may then result to a greater extent.

\section{Agricultural Patterns:}

\section{Priorities:}

Across all 6 zones, wheat and barley are the main staple crops cultivated for human consumption, together with alfalfa and vetch, both of which straddle the border between providing animal fodder and human food - particularly in Bamiyan Upper Valley, Malestan and Nawor High Plateau (although perhaps to a lesser extent elsewhere).

Household type A often tends to sell any surplus wheat in exchange for other goods - whilst also using the crop to meet various expenditures - including the miller, the mullah, the blacksmith and the carpenter. In certain instances, household type D may also do this - usually when its livestock numbers are relatively large and family size relatively small. Household types B and C, meanwhile, as with types $E$ and $F$, are more prone to consume all the wheat possible (above and beyond any necessary expenditures), whilst also having to purchase additional amounts on the market. Similarly for barley. While potatoes are prominent especially around Bamiyan, they tend, even if only on a small scale, to be more important as a further source of cash income.

In general, wheat is the most important crop and will, where a choice exists, be planted in the most fertile area of land. Moreover, where access to manure and/or chemical fertiliser is limited, any amounts obtained will be used first and foremost for the field(s) of wheat, even if just a corner of this. Wheat is also the principal medium of in-kind exchange: for the blacksmith, shepherd, mullah and so on. However, at higher altitudes (Upper Bamiyan and Nawor High Plateau, for instance), the emphasis on barley is usually greater than that on wheat due to its greater adaptability to cold weather conditions. 
In Ajarestan, Jaghoori and Malestan, winter wheat (garma in particular) seems to be preferred to spring wheat, which is dominant elsewhere (usually the wex variety) ${ }^{66}$. Throughout the Hazarajat, wheat in irrigated land tends to be rotated with a legume due to the latter's nitrogen-fixing properties and ability to enhance soil fertility. In most instances, this is done on a 2-3 years basis, either with another cereal intervening, or with another legume depending on soil quality. In Nawor, however, the tendency appears to be more towards a 2 years rotation - perhaps due to the higher amounts of organic manure used.

In Nawor High Plateau the cultivation of rainfed land has gained significant importance over time due to demographic pressures - something also evident in Bamiyan Upper Valley and parts of Malestan, but to a considerably lesser extent. In all cases, wheat is the primary crop grown on rainfed land (although some alfalfa and clover may be found in Bamiyan Upper Valley). However, due to the risks associated neither organic manure nor chemical fertiliser are used should these be wasted due to adverse weather conditions.

\section{Crop Production (see Appendix I for Technical Calendars):}

Field sizes tend to be measured in seed rate - often to the common denominator of wheat, which has an average seed rate of 5 sers per jerib, or $35 \mathrm{~kg}$ per 0.2 hectares, in irrigated land (in rainfed land, the seed rate diminishes to around 2-3 sers, or 14-21 kg, maximum, given the risks associated with such dryland cultivation).

Only the more wealthy (particularly household type A and to a lesser extent, B) appear able to afford leaving land fallow during the growing season. Others may leave the land fallow due to a lack of money to cultivate it - particularly household type C.

Preparation of the land usually begins witl the sprinkling of soil and/or ashes to encourage snowmelt - something which may take a considerably long time at high altitudes, particularly in Nawor where in addition, the land surface to be cultivated generally appears to be greater.

Seeds for the next planting season are usually saved for the following year, although among the more wealthy (household types A, B and often D), they may be obtained through purchase so as to renew and change the quality after a few years. Among other families (especially $C$ then), seeds are bought due to consumption needs. Often money will be borrowed for this. In Jaghoori, Bamiyan Lower Valley and to a lesser extent, Malestan, there was evidence of improved variety seeds being supplied by GRSP and Solidarités.

Seeds are broadcast by hand, although subsequent ploughing may be done either using a pair of oxen and plough or by hand, depending on the financial situation of the farmer, his place in any queue to borrow any available oxen and climatic conditions. Ploughing by hand using a rake or ploughing by donkey seems quite common in Jaghoori due to a lack of traction power (combined with relatively limited pastures and meadows for livestock). Where manure is used (mainly for cereals since legumes tend to have nitrogen-fixing properties favourable to fertility rates), it tends to be in a ratio of 1:4 with soil and will only be the manure of cows, sheep and goats. ${ }^{67}$ Jaghoori and Returnee Tajiks in Lower Bamiyan, however, have significant problems in obtaining this, however again due to limited livestock numbers.

In terms of chemical fertiliser, only white fertiliser, urea, was found to be available in the north (to those having the means to purchase it), being supplied by something of an oligipolistic, if not a

\footnotetext{
${ }^{66}$ Varieties, however, proliferate in Bamiyan Lower Valley, probably due to the work of Solidarités

${ }^{67}$ Donkey manure tends to be used uniquely to meet fuel needs.
} 
monopolistic factory in Mazar-i Sharif - run at least prior to Talêban control, by local commanders. The factory has a rated annual capacity of 105,000 tons. This in part, might explain the difference in white fertiliser price compared to elsewhere (approximately $\$ 26.80$ for a sack of $50 \mathrm{~kg}$ in July 1998 , compared to $\$ 24.00$ ). In the southern Hazarajat, both white and grey (DAP) fertiliser are available imported from Pakistan, with the latter costing around $\$ 17.80$ for a sack of $50 \mathrm{~kg}^{68}$.

Most crops are flood irrigated to a depth of about $4 \mathrm{~cm}$, although crops such as potato and tomato are furrow irrigated. Some are subject to water constraints (see relevant section).

Harvesting tends to take place anything from 1 week to 1 month earlier in lower elevation areas such as Lower Bamiyan Valley, Jaghoori and Ajarestan, compared to Bamiyan Upper Valley and Nawor. Approximately 20 days in the colder areas or 2-3 days in the warmer areas after harvesting, family members may go and camp on their fields to begin the threshing process and to separate the seeds from the strawer. For those families with a sufficient amount, next year's seed rate will be kept aside, while the remainder will be mixed with any other relevant legume or taken separately to the mill for grinding. For the various technical calendars, see annex.

In Upper Bamiyan the land may not be ploughed before winter due to lack of time - although it is acknowledged that this would be better for the land.

Crop Pathologies:

Throughout the Hazarajat problems of rust and smut are rife. In areas of Malestan in particular including along the road from Miridineh to Shinideh - around 20-35\% of wheat fields appeared to have been seriously attacked by rust which, being windborne, is easily spread. Reports abound of yields being reduced by more than $60 \%$ as a result of either one or both these problems. While the herbicide Carboxin (available in Pakistan), could apparently be used to treat both, improved, better adapted seed varieties would probably be a more viable option - something Solidarités is already working on in Bamiyan.

A further and separate problem is that of lodging, again most evident in Malestan with up to 15$25 \%$ of wheat fields affected. Some lodging was also visible in Ajarestan and Lower Bamiyan - this being mainly a problem of too much nitrogen in the soil - something that could perhaps be remedied by training on effective fertiliser use for instance.

Grass weeds and wild oats tend to be a general problem, while in the warmer climates of Ajarestan and Jaghoori, for instance, tendril weeds can be a problem. Other cited problems included cutworm which affects virtually all crops (boring holes in potato tubers and in the cluster of wheat and barley), together with aphids, particularly virulent among broad bean and pea. Metacystox is one treatment that can be given to prevent cutworm and aphids, being available in small amounts in July 1998 at a recently opened shop in Bamiyan town (US $\$ 0.03$ for $1 \mathrm{cc}$.). Locusts were sometimes cited as well.

\footnotetext{
${ }^{68}$ According to a 1989 SCA survey in Bamiyan Province (thus encompassing more than Bamiyan Lower and Upper Valleys), $15 \%$ of farmers did not use any fertiliser for irrigated wheat, $63 \%$ used both Urea and DAP, $20 \%$ used only urea and $2 \%$ used only DAP. The farmers using both urea and DAP applied on average one sack of urea and 0.7 sack of DAP per jerib (each sack containing $50 \mathrm{~kg}$ ). The application rate for urea only, was 0.4 sacks per jerib and for DAP only, 0.3 sacks per jerib.
} 
In terms of wheat yields, Malestan, Nawor and Bamiyan lower Valley tend to have the most productive returns, followed by Ajarestan, Jaghoori and lagging somewhat behind, Bamiyan Upper Valley. The variation is probably due to the difference in soil quality in Malestan, the higher use of organic manure in Nawor - and thus, the greater soil fertility - and relatively more favourable climatic and financial conditions in Bamiyan Lower Valley. The latter also seems to gain most from barley and potato cultivation as well. The use of organic manure appears to double crop yields, with the use of chemical fertiliser (no longer feasible for household type $\mathrm{C}$ ), potentially causing a further increase of $30-50 \%$. Improved seed varieties would also act favourably on this.

HABITAT in Bamiyan Lower Valley in particular, was active in the distribution of chemical fertiliser over the last growing season - in conjunction with Solidarités. Solidarités, under contract from $\mathrm{FAO}$, is currently experimenting with improved seed varieties, and prior to evacuation, had hopes of expanding and sharing its work elsewhere in the region (see annex for details). It already works in partnership with Madéra in Behsud. The Swedish Committee for Afghanistan had a long history of intervention in the country as a whole, but since the outbreak of interfactional fighting, its presence has been significantly scaled down - although it, too, had undertaken some important work on seed multiplication and a number of surveys on the agricultural situation.

\section{Crop Storage:}

Wheat and barley tend to be stored in wicker-baskets made from willow and then packed with mud around the outside and set above ground level on stones. The resulting structure tends to be kept in the darkest room at the interior of the house, although in Bamiyan Upper Valley and Malestan, they were visible outside on the roofs - due to lack of space in the first instance, and due to problems of damp in the second. Those who are rich, however, may use metal drums.

Potatoes, meanwhile, are stored underground in special potato storehouses (due to the importance of the crop in cultivation) in Bamiyan Lower and Upper Valleys (with no covering), or in holes in the ground as in Jaghoori (with soil placed on top). In the first instance, the storehouse may reach 4$5 \mathrm{~m}$ below ground level; in the second, only $1.5 \mathrm{~m}$.

\section{Horticulture:}

Fruit and vegetables grown in kitchen gardens and/or orchards, meanwhile, were most visible within household compounds in Bamiyan Lower Valley and Jaghoori - although not entirely invisible in Ajarestan, Malestan and to a much lesser extent, Bamiyan Upper Valley (south-facing only), where they tended to be out in the open as opposed to enclosed. Kitchen garden size appeared to vary immensely, being largest in Jaghoori and Bamiyan Lower Valley - perhaps to the tune of $90 \mathrm{sq}$. $\mathrm{m}$ or more - and significantly smaller in Malestan due to lack of space - from $5 \mathrm{sq} . \mathrm{m}$ to $25 \mathrm{sq} . \mathrm{m}$, perhaps. In many places, however, vegetables such as carrot and turnip would often be planted on a small area of land reserved to wheat or barley cultivation, for example. However, the general lack of kitchen gardens is indicative of the lack of diet diversification ${ }^{70}$.

The trend is to buy the vegetable seeds from the principal market: carrot and turnip being the most popular. Thus, $5 \mathrm{~g}$ of leak costs around US $\$ 0.20,5 \mathrm{~g}$ of cucumber around US $\$ 0.34$, and $5 \mathrm{~g}$ of both turnip and carrot seed, for instance, approximately US $\$ 0.01$. Compared to carrot and turnip seed and given general standards of income, seeds for leak and cucumber are really quite expensive.

\footnotetext{
${ }^{69}$ See Appendix II for more detail

${ }^{70}$ A distinction by household type was to be done in the second phase of surveys, but unfortunately was not possible.
} 
In Bamiyan Lower Valley, Jaghoori and Malestan work is being undertaken to promote fruit and vegetable-growing - by Solidarites in the first instance and by GRSP (Ghazni Rural Support Programme), ${ }^{71}$ elsewhere: both with FAO financing. Solidarités in particular, has a kitchen garden programme whereby demonstration plots have been established and seeds and tools are given to willing farmers who also gain a training in vegetable growing. Support has also been given to farmers who eventually would be able to sell the vegetable seeds on the open market in Bamiyan (see Appendix III for details).

\section{Agricultural Tools ${ }^{72}$ :}

In general, agricultural tools are locally made, often within the village in a joint effort between carpenter and blacksmith, or - one or other of these being absent - in the nearest large market (although most villages tend to have someone). During the growing season, a blacksmith will regularly sharpen any tools for a flat rate depending upon the number of tools owned (in turn depending on the size of the land and the financial status of the family). This, as a rule, is paid in the staple cereal of wheat. Any tools beyond this, require a separate fee.

In fact, agricultural tools represent quite an expense, particularly for those communities having little poplar wood of their own and having to buy this from outside - Nawor High Plateau being a case in point. Ajarestan again proves to be a slight exception to the rule with a higher number of tools apparently from Pakistan, and tending to be cheaper than the same tools sold elsewhere in the surveyed areas. This is probably due to the privileged relationship reigning between the Talêban and Pakistan - whether Pakistani authorities, business communities and so on.

Nevertheless, for those families unable to purchase a full range of tools, or having to sell their tools (household types $\mathrm{C}$ and $\mathrm{D}$ in particular, although $\mathrm{B}$ may be affected to a lesser extent), sharing among co-villagers provides an important community fall-back mechanism not to be underestimated. This said, general tool depreciation trends are not particularly encouraging. Thus, those tools that are perhaps the most often used, among them the shovel and the sickle, tend to be imported from either China or Pakistan due to their reputed superior quality.

Interestingly enough though, most tools in Jaghoori seem to last almost 2 years longer than elsewhere. This may well be due to better handling and in the case of locally produced materials, improved production methods generating a higher degree of efficiency (more likely given that Jaghoori was noted as an exporter of agricultural tools by UNIDATA in 1990). If this is the case, then the implication is that the durability of tools elsewhere could also be improved through training.

\section{WATER SOURCES AND IRRIGATION SYSTEM:}

\section{Problems and Interventions:}

Snowmelt is of significant importance in Spring, often with the potential of flooding, this being most evident in Malestan, Bamiyan Lower and Upper Valleys, and Ajarestan. It is particularly detrimental in those areas where there are large numbers of small landholders - parts of Malestan and Bamiyan being a case in point. In this, cultivated land is significantly reduced, particularly where families do not have the manpower or financial means to remove any stones deposited. This

\footnotetext{
${ }^{71}$ GRSP's main office is in Peshawar, Pakistan.

${ }^{72}$ See Appendix IV for details.
} 
flooding has been exacerbated by deforestation resulting in leaching and soil erosion, which have further caused damage to irrigation systems, causing both water absorption in the channel as well as water seepage outside the channel. Where this is particularly heavy (most evident in Malestan and to a lesser extent in Ajarestan), meadows and marshland prevail. Some years ago, in Malestan, the Austrian Relief Committee did some work to strengthen irrigation dividers and construct flood protection walls, but since then, little of the much needed work has been undertaken. Solidarités and DHSA, however, have been working to this effect in Bamiyan Lower Valley with plans to expand into the Upper Valley (See Appendix V for Details).

\section{Community Activities:}

Irrigation channels tend to have been made by villagers at the time of settlement, using mud and stones for both channels and dividers. Where possible, trees have been placed along the main channels and along rivers, something most evident in Malestan where willow and poplar are relatively abundant and flooding an important problem, and to a lesser extent elsewhere. However, this has essentially been dependent on the financial abilities of the relevant landholder. In Nawor High Plateau, a considerably higher number of irrigation channels tend to be exposed to the elements due to complete lack of tree cover. Sluices or floodgates all appear to be constructed from packed mud and/or turf (Bamiyan Upper Valley and Nawor), and shovelled in and out to regulate waterflow which is generally released early in the morning and cut towards the end of the day

\section{Ownership:}

In principle, the water source and the irrigation channels are common property, with each (male) landowner being charged to clean and repair that part of the channel touching his land, and all being responsible for more general repairs upstream.

\section{Social Organisation:}

In Bamiyan Upper and Lower Valleys and in Ajarestan, a Mihrab is usually elected every year in each village for the period of the growing season, his task being to ensure that repairs are undertaken when and where necessary, and to regulate the water flow according to land size. Essentially, the Mihrab will identify the points along the network requiring repair and then call all landowners from the Mosque, and organise a communal effort which he then supervises. The Mihrab is also responsible for resolving any conflicts over the water flow, and will be paid in-kind at the end of the growing season, with about 2-3 sers (14-21 kg) of wheat or barley.

In Malestan and Nawor, meanwhile, organisation of general repairs and cleaning falls to the village chief and the elders, while the water-flow is self-regulatory, that is, it is undertaken by the villagers themselves. This they do, according to a rotation system and the amount of land owned by
each landholder.

In Jaghoori, however, the system is somewhat different including springs, but being essentially based on karezes, an underground water system. In this, a series of water channels anything from 3$20 \mathrm{~m}$ underground (and around $0.5 \mathrm{~m}$ wide and $1 \mathrm{~m}$ high), link up a network of small pond-like structures - each one situated in a line further downhill from the other. The distance between karezes varies and can be anything from $100 \mathrm{~m}$ to $1 \mathrm{~km}$. It is in these pond-like structures that water is collected to a depth of about $20 \mathrm{~cm}$ and from where, at the end of the day, water is released to the 
fields. Several families (perhaps 5-10) tend to share one kareze, being responsible for its cleaning and any fepairs, as well as for regulation of the water flow according to the land area to be cultivated.

\section{LIVESTOCK AND POULTRY SYSTEM:}

Across the Hazarajat, livestock form an essential and integrated part of livelihood systems, used to compensate for land constraints. It is through their livestock and poultry that communities in the Hazarajat have been able supplement their calorific intake (particularly during the 'hunger gap', over the spring/summer period), and diversify their diets, as well as have access to cash income and wann clothes for the long winter period. However, livestock numbers very much change according to topographical and politico-economic constraints.

\section{Ecological Constraints:}

Ajarestan: pastureland is an important asset, as a result of which, the province is also home to a number of Koutchis and their livestock, for around 3 to 4 months during the growing season. While the resident, or sedentary, population tends to have a high number of cattle, but few sheep and goats, the Koutchis have significantly larger numbers of the latter.

Bamiyan Lower Valley: pastureland is less for sheep and goats, so the emphasis is more on cattle: most families seem to have at least 1 ox and 1 cow.

Bamiyan Upper Valley: pastureland appears to be better here and able to sustain higher numbers of livestock. Cattle again, feature relatively more.

According to an SCA survey in 1989, in Bamiyan Province, $89 \%$ of the farmers owned oxen while another $11 \%$ depended on hired oxen. Of those owning oxen, $58 \%$ owned one ox, $29 \%$ owned two oxen and $2 \%$ owned three oxen.

Jaghoori: in a large part of the area, there appears to be a dearth of both meadow and pastureland. Animal pens appeared quite common, in addition to winter stables. Small livestock also tended to be more common than larger cattle.

Malestan: meadowland is available, while pastureland is more limited. Perhaps for this reason cattle appear more prevalent - with open air mangers being a common feature on the landscape, in addition to winter stables.

Nawor High Plateau: in Nawor, pastureland is plentiful and arguably, the greatest livelihood asset of the zone, given the lack of water for agricultural use and the semi-arid terrain. The land is favourable for both cattle and smaller livestock. Nawor District was estimated by the Governor to have around 600,000 animals. 
According to an SCA survey in 1989, in Ghazni Province as a whole, $59 \%$ of farmers had no oxen, $20 \%$ had only one ox and only $19 \%$ had 2 oxen. A very small number of tractors were also in evidence.

\section{Land Ownership Constraints:}

Across the board, pastureland and meadows tend to be owned by the larger landlords who, with the possible exception of Bamiyan Upper Valley and Jaghoori where fewer restrictions appear to apply, reserve the better part of it for their own animals. The remainder may then be used by their tenants, any landless labourers and other villagers.

\section{Coping Mechanisms:}

Livestock form an integral part of livelihood systems. Moreover, in times of stress or need, small male livestock (goats in particular), will often be the first to be sold, followed by any female counterparts.

\section{Other Comments:}

Across the board, animal breeding declined visibly during the Soviet occupation due to heavy bombardment by the Kabul government and the explosion of mines - particularly around Jaghoori. Import of animals to high elevation areas was also reported to be problematic due to the scarcity of breeds. 


\begin{tabular}{|c|c|c|c|}
\hline Animal & Gender Involved & Use & Working life \\
\hline $\begin{array}{l}\text { Camels - among } \\
\text { the Koutchis } \\
\text { only }\end{array}$ & men onily & $\begin{array}{l}\text { - milk and meat för consumption; } \\
\text { - } \text { manure for fuel; } \\
\text { - } \text { hide for clothes or for sale; } \\
\end{array}$ & $20-25$ years \\
\hline Cows & 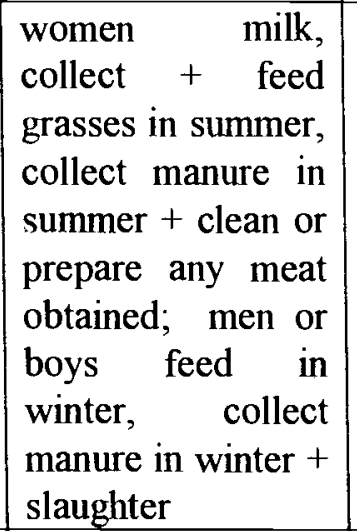 & $\begin{array}{l}\text { - milk and meat (the latter usually } \\
\text { being sold in the marketplace } \\
\text { unless household type A); } \\
\text { - manure for land and fuel; } \\
\text { - hide (usually sold in the market) }\end{array}$ & $\begin{array}{l}10-12 \text { years }(15 \\
\text { years in Jaghoori) }\end{array}$ \\
\hline Donkeys & mainly males & $\begin{array}{l}\text { - transport - fuel and bushes from the } \\
\text { mountains, crops after harvest, } \\
\text { goods and people (particularly } \\
\text { women and small children), to the } \\
\text { nearest town or clinic; } \\
\text { - manure for fuel only } \\
\end{array}$ & $\begin{array}{l}20-25 \text { years }(15 \\
\text { years in Bamiyan } \\
\text { Upper Valley) }\end{array}$ \\
\hline $\begin{array}{l}\text { Goats and } \\
\text { Sheep - } \\
\text { Hazaragi breed } \\
\text { everywhere } \\
\text { except in } \\
\text { Ajarestan where } \\
\text { goats tend to be } \\
\text { without horns } \\
\text { and sheep of the } \\
\text { Seyah Paicha or } \\
\text { Shinwari type }\end{array}$ & 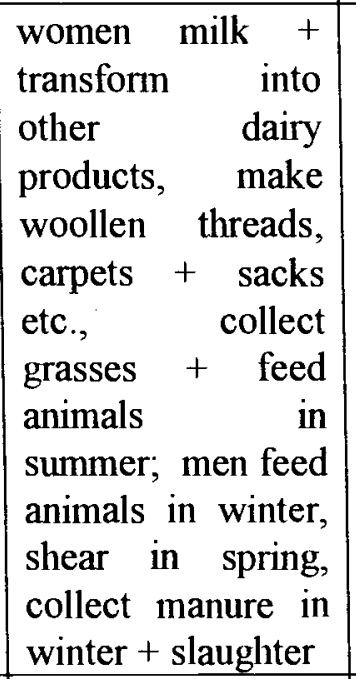 & $\begin{array}{l}\text { - milk and meat for consumption } \\
\text { (whether direct or, in the case of } \\
\text { meat, for sale in the market); } \\
\text { - manure for land and fuel; } \\
\text { - wool for gilims (carpets - requiring } \\
\text { about } 10.5 \mathrm{~kg} \text { ), namad (felt rugs - } \\
\text { requiring about } 3.5 \mathrm{~kg} \text { ), sacks for } \\
\text { wheat flour and clothes (either } \\
\text { directly or for sale); } \\
\text { - hide (usually for sale); } \\
\text { - stomach lining and intestines }\end{array}$ & $\begin{array}{l}\text { until teeth are lost: } \\
6-7 \text { years for } \\
\text { females; } 7-8 \text { years } \\
\text { for males }\end{array}$ \\
\hline Horses & men only & $\begin{array}{l}\text { - transport - people; } \\
\text { - manure for fuel }\end{array}$ & 15 years \\
\hline Oxen & males only & $\begin{array}{l}\text { traction power for ploughing, } \\
\text { levelling, threshing; } \\
\text { - manure for land and fuel }\end{array}$ & $\begin{array}{l}15 \text { years }(8-10 \\
\text { years in Bamiyan } \\
\text { Upper Valley) }\end{array}$ \\
\hline
\end{tabular}




\section{Feeding Patterns:}

\section{Cattle:}

As from late April/early May, cattle (usually males and those females lacking milk) tend to be sent out primarily to meadowland, or that failing, after mid-June to the nearest pasture until the first snows. In Nawor, cattle may be herded together in groups of 200 per cattle-herder (the cattle herder earning perhaps $1 \mathrm{ser}$, or $7 \mathrm{~kg}$, of wheat per animal for the whole season), but elsewhere they tend to be left individually, attached to a rope so that they do not stray. After harvest, however, they are generally left to graze on the fields. In some instances, cattle are not allowed onto the alfalfa fields at this time, for fear they might trample the plant underground; in others, cattle get priority over all other animals for all fields.

During the winter months, the cattle are stabled in a separate room within the house compound and fed three times a day usually by the male adult of the family. Cattle are usually given alfalfa, although pregnant cows may be given vetch by the more wealthy households (A and B) for 2-3 weeks after giving birtl. In Upper Bamiyan, cows are reputed to eat $7 \mathrm{~kg}$ of fodder per day.

\section{Sheep and Goats:}

In Bamiyan Upper Valley, sheep and goats are sent to the mountains for 2-3 months (end-June to end-August) with 2-3 women and men, some moving with tents, others making a temporary shelter from wood for this duration. Elsewhere, sheep and goats are sent out to pasture on a daily basis in the mountains for around six months of the year (mid-April to mid-October), with the female sheep being brought back to the house for milking at mid-day. Male and female sheep are grazed separately. Both return to the house at nightfall. During the day, a shepherd (usually a small boy of 7 or more years) keeps vigilance - either one for the flock of a specific family or one for several families, depending upon the area of the pastureland, the flock size (in Nawor this can average around 200), and family manpower and financial status. The shepherd, if not of the same family, tends to be paid in wheat - perhaps $1 / 2$ ser (or $3.5 \mathrm{~kg}$ ) per animal for the whole season.

In summer, one sheep may be fed an additional $2.5 \mathrm{~kg}$ of wet grass per day, and after harvest, the animals are usually left to graze on the fields. Pregnant sheep may be given vetch in particular.

For the winter period, all animals are constantly kept in a stable, usually a small room to one side of the house or a little further away within the compound should there be one. During this time, they are fed the hay collected over the spring/summer period by female members of the family. In Upper Bamiyan, 3 sheep/goats will eat about 7 kilos of fodder per day. It is the male members of the family - usually the adult - who are responsible for winter feeding which occurs three times a day.

They too, are responsible for daily collection of the night-soil, which is divided into two parts: one part for winter fuel needs, another part (which may be mixed with ashes, human manure and compost), for the following growing season. 


\section{Reproduction:}

Cattle:

In most villages, perhaps only one person (usually of household type A) will maintain a bull, to which all have free access for reproduction purposes. Cows tend to give birth all year round after reaching 3 years of age (although the peak period tends to be spring), and often may be milked for human consumption just a few hours after birth (with 2 teats reserved for the calf and 2 for the family). Castration of male calves in Ajarestan, Bamiyan Upper Valley, Malestan and Nawor takes place at 2-4 years, unless the animal is to be sold. A small fee tends to be charged only to those who have the means. In Ajarestan, it is thought that $4 \%$ of calves die after castration - more than likely due to infection.

\section{Sheep and Goats:}

The Koutchis aside, only the more wealthy households (usually those of household type A and to a lesser extent, household type B), will keep a male sheep or goat beyond one year of age. However, all villagers tend to have free access to the male sheep or goat for reproduction purposes - something taken in charge by male family members. Sheep and goats tend to give birth in early spring after 2 years of age, with lambs and sheep only going out to graze after 3 months - after which time milking may also take place for human consumption. Castration of male lambs and kids tends to occur (unless the animal is due to be sold), at 1 year of age in Ajarestan, Bamiyan and Jaghoori, while at 2 $1 / 2$ years in Malestan and Nawor - usually in autumn.

\section{Pathologies and External Interventions (See Appendix VII for More Detail):}

Among the villages surveyed throughout the six zones, four main diseases (in addition to diarrhoea) were cited as most prevalent and causing the most problems: tatla (or water retention in the liver and lungs, found in sheep, lambs and to a lesser extent goats), burgma (a form of colic or abdominal constipation in donkeys, cattle and sheep), amrhu (or foot and mouth disease in cattle), and blackleg. Nawor in particular, seems to have high mortality rates, with these quoted at as much as $15-20 \%$ from amrhu.

Across the Hazarajat, a number of veterinary clinics have been established under the aegis of the Food Agricultural Organisation, FAO, which has contracted the work out to another agency. Ajarestan, however, is devoid of any such clinic despite being one of the zones perhaps most at risk: the presence of the Koutchis may well be an important factor in spreading disease and increasing mortality rates. Other clinics do nonetheless exist elsewhere: in Bamiyan (for both Lower and Upper Valleys - with a travelling distance of 2-4 hours for the latter), Jaghoori, Malestan and Nawor.

As the donor, FAO gives the medicines and salaries, sets standards and targets, and monitors the work once or twice a year. The implementing agency, meanwhile, supervises and makes a monthly report to FAO, also distributing the materials and salaries given by FAO to the clinic personnel.

The clinics are busiest in spring and autumn, and by all accounts, given the ambit of the areas each is supposed to cover, are intended to be proactive, but in reality tend to be reactive, waiting for patients to come. This said, only the clinic in Nawor claimed to have any space for in-patients although Jaghoori does have a demonstration stable apparently used by its own sheep. 
In essence, each clinic is supposed to be equipped with enough medicines and vaccinations to undertake outreach activities for at least 6 months of the year, in addition to in-house activities, and two vaccination campaigns covering the basic immunisable diseases. The Spring vaccination campaign tends to include the following vaccines: Ovipan F (for diarrhoea), Antrax (for latla), Blackleg, Sheep-Pox, CCPP and Introtexemia, while the Autumn vaccination campaign includes: Ovipan F, Blackleg and Pastraluze. In Bamiyan, for example, the target number of animals to be immunised this year using Ovipan F was that of 20,000; while for Sheep-Pox and Blackleg, it was 5,000 respectively. The clinic in Bamiyan, however, is definitely better equipped and more active. Elsewhere, storage facilities for vaccines together with medicine supplies are more problematic particularly so in Nawor and to a lesser extent, in Malestan. Neither have access to a coolbox or refrigerator, although Malestan is at least able to exploit the nearby river for vaccines. This has serious implications for the efficacy and value of any vaccinations given. Moreover, both clinics, but particularly that of Nawor, were significantly lacking in needed products - much more so than the other clinics - while for a number of those products in stock, the expiry dates had already been passed - also affecting the quality and utility of the products.

In terms of supplies, the blockade has no doubt been an important factor with the passage of medicines being impeded and hence, treatments more than doubling in price. This, however, would also appear to have occurred in conjunction with a reduction in purchasing power - at least for those who would have access to cash income through cash crops (potatoes, apricots, almonds, poplar), livestock and poultry sales (at least household types A, B, C and D). Both supply and demand then, would tend to have diminished. Given that the outreach staff in particular are dependent upon the vaccines and sale of medicines for their income, they may also find themselves relatively demoralised so further reducing any work undertaken.

In both Nawor and Malestan, few if any people claimed to have had any contact with their respective clinic (even when living in the immediate vicinity), and many had not even heard of it. In Nawor, given the clinic's recent establishment, this might be understandable; less so in Malestan. Interestingly, all clinics, excluding that of Bamiyan, mentioned that monitoring by the donor agency, FAO, had decreased over the last eighteenth months. In addition - and again affecting the Malestan and Nawor clinics in particular - external support - whether through further training (given that levels were quite basic and professional veterinary staff lacking), or simple constructive criticism - seemed inadequate.

\section{Livestock and Poultry Yields ${ }^{73}$ :}

Among the Koutchis, camels and sheep are seen as the most essential assets: camels to facilitate mobility and maintain migratory traditions, and sheep for a quick and easy sale to buy other necessities such as wheat, clothes - and jewellery (of which, relative to other groups, the Koutchis wear a fair amount). Among the more sedentary population cattle gain pre-eminence: to plough the land (the epitome of sedentarism) and to provide milk. In all cases, sheep are preferred to goats perhaps for their place in religion.

\section{Dairy Products:}

In Ajarestan, Bamiyan Lower Valley and Malestan, sheep and goats appear to give at least 0.5 litres of milk per day for 2 if not 3 months. In Bamiyan Upper Valley 1 litre per day for 3 months was more likely, while in both Jaghoori and Nawor High Plateau, figures ranged between 0.5-1.5 litres per day for 3 months - although tending more towards the latter. Cows on the other hand, gave

\footnotetext{
${ }^{73}$ See Appendix VIII for More Detail
} 
anything from 1-3 litres per day for 6 or 7 months in five of the zones, except in Jaghoori where yields tended to be higher at 6 litres per day for 7 months - with a diminishing amount possibly following later. In both cases, women and girls do the milking. Camels in Ajarestan, meanwhile, seemed to give an average of 3-4 litres per day for 5-6 months - and were milked by the men only.

The difference in milk yields suggests variations in feeding practices and habits, which could well be improved through targeted health and nutrition education.

Meat:

Across the board, male calves, lambs and kids are the first to be sold to provide for a family's cash income. Their female counterparts, meanwhile, tend to be kept to add to capital stocks unless the family is pushed to sell. Ideally, both are sold in autumn - once the animals are fatter after six months of grazing and so that winter needs may be met (with storage also being facilitated due to cold weather conditions); cows are sold at 3-4 years of age and sheep and goats at 1 year of age, although increasingly (Ajarestan excepted), both are being sold younger, throughout the year, to meet immediate family needs. Having been subject to perhaps a $30 \%$ reduction in prices due to the blockade, numbers being sold have increased for certain households (Ajarestan again excepted), which under normal conditions would theoretically push prices further down. The other implication is rising levels of decapitalisation (particularly, and most significantly, among household types $\mathrm{C}, \mathrm{E}$, $\mathrm{F}$ and $\mathrm{G}$ - where still relevant). However, in an important number of instances, livestock have been unable to be sold, or their owners unwilling to sell due to the lower prices. In these cases, debts seem to have been contracted instead so as to help tide the family over the hunger gap, for instance.

Usually, merchants come to the villages to purchase the livestock and then either sell them in the nearest largest market or transport them to Ghazni for sale. This they do either in herds by foot (particularly in Nawor), or by truck (subject then, to the concomitant high transport prices). In some of the less frequent cases, livestock are sold directly by their owners in the market (where the merchant has failed to arrive and/or other purchases are immediately required). It is men who are involved in any market transaction and transportation.

\section{Poultry:}

In most places, 4-5 eggs per week were the norm, although this could reach as many as 7 , particularly in Bamiyan Upper Valley. In each case, this was for a duration of 5-6 months, over the spring and autumn periods when temperatures were not too extreme.

\section{Wool:}

The amount of wool gained varied from $0.5-1.0 \mathrm{~kg}$ according to the size of the sheep. In some areas, the shearing occurred twice, while in others, such as Ajarestan and Bamiyan Lower Valley, this occurred only once a year.

After shearing by the male, women usually collect the wool, wash it and make threads. These may either be sold or collected for weaving into gilims, or carpets, and namad, or felt - used to cover the floor or to cover food in storage, or sold to bring in a cash income. Women in Jaghoori, in particular, seem quite active in the latter. 


\section{E. FUEL COLLECTION AND CONSUMPTION:}

Fuel is usually obtained from four sources:

- gorse bushes and rhubarb leaves from the mountainis;

- livestock manure - particularly donkey, whereas that of cattle, sheep and goats is often divided for use on the land (where applicable);

- willow trees and to a lesser extent, poplar and Judas;

- dried turf, at higher altitudes, including Nawor and Upper Bamiyan.

\section{Ecological Constraints and Demography:}

In Malestan and Jaghoori, a relative scarcity of bushes for fuel exists to the extent that night watchmen often keep guard over the mountains so as to limit over-use and/or external encroachment. Given the relative lack of pastureland, the availability of manure is also limited. The problem is perhaps all the more acute for Jaghoori given that it is one of the more heavily populated areas of the Hazarajat. Nawor, meanwhile, has significantly fewer trees than elsewhere and relies more heavily on mountain bushes.

On the whole, while Ajarestan, Nawor and both Lower and Upper Bamiyan would appear to be subject to fewer constraints, growing deforestation due to demographic growth and needs, as well as the effects of the blockade, are also taking their toll. Thus, reforestation, while perhaps more urgent in Malestan (particularly given the high rates of flooding), and Jaghoori would not be inapplicable elsewhere.

\section{Land Ownership Constraints:}

Villages and villagers tend to have specific and mentally demarcated plots allocated to them in the mountains. The tendency, although less visible in Jaghoori and Upper and Lower Bamiyan, is for a small number of large landowners to own these mountains and subsequently permit their use to tenants and other villagers - free of charge.

\section{Fuel Collection:}

Throughout the zones surveyed, this tends to take place in the mountains as from mid-May to the end of August, and may often be done at the same time as grass collection. It is usually done by men and young boys who will either go individually or in small groups and may take anything from 3 hours in Nawor, to 8 hours in Malestan - usually taking place at the crack of dawn, perhaps 3-4 days a week. Where available, donkeys are used to carry the loads collected. Perhaps 5-6 sers, or 35-42 $\mathrm{kg}$, will be collected in one day by one adult male - less for a young boy. The bushes are then stored around or on the roof of the house for later use - mostly in winter.

Turf is cut from meadow areas at high altitudes, and will be left to dry and then burnt, while branches from willow and Judas trees will be cut as and when needs dictate, although for those with no trees, a small pile may be kept to one side. Branches from poplar trees, given the commercial use of the poplar, tend to be obtained primarily when the tree is felled for sale. 
Donkey manure is collected and used all year around by men and young boys, while all other manure tends to be divided according to use for the land and for the house. From this, young children, particularly boys, will make fuel cakes of up to half a metre in diameter, which will be burnt with branches and bushes when necessary.

\section{Fuel Use:}

In summer, and for those who have the means, perhaps 3 fuel cakes together with $3 \mathrm{~kg}$ of wood will be used every 3 days to make bread and so on. Fuel use tends to limited as much as possible to enable greater amounts over winter. During the latter period and in the colder areas, perhaps half a ser, or 3-4 kg, of wood, together with 6 manure cakes, might be used per day to heat a house of 3 small rooms. The rooms are heated using a form of underground heating system which works through pipes connecting the tandoor (oven) with the rest of the house, beneath the floor and then up through the walls.

\section{F. LABOUR CALENDARS:}

The labour calendar below was calculated for a household of type C in Bamiyan Upper Valley, having 1.9 jeribs of land, 1 cow, 1 donkey and 3 sheep/goats. It can be seen that peak labour power periods occur as from mid-March to mid April, from the last week of May to the third week of August, and from mid-September to mid-October. These periods coincide with the requirements of land preparation, weeding and harvesting and threshing - all of which may in fact, be further constrained than shown below due to queuing for oxen, problems of early cold and so on. Introducing new work at these periods in particular would then, be detrimental to households - given that it is probable that most households are subject to relatively similar constraints.

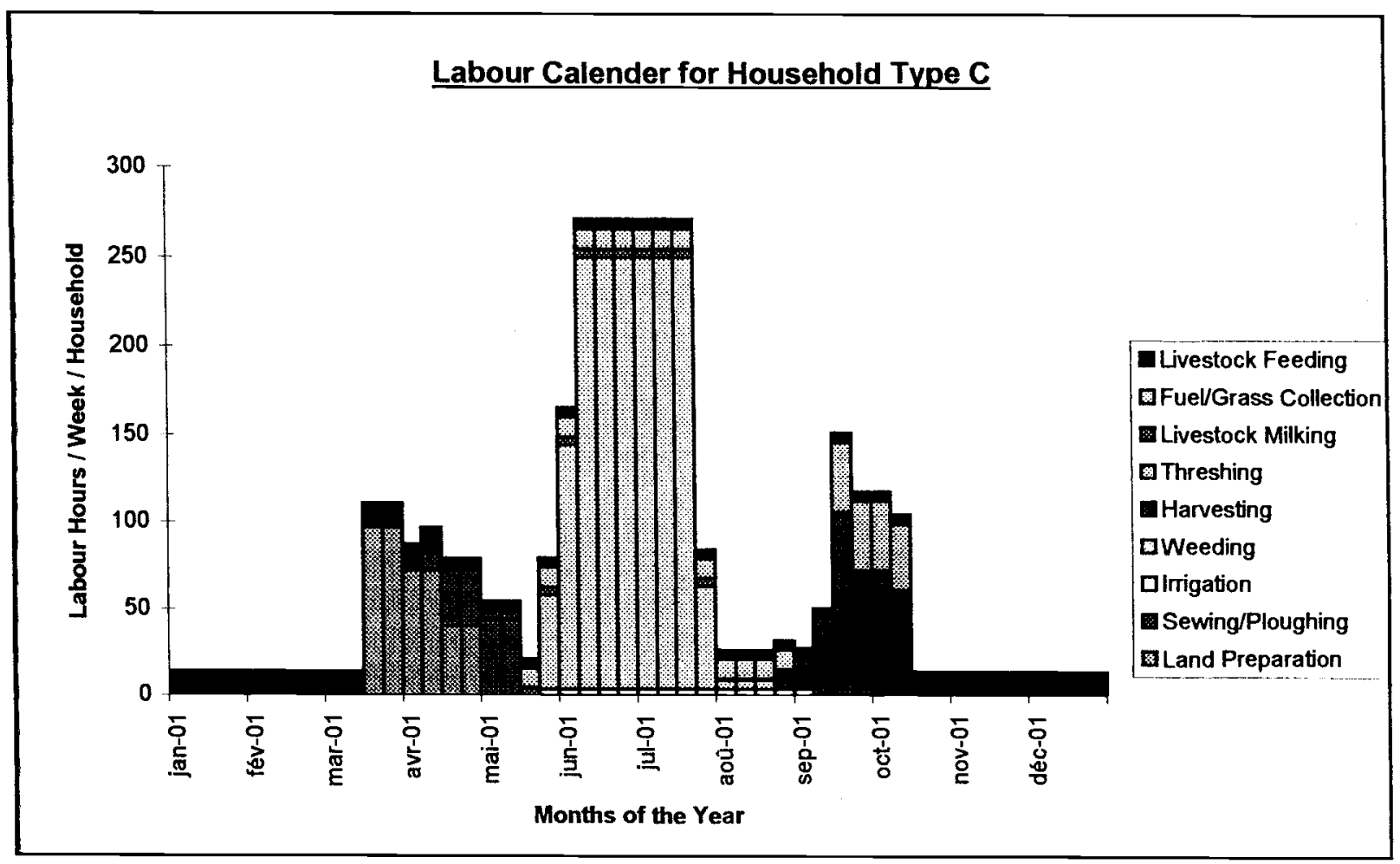


Depending upon sanitary conditions and access to health services, certain households may also be subject to disease, so weakening members and reducing their capacity to work. Across the board, most cited were problems of diarrhoea over the spring/summer period - particularly prevalent among children, but also affecting adults. Cholera was also evident in certain areas, notably Malestan and Bamiyan Upper Valley and to a slightly lesser extent, Ajarestan - probably due to the higher risks of flooding and stagnant water pools in these areas - while rheumatoid arthritis was also mentioned as a problem during damp periods, particularly by women involved in weeding. It may be that this is aggravated at higher altitudes due to the colder weather. All of these, then, might be presumed to negatively affect the labour power of each household - an effect which could be at least partially reduced through better sanitary facilities and health education.

Diet is also a factor to be taken into consideration. While food quantity may have become reduced during the hunger gap/growing season - particularly due to the effects of the blockade - it might well be that quality (given increased amounts of wild vegetables in a diet that otherwise lays relatively little importance on these), has become slightly better. However, such an observation would require studied confirmation - not possible given the constraints of the present report.

\section{Increasing the Labour Power Available:}

In terms of those working the land and taking care of livestock, Afghan society, whether Pashtun, Tajik or Hazara is essentially a patrilineal society, tracing descent through the male, and placing visibility and recognition on the roles and activities of men. There is then a strong division of labour according to gender, with males being involved in all that entails entry into the public domain working the land or purchasing in the market, for instance - while females are essentially circumscribed to the more private, household domain: caring for the children, preparing the food or milking the livestock.

At the same time, however, seasonal and manpower constraints are such (if the household were to be considered as having only two working persons, each working an average of 9 hours per day, then a cut-off point at 126 hours per week would be in evidence), that women in the Hazarajat have also been compelled to assist with more public tasks such as clearing the land before sowing, weeding and helping to reap the harvest. Without their contribution, and given the short growing season experienced across the mountainous enclave, the agricultural system as it is currently practised, would encounter some serious bottlenecks. This is particularly so given the suitability of the climate to potato cultivation and the immense amount of manpower required for this.

\begin{tabular}{|l|l|l|}
\hline Activities & Males & Females \\
\hline Productive & $\begin{array}{l}\text { adult }+ \text { young men: manure } \\
\text { collection, snow clearance, }\end{array}$ & $\begin{array}{l}\text { adult + young women: land clearance } \\
\text { before sowing, weeding and grass }\end{array}$ \\
& ploughing, sowing, irrigating, & collection, reaping, separating seed \\
weeding (but less often than & from strawer, milking, food \\
& women), reaping, threshing, milling, & transformation, sewing of clothes, \\
& sheep + goat shearing, slaughter of & weaving of gilims/ namads; \\
& livestock, feeding of livestock during & - elderly women: weeding; \\
& winter, market transactions; & - girls: collection of wild vegetables, \\
& boys: collection of wild vegetables, & weeding and grass collection, bird- \\
& fishing, accompaniment of livestock & scaring, accompaniment of livestock \\
& to pastures during spring/summer, & to pasture (not so common), manure \\
& manure collection, bird-scaring & collection in summer \\
\hline
\end{tabular}




\begin{tabular}{|c|c|c|}
\hline Reproductive & $\begin{array}{l}\text { adult }+ \text { young men: food } \\
\text { procurement where necessary, fuel } \\
\text { collection (particularly where far), } \\
\text { accompaniment of elderly, infirm or } \\
\text { unwell to nearest clinic; } \\
\text { - elderly men: fuel and grass collection } \\
\text { from mountains; } \\
\text { - boys: fuel and water collection }\end{array}$ & $\begin{array}{l}\text { - adult + young women: child care, } \\
\text { food preparation, house-cleaning, } \\
\text { laundry, fuel and water collection } \\
\text { - (where not too far from the house); } \\
\text { - elderly women: child care, food } \\
\text { preparation; } \\
\text { - girls: water collection }\end{array}$ \\
\hline Community & $\begin{array}{l}\text { - adult + young men: organisation and } \\
\text { regulation of water flow for } \\
\text { irrigation, election of village } \\
\text { representative, military call-up; } \\
\text { - elderly men: resolution of disputes, } \\
\text { allocation of surplus or donated } \\
\text { resources, election of village } \\
\text { representative, organisation of social } \\
\text { obligations; }\end{array}$ & $\begin{array}{l}\text { - adult }+ \text { young women: food } \\
\text { preparation for important festivals }\end{array}$ \\
\hline
\end{tabular}




\section{A. NUTRITION AND HEALTH:}

\section{Conclusion:}

The problems of the Hazarajat are therefore socio-economic, political and environmental, affecting the level of health and nutrition within the community. Malnutrition is and has been affecting the population, particularly poorer people. Farming is practised on eroded soil and harsh weather conditions have contributed to a poor level of nutrition for some time. Health and nutrition resources, which are already scarce and expensive as a result of the blockade imposed by the Talêban, are out of the reach of most people. Although most of the families grow their own food and buy in the deficit, access and availability of food has been affected, albeit in varying degrees, according to regions. Coping mechanisms, such as the collection of wild foods and consumption of what was once animal feed, have been adopted, as well as cutting down on the quality and quantity of food. The number of meals per day has not as yet been affected, still standing at three per day.

Action contre la faim carried out a nutritional surveillance, consisting of the collection of anthropometric measurements of children aged 0-59 months. In a given population, this age group is normally the most vulnerable and the first to be affected by any food insecurity. A regular surveillance of these children long term, will enable a realistic picture to be drawn of their nutritional status, as well as give a warning of any impending food crisis. The survey took the form of a screening in a handful of villages within each region and the results may therefore not be representative of the whole population. The population as a whole is well represented in terms of sex, the ratio being 1.04. The results found in this survey can be used as a baseline for future surveys. They cannot be compared with previous data, as none was available on the regions covered. The acute malnutrition rates were found not to be alarming, considering the restrictions of food availability and accessibility caused by the long standing Talêban blockade.

The level of acute malnutrition was not alarming. However, Malestan should be further investigated, in order to determine any future need for nutritional intervention, since there is twice the level of malnutrition, particularly in the 6-29 months category where it is reaching levels of concern $(8.0 \%)$, compared to other areas. What was evident was that there was a great lack of food available, in variety and quantity, compared to other regions. Up to a third of the crops had also failed $^{74}$ in the region, making the burden carried as a result of the blockade, harder to cope with.

There was some difference in the moderate malnutrition rates of the sexes in the 6-29 months age group, with $9.0 \%$ of boys and $6.9 \%$ of girls being acutely malnourished across the Hazarajat regions covered. In Ajarestan and Bamiyan Upper Valley differences were quite considerable, where $16.7 \%$ of boys and no girls and $12.0 \%$ of boys and $4.0 \%$ of girls were acutely malnourished, respectively. In the 30-59 months age group, a considerable difference was noted in Malestan, between the sexes, where there was $10.8 \%$ in boys and $1.4 \%$ in girls, of acute moderate malnutrition. Throughout the Hazarajat, the figures were $6.2 \%$ and $3.9 \%$ for boys and girls respectively. No explanation is known for this, but future surveys may be able to investigate it.

Although a considerable amount of chronic malnutrition was seen throughout the Hazarajat, the figures must be questioned somewhat, as even with the aid of a local calendar of events adapted to each region, difficulty was found in giving an accurate age for children (particularly in Ajarestan,

\footnotetext{
${ }^{74}$ See Food Security section.
} 
where fathers estimated ages). Ages being approximate therefore, it is difficult to draw any statistically reliable conclusions. It also has to be noted that the Hazaras are of Mongol descent and may be prone to a short stature genetically. However, there does seem to be a large proportion of children suffering from growth retardation. Living in such a remote area as the Hazarajat, the population has certainly been subjected to a shortage in food quality, if not quantity at certain times of the year, impeding children's growth. Ajarestan and Jaghoori though, have less stunting than other regions, but a better food supply, not only of imported goods, but of their own production. With a poor quality diet and insufficient micro-nutrients, being prone to infections is another likelihood for the younger Hazara population.

The most vulnerable areas in terms of diet and acute malnutrition therefore, are Jaghoori and Malestan. Surprisingly, despite the fact that more food and health facilities are available in the area, Jaghoori has the highest rate of acute severe malnutrition at $0.9 \%$ for children aged 6-59 months and $2.0 \%$ for those aged 6-29 months, which are approaching levels of concern.

With a lack of fruit and vegetables as well as variety in the diet, the Hazaras are more likely to be prone to micro-nutrient deficiencies. The accumulated deficiencies, over a long period of time, can cause inter-uterine growth retardation, leading to low birth weight babies being born. This may be reflected in the deaths found in Jaghoori and Nawor. Although Jaghoori does have much better access to a variety of foods and health facilities than Nawor, it is likely that the families themselves are suffering from a lack of variety and quality, as far as their diets are concerned. This in turn is reflected in their state of health and consequently levels of morbidity and mortality, particularly in infants.

The overall mortality rate of 0.64 over 10,000 children per day is within an acceptable level. However, in Jaghoori and Nawor, rates of 1.36 and 1.96 over 10,000 children per day, respectively, are close to the alert level of 2 over 10,000 children per day. Within the villages where deaths were recorded, a mortality rate of 5.3 and 8.0 over 10,000 children per day was recorded in Jawdari and Qarge Bayee, respectively. It must be remembered however, that although at each screening all families with children under five years of age were asked to attend, there is no certainty that they did and therefore there may be more children in this age range who may be living in the village and were not screened or taken in to account when calculating the mortality rate. Acute respiratory infections and particularly pneumonia, seemed to be the most common cause of death for children. Harsh living conditions in the winter, as well as a poor nutritional status, may contribute to these deaths. With a lack of health facilities in many areas and therefore no means of treating an illness, children are vulnerable and likely, unable to fight infections, which can prove to be fatal.

Cholera is becoming an increasing problem in Ajarestan, Bamiyan and Malestan. This could be due to the problem of flooding that these areas encounter. Ignorance of the disease is contributing to its increase. Awareness of the nature of cholera, its prevention and treatment, needs to be inserted into the lives of the communities affected.

At least one clinic, offering general basic health services, but particularly dealing with mother and child health, both pre and post natal, is needed in Ajarestan. A supplementary programme, building up micro-nutrient levels in women of child bearing age, may help in cutting down on the level of LBW babies being born and the sometimes fatal results thereafter. Training of birth attendants, within the health structure programme, would enable safer home deliveries, with a reduction in the fatal consequences of mothers and babies. Health education and vaccinations would obviously need to be implemented into this programme. Since there is obviously such a problem with dental care, perhaps a dental facility ought to be considered in addition. 
The villages scattered around Bamiyan Upper Valley and beyond, have very difficult access to the health facilities available within Bamiyan city limits. Basic health care, including vaccinations and mother and child health care need to be implemented in the area.

In $\mathrm{Du} \mathrm{Abi}$, the centre of Nawor, where a vaccination programme currently runs from the site of the old clinic, additional health facilities, but particularly concerning mother and child health, need to be implemented. Again, midwifery training and health education, along with the ongoing vaccination service, should be a part of the programme.

An Expanded Programme on Immunisation usually aims at an $80 \%$ coverage rate for all vaccinations to be given before the age of one. This is with the aim of 'mass immunity', so that the whole population may be protected when the majority have been vaccinated. However, this is all very dubious when the proportion of a population that needs to be immunised in order to significantly reduce transmission of various diseases can differ from one antigen to another. It is very obvious that none of these areas are anywhere near such coverage, though Bamiyan is a long way ahead of the other regions. A shortage of health facilities is again highlighted by this problem. There was a great lack of awareness for keeping vaccination cards for future reference, which may mean that vaccination coverage is higher than what was found. However, even calculation by the mother's word, still shows a low rate of coverage.

Knowledge of vaccinations is not of a high level, which could be one of the reasons for low coverage. Others include the lack and the distance of health facilities. The importance of additional doses of vaccines for complete coverage are also unknown and need to be emphasised. The effectiveness of mobile vaccinators and their role in giving advice on the importance of vaccinations in protecting the child are lacking in the area.

The aim of the Expanded Programme on Immunisation and UNICEF for 1998, is to reach $90 \%$ of immunisation coverage against all six target diseases. Which ever figure is taken, it is clear that a great effort needs to be made for immunisation to be effective.

\section{Recommendations:}

- To complete the aims of the survey, by returning to the vulnerable areas and carrying out additional assessments concerning the health and nutritional status of certain vulnerable households (identified by the food security survey) as well as a food basket monitoring survey

- To implement similar regular surveys, in order to monitor the nutritional and health status of the population, or at least an additional survey just after the winter period, for a comparison of needs at various times of the year

- To find out through future surveys, why, in most areas, acute malnutrition is greater in boys than in girls aged 6-29 months

- To implement a nutritional and health programme in Malestan, working with other organisations present, to:

$\Rightarrow$ detect malnutrition, through a series of training sessions, at the community health level, through various health structures

$\Rightarrow$ distribute supplementary food to moderately malnourished, in order to avoid severe malnutrition 
$\Rightarrow$ reduce severe malnutrition, by complementing existing $\mathrm{MCH}$ care, in facilities such as the Swedish Committee in Miradina (and other health facilities) by providing the resources and training to treat malnutrition

- To implement health care, particularly in Ajarestan and Nawor and the remote surrounding areas of Bamiyan, either by collaborating with any existing health facilities, whether operational or not, or by setting up new facilities, where none exist

- To encourage ongoing and implement where needed, EPI, so that there is a better and more effective coverage of the targeted diseases

- To increase public awareness regarding nutrition, breast feeding, mother and child health including vaccinations and the dangers of resistance to drugs, particularly in fighting TB, through regular health education sessions within the community (at the mombar) and health structures as well as sessions within schools, both Qu'ranic and scientific

- To increase the level micro-nutrient intake by encouraging vegetable growth in kitchen gardens, providing nutrition education and distributing micro-nutrients to mothers and children, from any health structures that may be operational

- To reduce infant and maternal mortality by establishing a network of trained birth attendants within the community, working in close collaboration with the health facilities set up, in order to identify high risk pregnancies for referral and offer improved hygiene during home deliveries

- To set up a co-ordination body for all agencies involved within each area, so that with collaboration, more efficient and effective programmes may be functional

\section{B. FOod SECURITY:}

All in all, the food security situation as it was at the end of August, was at best precarious, subject to structural constraints requiring a medium to long-term response (rehabilitation of, and improvement to agricultural and animal husbandry systems), and aggravated by war hostilities, certain effects of which could, for particular households, be at least partially alleviated in the shortterm (distribution of subsidised inputs and/or temporary employment creation).

Key indicators which might permit regular and periodic follow-up of the food security situation include:

- Price changes for wheat, barley and potatoes (increases being detrimental), as well as for livestock, fruit and nuts (reductions being a problem);

- Changes in seasonal/temporary migration patterns (although these already seem significantly reduced);

- Changes in debt levels - either through loans or mortgages - by household type and in systems of community intra-assistance;

- Twists and turns of the ethno-religious conflict: displacement and massacres obviously being of most concern.

Monitoring of the above, would inevitably enable assessment of any potential change in the population's nutrition status. While no serious levels of acute malnutrition were encountered, the 
potential for this to become a problem in the future, is now a real one, for perhaps three main

- A number of flash floods notably in Bamiyan together with problems of rust and smut in the wheat $f$ ields of Malestan in particular, have led to crop damage and lower crop yields for this year - although prior to evacuation, at least, DHSA had undertaken to work on mitigating the
impact of future floods in Bamiyan;

- Across the Hazarajat (although to a somewhat lesser extent in Pashtun Ajarestan), the blockade has had the effect of weakening people's coping mechanisms, triggering asset depletion, affecting capacities to maximise land production, and diminishing the abilities of communities to unite in
the face of adversity;

- The advance of the Taleban into Northern Alliance territory, and particularly Bamiyan, has engendered population flight to the mountains, in a number of instances disrupting harvests. It is not known what other damage their advent might wreak on lives and livelihoods, although reports
of looting are already filtering through.

To prevent such a crisis, it may well be necessary to envisage a series of short-term measures to go hand-in-hand with those aiming to tackle more entrenched, but nonetheless related, vulnerabilities. In this instance, cash or food-for-work projects might be of use, targeting Household Types E, F and G having available labour-power, or even food distribution for those having no available labour-power (either dry ration given fuel stockpiling and therefore, availability for the winter period, or through canteens depending on what possessions (pots and pans?), have been looted). However, it should be noted that these changes have occurred since the exploratory study was undertaken and still require confirmation (as well as access), before any such actions be
undertaken.

With regard to more longer-term activities, chronic malnutrition, manifest in stunted growth, was already visible throughout the Hazarajat - most notably in Bamiyan (Lower and Upper Valleys), Malestan and Nawor High Plateau. This can only be effectively tackled through an approach premised on long-term improvements to both food quantity and quality.

This said, while an NGO such as Action contre la faim might be able to intervene to alleviate some of the effects of the above, to be effective and sustainable any assistance requires a minimum of security conditions and organisation. That is, ultimately, what is required is a political solution, whether in order to ensure stability and the material and psychological reconstruction of war-weary communities, or at second best, simply at the level of facilitating NGO activities and/or collaborating with, and co-ordinating these according to the circumstances. In parallel, what may also be needed is assistance in the creation and development of government ministries capable of implementing policies leading to positive socio-economic progress - a pre-requisite of which would be recognition of the relevant government.

Beyond this, the following would constitute the main body of recommendations for nonemergency action, to be divided into two phases for reasons of time and logistics. An attempt has
been made to make them holistic:

\section{Activities in Phase I:}

\section{$\Rightarrow$ Distribution of subsidised fertiliser:}

- Prioritising household type $\mathrm{C}$ first of all, particularly in Malestan (where GRSP does not appear to be doing this), and in Nawor. However, assistance to household types A, B and D where 
necessary, would also have a trickle-down effect on any landless labourers (household types E and F); employed to work the land in question;

- So as to improve yields given limited cultivable land and soil fertility in both (while Upper Bamiyan also requires assistance on this score, the presence of Solidarités and the organisation's intention to expand its activities, Inshallah, mean that this area of work is already covered). In Malestan, for instance, winter wheat yields could potentially increase by more than $30 \%$. The introduction of large quantities of fertiliser may also serve to boost the market, reducing prices and so stimulating demand, which would then have a knock-on effect on supply, where increases of the latter might come to reduce prices in a more sustainable manner (that is, without external intervention);

- Distribution may need to be complemented by an alternative loan system given the high rates of interest that are practised within the community particularly vis-à-vis those most likely to default on repayments who are also most likely to be those vulnerable to food insecurity;

\section{$\Rightarrow$ Distribution of herbicide and pesticide:}

- Prioritising household type C first of all, particularly in Malestan given the high rates of rust (where GRSP again, does not appear to be doing this), as well as in Nawor. However, assistance to household types A, B and D where necessary, would also have a knock-on effect on any landless labourers (household types $\mathrm{E}$ and $\mathrm{F}$ ), employed to work the land in question;

- So as to improve yields harvested - where these too, might improve by up to $30 \%$ in some of the more extreme cases. The introduction of large quantities of herbicide and pesticide may also serve to boost the market and reduce prices over the long-term;

- Distribution may need to be facilitated by the establishment of a loan system so as to improve accessibility to products;

White fertiliser can be purchased in Mazaar, although the factory does have a limited capacity and prices may be subject to monopolostic conditions. On the other hand, grey and white fertiliser, together with a number of pesticides and herbicides are widely available in Pakistan (and are regularly sold in Kabul), and were Bamiyan airport to be open, could be brought in by plane and then trucked to its destination.

With both fertiliser, herbicide and pesticide distribution, extension work would be necessary to ensure correct and timely application (particularly for those having never before used such products), as well as to improve, where necessary, weeding, threshing and storage techniques. Such extension work should be free of charge, but farmers in return, would obviously need to agree to supervision and technical advice

\section{$\Rightarrow$ Construction and/or rehabilitation of flood protection walls:}

- In Malestan and Ajarestan (given the work of DHSA and Solidarités in Lower Bamiyan and the intention of the latter to extend its work to Upper Bamiyan);

- This would contribute to preventing, or at least, alleviating the impact of, floods and furthermore, might allow communities to eventually bring uncultivable land into cultivation or facilitate its use as a meadow for livestock. In the first instance, only landholders will benefit (essentially household types $\mathrm{A}, \mathrm{B}$ and $\mathrm{C}$ ); in the second instance, all those with livestock should be able to gain (A, B, C, D and E, and in certain instances, F). However, a trickle-down effect might be visible, with landowners, due to lack of manpower, perhaps having to employ a landless labourer to work the land - of benefit to households $\mathrm{E}$ and F; 
0 in the provision of manpower (given that cultural constraints would prohibit women from any such participation). This could be done on a monetised basis (Work for Cash), involving in particular, household types $F$ and $G$ so that they might have access to a cash income and gain some form of rudimentary training in the process that might be of use in the future.

\section{$\Rightarrow$ Rehabilitation of Drainage Channels and Irrigation Dividers:}

- In Malestan (given the work of DHSA and Solidarités in Lower Bamiyan and the intention of the latter to extend its work to Upper Bamiyan);

- This would contribute to palliating the problems of water shortage (especially during the dry season), due to water absorption within the channels (due to excess sand), and general seepage along the channels (particularly where prone to landslides), and at the point of the irrigation dividers (although to be more effective, reforestation efforts would be a second step). It would help to improve crop yields and might allow additional land to be brought into cultivation (perhaps as kitchen gardens) - of benefit to all landholders and indirectly, to any landless labourer working for the latter;

Community participation as above would again be essential.

\section{$\Rightarrow$ Support to the veterinary clinics:}

- Firstly, in Nawor (given the importance of livestock to the zone and high mortality rates, as well as the clinic's problems of chain supply and storage), and then in Malestan (also given problems of chain supply). Both might profit from closer monitoring and encouragement, together with improved and permanent training and facilitation of outreach services (since few villagers appear to have had contact with the clinics, especially in Nawor). Negotiation with FAO and the current implementing agencies would be necessary for this;

- This would contribute to reducing livestock mortality rates, so improving and/or encouraging an alternative source of food income (beyond land), contribute to improved livestock yields and in certain cases, encourage the diversification of diets and hence, the reduction of chronic malnutrition - actual and potential. It would assist household types A, B, C, D and E, and in certain cases $F$ and $G$ (where these often have poultry if nothing else);

- However, it may be necessary to complement activities with a loan service so that consultations and medicines might be accessible to all those with livestock and not just those having both livestock and the financial means to care for them;

A way of following-up activities and improving sustainability, may be to organise training courses in livestock production and management - health and mutrition: milking, foods to be given, vaccination of chickens and so on. Outreach staff would be essential for this. Given that it is mainly women who are responsible for livestock, this would not only tap into the existing division of labour but empower women within the household domain

\section{Activities in Phase II:}

$\Rightarrow$ Seed multiplication and distribution of improved seed varieties:

- Particularly in Nawor. This is something that could be done in conjunction with Solidarités in Bamiyan and Madéra in Behsud, two NGOs already working in this direction; 
- While this would be of assistance to all landed household types, targeting household type C might allow the latter to re-establish relative food security which, together with some of the other measures mentioned above, should reduce proximity to the vulnerability threshold;

- This would entail work to inprove seed varieties that are better adapted to high altitudes, extremes of temperature and a short growing season;

Seed multiplication essentially involves 4 main elements: breeding, testing and certification, commercial production and storage, marketing and distribution. The idea, then, following from the work of other organisations in the area, would be to have an experimental plot, followed by a series of demonstration plots where volunteer farmers would be provided with basic seed, other impuis and credit, and their work followed by an extension worker. Close to harvest, the extension agent should organise field days to which neighbouring farmers are imvited to look at the improved crops.

Seeds would then need to be sold (with credit extended where necessary), at sewing time in April, so as to reduce any incentive the farmer might otherwise have to eat them. However, given the potential for a degradation of the general situation, it would be judicial to assess food stocks at the time should further humanirarian assistance (food aid, for ins(ance), be necessary.

According to the Swedish Committee for Afghamistan, the seeds should be sold at approximately $125 \%$ of the local grain price, with a reduction to $110 \%$ should there be any alternative improved varieties available (which should ordinarily occur after one year). Uswally 110-125\% of the grain price allows the farmer a $2: 1$ benefit: cost ratio, so providing an incentive.

$\Rightarrow$ Support to the cleaning of Kareze:

- In Jaghoori, given that these are the principal water source for irrigation and the increasing problems of water shortage;

- This would be of benefit to all landholders and to any landless labourers working for them enabling higher crop yields and perhaps, the cultivation of previously uncultivated lands;

\section{$\Rightarrow$ Establishment of a veterinary clinic:}

- In Ajarestan, given the importance of livestock to the zone and high livestock mortality rates;

- This should help to secure livelihoods and strengthen food diversification;

It needs to be done with community participation, perhaps in the construction of the relevant building and the materials required for this. A number of undergraduates were also said to be willing to be trained and work in this

\section{$\Rightarrow$ Kitchen gardens:}

- Targeting household types $\mathrm{E}, \mathrm{F}$ and $\mathrm{G}$ where these have access to a small yard by their house or within the house compound, particularly in Malestan given increased consumption of toxic legumes and limited vegetable and fruit production despite relatively favourable climatic conditions (Bamiyan Upper Valley is due to be covered by Solidarités and HABITAT). This would require collaboration with GRSP which is already working in the area - although in the domain of fruit trees. Work in this area would also be beneficial in Nawor, but would probably involve the establishment of greenhouses. Useful lessons could be learnt from Solidarités in Bamiyan and Madéra in Behsud;

- To improve diet diversification and/or access to alternative sources of income; 
Such activities might involve women - adult and elderly - given that it would be a household activity (not contrary to cultural norms, pulling them out of the private domain - where any sales would be likely to occur either within he village or through roaming merchants), and a source of higher living standards (so also empowering women, Extension workee of training and giving them greater control over the quality of their lives).

demonstration plot (or a series participants could learn and sound out any problems would be essential, as would a This would need tor a series of these), to promote the development of kitchen gardens.

transformation of any vegetables and fruited by health and mutrition education to ensure proper preparation and these are destined for household consumption.

\section{$\Rightarrow$ Reforestation:}

- Prioritising Malestan (although Ajarestan, Jaghoori Nawor and Upper Bamiyan would also benefit from such projects), given the problems of flooding, soil erosion and damage to irrigation systems. On the surrounding slopes, at the bottom of the valleys and along the irrigation network in particular;

- This would reduce damage to cultivable land and if properly managed, contribute to meeting fuel needs;

\section{$\Rightarrow$ Subsidised sale of animals, particularly traction animals:}

- Prioritising household type $\mathrm{C}$ for traction animals, as well as household types $\mathrm{E}, \mathrm{F}$ and possibly $\mathrm{G}$ for other animals (cows, female sheep and goats in particular, for dietary reasons), and emphasising Jaghoori in the first instance (given that this area has a dearth of traction animals), and Malestan in the second (given the lack of diversified diets and the food shortages witnessed);

- Such action would need to be complemented by measures to increase the amount of pastureland available (accessibility for non-cultivation purposes being less of a constraint), and perhaps, complemented with a loan system so allowing the population to invest in the livestock and their maintenance (rather than consuming them in the short-term due to the facility of aid), while also increasing the number of families to benefit from this.

\section{Further Research:}

Research might also be done into the following:

$\Rightarrow$ Income generation projects aiming to improve access to food by securing an income for those with limited skills, limited manpower and limited physical assets (particularly land) - all the ingredients for vulnerability in a conflict-ridden and agricultural context. Such a study might look at tool durability and the difference encountered in Jaghoori as a starting point. Were this to prove valuable and feasible, an initial capital injection and training in production methods would not only help those with land but could also be a means of improving the situations of those without - notably household types $\mathrm{G}$, and to a lesser extent $\mathrm{F}$ who also have little or no livestock. The importance of this can only be underlined since most of the above recommendations essentially affect those households with land and/or livestock and largely ignore those with neither;

$\Rightarrow$ A loan system, to increase accessibility of measures undertaken to those households already in crisis financially and only having recourse to loans at $40-100 \%$ interest. HABITAT has already started doing some work on this in Bamiyan Lower Valley; 
Appendices for Part III

Materials and Methods 
Information recorded:

- Date of birth: the date (month and year - taken from vaccination card);

- Age: in months was calculated as accurately as possible with the aid of a Local Calendar of Events $^{75}$, which also converted the local calendar ${ }^{76}$ to the Christian one;

- Sex: recorded as $\mathrm{M} / \mathrm{F}$;

- Weight: in $\mathrm{kg}$, recorded to the nearest $100 \mathrm{~g}$, using a $25 \mathrm{~kg}$ Salter scale, with the child having as little clothes on as possible;

- Height: measured to the nearest $\mathrm{mm}$, children less than $85 \mathrm{~cm}$ were measured lying down, whilst those over $85 \mathrm{~cm}$ were measured standing (children over $110 \mathrm{~cm}$ were excluded, regardless of age as claimed by the mother);

- W/H in \%: calculated from Action contre la faim 'weight for height chart' to check for errors made in measuring and weighing;

- Oedema: absence or presence of bilateral oedema, determined by applying normal thumb pressure on both feet for 3 seconds - if a pit was evident in both feet, then the child was recorded as having oedema;

- MUAC: the Mid Upper Arm Circumference measured in mm, taken on the left arm at relaxed position, midway between the shoulder and elbow;

- Measles vaccination: recorded as 'yes' according to vaccination card (date recorded) or mother's word, or 'no';

- Number of $<5$ years: the number of children under 5 years of age in the family, regardless of whether they were present at the screening or not;

- Number of < 5 years deaths: any children in the family who had died in the last 30 days, recording the sex, age and cause of death (determined by asking the mother the symptoms and consulting a coded guideline);

\footnotetext{
${ }^{75}$ See Appendices for Part III: Appendix VI.

76 This calendar was re-adapted in each area, since varying seasonal and agricultural differences were found according to the region. Local elders and leaders of the community were asked to help with the adaptation.
} 


\section{Diagnosis of cause of death}

1. Diarrhoea: more than 3 watery stools per day;

2. Malaria: episodes of fluctuating high fever, shivering or convulsions with gastro-intestinal problems;

3. Measles: fever associated with red rash, with or without rhino-pharyngitis, conjunctivitis or xeropthalmia;

4. Acute Respiratory Infection (ARI): fever and cough associated with at least one of the following - expectoration; chest pains; dyspnoea (shortness of breath); wheezing;

5. Malnutrition: presence of bilateral oedema and/or emaciation;

6. Typhoid: high fever, severe headache, insomnia, diarrhoea or constipation;

7. Other: detailed description of symptoms;

\section{Definition of the nutritional status of children under 5 years:}

\section{Weight-for-height index}

Acute malnutrition (wasting) was determined using the weight-for-height index as an expression of the nutritional status of the target population. The results were compared to a normal distribution curve of children in a reference population (NCHS data ${ }^{77}$ ). The curve shows the median weight (the weight value separating the population into two groups of equal size) and the standard deviation (SD). The weight-for-height index $(\mathrm{W} / \mathrm{H})$ of any child within the studied population being expressed either as a percentage of the median or as a Z-Score.

The weight-for-height index expressed as a percentage of the median (WHM) measures the difference between the observed weight (OW) and the median weight (MW) of the reference population, for children of the same height:

$$
\mathrm{WHM}=(\mathrm{OW} / \mathrm{MW}) \times 100
$$

The weight-for-height percentage is calculated in order to provide an interpretation of the data. However, a child with a weight-for-height index at $80 \%$ of the median is more malnourished if he is 6 months old than if he is 59 months old for example, since the distribution of weight around the median value varies inversely to the specific age or height of the NCHS reference curves.

The weight-for-height index expressed as a Z-Score (WHZ) compares the observed weight (OW) of the child surveyed to the mean weight (MW - for the same height) of the reference population (NCHS data). The standard deviation (SD) of the reference population curve is used as a unit of measurement:

$$
\mathrm{WHZ}=\frac{(\mathrm{OW}-\mathrm{MW})}{\mathrm{SD}}
$$

\footnotetext{
${ }^{77}$ National centre for Health Statistics (1977): NCHS growth curves for children, birth - 18 years, United States. Vital Health Statistics. 165, 11-74.
} 
The Z-Score expresses the probability of observing a similar nutritional status amongst the reference population. Since it is based on the mean weight and standard deviation of the normal distribution curve, the Z-Score provides a description of severe malnutrition with a higher statistical value by extrapolation. All the children in the survey were included in this calculation (0-59 months)

Acute malnutrition according to the weight-for-height index expressed as a Z-Score or a percentage of the median is defined as:

\begin{tabular}{lcc}
\hline MALNUTRITION & Z-Score & $\%$ of the median \\
\hline Normal & W/H $\geq-$ 2SD & W/H $\geq 80 \%$ \\
Moderately malnourished & - 3SD $\leq$ W/H $<-$ 2SD & $70 \% \leq W / H<80 \%$ \\
Severely malnourished & W/H $<$ - 3SD & W/H $<70 \%$ \\
\hline
\end{tabular}

\section{Bilateral oedema}

Bilateral oedema is a sign of kwashiorkor, one of the main forms of severe acute malnutrition. Children with bilateral oedema are automatically classified as being severely malnourished, regardless of their weight-for-height percentage.

\section{Height-for-age index}

The height-for-age (H/A) index indicates whether a child of a certain given height is stunted, but does not differentiate between two children of the same age and height with regard to their weight. The past nutritional state of the child is indicated using this index by identifying stunting (chronic malnutrition). By taking the reference population (NCHS data), it is possible to draw a distribution curve of the height of children of a given age. Only children aged 6-59 months were included in this calculation. The height-for-age index of a child, indicating stunting, is expressed as a Z-Score (HAZ) or the percentage of the median:

\begin{tabular}{lcc}
\hline STUNTING & Z-Score & $\%$ of the median \\
\hline Normal & H/A $\geq-2$ SD & H $/ \mathrm{A} \geq 90 \%$ \\
Moderately stunted & - 3SD $\leq$ H/A $<-$ 2SD & $80 \% \leq \mathrm{H} / \mathrm{A}<90 \%$ \\
Severely stunted & $\mathrm{H} / \mathrm{A}<-$ 3SD & $\mathrm{H} / \mathrm{A}<80 \%$ \\
\hline
\end{tabular}




\section{Mid Upper Arm Circumference (MUAC)}

The mid upper arm circumference changes very little between the ages of 12-59 months (75-1 10 $\mathrm{cm})$. It stands alone as being the only unit of measurement that is of some value on its own. It does not need to be related to any other anthropometric measurement. It is used to identify children with a risk of high mortality, since a decreasing MUAC correlates to an increase in the risk of mortality. The cut off values vary according to different schools of thought. The following were the figures used for this survey:

\begin{tabular}{lccc}
\hline MUAC & MUAC $<110 \mathrm{~cm}$ & $110 \mathrm{~cm} \leq$ MUAC $<120 \mathrm{~cm}$ & $120 \mathrm{~cm} \leq$ MUAC \\
\hline Risk & High & Moderate & Low \\
\hline
\end{tabular}

All children in the survey were measured for MUAC. However, only children above 1 year or $\geq$ $75 \mathrm{~cm}$ were considered for risk of mortality.

\section{Mortality rate:}

The assessment of the mortality rate is a good indicator of the health situation within a given population. The Crude Mortality Rate (CMR) is calculated per 10,000 people per day over a 30 day period:

$$
\begin{aligned}
& \mathrm{n}=\text { the number of }<5 \text { years deaths within the last } 30 \text { days } \\
& \mathrm{N}=\text { the number of }<5 \text { years alive on the day of the survey }
\end{aligned}
$$

$$
\mathbf{C M R}=\mathrm{n} /[((\mathrm{n}+\mathrm{N})+\mathrm{N})) / 2]
$$

Mortality Rate $=$ CMR x 10,000/30 days

The cut off points ${ }^{78}$ for the mortality rate amongst children aged 0-59 months are:

- A mortality rate of $2 / 10,000$ children per day is defined as being alarming

- A mortality rate of $4 / 10,000$ children per day is defined as being an emergency situation

\footnotetext{
${ }^{78}$ Health and nutrition information systems among refugees and displaced persons, Workshop report on refugees' nutrition, ACC/SCN, Nov. 95.
} 
Appendix II: Names of Villages Screened

\begin{tabular}{|l|l|}
\hline Ajarestan & Arral \\
& Khoshal Khil \\
& Nomads (Koutchis) \\
\hline Bamiyan Upper Valley & Jawkar \\
& Kamati \\
& Qala-i Ali Beg \\
& Syalayac \\
\hline Jaghoori & Ambulogh \\
& Jowdari \\
& Khwajali \\
& Pashtana \\
& Qondol Qash \\
& Sabz Choob \\
& Tabarghanak Mirdad \\
\hline Malestan & Dahan Boom \\
& Jambot \\
& Kharzar \\
& Korsang \\
& Nawdeh \\
& Qol Adam \\
& Qoshnak \\
& Sabzak \\
& Wali \\
\hline Nawor & Amro \\
& Bakhti \\
& Ghoreh Bayee \\
& Khawat \\
& Kohnaday \\
& Qarcha \\
& Qargeh Balah \\
\hline
\end{tabular}




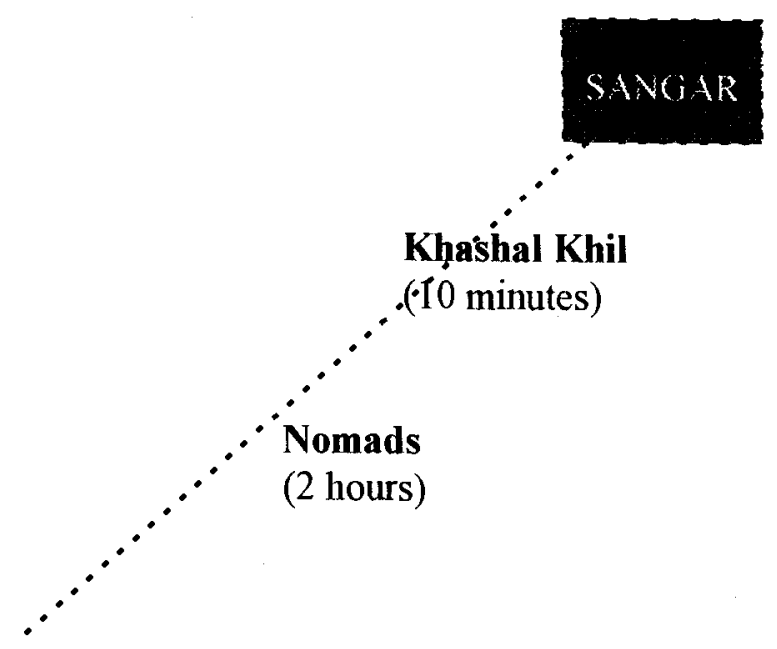

Arral (31/2 hours)

\section{BAMIYAN UPPER VALLEY:}

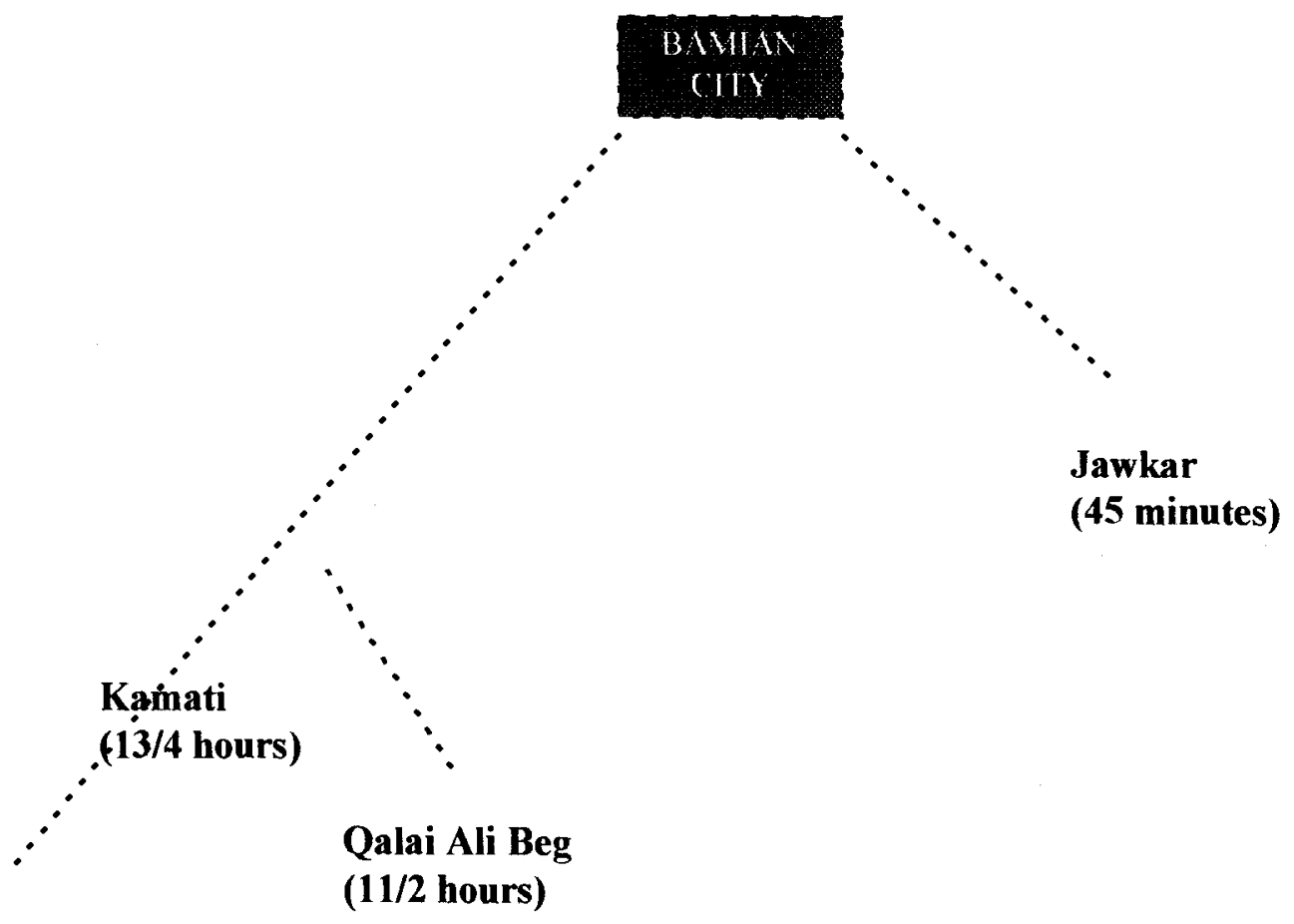

Syalayac

(2 hours) 


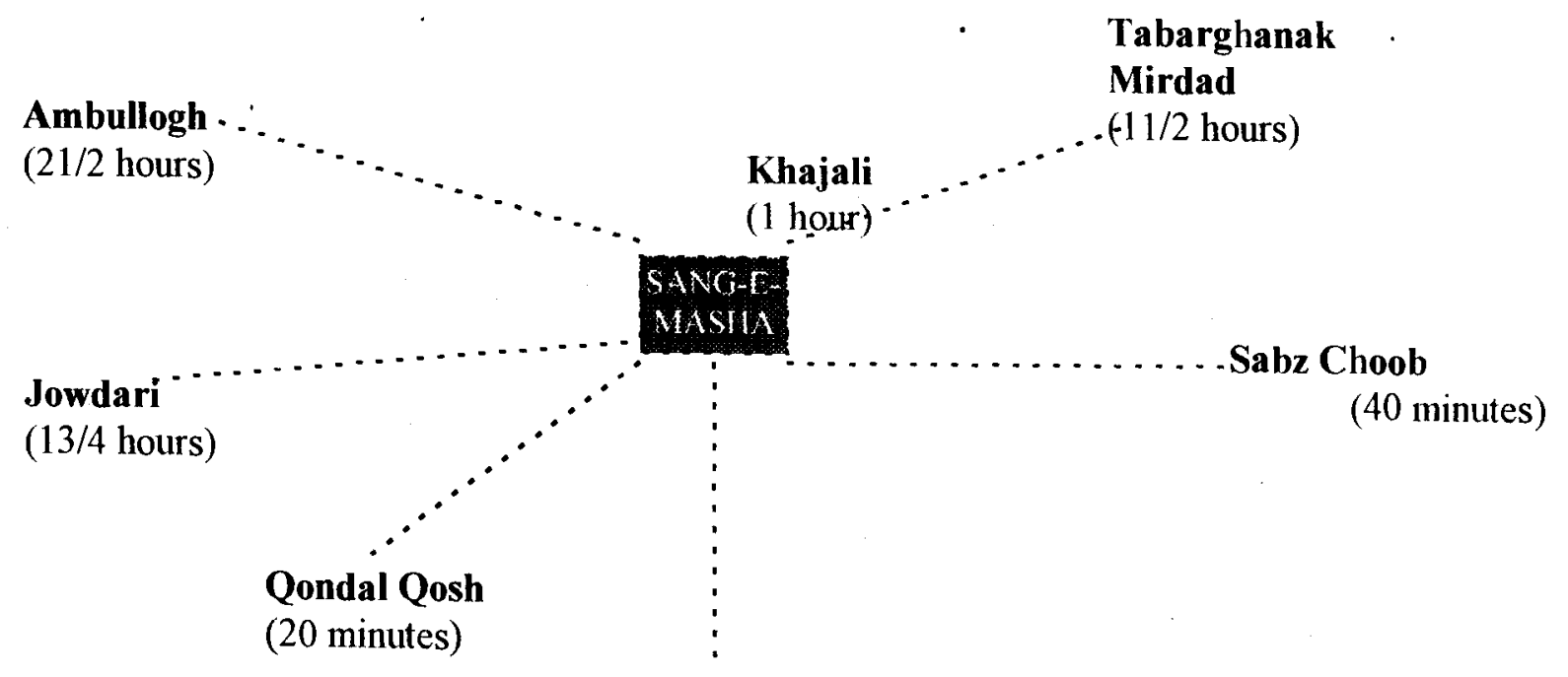

Pashtaneh

(1/2 hour)

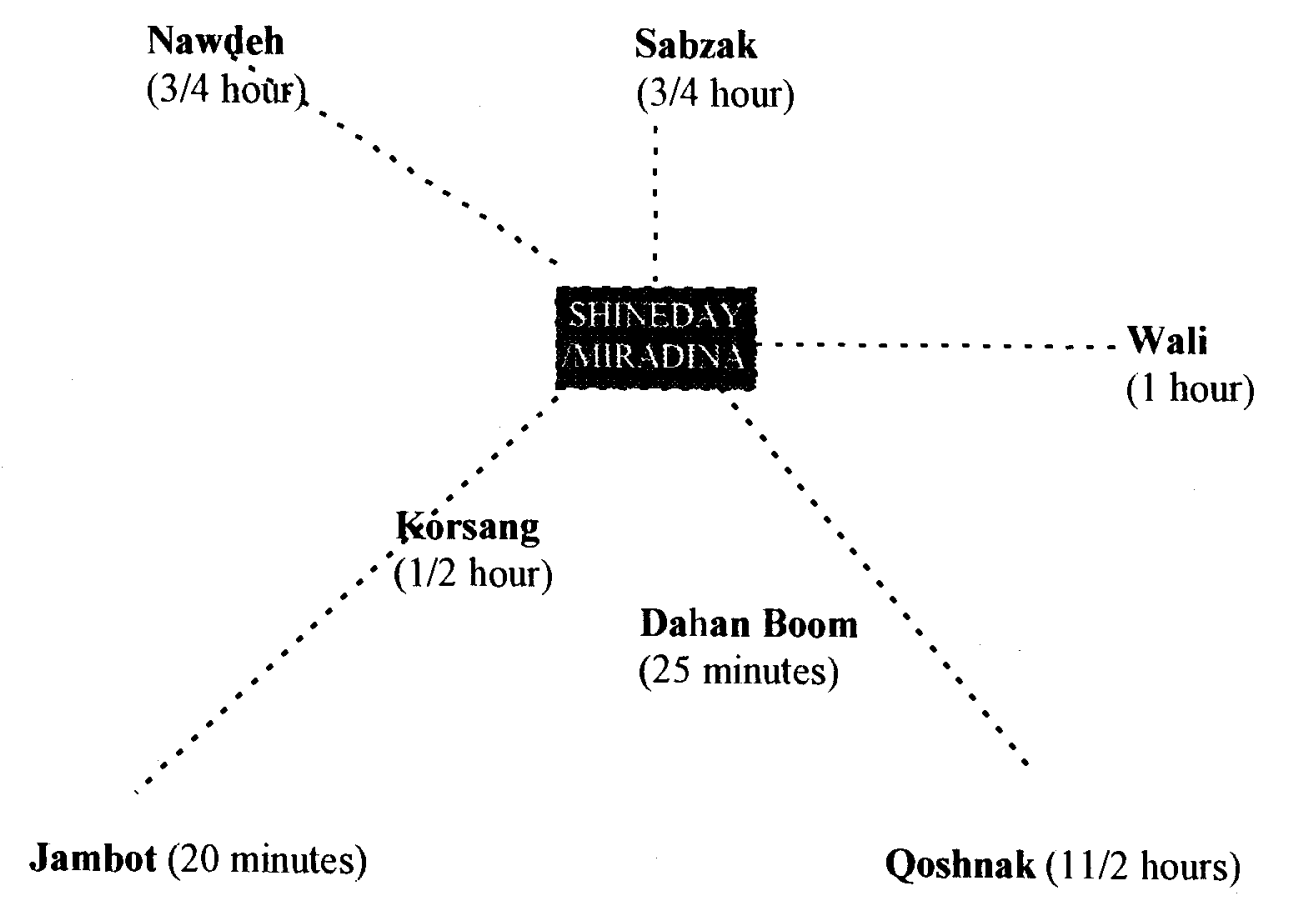




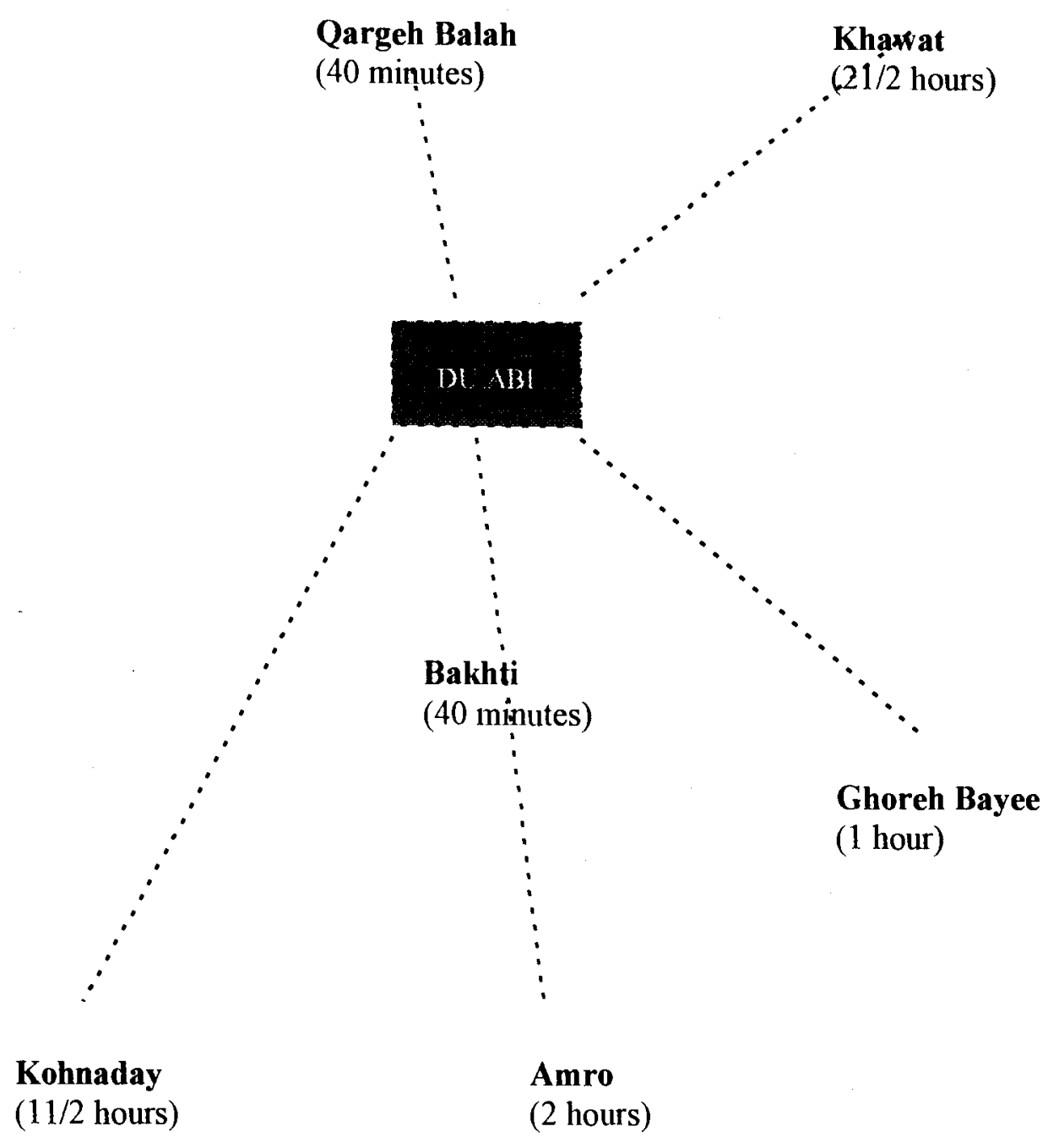




\section{Appendix IV: Data Collection Sheet}

HAZARAJAT ANTHROPOMETRIC SURVEY - VILLAGES

Date: Team number: Village:

INCLUSION DATES: from

(July/August 1993) to

(June/July 1998)

\begin{tabular}{|c|c|c|c|c|c|c|c|c|c|c|c|c|c|}
\hline उB & $\begin{array}{c}\text { AGE } \\
\text { months }\end{array}$ & $\begin{array}{l}\text { SEX } \\
\text { M/F }\end{array}$ & $\begin{array}{c}\text { WEIGHT } \\
\mathrm{Kg}\end{array}$ & $\begin{array}{l}\text { IIEIGHT } \\
\mathrm{cm}\end{array}$ & $\begin{array}{c}\text { W/H } \\
\%\end{array}$ & $\begin{array}{l}\text { OEDEMA } \\
\text { Y/N }\end{array}$ & $\begin{array}{c}\text { MUAC } \\
\mathrm{cm}\end{array}$ & $\begin{array}{l}\text { MEASLES } \\
\text { VACCS.? } \\
\text { date from } \\
\text { vaccs. card }\end{array}$ & $\begin{array}{l}\text { No. of } \\
<5 y r s \text { in } \\
\text { family }\end{array}$ & \begin{tabular}{|l|}
$\begin{array}{l}\text { No. of } \\
<5 y r s \\
\text { deaths in } \\
\text { the last } \\
\text { month }\end{array}$ \\
\end{tabular} & $\begin{array}{l}\text { SEX } \\
M / F\end{array}$ & $\begin{array}{c}\text { AGE } \\
\text { months }\end{array}$ & CAUSE \\
\hline & & & & & & & & & & & & & \\
\hline & & & & & & & & & & & & & \\
\hline & & & & & & & & & & & & & \\
\hline & & & & & & & & & & & & & \\
\hline & & & & & & & & & & & & & \\
\hline & & & & & & & & & & & & & \\
\hline & & & & & & & & & & & & & \\
\hline & & & & & & & & & & & & & \\
\hline & & & & & & & & & & & & & \\
\hline & & & & & & & & & & & & & \\
\hline & & & & & & & & & & & & & \\
\hline & & & & & & & & & & & & & \\
\hline & & & & & & & & & & & & & \\
\hline & & & & & & & & & & & & & \\
\hline & & & & & & & & & & & & & \\
\hline & & & & & & & & & & & & & \\
\hline & & & & & & & & & & & & & \\
\hline & & & & & & & & & & & & & \\
\hline & & & & & & & & & & & & & \\
\hline & & & & & & & & & & & & & \\
\hline & & & & & & & & & & & & & \\
\hline & & & & & & & & & & & & & \\
\hline & & & & & & & & & & & & & \\
\hline & & & & & & & & & & & & & \\
\hline & & & & & & & & & & & & & \\
\hline & & & & & & & & & & & & & \\
\hline
\end{tabular}

CAUSE OF DEATH:
1. Diarrhoea
2. Malaria
3. Measles
4. Acute Respiratory Infection
5. Malnutrition
6. Typhoid
7. Other (specify) 
Appendix V: Description of Villages

AJARESTAN:

Name of village: ARRAL

\begin{tabular}{|c|c|c|c|c|c|c|c|c|c|}
\hline \multirow{3}{*}{$\begin{array}{l}\text { General } \\
\text { information }\end{array}$} & \multirow[t]{2}{*}{ Houses } & \multicolumn{3}{|c|}{ Families } & \multirow[t]{2}{*}{ People } & \multirow[t]{2}{*}{$<5$ years } & \multicolumn{3}{|c|}{ Water sources } \\
\hline & & Total & IDPs & From where & & & Kind of & Who & Quantity \\
\hline & 10 & 23 & 7 & $\begin{array}{c}\text { Danghalori } \\
\text { Chackmak } \\
\text { Sangar } \\
\end{array}$ & 179 & 35 & $\begin{array}{l}\text { spring } \\
\text { river }\end{array}$ & men & $\begin{array}{c}6 \text { buckets/day } / 9 \\
\text { people }\end{array}$ \\
\hline \multirow[t]{2}{*}{ Education } & Nearest school & \multicolumn{3}{|c|}{ Qu'ranic school } & \multicolumn{3}{|c|}{ Shopping town } & \multicolumn{2}{|c|}{ Frequency of travel } \\
\hline & None & \multicolumn{3}{|c|}{ Yes } & \multirow{2}{*}{\multicolumn{2}{|c|}{$\begin{array}{r}\text { Sangar } \\
\text { edicine \& TBAs }\end{array}$}} & & \multicolumn{2}{|c|}{20 times per year } \\
\hline \multirow[t]{2}{*}{ Health } & Clinic & \multicolumn{2}{|c|}{ Vaccination } & Trad. medicine \& TBAs & & & \multicolumn{3}{|c|}{ Most common diseases } \\
\hline & $\begin{array}{l}\text { none, private } \\
\text { pharmacy in } \\
\text { Sangar - } 5 \\
\text { hours walk }\end{array}$ & \multicolumn{2}{|c|}{$\begin{array}{l}\text { With } \\
\text { previous } \\
\text { government } \\
\text { Last visit: } 7 \\
\text { years ago }\end{array}$} & \multicolumn{3}{|c|}{$\begin{array}{l}\text { There are no TBAs, but the women } \\
\text { help each other. Birthing takes place } \\
\text { on the ground where some dust is } \\
\text { placed and there are many deaths due } \\
\text { to tetanus. } 5-6 / 10 \text { babies are thought } \\
\text { to die, due to tetanus, LBW and being } \\
\text { 'floppy'. There are many LBW } \\
\text { babies, most because they are born } \\
\text { prematurely - } 4 \text { babies died for this } \\
\text { reason, so far this year (in } 6 \text { months). } \\
\text { There seems to be no reason, } \\
\text { according to the village, why there are } \\
\text { so many LBW babies, but they say } \\
\text { that women do tend to give birth } 1-2 \\
\text { months early. } 1-2 / 10 \text { women die in } \\
\text { labour due to haemorrhaging. Others } \\
\text { can be healthy during delivery and } \\
\text { then suddenly die } 3 \text { days later. }\end{array}$} & \multicolumn{3}{|c|}{$\begin{array}{l}\text { ADULTS: } 1 \text { TB; malaria; } \\
\text { rheumatism; tonsillitis; dental } \\
\text { problems; hepatitis } \\
\text { CHILDREN: measles; eye } \\
\text { problems; nocturnal itching; } \\
\text { malnutrition, particularly after } 1 \\
\text { year of age } \\
\text { GOITRE: } \\
\text { NIGHT BLINDNESS: 15, } \\
\text { particularly men }\end{array}$} \\
\hline \multirow[t]{3}{*}{ Nutrition } & \multicolumn{6}{|c|}{ Breast feeding } & \multicolumn{3}{|c|}{ Weaning } \\
\hline & Start & \multicolumn{4}{|c|}{ Cessation during pregnancy } & Length & \multicolumn{2}{|c|}{ Time } & Weaning food \\
\hline & immediately & \multicolumn{4}{|c|}{$\begin{array}{l}\text { depends on development of child - } \\
\text { can be straight away up to } 3 \text { months } \\
\text { after finding out, whilst others } \\
\text { continue to end of pregnancy. }\end{array}$} & 2 years & $\begin{array}{l}\text { up to } 1 \\
\text { have } \\
\text { milk }\end{array}$ & $\begin{array}{l}\text { year, if } \\
\text { enough }\end{array}$ & butter; dried milk \\
\hline
\end{tabular}

CHANGE IN LIFE WITH THE BLOCKADE: have had to sell livestock, borrow and send elder sons to work abroad, in order to survive. Food is available in the market, but is simply not accessible due to price. However, despite all this, life has improved for them compared to 3 years ago, when the opposition were here, although health problems are worse, as there are no facilities.

\begin{tabular}{|l|l|l|}
\hline DIET & AFTER BLOCKADE: & BEFORE BLOCKADE: same diet, \\
& BREAKFAST: tea; bread \\
& LUNCH: tea; bread; doughe \\
& DINNER: greens; rice; MEAT: $1 / 30$ & \\
\hline
\end{tabular}

COMMENTS: 2 years ago some NGOs came and distributed seeds, tools and flour. The distribution was not very fair and much ended up in the market. There has been a lot of soil erosion and crops have been ruined. They get no help from the Talêban - who came to build a mosque and ran out of finances half way through and now the village has a half built mosque which they cannot afford to complete. There are no drugs available for them, their livestock or their crops and their irrigation systems are failing as they cannot afford to fix them. Their crops yield about 2-3 months supply of food and the deficit has to be bought in Sangar. There are a lot of dental problems and no dentist, so work is carried out by the villagers, resulting in many infections leading to death. Around 5 people a year die from a tooth infection, where their neck and face swells, they can't breathe and die. 
Name of village: KHOSHAL KHIL

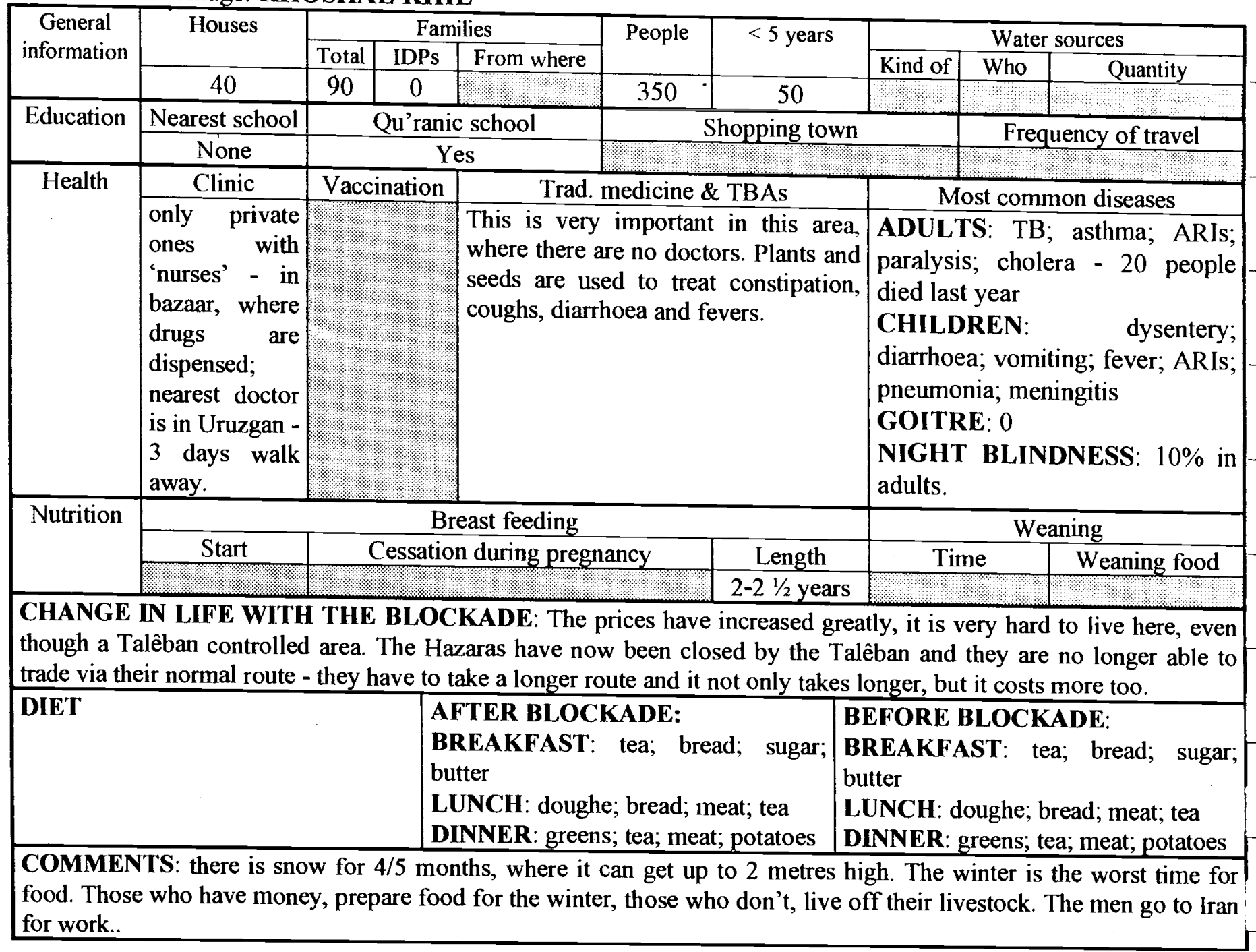


Name of village: nomads, from KALANDAR KHIR

\begin{tabular}{|c|c|c|c|c|c|c|c|c|}
\hline \multirow{3}{*}{$\begin{array}{c}\text { General } \\
\text { information }\end{array}$} & \multirow[t]{2}{*}{ Houses } & \multicolumn{2}{|c|}{ Families } & \multirow[t]{2}{*}{ People } & \multirow[t]{2}{*}{$<5$ years } & \multicolumn{3}{|c|}{ Water sources } \\
\hline & & Total & From where & & & Kind of & Who & Quantity \\
\hline & 8 & 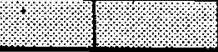 & 2. & & 1.8 & & & $2=$ \\
\hline \multirow[t]{2}{*}{ Education } & Nearest school & \multicolumn{2}{|c|}{ Qu'ranic school } & \multicolumn{3}{|c|}{ Shopping town } & \multicolumn{2}{|c|}{ Frequency of travel } \\
\hline & 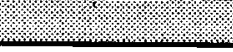 & \multicolumn{2}{|c|}{ 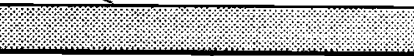 } & \multirow{2}{*}{\multicolumn{2}{|c|}{$\begin{array}{r}\text { Sangar } \\
\text { nedicine \& TBAs }\end{array}$}} & & \multicolumn{2}{|c|}{ 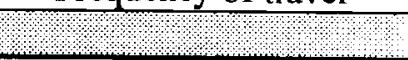 } \\
\hline \multirow[t]{2}{*}{ Health } & Clinic & Vaccination & Trad. medicine \& TBAs & & & \multicolumn{3}{|c|}{ Most common diseases } \\
\hline & $\begin{array}{l}\text { Use private } \\
\text { 'clinics', but if } \\
\text { serious } \\
\text { problem, go to } \\
\text { Miridineh } \\
\text { (Malestan), } \\
\text { Pakistan or } \\
\text { Uruzgan }\end{array}$ & $\begin{array}{l}\text { None, since } \\
4 \text { years ago }\end{array}$ & \multicolumn{3}{|c|}{ Practised. } & \multicolumn{3}{|c|}{$\begin{array}{l}\text { ADULTS: TB; malaria; fever; } \\
\text { diarrhoea; vomiting; cholera; } \\
\text { dysentery; tonsillitis; laryngitis } \\
\text { CHILDREN: colds; sun stroke; } \\
\text { diarrhoea; vomiting } \\
\text { GOITRE: } 20 \% \\
\text { NIGHT BLINDNESS: } 30 \%\end{array}$} \\
\hline \multirow[t]{3}{*}{ Nutrition } & \multicolumn{5}{|c|}{ Breast feeding } & \multicolumn{3}{|c|}{ Weaning } \\
\hline & Start & \multirow{2}{*}{\multicolumn{3}{|c|}{$\begin{array}{l}\text { Cessation during pregniancy } \\
\text { Immediately upon finding out }\end{array}$}} & Length & \multirow{2}{*}{\multicolumn{2}{|c|}{$\frac{\text { Time }}{1 \text { year }}$}} & Weaning food \\
\hline & & & & & $2-3$ years & & & $\begin{array}{l}\text { Same as adult } \\
\text { food }\end{array}$ \\
\hline
\end{tabular}

CHANGE IN LIFE WITH THE BLOCKADE: These are self sufficient people, who need only buy products such as sugar and tea. Life for them is really no different now to how it used to be. Livestock and wheat are sold in order to buy other goods.

\begin{tabular}{|l|l|l|}
\hline DIET & $\begin{array}{l}\text { AFTER BLOCKADE: } \\
\text { BREAKFAST: tea; bread; yoghurt; } \\
\text { sugar } \\
\text { LUNCH: bread; yoghurt; milk; } \\
\text { doughe } \\
\text { DINNER: bread; yoghurt; milk; } \\
\text { doughe; butter; meat } \\
\text { MEAT: 15/30. }\end{array}$ \\
\hline $\begin{array}{l}\text { COMME. } \\
\text { cultivate. They rent the land off landowners from Qher Qhera, Kharzarjil and Ali Jah, who own land here and use it to } \\
\text { cultivate wheat and provide grazing for their livestock. They travel in packs or alone, depending on their situation. } \\
\text { Some own shops in Pakistan and therefore have an additional income from there. }\end{array}$ \\
\hline
\end{tabular}




\section{BAMIYAN:}

Name of village: JAWKAR

\begin{tabular}{|c|c|c|c|c|c|c|c|c|c|}
\hline \multirow{3}{*}{$\begin{array}{c}\text { General } \\
\text { information }\end{array}$} & \multirow[t]{2}{*}{ Houses } & \multicolumn{3}{|c|}{ Families } & \multirow[t]{2}{*}{ People } & \multirow[t]{2}{*}{$<5$ years } & \multicolumn{3}{|c|}{ Water sources } \\
\hline & & Total & IDPs & From where & & & Kind of & Who & Quantity \\
\hline & 20 & 40 & 2. & & 220 & 50 & & & \\
\hline \multirow[t]{2}{*}{ Health } & Clinic & Vacci & nation & \multicolumn{3}{|c|}{ Trad. medicine \& TBAs } & \multicolumn{3}{|c|}{ Most common diseases } \\
\hline & $\begin{array}{l}2 \text { hours by } \\
\text { foot, small } \\
\text { fee, have to } \\
\text { buy own } \\
\text { drugs. }\end{array}$ & $\begin{array}{l}\text { Yes; } \\
\text { Mobil } \\
\text { comes } \\
\text { yearly. }\end{array}$ & team & & Practised & & & & \\
\hline
\end{tabular}

Name of village: KAMATI

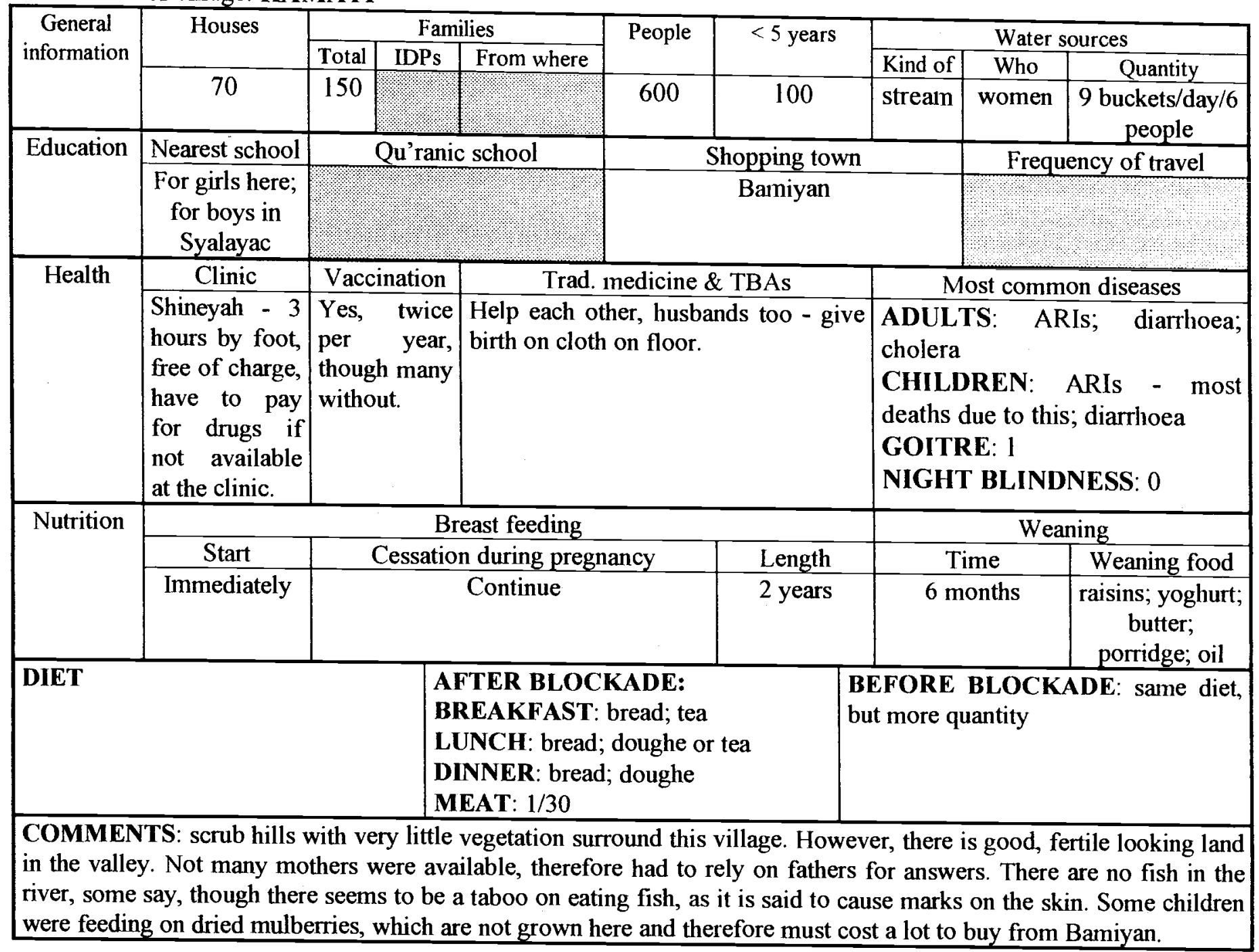


Name of village: QALA-I ALI BEG

\begin{tabular}{|c|c|c|c|c|c|c|c|c|c|}
\hline \multirow{3}{*}{$\begin{array}{c}\text { General } \\
\text { information }\end{array}$} & \multirow[t]{2}{*}{ Houses } & \multicolumn{3}{|c|}{ Families } & \multirow[t]{2}{*}{ People } & \multirow[t]{2}{*}{$<5$ years } & \multicolumn{3}{|c|}{ Water sources } \\
\hline & & Total & IDPs & From where & & & Kind of & Who & Quantity \\
\hline & 40 & 80 & Yes & Mazar & 300 & 60 & stream & women & $\begin{array}{c}7 \text { buckets/day } / 6 \\
\text { people }\end{array}$ \\
\hline \multirow[t]{2}{*}{ Health } & Clinic & \multicolumn{2}{|c|}{ Vaccination } & \multicolumn{3}{|c|}{ Trad. medicine \& TBAs } & \multicolumn{3}{|c|}{ Most common diseases } \\
\hline & $\begin{array}{l}\text { Pharmacy }-2 \\
\text { hours walk, } \\
\text { very } \\
\text { expensive; } \\
\text { Siniyah }-3 \\
\text { hours by foot; } \\
\text { drugs can cost } \\
15,000 \text { for } 5 \\
\text { pills }\end{array}$ & $\begin{array}{l}\text { Yes, } \\
\text { month } \\
\text { come } \\
\text { times } \\
\text { year. }\end{array}$ & $\begin{array}{r}\text { last } \\
- \\
3 \\
\text { per }\end{array}$ & \multicolumn{3}{|c|}{$\begin{array}{l}\text { Yoghurt, for treatment of diarrhoea; } \\
\text { TBAs: one, who has gifts for he } \\
\text { services. }\end{array}$} & \multicolumn{3}{|c|}{$\begin{array}{l}\text { ADULTS: diarrhoea; blindness } \\
\text { bronchitis } \\
\text { CHILDREN: } \\
\text { vomiting; coughs; bronchitis } \\
\text { deaths due to ARIs; measles } \\
\text { though reduced } \\
\text { vaccinations started } \\
\text { GOITRE: } 3 \\
\text { NIGHT BLINDNESS: some }\end{array}$} \\
\hline \multirow[t]{3}{*}{ Nutrition } & \multicolumn{6}{|c|}{ Breast feeding } & \multicolumn{3}{|c|}{ Weaning } \\
\hline & Start & & essatio & n during preg & ancy & Length & & ime & Weaning food \\
\hline & Immediately & Dor & ot stop & until new-bor & arrives. & $11 / 2-2$ year & $6 \mathrm{~m}$ & onths & $\begin{array}{l}\text { boiled water; } \\
\text { bread; milk; oil }\end{array}$ \\
\hline \multicolumn{2}{|l|}{ DIET } & & \multicolumn{4}{|c|}{$\begin{array}{l}\text { AFTER BLOCKADE: } \\
\text { BREAKFAST: bread; boiled water } \\
\text { LUNCH: bread (made from broad } \\
\text { bean flour); barley; boiled water } \\
\text { DINNER: oil - if available; potatoes; } \\
\text { bread; doughe - if available } \\
\text { MEAT: if animal dies - share with } \\
\text { neighbours and vice versa }\end{array}$} & \multicolumn{3}{|c|}{$\begin{array}{l}\text { BEFORE BLOCKADE: same diet, } \\
\text { but more quantity }\end{array}$} \\
\hline
\end{tabular}

Name of village: SYALAYAC

\begin{tabular}{|c|c|c|c|c|c|c|c|c|c|}
\hline \multirow{3}{*}{$\begin{array}{c}\text { General } \\
\text { information }\end{array}$} & \multirow[t]{2}{*}{ Houses } & \multicolumn{3}{|c|}{ Families } & \multirow[t]{2}{*}{ People } & \multirow[t]{2}{*}{$<5$ years } & \multicolumn{3}{|c|}{ Water sources } \\
\hline & & Total & IDPs & From where & & & Kind of & Who & Quantity \\
\hline & 50 & 60 & & 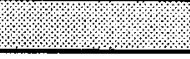 & 300 & 55 & & & \\
\hline \multirow[t]{2}{*}{ Health } & Clinic & \multicolumn{2}{|c|}{ Vaccination } & \multicolumn{3}{|c|}{ Trad. medicine \& TBAs } & \multicolumn{3}{|c|}{ Most common diseases } \\
\hline & $\begin{array}{l}\text { Have own } \\
\text { 'nurse', who is } \\
\text { self taught and } \\
\text { not educated - } \\
\text { gives } \\
\text { injections; } \\
\text { Shineyah - } 3 \\
\text { hours away }\end{array}$ & & & \multicolumn{3}{|c|}{ 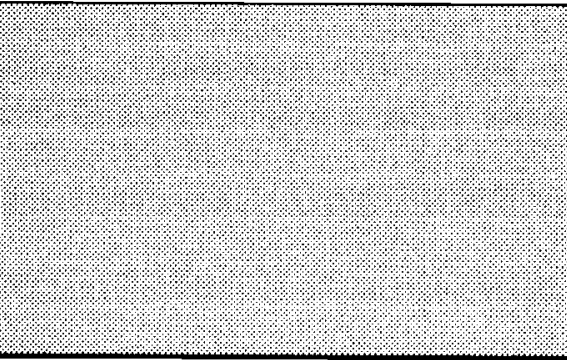 } & \\
\hline \multirow[t]{3}{*}{ Nutrition } & \multicolumn{6}{|c|}{ Breast feeding } & \multicolumn{3}{|c|}{ Weaning } \\
\hline & Start & \multicolumn{4}{|c|}{ Cessation during pregnancy } & Length & \multicolumn{2}{|c|}{ Time } & Weaning food \\
\hline & 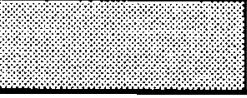 & \multicolumn{4}{|c|}{$\begin{array}{c}\text { Stop the older one as soon as give } \\
\text { birth }\end{array}$} & & & & \\
\hline
\end{tabular}




\section{JAGHOORI:}

Name of village: AMBULOGH

\begin{tabular}{|c|c|c|c|c|c|c|c|c|c|}
\hline \multirow{3}{*}{$\begin{array}{l}\text { General } \\
\text { information }\end{array}$} & \multirow[t]{2}{*}{ Houses } & \multicolumn{3}{|c|}{ Families } & \multirow[t]{2}{*}{ People } & \multirow[t]{2}{*}{$<5$ years } & \multicolumn{3}{|c|}{ Water sources } \\
\hline & & Total & \multirow{2}{*}{$\frac{\text { IDPs }}{2}$} & \multirow{2}{*}{ From where } & & & Kind of & Who & Quantity \\
\hline & 40 & 100 & & & 400 & 70 & & 4 & \\
\hline \multirow[t]{2}{*}{ Education } & Nearest school & \multicolumn{3}{|c|}{ Qu'ranic school } & \multicolumn{3}{|c|}{ Shopping town } & \multicolumn{2}{|c|}{ Frequency of travel } \\
\hline & $\begin{array}{r}\text { Hediat }-2 \\
\text { hours walk } \\
\end{array}$ & \multicolumn{3}{|c|}{ Yes } & & & & & \\
\hline \multirow[t]{2}{*}{ Health } & Clinic & \multicolumn{2}{|c|}{ Vaccination } & \multicolumn{3}{|c|}{ Trad. medicine \& TBAs } & \multicolumn{3}{|c|}{ Most common diseases } \\
\hline & $\begin{array}{l}\text { LEPCO - 1 } \\
\text { hour away; } \\
\text { Mazar Bibi - } \\
25 \text { minutes - } \\
10,000 \\
\text { Afghanis } \\
\text { consultation } \\
\text { fee, free drugs }\end{array}$ & & & & & & $\begin{array}{l}\text { ADUL' } \\
\text { CHILD } \\
\text { coughs; } \\
\text { GOITR } \\
\text { NIGHT } \\
\text { little. }\end{array}$ & $\begin{array}{l}\text { S: arth } \\
\text { REN: } \\
\text { diarrho } \\
\text { E: } 5 \% \\
\text { BLI }\end{array}$ & $\begin{array}{l}\text { ritis } \\
\text { mpetigo; measles; } \\
\text { ea } \\
\text { NDNESS: very }\end{array}$ \\
\hline \multicolumn{10}{|c|}{$\begin{array}{l}\text { CHANGE IN LIFE WITH THE BLOCKADE: all are very hungry, even the Mullah now has half of what he used to } \\
\text { have. Many go to Pakistan/Iran for work, but could not afford to this year. Salaries have halved and prices have } \\
\text { doubled. }\end{array}$} \\
\hline DIET & & & \multicolumn{4}{|c|}{$\begin{array}{l}\text { AFTER BLOCKADE: } \\
\text { BREAKFAST: tea; bread } \\
\text { LUNCH: tea; bread } \\
\text { DINNER: tea; bread; doughe - if } \\
\text { available } \\
\text { MEAT: } 1 / 30\end{array}$} & \multicolumn{3}{|c|}{$\begin{array}{l}\text { BEFORE BLOCKADE: } \\
\text { BREAKFAST: tea; bread } \\
\text { LUNCH: tea; bread } \\
\text { DINNER: daal; meat; rice } \\
\text { MEAT: } 1 / 10\end{array}$} \\
\hline \multicolumn{10}{|c|}{$\begin{array}{l}\text { COMMENTS: this village is only } 4 \text { hours walk from Talêban territory. Shopping is d } \\
\text { seized. It is situated in a valley, between tall mountains. }\end{array}$} \\
\hline
\end{tabular}

Name of village: JOWDARI

\begin{tabular}{|c|c|c|c|c|c|c|c|c|c|}
\hline \multirow{3}{*}{$\begin{array}{l}\text { General } \\
\text { information }\end{array}$} & \multirow[t]{2}{*}{ Houses } & \multicolumn{3}{|c|}{ Families } & \multirow[t]{2}{*}{ People } & \multirow[t]{2}{*}{$<5$ years } & \multicolumn{3}{|c|}{ Water sources } \\
\hline & & Total & IDPs & From & & & Kind of & Who & Quantity \\
\hline & 105 & 120 & No & & 600 & 100 & $\begin{array}{l}\text { spring } \\
\text { river }\end{array}$ & men & $\begin{array}{c}6 \text { buckets/day } / 9 \\
\text { people }\end{array}$ \\
\hline \multirow[t]{2}{*}{ Education } & Nearest school & \multicolumn{3}{|c|}{ Qu'ranic school } & \multicolumn{3}{|c|}{ Shopping town } & \multicolumn{2}{|c|}{ Frequency of travel } \\
\hline & $\begin{array}{l}\text { Sang-e-Masha, } \\
1 \text { hour away }\end{array}$ & \multicolumn{3}{|c|}{ Yes } & & & & & \\
\hline \multirow[t]{2}{*}{ Health } & Clinic & \multicolumn{2}{|c|}{ Vaccination } & \multicolumn{3}{|c|}{ Trad medicine \& TBAs } & \multicolumn{3}{|c|}{ Most common diseases } \\
\hline & $\begin{array}{l}\text { Sang-e-Masha, } \\
1 \text { hour away }\end{array}$ & \multicolumn{2}{|c|}{$\begin{array}{l}\text { With previous } \\
\text { government } \\
\text { Last visit: } 7 \\
\text { years ago }\end{array}$} & \multicolumn{3}{|c|}{$\begin{array}{l}\text { None, help each other and give } \\
\text { birth on cloth. }\end{array}$} & \multicolumn{3}{|c|}{$\begin{array}{l}\text { ADULTS: typhoid; hypertension; } \\
\text { fever } \\
\text { CHILDREN: impetigo; diarrhoea } \\
\text { GOITRE: 15, mostly in women } \\
\text { NIGHT BLINDNESS: little } \\
\end{array}$} \\
\hline \multirow[t]{3}{*}{ Nutrition } & \multicolumn{6}{|c|}{ Breast feeding } & \multicolumn{3}{|c|}{ Weaning } \\
\hline & Start & \multicolumn{4}{|c|}{ Cessation during pregnancy } & Length & \multicolumn{2}{|c|}{ Time } & Weaning food \\
\hline & Immediate y & \multicolumn{4}{|c|}{$\begin{array}{l}3 \text { months after finding out } \\
\text { they are pregnant. }\end{array}$} & $\begin{array}{l}\text { Boys: } 2 \text { years, } \\
\text { Girls: } 1 \text { 1/2 yr. }\end{array}$ & & & \\
\hline
\end{tabular}


CHANGE IN LIFE WITH THE BLOCKADE: expense - before the blockade had enough money to save up for up to 10 years, now have to spend for the 'here and now'. What was consumed in cash in 10 years is now used up in 2 years - what cost 5 Lacks, now costs 20 Lacks.

\begin{tabular}{|l|l|l|}
\hline DIET & AFTER BLOCKADE: & BEFORE BLOCKADE: \\
& BREAKFAST: tea; bread & BREAKFAST: eggs; milk; tea; bread; \\
& LUNCH: tea; bread; doughe & Sugar \\
& DINNER: tea; bread; 1/7 mung & LUNCH: rice; meat; potatoes \\
& beans; 1/7 potatoes; oil if & DINNER: rice; meat; potatoes \\
& available; greens - boiled in & MEAT: often \\
& water & \\
& MEAT: very rare &
\end{tabular}

Name of village: KHWAJALI

\begin{tabular}{|c|c|c|c|c|c|c|c|c|c|}
\hline \multirow{3}{*}{$\begin{array}{l}\text { General } \\
\text { information }\end{array}$} & \multirow[t]{2}{*}{ Houses } & \multicolumn{3}{|c|}{ Families } & \multirow[t]{2}{*}{ People } & \multirow{2}{*}{$\begin{array}{c}<5 \\
\text { years }\end{array}$} & \multicolumn{3}{|c|}{ Water sources } \\
\hline & & Total & IDPs & & & & Kind & Who & Quantity \\
\hline & 75 & 120 & None & $\begin{array}{c}\text { But } 3 / 4 \text { are } \\
\text { returnees }\end{array}$ & 700 & 250 & & & \\
\hline \multirow[t]{2}{*}{ Education } & Nearest school & \multicolumn{3}{|c|}{ Qu'ranic school } & \multicolumn{3}{|c|}{ Shopping town } & \multicolumn{2}{|c|}{ Frequency of travel } \\
\hline & Sang-i Masha & \multicolumn{3}{|c|}{ Yes } & \multicolumn{3}{|c|}{ Sang-i Masha or Ghazni } & \multicolumn{2}{|c|}{$\begin{array}{l}\text { Depends on income: if have } \\
\text { enough money, do one big } \\
\text { main shop, if not, have to go } \\
\text { often, mostly monthly or } 3 \\
\text { monthly. }\end{array}$} \\
\hline \multirow[t]{2}{*}{ Health } & Clinic & \multicolumn{2}{|c|}{ Vaccination } & \multicolumn{3}{|c|}{ Trad. medicine \& TBAs } & \multicolumn{3}{|c|}{ Most common diseases } \\
\hline & Sang-i Masha & \multicolumn{2}{|c|}{$\begin{array}{l}\text { Yes, but only polio } \\
\text { the last few times; } \\
\text { now have to go } \\
\text { themselves, to clinic } \\
\text { - no mobile teams. } \\
\text { Last visit: } 3 \text { months } \\
\text { ago. }\end{array}$} & \multicolumn{3}{|c|}{$\begin{array}{l}\text { None, but help each other; } \\
\text { give birth on nylon or cloth on } \\
\text { the ground }\end{array}$} & \multicolumn{3}{|c|}{$\begin{array}{l}\text { ADULTS: ARIs; rheumatoid } \\
\text { arthritis } \\
\text { CHILDREN: ARIs; diarrhoea; } \\
\text { malnutrition } \\
\text { GOITRE: little } \\
\text { NIGHT BLINDNESS: lots, } \\
\text { mostly adults }\end{array}$} \\
\hline \multirow[t]{3}{*}{ Nutrition } & \multicolumn{6}{|c|}{ Breast feeding } & \multicolumn{3}{|c|}{ Weaning } \\
\hline & Start & \multirow{2}{*}{\multicolumn{4}{|c|}{$\frac{\text { Cessation during pregnancy }}{\text { Continue }}$}} & Length & & ime & Weaning food \\
\hline & $\begin{array}{c}3 \text { days after } \\
\text { birth }\end{array}$ & & & & & 2 years & $7-8 n$ & months & $\begin{array}{l}\text { Top of milk; } \\
\text { yoghurt; bread }\end{array}$ \\
\hline
\end{tabular}

CHANGE IN LIFE WITH THE BLOCKADE: prices have doubled. Meat was eaten regularly, now wheat only. $80 \%$ of people ate meat during the winter, pretty much every other day and in the spring and summer 2-3 per month. before the blockade, livestock were purchased from Pakistan border. Were able to buy glass, cotton, wheat, sugar, anything, but not now.

\begin{tabular}{|c|c|c|}
\hline DIET & $\begin{array}{l}\text { AFTER BLOCKADE: } \\
\text { BREAKFAST: tea; bread } \\
\text { LUNCH: tea; bread; doughe } \\
\text { DINNER: tea; bread; doughe; potato } \\
\text { soup } \\
\text { MEAT: hardly ever }\end{array}$ & $\begin{array}{l}\text { BEFORE BLOCKADE: } \\
\text { BREAKFAST: tea; bread } \\
\text { LUNCH: tea; bread; doughe } \\
\text { DINNER: tea; bread; doughe; } \\
\text { potato soup } \\
\text { MEAT: } 15 / 30\end{array}$ \\
\hline
\end{tabular}

COMMENTS: most families have land, but the yield is only about 2 months worth. Only a few families are without land and around $80 \%$ own livestock. Saw 'spoon-shaped' nails on one young mother's hands. These were generally thin people, quite poor and not very clean and looked stunted and very tired. This mid-mountain village had a reputation for being one of the poorest in the area. One case of oedema was observed here, but was not bilateral and therefore was not considered to be nutritionally significant. Not much livestock was seen, although $80 \%$ were supposed to own some. Breast feeding is practised during diarrhoea. 
Name of village: PASHTANA

\begin{tabular}{|c|c|c|c|c|c|c|c|c|c|}
\hline \multirow{3}{*}{$\begin{array}{l}\text { General } \\
\text { information }\end{array}$} & \multirow[t]{2}{*}{ Houses } & \multicolumn{3}{|c|}{ Families } & \multirow[t]{2}{*}{ People } & \multirow[t]{2}{*}{$<5$ years } & \multicolumn{3}{|c|}{ Water sources } \\
\hline & & Total & IDPs & From where & & & Kind of & Who & Quantity \\
\hline & 130 & 250 & 12 & $\begin{array}{l}\text { Kabul } \\
\text { Ghazni }\end{array}$ & 700 & 150 & & & \\
\hline \multirow[t]{2}{*}{ Education } & Nearest school & \multicolumn{3}{|c|}{ Qu'ranic school } & \multicolumn{3}{|c|}{ Shopping town } & \multicolumn{2}{|c|}{ Frequency of travel } \\
\hline & Sang-i Masha & 8.8 & 4.9 .8 .9 & & . & 48 & & & \\
\hline \multirow[t]{2}{*}{ Health } & Clinic & \multicolumn{2}{|c|}{ Vaccination } & \multicolumn{3}{|c|}{ Trad. medicine \& TBAs } & \multicolumn{3}{|c|}{ Most common diseases } \\
\hline & $\begin{array}{l}\text { Sang-i Masha } \\
-20 \text { minutes, } \\
\text { by car }\end{array}$ & \multicolumn{2}{|c|}{$\begin{array}{l}\text { Since } \\
\text { blockade, no } \\
\text { visits, just } \\
\text { take children } \\
\text { to Sang-i } \\
\text { Masha when } \\
\text { campaign }\end{array}$} & \multicolumn{3}{|c|}{$\begin{array}{l}\text { Use one from hospital, who is } \\
\text { technically trained }\end{array}$} & \multicolumn{3}{|c|}{$\begin{array}{l}\text { ADULTS: dysentery } \\
\text { CHILDREN: TB; typhoid; } \\
\text { fever; diarrhoea } \\
\text { GOITRE: } 10 \% \\
\text { NIGHT BLINDNESS: } 1 \%\end{array}$} \\
\hline \multirow[t]{3}{*}{ Nutrition } & \multicolumn{6}{|c|}{ Breast feeding } & \multicolumn{3}{|c|}{ Weaning } \\
\hline & Start & \multirow{2}{*}{\multicolumn{4}{|c|}{$\frac{\text { Cessation during preg }}{\text { Immediately }}$}} & Length & \multicolumn{2}{|c|}{ Time } & Weaning food \\
\hline & $\begin{array}{l}3 \text { days after } \\
\text { birth; oil, } \\
\text { butter }\end{array}$ & & & & & $1 / 2$ years & & & \\
\hline
\end{tabular}

CHANGE IN LIFE WITH THE BLOCKADE: prices have increased and life is very difficult and different. Wheat used to cost 300,000 and now costs $1,600,000$.

DIET

AFTER BLOCKADE:
BREAKFAST: bread; tea
LUNCH: bread; tea
DINNER: bread; tea
MEAT: $1 / 14$

BEFORE BLOCKADE:

BREAKFAST: bread; tea

LUNCH: bread; tea; potatoes

DINNER: bread; tea; potato soup

MEAT: $1 / 7$

COMMENTS: very few have land, can have a yield of up to 120 sears over one year - this lasts a family of 14 around 3 months, with 20 sears being given to the school and another 20 sears kept as seeds for next year's planting. Those who have land may have a cow or if not will share an oxen in a co-operative.

Name of village: QONDOL QASH

\begin{tabular}{|c|c|c|c|c|c|c|c|c|}
\hline \multirow{3}{*}{$\begin{array}{c}\text { General } \\
\text { information }\end{array}$} & \multirow[t]{2}{*}{ Houses } & \multicolumn{2}{|c|}{ Families } & \multirow[t]{2}{*}{ People } & \multirow[t]{2}{*}{$<5$ years } & \multicolumn{3}{|c|}{ Water sources } \\
\hline & & \begin{tabular}{l|l} 
Total & IDPs \\
\end{tabular} & From where & & & Kind of & Who & Quantity \\
\hline & 45 & 60 & & 450 & 80 & & & \\
\hline \multirow[t]{2}{*}{ Education } & Nearest school & \multicolumn{2}{|c|}{ Qu'ranic school } & \multicolumn{3}{|c|}{ Shopping town } & \multicolumn{2}{|c|}{ Frequency of travel } \\
\hline & Sang-i Masha & \multicolumn{2}{|c|}{ Yes } & \multirow{2}{*}{\multicolumn{2}{|c|}{$\frac{\text { Sang-i Mash }}{\text { eedicine \& TBAs }}$}} & & \multicolumn{2}{|c|}{ When needed } \\
\hline \multirow[t]{2}{*}{ Health } & Clinic & Vaccination & Trad. medicine \& TBAs & & & \multicolumn{3}{|c|}{ Most coinmon diseases } \\
\hline & $\begin{array}{l}\text { Sang-i Masha } \\
-20 \text { minutes, } \\
\text { by car }\end{array}$ & $\begin{array}{ll}\text { Yes; last } \\
\text { visit, one } \\
\text { month ago. }\end{array}$ & \multicolumn{3}{|c|}{$\begin{array}{l}\text { None, help each other, but for } \\
\text { complicated births, if they can afford, } \\
\text { go to Sang-i Masha. }\end{array}$} & \multicolumn{3}{|c|}{$\begin{array}{l}\text { ADULTS: dysentery } \\
\text { CHILDREN: TB; typhoid; fever; } \\
\text { diarrloea } \\
\text { GOITRE: } 10 \% \\
\text { NIGHT BLINDNESS: } 1 \% \\
\end{array}$} \\
\hline \multirow[t]{3}{*}{ Nutrition } & \multicolumn{5}{|c|}{ Breast feeding } & \multicolumn{3}{|c|}{ Weaning } \\
\hline & Start & Cessation & during pregn & ncy & Length & \multicolumn{2}{|c|}{ Time } & Weaning food \\
\hline & $\begin{array}{c}3 \text { days after } \\
\text { birth; oil, } \\
\text { butter }\end{array}$ & \multicolumn{3}{|c|}{ At 8 months } & 2 years & & & \\
\hline AANGE & $\mathbf{W I}$ & . & $x_{1}$ & & & & & \\
\hline
\end{tabular}




\begin{tabular}{|l|l|l|}
\hline DIET & AFTER BLOCKADE: & BEFORE BLOCKADE: \\
& BREAKFAST: tea; bread & BREAKFAST: sugar; tea; bread \\
& LUNCII: tea; bread; doughe & LUNCII: potatoes; eggs; lentils \\
& DINNER: potato soup; eggs; lentils & DINNER: rice; meat; greens \\
& MEAT: rarely & MEAT: most meals \\
\hline
\end{tabular}

Name of village: SABZ CHOOB

\begin{tabular}{|c|c|c|c|c|c|c|c|c|c|}
\hline \multirow{3}{*}{$\begin{array}{c}\text { General } \\
\text { information }\end{array}$} & \multirow[t]{2}{*}{ Houses } & \multicolumn{3}{|c|}{ Families } & \multirow[t]{2}{*}{ People } & \multirow{2}{*}{$\begin{array}{c}<5 \\
\text { years }\end{array}$} & \multicolumn{3}{|c|}{ Water sources } \\
\hline & & Total & IDPs & From where & & & Kind & Who & Quantity \\
\hline & 90 & 200 & $5 \%$ & & 800 & 150 & & & 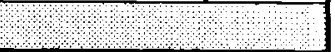 \\
\hline \multirow[t]{2}{*}{ Education } & Nearest school & \multicolumn{3}{|c|}{ Qu'ranic school } & \multicolumn{3}{|c|}{ Shopping town } & \multicolumn{2}{|c|}{ Frequency of travel } \\
\hline & Sang-i Masha & \multicolumn{3}{|c|}{ Yes, mixed } & \multicolumn{3}{|c|}{ Sang-i Masha } & \multicolumn{2}{|c|}{$\begin{array}{l}\text { Depending on funds - more } \\
\text { often if less money - to } \\
\text { spread the costs; go by } \\
\text { donkey or by foot }\end{array}$} \\
\hline \multirow[t]{2}{*}{ Health } & Clinic & \multicolumn{2}{|c|}{ Vaccination } & \multicolumn{3}{|c|}{ Trad. medicine \& TBAs } & \multicolumn{3}{|c|}{ Most common diseases } \\
\hline & Sang-i Masha & \multicolumn{2}{|c|}{$\begin{array}{l}\text { Yes; } \\
\text { Last visit: } 1 \text { month } \\
\text { ago. }\end{array}$} & \multicolumn{3}{|c|}{$\begin{array}{l}\text { Use grass for fever - it is } \\
\text { boiled and the juice is drunk, } \\
\text { whilst the pulp is put onto the } \\
\text { head and neck } \\
\text { TBAs: there is no TBA, they } \\
\text { help each other and give birth } \\
\text { on plastic sheeting }\end{array}$} & \multicolumn{3}{|c|}{$\begin{array}{l}\text { GOITRE: } 2 \% \\
\text { NIGHT BLINDNESS: } 5 \%\end{array}$} \\
\hline \multirow[t]{3}{*}{ Nutrition } & \multicolumn{6}{|c|}{ Breast feeding } & \multicolumn{3}{|c|}{ Weaning } \\
\hline & Start & \multicolumn{4}{|c|}{ Cessation during pregnancy } & Length & & ime & Weaning food \\
\hline & $\begin{array}{l}\text { days after } \\
\text { birth; tea, } \\
\text { butter }\end{array}$ & \multicolumn{4}{|c|}{ As soon as find out } & \begin{tabular}{c|c}
$11 / 2-3$ \\
$1 / 2$ years
\end{tabular} & & & \\
\hline \multicolumn{10}{|c|}{$\begin{array}{l}\text { CHANGE IN LIFE WITH THE BLOCKADE: prices have increased up to five fold - tea from } 20,000 \text { to } 60,000 \text {; } \\
\text { wheat from } 400,000 \text { to } 1,800,000 \text {; salt from } 10,000 \text { to } 50,000 \text {; oil from } 30,000 \text { to } 120,000 \text {. }\end{array}$} \\
\hline \multicolumn{2}{|l|}{ DIET } & & \multicolumn{4}{|c|}{$\begin{array}{l}\text { AFTER BLOCKADE: } \\
\text { BREAKFAST: tea; bread } \\
\text { LUNCH: tea; bread; greens/clover } \\
\text { DINNER: tea; bread; potato soup; } \\
\text { doughe } \\
\text { MEAT: } 1 / 365\end{array}$} & \multicolumn{3}{|c|}{$\begin{array}{l}\text { BEFORE BLOCKADE: } \\
\text { BREAKFAST: eggs; beans; bread; } \\
\text { tea; sugar/candy } \\
\text { LUNCH: potatoes; rice } \\
\text { DINNER: rice; potatoes; beans; } \\
\text { meat } \\
\text { MEAT: } 1 / 7\end{array}$} \\
\hline \multicolumn{10}{|c|}{$\begin{array}{l}\text { COMMENTS: about half the people do not own land, yields last for } 5-7 \text { months; not many have cattle here as the land } \\
\text { is unsuitable, but some have sheep - } 95 \% \text { have sheep, } 2 \% \text { have cows and } 3 \% \text { have nothing. The population look tired } \\
\text { and thin and there were quite a few children with diarrhoea, however, they looked like quite 'well off' people. }\end{array}$} \\
\hline
\end{tabular}


MALESTAN:

Name of village: DAHAN BOOM

\begin{tabular}{|c|c|c|c|c|c|c|c|c|c|}
\hline \multirow{3}{*}{$\begin{array}{c}\text { General } \\
\text { information }\end{array}$} & \multirow[t]{2}{*}{ Houses } & \multicolumn{3}{|c|}{ Families } & \multirow{2}{*}{ Peóple } & \multirow{2}{*}{$\begin{array}{c}<5 \\
\text { years }\end{array}$} & \multicolumn{3}{|c|}{ Water sources } \\
\hline & & Total & IDPs & From where & & & Kind & Who & Quantity \\
\hline & 42 & 60 & 10 & $\begin{array}{c}\text { Ajarestan } \\
\text { Shahrestan } \\
\text { Malestan }\end{array}$ & 320 & 60 & & & \\
\hline \multirow[t]{2}{*}{ Education } & Nearest school & \multicolumn{3}{|c|}{ Qu'ranic school } & \multicolumn{3}{|c|}{ Shopping town } & \multicolumn{2}{|c|}{ Frequency of travel } \\
\hline & $\begin{array}{c}\text { Abo Ali Sina - } \\
80 \text { minutes by } \\
\text { foot }\end{array}$ & \multicolumn{3}{|c|}{ Yes } & & & & & \\
\hline \multirow[t]{2}{*}{ Health } & Clinic & \multicolumn{2}{|c|}{ Vaccination } & \multicolumn{3}{|c|}{ Trad. medicine \& TBAs } & \multicolumn{3}{|c|}{ Most common diseases } \\
\hline & $\begin{array}{l}S C A-80 \\
\text { minutes by } \\
\text { foot - } 500 \\
\text { Afghanis for } \\
\text { consultation }\end{array}$ & \multicolumn{2}{|c|}{$\begin{array}{l}\text { Yes; } \\
\text { Last visit: } 2 \text { months } \\
\text { ago. }\end{array}$} & \multicolumn{3}{|c|}{$\begin{array}{l}\text { TBAs: there are } 2 \text {, without } \\
\text { technical training. Women } \\
\text { give birth onto a cloth on } \\
\text { the ground. }\end{array}$} & \multicolumn{3}{|c|}{$\begin{array}{l}\text { ADULTS: } \\
\text { appendicitis; cholera; arthritis; UTIs } \\
\text { CHILDREN: epilepsy; diarrhoea; } \\
\text { pneumonia; ARIs; measles; } \\
\text { whooping cough } \\
\text { GOITRE: } 2 \\
\end{array}$} \\
\hline \multirow[t]{3}{*}{ Nutrition } & \multicolumn{6}{|c|}{ Breast feeding } & \multicolumn{3}{|c|}{ Weaning } \\
\hline & Start & \multicolumn{4}{|c|}{ Cessation during pregnancy } & Length & & & Weaning food \\
\hline & $\begin{array}{l}10-12 \text { hours } \\
\text { after birth }\end{array}$ & \multicolumn{4}{|c|}{ At 5 months } & $\begin{array}{l}1 \frac{1}{2}-2 \\
\text { years }\end{array}$ & $3-5$ & onths & $\begin{array}{l}\text { bread; oil; top of } \\
\text { milk; butter }\end{array}$ \\
\hline \multicolumn{10}{|c|}{$\begin{array}{l}\text { CHANGE IN LIFE WITH THE BLOCKADE: were able to buy food easily, which came from Ghazni, but now not } \\
\text { even able to buy } 2 \text { sears of flour. It is not only food items, clothes and shoes have gone up tremendously in price. } \\
\text { People are now forced to eat alfalfa and clover - originally animal feed, some claim that they get sick and have oedema } \\
\text { as a result of eating these greens. }\end{array}$} \\
\hline DIET & & & \multicolumn{4}{|c|}{$\begin{array}{l}\text { AFTER BLOCKADE: } \\
\text { BREAKFAST: barley bread; boiled } \\
\text { water (tea when available) } \\
\text { LUNCH: bread; greens; doughe } \\
\text { DINNER: bread; greens; doughe } \\
\text { MEAT: none since the blockade }\end{array}$} & \multicolumn{3}{|c|}{$\begin{array}{l}\text { BEFORE BLOCKADE: } \\
\text { BREAKFAST: bread; tea; sugar; } \\
\text { milk } \\
\text { LUNCH: rice; potato; yoghurt } \\
\text { DINNER: rice; yoghurt; Croute soup } \\
\text { MEAT: } 2 / 7\end{array}$} \\
\hline
\end{tabular}

Name of village: KHARZAR

\begin{tabular}{|c|c|c|c|c|c|c|c|c|c|}
\hline \multirow{3}{*}{$\begin{array}{c}\text { General } \\
\text { information }\end{array}$} & \multirow[t]{2}{*}{ Houses } & \multicolumn{3}{|c|}{ Families } & \multirow[t]{2}{*}{ People } & \multirow{2}{*}{$\begin{array}{l}<5 \\
\text { years }\end{array}$} & \multicolumn{3}{|c|}{ Water sources } \\
\hline & & Total & IDPs & From where & & & Kind & Who & Quantity \\
\hline & 1 & 4 & 10 & 9.1 .8 .8 & 17 & 3 & & & 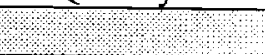 \\
\hline \multirow[t]{2}{*}{ Health } & Clinic & \multicolumn{2}{|c|}{ Vaccination } & \multicolumn{3}{|c|}{ Trad. medicine \& TBAs } & \multicolumn{3}{|c|}{ Most common diseases } \\
\hline & $\begin{array}{c}S C A-2 \text { hours by } \\
\text { foot }\end{array}$ & & & & & & & & \\
\hline \multirow[t]{3}{*}{ Nutrition } & \multicolumn{6}{|c|}{ Breast feeding } & \multicolumn{3}{|c|}{ Weaning } \\
\hline & Start & \multicolumn{4}{|c|}{ Cessation during pregnancy } & Length & & & Weaning food \\
\hline & $\begin{array}{c}3 \text { days after birth; } \\
\text { oil \& butter }\end{array}$ & & & & & 2 years & & & \\
\hline \multicolumn{2}{|l|}{ DIET } & & \multicolumn{4}{|c|}{$\begin{array}{l}\text { AFTER BLOCKADE: } \\
\text { BREAKFAST: tea; bread } \\
\text { LUNCH: tea; bread; doughe } \\
\text { DINNER: bread; doughe; Croute soup } \\
\text { MEAT: } 1 / 30\end{array}$} & \multicolumn{3}{|c|}{$\begin{array}{l}\text { BEFORE BLOCKADE: } \\
\text { basically the same, but more of it }\end{array}$} \\
\hline
\end{tabular}


Name of village: JAMBOT

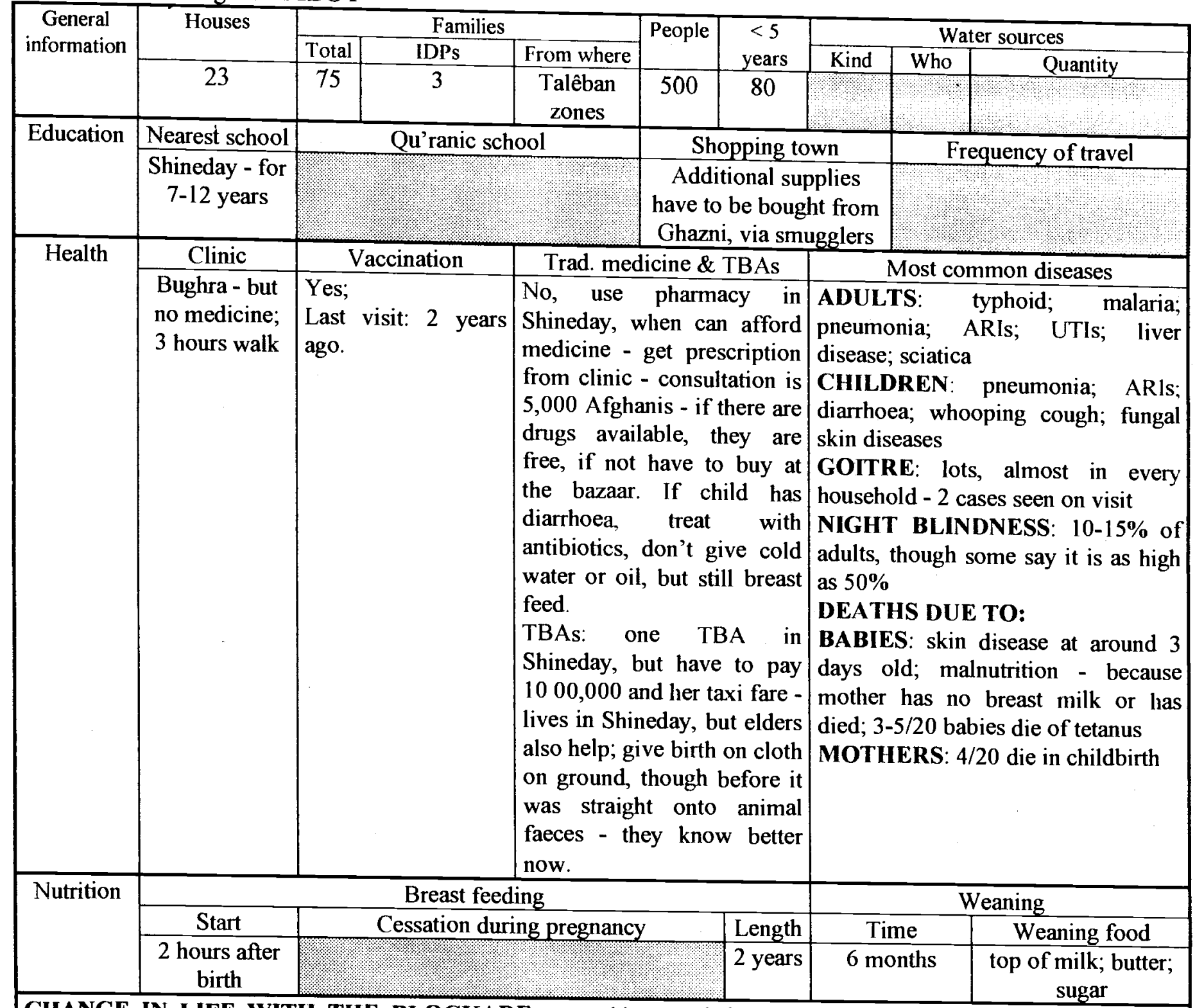

CHANGE IN LIFE WITH THE BLOCKADE: everything needed was bought in Shineday, where credit was available, but not now, prices have increased greatly - a $7 \mathrm{~kg}$ bag of wheat flour used to cost 5,000 but now it costs 90,000. In Spring 1995, for instance, there was much more food available - sugar, candy, meat, tea.

\section{DIET}

AFTER BLOCKADE:
BREAKFAST: bread; tea
LUNCH: bread; greens (raw/cooked);
oil - if available
DINNER: rice; tea; beans; bread
MEAT: $2 / 30$
DAIRY PRODUCTS: $1 / 30$

BEFORE BLOCKADE:

basically the same, but more of it

\footnotetext{
COMMENTS: very difficult in winter, lots of ARIs and in summer, lots of diarrhoeal diseases. The best time for food is in the winter, when they have a store of food, the Hunger Gap is in the spring, because they have ran out of food and the crops have not been harvested yet. Since there is no doctor available, the majority of cases are left to their own devices, and may die. Leprosy was very common here until the arrival of LEPCO at the Bughra clinic. Old houses with insects living in roof, causing diseases. This is a nice little village, divided by a river, with fertile looking land and poplars, surrounded by rocky hills. No livestock was seen. It is 15 minutes by car, from Shineday. There was a generator in the mombar. There was no WFP distribution here, but there was in nearby Shineday, though not a very fair distribution, they say.
} 


\begin{tabular}{|c|c|c|c|c|c|}
\hline \multirow[t]{3}{*}{ Nutrition } & \multicolumn{3}{|c|}{ Breast feeding } & \multicolumn{2}{|r|}{ Weaning } \\
\hline & Start & Cessation during pregnancy & Length & Time & Weaning food \\
\hline & $\begin{array}{c}1 \text { hour after } \\
\text { birth }\end{array}$ & Up to 1 month before birth. & $\begin{array}{l}\text { Boys: } 2 \text { years, } \\
\text { Girls: } 11 / 2 \text { yr. }\end{array}$ & 6 months & $\begin{array}{l}\text { Cow's milk; oil; bread; } \\
\text { top of milk. }\end{array}$ \\
\hline \multicolumn{6}{|c|}{$\begin{array}{l}\text { CHANGE IN LIFE WITH THE BLOCKADE: cannot afford clothes, food, flour, fertiliser, tea. All prices have } \\
\text { gone up } 10 \text { fold. }\end{array}$} \\
\hline DIET & & \multicolumn{2}{|c|}{$\begin{array}{l}\text { AFTER BLOCKADE: } \\
\text { BREAKFAST: tea; bread } \\
\text { LUNCH: doughe; yoghurt; tea; } \\
\text { bread } \\
\text { DINNER: doughe; yoghurt; tea; } \\
\text { bread; oil - if available } \\
\text { MEAT: } 2 / 365\end{array}$} & \multicolumn{2}{|c|}{$\begin{array}{l}\text { BEFORE BLOCKADE: } \\
\text { BREAKFAST: tea; bread } \\
\text { LUNCH: doughe; yoghurt; tea; bread } \\
\text { DINNER: doughe; yoghurt; tea; bread } \\
\text { MEAT: } 3 / 365\end{array}$} \\
\hline
\end{tabular}

Name of village: QOSHNAK

\begin{tabular}{|c|c|c|c|c|c|c|c|c|c|}
\hline \multirow{3}{*}{$\begin{array}{c}\text { General } \\
\text { information }\end{array}$} & \multirow[t]{2}{*}{ Houses } & \multicolumn{3}{|c|}{ Families } & \multirow[t]{2}{*}{ People } & \multirow{2}{*}{$\begin{array}{c}<5 \\
\text { years }\end{array}$} & \multicolumn{3}{|c|}{ Water sources } \\
\hline & & Total & IDPs & From where & & & Kind & Who & Quantity \\
\hline & 70 & 130 & 60 & \begin{tabular}{|} 
Ajarestan \\
Malestan \\
Shahrestan
\end{tabular} & 600 & 100 & & & \\
\hline \multirow[t]{2}{*}{ Education } & Nearest school & \multicolumn{3}{|c|}{ Qu'ranic school } & \multicolumn{3}{|c|}{ Shopping town } & \multicolumn{2}{|c|}{ Frequency of travel } \\
\hline & $\begin{array}{c}\text { Miridineh - } 2 \\
\text { hours walk }\end{array}$ & & & \multicolumn{3}{|c|}{ 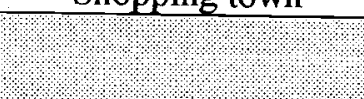 } & & \\
\hline \multirow[t]{2}{*}{ Health } & Clinic & \multicolumn{2}{|c|}{ Vaccination } & \multicolumn{3}{|c|}{ Trad. medicine \& TBAs } & \multicolumn{3}{|c|}{ Most common diseases } \\
\hline & $\begin{array}{l}\text { Miridineh - } 2 \\
\text { hours walk - } \\
\quad 4,000 \\
\text { Afghanis for } \\
\text { consultation }\end{array}$ & & & \multirow{2}{*}{\multicolumn{3}{|c|}{ Plants used a lot. }} & \multicolumn{3}{|c|}{$\begin{array}{l}\text { ADULTS: paralysis; epilepsy; TB; } \\
\text { hypertension; rheumatism; typhoid } \\
\text { CHILDREN: measles; pneumonia; } \\
\text { whooping cough; diarrhoea; worms } \\
\text { GOITRE: } 10 \% \\
\text { NIGHT BLINDNESS: } 5 \%\end{array}$} \\
\hline \multirow[t]{3}{*}{ Nutrition } & \multicolumn{3}{|c|}{ Breast feeding } & & & & \multicolumn{3}{|c|}{ Weaning } \\
\hline & Start & \multirow{2}{*}{\multicolumn{4}{|c|}{$\frac{\text { Cessation dunng pregnancy }}{7-8 \text { months }}$}} & Length & & ne & Weaning food \\
\hline & Immediately & & & & & 2 years & $3-61$ & onths & $\begin{array}{l}\text { Top of milk; butter; } \\
\text { rice; porridge }\end{array}$ \\
\hline
\end{tabular}

Water is in Water is in short supply, because of poor irrigation, as people cannot afford to clean irrigation channels. Drugs are in short supply, both for human and animal consumption. People are eating what used to be animal feed.

\begin{tabular}{|l|l|}
\hline DIET & AFTER BLOCKADE: \\
& BREAKFAST: tea; bread \\
& LUNCH: doughe; bread \\
& DINNER: tea; bread \\
\hline
\end{tabular}

BEFORE BLOCKADE:

BREAKFAST: tea; bread; sugar

LUNCH: tea; bread; meat; yoghurt

DINNER: Croute; meat; rice

COMMENTS: there are good relations with Ajarestan, where buying, exchanges and borrowing take place. Such goods as wheat flour, oil and Kalool (a bean that seems to paralyse children when eaten). 
Name of village: SABZAK

\begin{tabular}{|c|c|c|c|c|c|c|c|c|c|}
\hline \multirow{3}{*}{$\begin{array}{c}\text { General } \\
\text { information }\end{array}$} & \multirow[t]{2}{*}{ Houses } & \multicolumn{3}{|c|}{ Families } & \multirow[t]{2}{*}{ People } & \multirow{2}{*}{$\begin{array}{l}<5 \\
\text { years }\end{array}$} & \multicolumn{3}{|c|}{ Water sources } \\
\hline & & Total & IDPs & From where & & & Kind & Who & Quantity \\
\hline & 18 & 40 & Yes & Kabul & 150 & 30 & & & 2 \\
\hline \multirow[t]{2}{*}{ Education } & Nearest school & \multicolumn{3}{|c|}{ Qu'ranic school } & \multicolumn{3}{|c|}{ Shopping town } & \multicolumn{2}{|c|}{ Frequency of travel } \\
\hline & None & \multicolumn{3}{|c|}{ Yes, mixed. } & \multicolumn{3}{|c|}{$\begin{array}{l}\text { Have to buy most of the } \\
\text { food from local bazaar, } \\
\text { as own yields only } \\
\text { stretch to about } 1 \\
\text { month supply. }\end{array}$} & & \\
\hline \multirow[t]{2}{*}{ Health } & Clinic & \multicolumn{2}{|c|}{ Vaccination } & \multicolumn{3}{|c|}{ Trad. medicine \& TBAs } & \multicolumn{3}{|c|}{ Most coinmon diseases } \\
\hline & $\begin{array}{l}\text { Bughra - but } \\
\text { no medicine; } \\
3 \text { hours walk }\end{array}$ & \multicolumn{2}{|c|}{$\begin{array}{llll}\text { Yes; } & & & \\
\text { Last } & \text { visit: } 2 & \text { years } \\
\text { ago. } & & & \end{array}$} & \multicolumn{3}{|c|}{$\begin{array}{l}\text { TBAs: have } 2 \text {, but no } \\
\text { technical training, there is } \\
\text { no charge; the family help } \\
\text { also, the child is born onto a } \\
\text { cloth on the ground. }\end{array}$} & \multicolumn{3}{|c|}{$\begin{array}{l}\text { CHILDREN: pneumonia; } \\
\text { malnutrition - } 20 \text { children were } \\
\text { reported dead last winter, having } \\
\text { eaten a plant not normally eaten by } \\
\text { humans and getting oedema } \\
\text { GOITRE: yes, quite a bit, though } \\
\text { only saw a few cases } \\
\text { NIGHT BLINDNESS: lots, with } \\
\text { evidence of a few blind people too. } \\
\text { DEATHS: } \\
\text { BABIES: } 3 / 10 \text { babies die at birth, or } \\
\text { soon after - within } 6 \text { months, with } 1- \\
\text { 2/10 dying of tetanus } \\
\text { MOTHERS: don't usually die in } \\
\text { child birth. }\end{array}$} \\
\hline \multirow[t]{3}{*}{ Nutrition } & \multicolumn{6}{|c|}{ Breast feeding } & \multicolumn{3}{|c|}{ Weaning } \\
\hline & Start & \multicolumn{4}{|c|}{ Cessation during pregnancy } & Length & Tir & & Weaning food \\
\hline & Immediately & & & & & 2 years & $6 \mathrm{mc}$ & nths & $\begin{array}{c}\text { Doughe; cow's } \\
\text { milk; top of milk; } \\
\text { yoghurt }\end{array}$ \\
\hline
\end{tabular}

CHANGE IN LIFE WITH THE BLOCKADE: prices have increased dramatically - have a borrowing system now, for example, 1,800,000 can be borrowed, but 5,000,000 have to be paid back within 2 months, if not, then $1,0000,000$ have to be paid back in 4 months etc.

\begin{tabular}{|c|c|c|}
\hline $\begin{array}{l}\text { DIET } \\
\text { Mothers and children are reported to } \\
\text { have had oedema and died. Things are } \\
\text { so bad that they are now eating animal } \\
\text { feed - they say that this causes } \\
\text { paralysis, but they have been forced to } \\
\text { eat this for the past } 2 \text { years. Dogs who } \\
\text { sleep on the vegetation are also } \\
\text { reported to have paralysis. }\end{array}$ & $\begin{array}{l}\text { AFTER BLOCKADE: } \\
\text { BREAKFAST: barley bread; tea } \\
\text { LUNCH: doughe; tea; barley bread } \\
\text { DINNER: bread; tea; doughe } \\
\text { MEAT: } 2 / 365 \\
\text { DAIRY PRODUCTS: doughe daily }\end{array}$ & $\begin{array}{l}\text { The same, though } \\
\text { and more meat. }\end{array}$ \\
\hline \multicolumn{3}{|c|}{$\begin{array}{l}\text { COMMENTS: travel to this area is rather difficult, through very high, dry rocky mountains, with very little vegetation. } \\
\text { This is one of a few sporadic villages, which have evolved around a water source, with some fertile land - red soil. A } \\
\text { lush valley in the middle of dry red mountains. This is a smart village with a huge mombar, with a generator, lots of } \\
\text { rugs and wall hangings and a loud speaker. Despite this, they looked like quite poor, thin people, who looked tired and } \\
\text { hungry. There are IDPs here, who came with no belongings and live as beggars, feeding on greens - they borrow money } \\
\text { from shop keepers and land owners, some as far away as Jaghoori. WFP distributed, per family, } 35 \mathrm{Kg} \text { of barley and } \\
\text { lentil flour to everybody about } 10 \text { days before our arrival (mid June). }\end{array}$} \\
\hline
\end{tabular}


Name of village: WALI

\begin{tabular}{|c|c|c|c|c|c|c|c|c|c|c|}
\hline \multirow{3}{*}{$\begin{array}{l}\text { General } \\
\text { information }\end{array}$} & \multirow[t]{2}{*}{ Houses } & \multicolumn{4}{|c|}{ Families } & \multirow[t]{2}{*}{ People } & \multirow{2}{*}{$\begin{array}{c}<5 \\
\text { years } \\
\end{array}$} & \multicolumn{3}{|c|}{ Water sources } \\
\hline & & Total & & IDPs & From where & & & Kind & Who & Quantity \\
\hline & 30 & 42 & & No & & 300 & 50 & & & \\
\hline \multirow[t]{2}{*}{ Education } & Nearest school & \multicolumn{4}{|c|}{ Qu'ranic school } & \multicolumn{3}{|c|}{ Shopping town } & \multicolumn{2}{|c|}{ Frequency of travel } \\
\hline & Miridineh & \multicolumn{4}{|c|}{ Yes } & & & \multicolumn{2}{|c|}{ 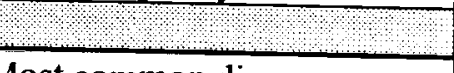 } \\
\hline \multirow[t]{2}{*}{ Health } & Clinic & \multicolumn{3}{|c|}{ Vaccination } & \multicolumn{3}{|c|}{ Trad. medicine \& TBAs } & \multicolumn{3}{|c|}{ common diseases } \\
\hline & $\begin{array}{c}\text { Swedish } \\
\text { Committee }\end{array}$ & \multicolumn{3}{|c|}{$\begin{array}{l}\text { Yes, but just polio } \\
\text { recently; } \\
\text { Last visit: } 1 \text { month } \\
\text { ago. }\end{array}$} & \multicolumn{3}{|c|}{$\begin{array}{l}\text { TBAs: not the custom to } \\
\text { have TBAs, but help each } \\
\text { other. Some women give } \\
\text { birth straight onto the } \\
\text { ground and some onto a } \\
\text { sheet on the ground. There } \\
\text { was a tiny baby here - LBW } \\
\text { and } 4 \text { weeks premature, } \\
\text { mother said to be suffering } \\
\text { from rheumatism, looked } \\
\text { quite haggard. } 4 / 10 \text { women } \\
\text { die in labour here, usually } \\
\text { from haemorrhaging, whilst } \\
2 / 10 \text { babies die in/soon after } \\
\text { child birth. }\end{array}$} & \multicolumn{3}{|c|}{$\begin{array}{l}\text { ADULTS: cholera }-5 \text { deaths last } \\
\text { year; rheumatism; TB; diarrhoea; } \\
\text { appendicitis } \\
\text { CHILDREN: } \\
\text { malnutrition } \\
\text { GOITRE: } 0 \\
\text { NIGHT BLINDNESS: } 0\end{array}$} \\
\hline \multirow[t]{3}{*}{ Nutrition } & \multicolumn{7}{|c|}{ Breast feeding } & \multicolumn{3}{|c|}{ Weaning } \\
\hline & Start & & Length & \multicolumn{2}{|c|}{ Time } & Weaning food \\
\hline & $\begin{array}{c}3 \text { days after } \\
\text { birth; oil. }\end{array}$ & \multicolumn{5}{|c|}{ Continue until last trimester } & $\begin{array}{l}11 / 2-2 \\
\text { years }\end{array}$ & \multicolumn{2}{|c|}{6 months } & $\begin{array}{c}\text { Oil; wheat; porridge; } \\
\text { cow's milk }\end{array}$ \\
\hline \multicolumn{11}{|c|}{$\begin{array}{l}\text { CHANGE IN LIFE WITH THE BLOCKADE: prices have increased and tea, sugar, wheat and barley are hard to } \\
\text { come by. They have livestock, but are forced to sell as they do not have the pastures needed to feed them, so keep a } \\
\text { limited number. }\end{array}$} \\
\hline \multicolumn{4}{|c|}{$\begin{array}{l}\text { DIET } \\
\text { Mothers and children are reported to } \\
\text { have had oedema and died. Things are } \\
\text { so bad that they are now eating animal } \\
\text { feed - they say that this causes } \\
\text { paralysis, but they have been forced to } \\
\text { eat this for the past } 2 \text { years. Dogs who } \\
\text { sleep on the vegetation are also } \\
\text { reported to have paralysis. }\end{array}$} & \multicolumn{4}{|c|}{$\begin{array}{l}\text { AFTER BLOCKADE: } \\
\text { BREAKFAST: tea; bread } \\
\text { LUNCH: doughe; tea; bread } \\
\text { DINNER: doughe; tea; bread; potato } \\
\text { soup; rice. }\end{array}$} & \multicolumn{3}{|c|}{$\begin{array}{l}\text { BEFORE BLOCKADE: } \\
\text { BREAKFAST: tea; bread } \\
\text { LUNCH: doughe; tea; bread } \\
\text { DINNER: doughe; tea; bread; potato } \\
\text { soup; rice; oil. }\end{array}$} \\
\hline
\end{tabular}


NAWOR:

Name of village: AMRO

\begin{tabular}{|c|c|c|c|c|c|c|c|c|c|}
\hline \multirow{3}{*}{$\begin{array}{c}\text { General } \\
\text {.information }\end{array}$} & \multirow[t]{2}{*}{ Houses } & \multicolumn{3}{|c|}{ Families } & \multirow[t]{2}{*}{ People } & \multirow{2}{*}{$\begin{array}{c}<5 \\
\text { years }\end{array}$} & \multicolumn{3}{|c|}{ Water sources } \\
\hline & & Total & IDPs & From where & & & Kind & Who & Quantity \\
\hline & 7 & 13 & Yes & Kabul & 60 & 15 & well & $\begin{array}{l}\text { men \& } \\
\text { women }\end{array}$ & $\begin{array}{c}16 \text { buckets/day } / 10 \\
\text { people }\end{array}$ \\
\hline \multirow[t]{2}{*}{ Education } & Nearest school & \multicolumn{3}{|c|}{ Qu'ranic school } & \multicolumn{3}{|c|}{ Shopping town } & \multicolumn{2}{|c|}{ Frequency of travel } \\
\hline & $\begin{array}{c}\text { Ab Dini - } 7 \\
\text { hours walk, } \\
\text { where the } \\
\text { children board } \\
\end{array}$ & \multicolumn{3}{|c|}{ Yes } & \multicolumn{3}{|c|}{ Ghazni } & \multicolumn{2}{|c|}{$\begin{array}{l}\text { 3-4 times per year, as cannot } \\
\text { afford to do one trip }\end{array}$} \\
\hline \multirow[t]{2}{*}{ Health } & Clinic & & ccination & \multicolumn{3}{|c|}{ Trad. medicine \& TBAs } & \multicolumn{3}{|c|}{ Most common diseases } \\
\hline & Ghazni & \multicolumn{3}{|c|}{$\begin{array}{l}\text { Yes; } \\
\text { Last visit: } 5 \text { months } \\
\text { ago, but only polio } \\
\text { and vitamin A. }\end{array}$} & & & \multicolumn{3}{|c|}{$\begin{array}{l}\text { ADULTS: UTIs; aches and pains } \\
\text { CHILDREN: chest pains; } \\
\text { pneumonia; diarrhoea; stomach } \\
\text { obstructions } \\
\text { GOITRE: } 0 \\
\text { NIGHT BLINDNESS: some }\end{array}$} \\
\hline \multirow[t]{3}{*}{ Nutrition } & \multicolumn{6}{|c|}{ Breast feeding } & \multicolumn{3}{|c|}{ Weaning } \\
\hline & Start & \multicolumn{4}{|c|}{ Cessation during pregnancy } & Length & \multicolumn{2}{|c|}{ Time } & Weaning food \\
\hline & Immediately & \multicolumn{4}{|c|}{ Immediately } & 2 years & \multicolumn{2}{|c|}{5 months } & $\begin{array}{l}\text { Top of milk; oil; } \\
\text { bread; cow's milk }\end{array}$ \\
\hline
\end{tabular}

CHANGE IN LIFE WITH THE BLOCKADE: prices higher, particularly salt, wheat flour, drugs, tea, oil, fuel and sugar. Food is difficult to get and sometimes the only thing available is greens. Salt, before the blockade cost 5,000 Afghanis for 1 sear, now costs 70,000 Afghanis. Everything was available before the blockade, but food is too expensive now, rare and there is the risk of having everything seized by the Talêban.

\begin{tabular}{|l|l|l|}
\hline DIET & AFTER BLOCKADE: & BEFORE BLOCKADE: \\
& BREAKFAST: tea; bread & BREAKFAST: tea; bread; sugar \\
LUNCH: tea; bread; doughe & LUNCH: potato soup; doughe; rice \\
& DINNER: tea; bread; doughe; potato \\
& soup with oil \\
MEAT: $1 / 365$ & DINNER: potato soup; doughe; rice \\
& MEAT: $3 / 30$
\end{tabular}

COMMENTS: own yields last for 3 months, the deficit has to be bought. Money is gained by selling livestock, renting land and working abroad. All have land and livestock. 
Name of village: BAKHTI

\begin{tabular}{|c|c|c|c|c|c|c|c|c|}
\hline \multirow{3}{*}{$\begin{array}{c}\text { General } \\
\text { information }\end{array}$} & \multirow[t]{2}{*}{ Houses } & \multicolumn{2}{|l|}{ Families } & \multirow[t]{2}{*}{ People } & \multirow{2}{*}{$\begin{array}{l}<5 \\
\text { years }\end{array}$} & \multicolumn{3}{|c|}{ Water sources } \\
\hline & & Total & From where & & & Kind & Who & Quantity \\
\hline & 4 & 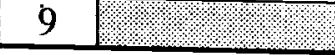 & & 75 & 6 & & & 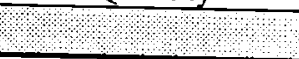 \\
\hline \multirow{2}{*}{ Education } & Nearest school & \multicolumn{2}{|c|}{ Qu'ranic school } & \multicolumn{3}{|c|}{ Shopping town } & \multicolumn{2}{|c|}{ Frequency of travel } \\
\hline & $\mathrm{Du}-\mathrm{Abi}$ & \multicolumn{2}{|c|}{ Yes } & \multicolumn{3}{|c|}{ Ghazni } & \multicolumn{2}{|c|}{$\begin{array}{l}\text { Impossible in winter, must } \\
\text { go between June and } \\
\text { October. Once per year, as it } \\
\text { takes } 2 \text { days by } \\
\text { donkey/horse }\end{array}$} \\
\hline \multirow[t]{2}{*}{ Health } & Clinic & Vaccination & \multicolumn{3}{|c|}{ Trad. medicine \& TBAs } & \multicolumn{3}{|c|}{ Most common diseases } \\
\hline & $\begin{array}{c}\text { Du-Abi, but } \\
\text { non fuctional. }\end{array}$ & $\begin{array}{l}\text { Yes; } \\
\text { Last visit: } 2 \text { years } \\
\text { ago. }\end{array}$ & \multicolumn{3}{|c|}{$\begin{array}{l}\text { For diarrhoea, use Bortang, } \\
\text { collected in the mountains } \\
\text { and boiled with water, } \\
\text { cooled and given to patient } \\
\text { to drink. } \\
\text { TBAs: no, but help each } \\
\text { other. } 5 / 15 \text { babies die at } \\
\text { birth, } 25 \% \text { because they are } \\
\text { premature/LBW; } 50 \% \\
\text { tetanus; } 25 \% \text { septicaemia. } 3- \\
5 \text { mothers die during child } \\
\text { birth, with } 2-3 \text { from } \\
\text { haemorrhaging and } 1-2 \text { from } \\
\text { unconsciousness. }\end{array}$} & \multicolumn{3}{|c|}{$\begin{array}{l}\text { ADULTS: rheumatoid arthritis } \\
\text { CHILDREN: pneumonia; coughs } \\
\text { GOITRE: } 0 \\
\text { NIGHT BLINDNESS: } 0\end{array}$} \\
\hline \multirow[t]{3}{*}{ Nutrition } & \multicolumn{5}{|c|}{ Breast feeding } & \multicolumn{3}{|c|}{ Weaning } \\
\hline & Start & \multicolumn{3}{|c|}{ Cessation during pregnancy } & Length & \multirow{2}{*}{\multicolumn{2}{|c|}{ Time }} & Weaning food \\
\hline & 9.1 .9 & \multirow{2}{*}{\multicolumn{4}{|c|}{$\begin{array}{l}\text { AFTER BLOCKADE: } \\
\text { BREAKFAST: tea; bread } \\
\text { LUNCH: Croute - diluted; bread } \\
\text { DINNER: potatoes; bread } \\
\text { MEAT: } 1 / 20\end{array}$}} & & & Doughe; yoghurt \\
\hline \multicolumn{2}{|l|}{ DIET } & & & & & \multicolumn{3}{|c|}{ BEFORE BLOCKADE: } \\
\hline \multicolumn{9}{|c|}{$\begin{array}{l}\text { COMMENTS: this is a tiny village, where they live off what they can and buy the rest from Ghazni. When shopping, a } \\
\text { no interest credit system is available at the shops. Shopping is done by selling livestock or money made from the sub- } \\
\text { letting of land, as no-one actually has their own land. The land belongs to someone in Sar Ab, Ghazni. The livestock } \\
\text { are their own, but are grazed on others land free of charge. Land is rented, on average, for } 20000,000 / \text { year, though this } \\
\text { amount can also cover a } 6-24 \text { month period. Houses do not belong to the inhabitants, though there is no rent paid. They } \\
\text { seemed relatively well off, having lots of wall hangings, rugs and pictures in their homes, which were in good repair } \\
\text { and looked relatively new. They have } 6 \text { months of snow, when it is impossible to travel. }\end{array}$} \\
\hline
\end{tabular}


Name of village: GOREH BAYEE

\begin{tabular}{|c|c|c|c|c|c|c|c|c|c|}
\hline \multirow{3}{*}{$\begin{array}{l}\text { General } \\
\text { information }\end{array}$} & \multirow[t]{2}{*}{ Houses } & \multicolumn{3}{|c|}{ Families } & \multirow{2}{*}{ People } & \multirow{2}{*}{$\begin{array}{l}<5 \\
\text { years }\end{array}$} & \multicolumn{3}{|c|}{ Water sources } \\
\hline & & Total & IDPs & From where & & & Kind & Who & Quantity \\
\hline & 10 & 16 & 0 & 1.98 & 100 & 20 & $\begin{array}{c}\text { strea } \\
\text { m }\end{array}$ & women & $\begin{array}{c}8 \text { buckets/day } / 8 \\
\text { people }\end{array}$ \\
\hline \multirow[t]{2}{*}{ Health } & Clinic & \multicolumn{2}{|c|}{ Vaccination } & \multicolumn{3}{|c|}{ Trad. medicine \& TBAs } & \multicolumn{3}{|c|}{ Most common diseases } \\
\hline & Ghazni & \multicolumn{2}{|c|}{$\begin{array}{l}\text { Yes; } \\
\text { Last visit: } 3 \text { years } \\
\text { ago. }\end{array}$} & \multicolumn{3}{|c|}{$\begin{array}{l}\text { TBAs: none, but help each } \\
\text { other. It is estimated that } \\
10 \% \text { women die in child } \\
\text { birth, whilst } 20 \% \text { of babies } \\
\text { die during or shortly after } \\
\text { birth. Main causes of death } \\
\text { for the mothers include, } \\
\text { haemorrhaging and tetanus, } \\
\text { whilst in babies it is mainly } \\
\text { tetanus. There are absolutely } \\
\text { no doctors, clinicians or any } \\
\text { form of medicine in the area. }\end{array}$} & \multicolumn{3}{|c|}{$\begin{array}{l}\text { ADULTS: pneumonia; rheumatism; } \\
\text { tetanus } \\
\text { CHILDREN: whooping cough ( } 10 \\
\text { children were said to it at the time of } \\
\text { our visit); diarrhoea; vomiting; } \\
\text { ARIs; malnutrition; tetanus } \\
\text { GOITRE: 0 } \\
\text { NIGHT BLINDNESS: some }\end{array}$} \\
\hline \multirow[t]{3}{*}{ Nutrition } & \multicolumn{6}{|c|}{ Breast feeding } & \multicolumn{3}{|c|}{ Weaning } \\
\hline & Start & \multirow{2}{*}{\multicolumn{4}{|c|}{ Cessation during pregnancy }} & Length & \multirow{2}{*}{\multicolumn{2}{|c|}{$\frac{\text { Time }}{6 \text { months }}$}} & Weaning food \\
\hline & Immediately & & & & & 2 years & & & Oil; bread; tea \\
\hline
\end{tabular}

CHANGE IN LIFE WITH THE BLOCKADE: diseases, particularly malnutrition, have increased since the blockade, according to the population. The cost of food and seeds has gone up dramatically. They have stopped buying fertiliser, as it is so very expensive - they used to use it all the time before.

COMMENTS: The people sounded quite desperate and what they do have in crops, has been destroyed by fungus. They have no improved seeds and say that what they do have is no good. Their livestock are suffering from anthrax, blood leech and foot and mouth disease. Diseases have increased because of the deficit in vaccines and drugs. This village has an animal clinic, which is mobile most of the time, however, drugs are out of date and with no cold chain. There was a government school in Ghoreh Bayee, but it closed down because of financial reasons and the lack of support from the fallen government. Their poor economic state is blamed on the lack of education. 
Name of village: KHAWAT

\begin{tabular}{|c|c|c|c|c|c|c|c|c|c|}
\hline \multirow{3}{*}{$\begin{array}{c}\text { General } \\
\text { information }\end{array}$} & \multirow[t]{2}{*}{ Houses } & \multicolumn{3}{|c|}{ Families } & \multirow[t]{2}{*}{ People } & \multirow{2}{*}{$\begin{array}{c}<5 \\
\text { years }\end{array}$} & \multicolumn{3}{|c|}{ Water sources } \\
\hline & & Total & IDPs & From where & & & Kind & Who & Quantity \\
\hline & 30 & 50 & 5 & $\begin{array}{l}\text { Gharmoa; } \\
\text { Sia Kakh - } \\
\text { because of } \\
\text { fighting } \\
\end{array}$ & 250 & 40 & $\begin{array}{l}\text { well, } \\
\text { river. }\end{array}$ & women & $\begin{array}{c}8 \text { buckets/day } / 8 \\
\text { people }\end{array}$ \\
\hline \multirow[t]{2}{*}{ Education } & Nearest school & \multicolumn{3}{|c|}{ Qu'ranic school } & \multicolumn{3}{|c|}{ Shopping town } & \multicolumn{2}{|c|}{ Frequency of travel } \\
\hline & $\begin{array}{l}\text { None, used to } \\
\text { have own, } 5 \\
\text { years ago, } \\
\text { supported by } \\
\text { the Pakistani } \\
\text { Mujaheedin }\end{array}$ & \multicolumn{3}{|c|}{ Yes, but only in winter. } & & & & & \\
\hline \multirow[t]{2}{*}{ Health } & Clinic & & accination & \multicolumn{3}{|c|}{ Trad. medicine \& TBAs } & \multicolumn{3}{|c|}{ Most common diseases } \\
\hline & $\begin{array}{l}\text { None, if can, } \\
\text { take people to } \\
\text { Ghazni or Du } \\
\text { Abi }\end{array}$ & $\begin{array}{l}\text { Yes, } \\
\& \text { vita } \\
\text { Last } \\
\text { but } 2 \\
\text { the oth }\end{array}$ & $\begin{array}{l}\text { ut only polio } \\
\text { nin A now; } \\
\text { visit: March, } \\
\text { years ago for } \\
\text { er vaccines. }\end{array}$ & \multicolumn{3}{|c|}{$\begin{array}{l}\text { TBAs: none, though help } \\
\text { each other. It is estimated } \\
\text { that around } 50 \% \text { of babies } \\
\text { born, die soon after birth. } \\
30-40 \% \text { are thought to die of } \\
\text { tetanus, whilst others have } \\
\text { blue lips and foam around } \\
\text { their mouths } 40 \% \text { of } \\
\text { women giving birth, die } \\
\text { during or soon after } \\
\text { delivery. Causes of death are } \\
\text { thought be to blacenta } \\
\text { haemorrhaging, the plat } \\
\text { not coming out, green } \\
\text { tongue with convulsions. }\end{array}$} & \multicolumn{3}{|c|}{$\begin{array}{l}\text { ADULTS: neuromuscular } \\
\text { complaints } \\
\text { CHILDREN: pneumonia; measles; } \\
\text { whooping cough; diarrhoea; } \\
\text { vomiting } \\
\text { GOITRE: yes, especially amongst } \\
\text { women } \\
\text { NIGHT BLINDNESS: } 30 \%\end{array}$} \\
\hline \multirow[t]{3}{*}{ Nutrition } & \multicolumn{6}{|c|}{ Breast feeding } & \multicolumn{3}{|c|}{ Weaning } \\
\hline & Start & \multicolumn{4}{|c|}{ Cessation during pregnancy } & Length & \multicolumn{2}{|c|}{ Time } & Weaning food \\
\hline & $\begin{array}{l}2 \text { days after } \\
\text { birth; diluted } \\
\text { sugar \& } \\
\text { buttermilk. }\end{array}$ & \multicolumn{4}{|c|}{ Do not stop. } & 2 years & & onths & $\begin{array}{l}\text { Top of milk; sugar; } \\
\text { cow's milk; butter. }\end{array}$ \\
\hline
\end{tabular}

CHANGE IN LIFE WITH THE BLOCKADE: The diet was pretty much the same before the blockade, except that Kalool was not eaten and meat was eaten more often. Quantities were also bigger. People have poultry, but eggs are for selling only. A bag of wheat now costs 150,000 Afghanis, whereas before the blockade it cost 50,000 Afghanis.

DIET

AFTER BLOCKADE:

BREAKFAST: tea; bread (or if not available, bread made with Kalool)

LUNCH: tea; bread; Croute; rice

DINNER: tea; bread; Croute; rice

MEAT: $1 / 365$, or when an animal dies.

COMMENTS: this was a very 'open' village, where we were free to talk to the women without any interference from the men. They seemed very aware people and were quite free to give information. The village and people were in 'good' condition. There are no drugs, medical personnel or health structures here. Du Abi is one day's walk/2 hours by car, if a car is found and can afford the fare. Their own yields last 3 months, the deficit is bought in Du Abi ( 1 day) or Ghazni (2-3 days), by donkey. 
Name of village: KOHNADAY

\begin{tabular}{|c|c|c|c|c|c|c|c|c|c|}
\hline \multirow{3}{*}{$\begin{array}{c}\text { General } \\
\text { information }\end{array}$} & \multirow{2}{*}{ Houses } & \multicolumn{3}{|c|}{ Families } & \multirow{2}{*}{ People } & \multirow{2}{*}{$\begin{array}{c}<5 \\
\text { years } \\
\end{array}$} & \multicolumn{3}{|c|}{ Water sources } \\
\hline & & Tota & IDPs & From where & & & Kind & Who & Quantity \\
\hline & 25 & 50 & 1 & \begin{tabular}{|c|} 
Mazar-i \\
Sharif, \\
husband \\
killed in \\
fighting, so \\
fled \\
\end{tabular} & 187 & 30 & stream & women & $\begin{array}{c}9 \text { buckets } / \text { day } / 10 \\
\text { people }\end{array}$ \\
\hline \multirow{2}{*}{ Education } & Nearest school & \multicolumn{3}{|c|}{ Qu'ranic school } & \multicolumn{3}{|c|}{ Shopping town } & \multicolumn{2}{|c|}{ Frequency of travel } \\
\hline & None & \multicolumn{3}{|c|}{ Yes } & \multicolumn{3}{|c|}{ Quiork } & \multicolumn{2}{|c|}{$\begin{array}{l}\text { 3-4 times per year, by } \\
\text { donkey, horse, mule or car }\end{array}$} \\
\hline \multirow[t]{2}{*}{ Health } & Clinic & \multicolumn{2}{|c|}{ Vaccination } & \multicolumn{3}{|c|}{ Trad. medicine \& TBAs } & \multicolumn{3}{|c|}{ Most common diseases } \\
\hline & $\begin{array}{c}\text { Du Abi, but } \\
\text { no-one goes } \\
\text { there anymore } \\
\text { - too far and } \\
\text { don't believe } \\
\text { in it } \\
\end{array}$ & \multicolumn{2}{|l|}{ No; } & \multicolumn{3}{|c|}{$\begin{array}{l}\text { Yoghurt and pepper given to } \\
\text { cholera patients. }\end{array}$} & \multicolumn{3}{|c|}{$\begin{array}{l}\text { ADULTS: paralysis; cholera; ARIs } \\
\text { CHILDREN: ARIs; diarthoea } \\
\text { measles } \\
\text { GOITRE: } 0 \\
\text { NIGHT BLINDNESS: lots }\end{array}$} \\
\hline \multirow[t]{3}{*}{ Nutrition } & \multicolumn{6}{|c|}{ Breast feeding } & \multicolumn{3}{|c|}{ Weaning } \\
\hline & Start & & Cessation & ring pregnanc & & Length & & ime & Weaning food \\
\hline & $\begin{array}{l}\text { Immediately, } \\
\text { unless sick; if } \\
\text { sick, feed oil } \\
\text { for a few days } \\
\text { and then start } \\
\text { on breast } \\
\text { milk, } \\
\text { particularly if } \\
\text { have 'dark } \\
\text { vein' in } \\
\text { umbilici } \\
\end{array}$ & & & nediate & & 2 years & $5 \mathrm{~m}$ & onths & $\begin{array}{l}\text { Cow's milk; } \\
\text { porridge of whea } \\
\text { flour and oil }\end{array}$ \\
\hline
\end{tabular}

CHANGE IN LIFE WITH THE BLOCKADE: drugs, wheat, oil, salt, tea, clothes, are all available throu smuggling, but are not accessible because of high prices. $1 \mathrm{cow}=1(90 \mathrm{Kg})$ bag of wheat, but before the blockade was worth 3 bags. Prices have increased 3-4 fold. It is a great risk to smuggle, as the Talêban will seize goods and $\mathrm{m}$ even kill the trader.

\begin{tabular}{|c|c|c|}
\hline$\overline{\text { DIET }}$ & $\begin{array}{l}\text { AFTER BLOCKADE: } \\
\text { BREAKFAST: tea; bread } \\
\text { LUNCH: doughe; tea; bread; oil -if } \\
\text { available, make Croute soup with } \\
\text { doughe - for celebrations } \\
\text { DINNER: doughe; tea; bread; oil -if } \\
\text { available, make Croute soup with } \\
\text { doughe - for celebrations } \\
\text { MEAT: none, unless livestock die }\end{array}$ & $\begin{array}{l}\text { BEFORE BLOCKADE: } \\
\text { BREAKFAST: butter; tea; mi } \\
\text { bread } \\
\text { LUNCH: doughe; tea; bread; } \\
\text { meat } \\
\text { DINNER: potato soup; rice; Crou } \\
\text { MEAT: } 1 / 20\end{array}$ \\
\hline
\end{tabular}

COMMENTS: most people are working others land. From each 10 sears produced, 2 sears are given to the owner. Most people have 2-3 livestock. Their crops feed them for 4 months, which they store for the winter. The res the time, shopping is done through the buying of smuggled goods from Ghazni and Quiork. Sources of income inc work in Pakistan/Iran, if possible, for 2-3 years. Poorer people exchange their livestock for wheat. 
Name of village: QARCHA

\begin{tabular}{|c|c|c|c|c|c|c|c|c|c|}
\hline \multirow{3}{*}{$\begin{array}{c}\text { General } \\
\text { information }\end{array}$} & \multirow[t]{2}{*}{ Houses } & \multicolumn{3}{|c|}{ Families } & \multirow[t]{2}{*}{ People } & \multirow{2}{*}{$\begin{array}{c}<5 \\
\text { years }\end{array}$} & \multicolumn{3}{|c|}{ Water sources } \\
\hline & & \begin{tabular}{|l|} 
Total \\
50
\end{tabular} & \multirow{2}{*}{$\frac{\mathrm{IDPs}}{15}$} & From where & & & Kind & Who & Quantity \\
\hline & 20 & & & $\begin{array}{l}\text { Burgeray; } \\
\text { Khawat; } \\
\text { Jaghoori; } \\
\text { Malestan } \\
\end{array}$ & 280 & 60 & stream & women & $\begin{array}{l}12 \text { buckets/day/6 } \\
\text { people }\end{array}$ \\
\hline \multirow[t]{2}{*}{ Education } & Nearest school & \multicolumn{3}{|c|}{ Qu'ranic school } & \multicolumn{3}{|c|}{ Shopping town } & \multicolumn{2}{|c|}{ Frequency of travel } \\
\hline & None & \multicolumn{3}{|c|}{ Yes } & & & & & \\
\hline \multirow[t]{2}{*}{ Health } & Clinic & \multicolumn{2}{|c|}{ Vaccination } & \multicolumn{3}{|c|}{ Trad. medicine \& TBAs } & \multicolumn{3}{|c|}{ Most common diseases } \\
\hline & None & \multicolumn{2}{|l|}{ No; } & \multicolumn{3}{|c|}{ (3) } & \multicolumn{3}{|c|}{$\begin{array}{l}\text { ADULTS: diarrhoea } \\
\text { CHILDREN: pneumonia; abdomina } \\
\text { pains; diarrhoea } \\
\text { GOITRE: } 0 \\
\text { NIGHT BLINDNESS: not much } \\
\end{array}$} \\
\hline \multirow[t]{3}{*}{ Nutrition } & \multicolumn{6}{|c|}{ Breast feeding } & \multicolumn{3}{|c|}{ Weaning } \\
\hline & Start & \multicolumn{4}{|c|}{$\frac{\text { Cessation during pregnancy }}{\text { When find }}$} & Length & \multicolumn{2}{|c|}{ Time } & Weaning food \\
\hline & \begin{tabular}{|l|} 
Most \\
immediately; \\
some 3 days; \\
oil
\end{tabular} & \multicolumn{4}{|c|}{ When find out } & $\begin{array}{c}21 / 2 \\
\text { years }\end{array}$ & \multicolumn{2}{|c|}{6 months } & Cow's milk; bread \\
\hline \multicolumn{10}{|c|}{$\begin{array}{l}\text { CHANGE IN LIFE WITH THE BLOCKADE: food very expensive and limited, smuggling has become common } \\
\text { practice, but has made life very difficult. }\end{array}$} \\
\hline ME & hy look & ng lot, & $\begin{array}{l}\text { ite cle } \\
\text { ence. }\end{array}$ & & & & & & \\
\hline
\end{tabular}

Name of village: QARGEH BALAH

\begin{tabular}{|c|c|c|c|c|c|c|c|c|c|}
\hline \multirow{3}{*}{$\begin{array}{c}\text { General } \\
\text { information }\end{array}$} & \multirow[t]{2}{*}{ Houses } & \multicolumn{3}{|c|}{ Families } & \multirow[t]{2}{*}{ People } & \multirow{2}{*}{$\begin{array}{c}<5 \\
\text { years } \\
\end{array}$} & \multicolumn{3}{|c|}{ Water sources } \\
\hline & & Total & IDPs & From & & & Kind & Who & Quantity \\
\hline & 50 & 120 & 10 & $\begin{array}{l}\text { Shahresta } \\
\text { nKabul; } \\
\text { Malestan; } \\
\text { Charsad } \\
\text { Khaneh } \\
\end{array}$ & 800 & 100 & \begin{tabular}{|c|} 
spring \\
-15 \\
minute \\
s walk \\
away \\
\end{tabular} & $\begin{array}{c}\text { wome } \\
n\end{array}$ & \\
\hline \multirow[t]{2}{*}{ Education } & Nearest school & \multicolumn{3}{|c|}{ Qu'ranic school } & \multicolumn{3}{|c|}{ Shopping town } & \multicolumn{2}{|c|}{ Frequency of travel } \\
\hline & $\begin{array}{c}\text { Du Abi scientific } \\
\text { school, have to } \\
\text { pay towards } \\
\text { teachers salary } \\
\end{array}$ & \multicolumn{3}{|c|}{ Yes } & \multicolumn{3}{|c|}{ 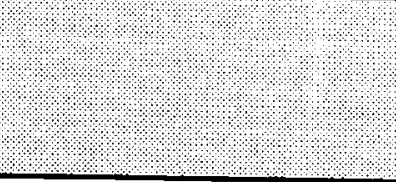 } & & \\
\hline \multirow[t]{2}{*}{ Health } & Clinic & \multicolumn{2}{|c|}{ Vaccination } & \multicolumn{3}{|c|}{ Trad. medicine \& TBAs } & \multicolumn{3}{|c|}{ Most common diseases } \\
\hline & $\begin{array}{l}\text { Du Abi, private } \\
\text { pharmacy, } 70 \\
\text { minutes walk, but } \\
\text { in fact go to } \\
\text { Behsud, Ghazni } \\
\text { or Jaghoori }\end{array}$ & \multicolumn{2}{|c|}{$\begin{array}{l}\text { Yes, the village is on } \\
\text { a rotational system } \\
\text { and goes to Du Abi } \\
\text { when its turn comes } \\
\text { up. } \\
\text { Last visit: May. }\end{array}$} & & & & \multirow{2}{*}{\multicolumn{3}{|c|}{\begin{tabular}{l} 
ADULTS: stomach pains; \\
diarrhoea \\
CHILDREN: \\
diarrhoea \\
GOITRE: 0 \\
NIGHT BLINDNESS: lots, some \\
have gone as far as ulceration of \\
the cornea and become blind \\
\multicolumn{2}{c}{ Weaning } \\
\end{tabular}}} \\
\hline \multirow[t]{3}{*}{ Nutrition } & \multicolumn{6}{|c|}{ Breast feeding } & & & \\
\hline & Start & \multirow{2}{*}{\multicolumn{4}{|c|}{$\begin{array}{l}\text { Cessation during pregnancy } \\
\text { Immediately on finding out. }\end{array}$}} & Length & & Weaning food \\
\hline & Immediately & & & & & 2 years & & & Bread \\
\hline
\end{tabular}


CHANGE IN LIFE WITH THE BLOCKADE: people are very poor, with not enough food and zero economy. Prices have increased greatly and there just is not enough money to buy anything. A lot of greens and alfalfa is now eaten. I sear of potatoes now costs 50,000 Afghanis.

\begin{tabular}{|l|l|l|}
\hline DIET & AFTER BLOCKADE: & BEFORE BLOCKADE: \\
& BREAKFAST: boiled water (tea & MEAT: $1 / 7$ \\
& when available); bread & \\
LUNCH: greens; potatoes/bread; tea & \\
& DINNER: greens; potatoes/bread; tea \\
& MEAT: never & \\
\hline
\end{tabular}




\begin{tabular}{|c|c|c|c|c|c|c|c|}
\hline & & \multicolumn{6}{|c|}{ SPECIAL ANNUAL EVENTS } \\
\hline & \begin{tabular}{|c|} 
RECURRING \\
ANNUAL \\
EVENTS \\
\end{tabular} & $\begin{array}{l}1372 \\
1993 \\
\end{array}$ & $\begin{array}{l}1373 \\
1994 \\
\end{array}$ & \begin{tabular}{|l|}
1374 \\
1995 \\
\end{tabular} & $\begin{array}{l}1375 \\
1996 \\
\end{array}$ & \begin{tabular}{|l|}
1376 \\
1997 \\
\end{tabular} & $\begin{array}{l}1377 \\
1998 \\
\end{array}$ \\
\hline $\begin{array}{l}\text { JANUARY } \\
\text { DALOO }\end{array}$ & $\begin{array}{l}\text { Winter } \\
\text { holidays for } \\
\text { schools }\end{array}$ & & 53 & 41 & 29 & 17 & 5 \\
\hline $\begin{array}{l}\text { FEBRUARY } \\
\text { HOUT } \\
\end{array}$ & $\begin{array}{c}\text { Delivery } \\
\text { of sheep and } \\
\text { goats } \\
\end{array}$ & & 52 & 40 & \begin{tabular}{|l|}
28 \\
Cold \\
winter \\
\end{tabular} & 16 & 4 \\
\hline $\begin{array}{l}\text { MARCH } \\
\text { HAMAL } \\
\end{array}$ & $\begin{array}{c}\text { New Year } \\
\text { Spring }\end{array}$ & & \begin{tabular}{|l|}
$\mathbf{5 1}$ \\
Scliools \\
start \\
\end{tabular} & \begin{tabular}{|l|}
39 \\
Schools \\
start \\
\end{tabular} & \begin{tabular}{|l|}
27 \\
Aide \\
Qorban \\
\end{tabular} & \begin{tabular}{|l|}
15 \\
Aide \\
Qorban \\
\end{tabular} & 3 \\
\hline $\begin{array}{l}\text { APRIL } \\
\text { SAUR }\end{array}$ & $\begin{array}{l}\text { Start of } \\
\text { mulberry } \\
\text { season }\end{array}$ & & \begin{tabular}{|l|}
$\mathbf{5 0}$ \\
Aide \\
Qorban \\
\end{tabular} & \begin{tabular}{|l|}
$\mathbf{3 8}$ \\
Aide \\
Qorban \\
\end{tabular} & 26 & $\begin{array}{l}14 \\
\text { Aashoora } \\
\end{array}$ & 2 \\
\hline $\begin{array}{l}\text { MAY } \\
\text { JOWZAR } \\
\end{array}$ & $\begin{array}{c}\text { Cutting of } \\
\text { wheat }\end{array}$ & & $\begin{array}{l}49 \\
\text { Aashoora } \\
\end{array}$ & $\begin{array}{l}37 \\
\text { Aashoora } \\
\end{array}$ & $\begin{array}{l}25 \\
\text { Aashoora }\end{array}$ & $\begin{array}{l}13 \\
\text { Prophet's } \\
\text { birthday } \\
\end{array}$ & 1 \\
\hline $\begin{array}{l}\text { JUNE } \\
\text { SARATAN }\end{array}$ & $\begin{array}{l}\text { Grape season } \\
\text { Ripe mulberries }\end{array}$ & & 48 & 36 & 24 & 12 & SURVEY \\
\hline $\begin{array}{l}\text { JULY } \\
\text { ASSAD } \\
\end{array}$ & $\begin{array}{c}\text { Independence } \\
\text { Day } \\
\text { Very Hot } \\
\end{array}$ & 59 & 47 & 35 & 23 & 11 & SURVEY \\
\hline $\begin{array}{l}\text { AUGUST } \\
\text { SUNBOLEH }\end{array}$ & $\begin{array}{l}\text { Pashtunistan } \\
\text { Day } \\
\text { End of crops }\end{array}$ & 58 & 46 & 34 & 22 & 10 & \\
\hline $\begin{array}{l}\text { SEPTEMBER } \\
\text { MEEZAN }\end{array}$ & $\begin{array}{l}\text { Closing of } \\
\text { irrigation } \\
\text { system/clean }\end{array}$ & 57 & 45 & 33 & 21 & 9 & \\
\hline $\begin{array}{l}\text { OCTOBER } \\
A Q R A B \\
\end{array}$ & $\begin{array}{c}\text { Sowing } \\
\text { of } \\
\text { seeds }\end{array}$ & 56 & 44 & 32 & 20 & 8 & \\
\hline $\begin{array}{l}\text { NOVEMBER } \\
\text { GHOOS }\end{array}$ & $\begin{array}{c}\text { Start } \\
\text { of } \\
\text { rain }\end{array}$ & 55 & 43 & 31 & 19 & 7 & \\
\hline $\begin{array}{l}\text { DECEMBER } \\
\text { JADI } \\
\end{array}$ & Very cold & 54 & 42 & $\begin{array}{l}30 \\
\text { Ramasan }\end{array}$ & $\begin{array}{l}18 \\
\text { Ramasan } \\
\end{array}$ & $\begin{array}{l}6 \\
\text { Ramasan }\end{array}$ & \\
\hline
\end{tabular}


Appendices for Part IV

Micro-Macro Context 
Afghanistan part of one or both of the two large empires dominating the region:

Sfavid Persia and Moghul India

1740s Weakening of these empires permits Ahmad Shah, a Durrani Pashtun and mercenary in the service of the Persian king, to establish the beginnings of an Afghan confederation.

1770s Dissolution of Shah's empire and increasing foreign (particularly Tsarist Russia and British) interest

1800s Kingdom of Kabul gradually established

1839-42 First Anglo-Afghan war to install a client ruler ends in failure

1878 Second Anglo-Afghan war

1879 Treaty of Gandanak gives the British control over Afghanistan's foreign policy and cedes certain border areas to British India

1880 Amir Abdur Rahman takes the reins of power

1893 Demarcation of the Durand Line defining the boundary between India and Afghanistan and cutting right through areas inhabited by Pashtun tribes

Hazarajat incorporated into the Afghan state under British-backed King Abd al-Rahman

Division of Hazarajat into 3 distinct provinces - for administrative purposes (tax collection) and to encourage disunity and so facilitate governance

Imposition of Sunni Islam onto Hazara Shia's leading to flight to Russia, Pakistan and Iran by some

1901 Amir Abdur Rahman replaced by Habibullah

1919 Assassination of Amir Habibullah

Independence from the British empire declared by King Amanullah with recognition by the new Soviet Government, the Turks and the Germans - but not by the British

Third Anglo-Afghan war leads to the Treaty of Rawalpindi and the reduction of British influence

1920s Policy of isolation against foreign interests pursued

A group known as the 'Young Afghans', styled along similar lines to the 'Young Turks' within the Ottoman Empire champion the cause of modernisation

1921 Creation of educational opportunities for women

Introduction of a Family Code banning child marriage and placing restrictions on the expenses associated with marriage

1923 Introduction of a new constitution abolishing slavery and granting equality to all Afghan citizens

Reorganisation of tax system (principally pertaining to land and livestock), to pay for reforms, with tax collection becoming monetarised (as opposed to in-kind) increasing recognition of private property and sale of crown lands

Reforms are made to attempt to 'modernise' Afghanistan along Western lines involving relaxation of foreign trade restrictions, the establishment of a few military-oriented smallscale industries in Kabul and improvements to some of the roads

Reduction in army salaries leads to demoralisation

1924 Rebellion in Paktia against increasing government interference revealed weakness of the army, with recourse having to be made to tribal soldiers

1927/8 Gaining influence of the policies of Kamal Ataturk in Turkey and Reza Shah in Iran leads to a drive to abolish hereditary titles, reduce corruption and introduce compulsory education for both girls and boys, discarding of the veil and the wearing of Western dress

1929 Overthrow of King Amanullah by Bach-i Saqao (a Tajik), triggers fight to restore the former

Abolition of Amanullah's policies 
Capture of Bach-i Saqao by General Mohammed Nadir Shah, subsequently declared King

Rebuilding of the army with British support and concessions to traditionalist forces:

1931 The ulama are given a stronger role in legal matters with the Hanafi Shari'a of Sunni Islam established as the official religion of the country .

The rural elite are given the power to veto changes in taxation through parliament, reducing the power of the State to finance development on its own.

1930s Pashtun administrators appointed for the Hazarajat and policy of Pashtunisation promulgated linguistically and culturally - with repression of Hazara intellectuals

Occupation of Hazara lands by Pashtun nomads - as promoted or sanctioned by the government

Conscription of Hazaras into army and employment into civil service - but no promotion beyond the level of colonel or director

Establishment of joint stock companies for trade together with Afghanistan's first bank, Bank-i Milli, in collaboration with the government

Credits are extended for cotton cultivation and the textile and sugar industries

1933 Assassination of Nadir Shah by a Hazara intellectual, Abdul Khaliq

Succession of Nadir Shah by Mohammed Zahir Shah

Further Pashtunisation of the Hazarajat causes a rebellion that is brutally suppressed with arrest and execution of well-known Hazara leaders

Re-writing of historical literature and documents to propound Pashtun supremacy

Hazaras forced to conceal their identity when seeking identity cards, believing that their security depended upon their silence

1947 Independence of India and the newly born Pakistani State bringing to the fore questions about the validity of the Durand Line

Support is given to the demand for self-determination by some of the Pashtuns in Pakistan's North West Frontier Province

1950 Closure of Pakistani border to Afghanistan causes Afghanistan to turn to the Soviet Union for trade

1953 Mohammed Daoud becomes Prime Minister

Pashtunisation of the country is intensified

Leads to a border dispute with Pakistan and skirmishes

Support by the Afghan government to secessionist movements in Pakistan's North-West Frontier and Baluchistan Provinces given high Pashtun numbers

Refusal of US to provide financial assistance for economic development and military expenditures leads to increasing reliance upon the Soviet Union (in search of allies and a desire to counterbalance American penetration in the region)

1955 Pakistan joins the Baghdad Pact and SEATO, two American-oriented treaties

1956 Soviet Union economic and military aid to Afghanistan is launched (low interest loans for the purchase of Soviet capital equipment, equipment and training of the Afghan army, covert development of pro-Soviet political groups within the Kabul-based intelligentsia, which voiced demands for structural political reforms)

First five year development plan is drawn up focusing on basic infrastructure (roads and power plants), together with investments in mining and, to a lesser extent, manufacturing

1950s Armed insurrection in the Hazarajat against taxes palliated by the repeal of certain taxes

1959 Law permitting removal of the veil for women

1961 Closure of the Afghan-Pakistan border causing a damaging economic crisis

1963 Resignation of Daoud, appointment of a replacement, improvement of relations with Pakistan and reopening of the border

1964 Constitution promulgated, but riddled with contradictions

1965 Agreement according duty-free access for Afghanistan-bound goods comes into force 
Parliamentary elections result in large numbers of the rural elite and the ulama gaining seats in the Loya Jirga - although final power still remained with the royal family

Some representatives of the various Communist parties also found seats

1967 Exploitation of natural gas reserves begins - estimated at 100 to 150 billion cubic metres mostly exported at prices below those of the world market, to the Soviet Union;

Attention in the third five year development plan shifts to supporting the productive capacity of small farmers and improving irrigation

11969 Parliamentary elections

1972 Establishment of an Industrial Development Bank

Musa Shafiq appointed to premiership and attempts to strengthen his political base by recourse to Islam

1973 Republican coup d'Etat by Prince Daoud bringing him back into politics overthrowing Zahir Shah - with help from the Parchamis and their sympathisers in the Air Force and Tank Brigade due to exclusion from prevailing patronage networks

Friendship with the Soviet Union is stressed

Banning of all political groups and suppression of Islamists and Maoists

Renewal of hostilities with Pakistan

1970s Institution of a non-communist one party system, the National Revolutionary Party

Removal of Parchamis from positions of power

Opening up of country to business interests from States other than the Soviet Union

Rapprochement with Pakistan (with closure of the border to Baluchi separatists), and oil rich States, particularly Iran, Saudi Arabia and Egypt - all regarded with mistrust by the Soviet Union

Campaign to strengthen Afghanistan's position in the Non-Aligned Movement

Drought in the Hazarajat, with many dying due to a dearth of emergency supplies

1975 Islamic-oriented uprising in the Panjsheer Valley

1977 Increasing establishment by Khalq of links to the military

Reconciliation between Khalq and Parcham

A new constitution provides for a one-party parliamentary system with real power vested in the president

Apr. '78 Communist coup under PDPA - without any kind of basis for a mass revolution - installs Nur Mohammed Taraki as President

Increasing dominance by the Khalq faction

July '79 Hazara rebellion gains importance in Hazarajat, in the event of which reprisals are suffered by the Hazara population of Kabul and arrests made of Hazara leaders

Sept. '79Coup d'Etat incited by Prime Minister Amin in the aftermath of a so-called revolution leading to the accession of the Parcham faction

Civil war begins

Dec. '79 Invasion by Soviet forces results in Babrak Kamal at head of a client state, in which Parcham dominates

1985 Perestroika and Glasnost begin in the Soviet Union

1986 Dr Najibullah (previously head of State Security), replaces Babrak Kamal

1987 A cease-fire is announced and reconciliation talks offered by the Kabuli government - and refused by the Mujahideen

Mar. '88UN-mediated multilateral negotiations begin

Feb '89 Soviet withdrawal following the Geneva Accords

Withdrawal of Soviet troops exposes underlying divisions within the Mujahideen

Formation of Hezb-i Wadhat in Iran

Afghan Interim Government takes over headed by Najibullah and integrating most of the Mujahideen groups - the seven main Peshawar parties - but the AIG is unable to function with any coherency 
Feb '90 Export ban imposed by Pakistan due to deteriorating state of Pakistani economy and distortionary effects created by trade with Afghanistan

Subsequent rise in cereal prices

May '90 Pakistani export ban lifted

1991 Collapse of the Soviet regime and effective halt to any remaining Soviet assistance

1992 Mujahideen close in on Kabul and Najibullah resigns

A Tajik-Uzbek coalition expels Hekmatyar and Hezb-i Islami fighters from Kabul

Mujahideen leaders agree on a framework for an interim government, with Sigbhatullah

Mojadedi to be head of state for two months, followed by Burhanuddin Rabbani for four months

Establishment of an Islamic state based on Sunni Hanafi law

Power reverts from Pashtuns to Tajiks under Burhanuddin Rabbani of the Jamat-i Islami

Two Hazaras participate in the formation of the cabinet

Inter-factional fighting among Mujahideen, with the ideological dimension of the conflict losing significance as non-Pashtun Sunni politco-ethnic considerations gain in importance reinforced by the integration of the once 'national' army - with weapons

Squabbling leads to a military offensive by Rabbani and his ally on Hezb-i Wadhat military bases and Hazara residential areas in Kabul

Hezbi-i Islamic, despite holding the premiership, bombard the capital

1993 Rabbani is chosen for a second term as president amid controversy

Divide and rule policy intensifies, with attempts made to fan the flames of ethnic

animosities and so divert attention away from the governing body: Shi'ite commanders are paid off by Rabbani and defect

An alliance is forged between Mazari of the Hezh-i Wadhat and Gulbuddin Hekmatyar's Hezb-i Islami

Fighting between Hezb-i Islami and Jamiat intensifies

Military and logistical support is given by Iran to Kabul (Tajiks)

1994 Restrictions imposed on goods destined for Afghanistan, due to diversion onto Pakistani markets and undermining of local assemblers and manufacturers, and strains with Kabul government

Pakistan declares intention to re-open trade routes to Central Asia shut down after the Soviet invasion

Advent of the Talêban who free the first convoy to ply the route from ambush by Mujahideen brigands

The Talêban overrun Kandahar

Military attack on Hazara community in Kabul

Mazari forges links with the Talêban

Mar'95 Military assault on Hazaras of Kabul allegedly due to attacks by Hezb-i Wadhat in conjunction with the Talêban on Kabul

Increasing numbers of Hazaras leave Kabul

Assassination of Mazari, leader of the Hazara Shi 'ite Hezb-i Wadhat Party by Talêhan

1995 The Talêban advance gains ground

Liberation of Hazarajat under forces of Khalili and establishment of Bamiyan as the command centre of Hezb-i Wadhat to rebuild the regime's civil and administrative structures

Expulsion of large numbers of Tajiks from the Hazarajat

May '96 Rabbani and Hekmatyar sign a power-sharing agreement - with Iran as the driving force behind this

Sept '96 Capture of Kabul by the Talêban

Hanging of Najibullah 
May '97 Temporary capture of Mazar-i Sharif by the Talêban due to defection within the Northern Alliance, followed by massacre of the Talêban forces

Repression in Kabul is stepped up due to fear of a similar popular uprising

Closure of border with Uzbekistan

Economic blockade of Hazarajat imposed

Aug '97 Plane 'crash in Bamiyan leads to death of the Pashtun prime minister of the Northern

Alliance, Abdur Rahim Ghafourzai, who could have appealed to the Talêban's support base

Oct '97 The country moves from being the Islamic State of Afghanistan to being the Islamic Emirate of Afghanistan

Nov'97 Pakistan authorises the UN to fly wheat (perhaps 2, 000 to 3,000 tons), to Bamiyan after the WHP reports tens of thousands of people on the verge of starvation in Hazarajat connivance of Taleban?

1998 Return of small numbers of Tajiks to the Hazarajat

July '98 Expulsion of NGOs from Kabul leaving the ICRC and UN only due to non-compliance with new Talêban regulations

Aug '98 Capture of Mazar-i Sharif and Pul-i Komri by the Talêban, followed by massacre of 300 Hazaras

Bombing of Afghanistan by Americans in search of Osama Bin Laden in connection with a number of terrorist attacks, including that in Nairobi, Kenya in the same month

Sept '98 Capture of Bamiyan, capital of the Hazarajat by the Talêban, signifies almost complete Talêban control over the country

Restoration of diplomatic ties between Iran and the West gains importance

Iran threatens war and mobilises more than 200, 000 troops on the shared border with Afghanistan

Oct '98 Talêban offer to combat drug trade in hope of international recognition 


\section{A. Trade, Power and Iñternationalism:}

In keeping with its geographical position, Afghanistan's key foreign exchange earners, fruit, vegetables and nuts, have traditionally been destined for Pakistani and Indian markets, with most of this foreign trade (as well as that of fur, cotton and carpets), being conducted through Pakistan's southern port city of Karachi. Similarly for food and material imports as mentioned earlier. The overland route through the Soviet Union only gained in importance during the latter's occupation. Today, however, with the assumption of power by the Talêban and the freer movement of traffic that has eventually accompanied their control, trade with Pakistan has resurfaced as the principal exit point and source of foreign goods, both food and non-food - with the damage sustained during almost 20 years of war furthering the need for such foreign trade. This then, has resulted in a significant level of dependence on one country alone, so doing little to alleviate the country's general vulnerability.

At the same time, the country's own reserves of oil and mineral deposits (iron, chrome, copper, bauxite, emeralds and so on - most of which are not presently commercially exploited), together with its access to the gas and oil rich CIS have gained in importance - all the more so as a result of the international ostracism of Iran.

It is thought that the oil route alone could, on day one, start pumping around one million barrels of oil per day, and that within a few years, once linked with other fields in Central Asia, the pipeline could pump 5 million barrels a day. Thus, an international consortium, spearheaded by Unocal of the United States and Delta of Saudi Arabia, have tried on successive occasions to negotiate with the Talêban over the construction of a gas pipeline stretching from Turkmenistan to the Pakistani port of Gwador - and avoiding all contact with Iranian soil via Afghanistan (so avoiding a flow of foreign exchange earnings into Iranian coffers). Other members of the consortium include the Turkmenistan government, Itochu of Japan, Hyundai of South Korea and Pakistan's Crescent group ${ }^{79}$. Indeed, the Pakistani government has a number of other important interests, including contracts to build transport infrastructures - as well as market possibilities both within Afghanistan and in the neighbouring States.

Such foreign interests have meant that Afghanistan has been subject to a significant level of 'outside' interference which has generally tapped into previously existing regional dynamics based on politico-cultural elements - both directly through neighbouring country government policy and indirectly through third party lobbying. Thus, America operates through Pakistan and Russia through the CIS states. Companies like Unocal, meanwhile, have links with American policy-makers, and in this particular case, Unocal has also gone so far as to offer donations to aid agencies operating in the country, and has set up a project to train Afghans to work on the proposed pipeline ${ }^{80}$.

The overall result, then, is that Afghanistan's political and militia groups are nurtured - and sometimes reprimanded - by a significant number of external players, themselves motivated by a mixture of both commercial and politico-cultural interests. This said, however, Iran's pariah status may be coming to an end, given that the restoration of diplomatic links with Britain, France and the United States is gaining pace. With the reduced ability of Pakistan to finance the Talêban following the reverberations of its nuclear test and its current economic crisis, and with the Talêban still unable

\footnotetext{
${ }^{79}$ Maley, W.; 1998; Fundamentalism Reborn? Afghanistan and the Talêban; Hurst \& Co.

${ }^{80}$ Economist Intelligence Unit; 1998; Afghanistan Country Profile; EIU; p.27.
} 
to gain international recognition (although trying its best through offers to combat the drug trade despite the-drug barons present in the movement - and so on), it may well be that the emphasis on commercial interests over the next few years, will shift towards Iran - leaving the Talêban, and by implication, Afghanistan, out in the cold.

Nevertheless, it should also be noted that to a certain degree, the Talêban have proved somewhat less malleable and less dependent than might otherwise be expected. An unprecedented depth of contacts and support in Pakistan in general has, at times, enabled them to defy the ISI by enlisting the help of regional government ministers or the transport Mafia. Moreover, their social history has also allowed them to be extremely well-connected to many Pakistani State institutions, political parties and business groups in what was already an extremely fragmented Pakistani power structure, such that the Talêban have never been beholden to one exclusive Pakistani lobby ${ }^{81}$. The diagram overleaf attempts to summarise this in some way.

\footnotetext{
${ }^{81}$ Maley, W.; 1998; Fundamentalism Reborn? Afghanistan and the Talêban; Hurst \& Co.
} 


\section{RUSSIA}

UZBEKISTAN
- a bulwark against Islamic resistance and drug trafficking;

- ethno-cultural links;

- potential border problems;

- commercial interests regarding access to Indian Ocean and gas pipeline;

- reaffirmation independence from Russia and former Soviet Union;

- humanitarian assistance admitted (military denied), including supplies of flour through Dostum;

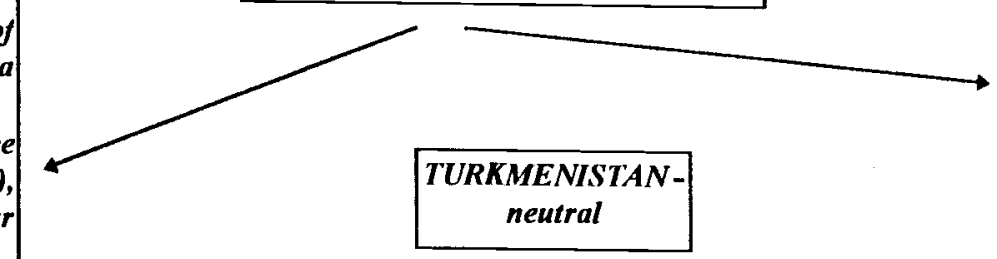

TA.JIKISTAN

- existence of Afghan refugees in territory;

- ethno-cultural links (Persian-speaking Sunnis);

- civil war means that support limited;

- use of Russian controlled Kerlyob airbase by Massoud + Rabbani (=Jamat-i Islami)

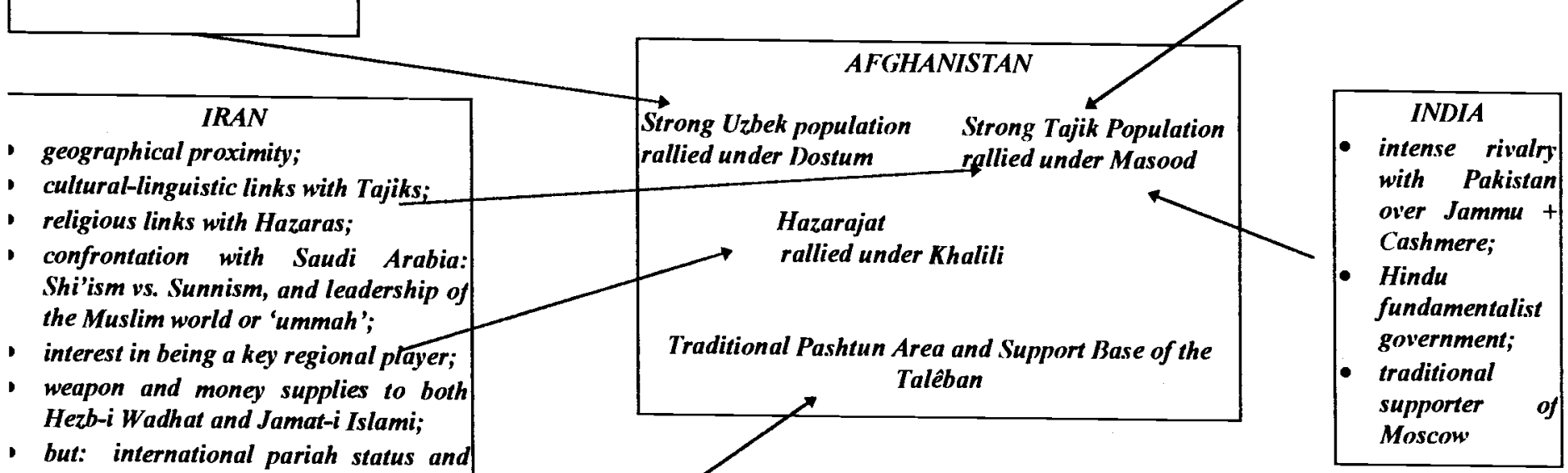

- but: international pariah status and need to change this - leading to the restoration of diplomatic links;

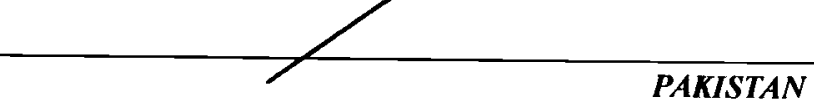

- border question, with Pashtun North West Frontier Province and Baluchistan - and need to install a Pakistani-friendly government;

- commercial interests in Central Asia: gas pipeline to Uzbekistan, highways and railways - and competition with Turkey and Iran given collapse of Soviet Union;

- official logistics, communications and training support given to Talêban through Pakistani Inter-Services Intelligence (previous support given to Hezb-i Islami);

- links nurtured between Afghan refugees and Pakistani Jamat Ulema-e Islami;

- informal, but strong, links between Pashtun business community and local government administrators in Pakistan on the one hand, and Talebban on the other;

- support from US and Saudi Arabia channelled through Pakistani government;

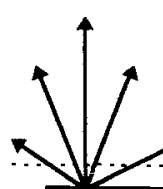

- but: economic crisis and nuclear test in July 1998 has called US support into question;

\section{UNITED NATIONS}

- agencies working Afghanistan;

- non-recognition Security Council Talêban administration due to human rights;
UNITED STATES OF AMERYCA

previously part of the Cold War game, support for Soviet opposition forces and then potential 'peace and stability makers' (the Taleban) channelled through CLA in particular, to American ally, Pakistan, but relationships with latter called into question due to nuclear test;

problems of human rights discourse and record of Talêban;

commercial interests of UNOCAL in gas pipeline link with Uzbekistan;

unilateral action taken in August 1998 to bomb Osama Bin Laden, reputed international terrorist and in hiding in Afghanistan;

weaponry and financial support;

\section{IMF and IBRD}

negotiations with Pakistan for release of needed

negotiations with Talêban for loans but reticence of member states

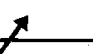

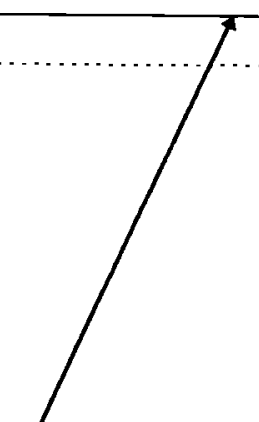

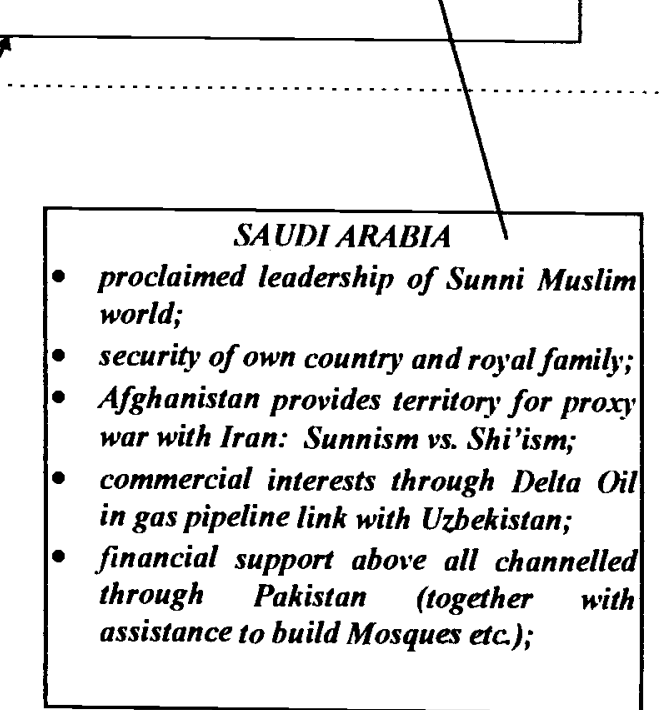

KEY PLA YERS IN THE AFGHAN CRISIS AUG/SEPT. 1998 


\section{B. THE STATE, DEVElopMENT AND AUTONOMY:}

The history of Afghanistan has been characterised by a weak State or by weak governing bodies, not just vis-à-vis the outside world, but also internally - confronted by a complex array of relatively strong micro-societies tending towards autonomy. Throughout, the State was effectively symbolised by a ruling dynasty or intervening government (whether British, Soviet or otherwise engendered), which exercised control over a certain number of cities or towns, serving as both military garrisons and centres of administration. Beyond these, the authority of the State corresponded to the extent of the fluctuating area where it was capable of levying taxes, itself dependent on different configurations of kinship and patronage - although trade, culture, moral values or religion often provided a bridge between the two.

Conquest of trade routes or agricultural regions was minimal and acquiescence to State authority and 'national' army loyalty tended rather to fluctuate with the strength and fortunes of micro-society leaders. British invasion and the later Jihaad against Soviet occupation both provided scope for tribal and religious elite to assume leadership of the resistance struggle and to strengthen their powers vis-à-vis the State ${ }^{82}$. War and continual dissent to State control meant that the State was constantly thwarted in its attempt to possess a continuous administrative and legal order with binding authority and a monopoly over the legitimate use of force. Thus, the Afghan State was continually subject to persistent difficulties in generating the revenue required both to maintain internal order and to undertake 'modernisation' activities. Hence, external dependence was reinforced.

By 1972, the bulk of the domestic revenue generated by the Afghan state was used to pay for the administration and army, the remainder being used to service foreign debts. By 1978, given the imperative to finance the costs of 'modernisation', Soviet assistance to Afghanistan totalled US \$ 1 , 265 million, while that of the United States amounted to US $\$ 40$ million $^{83}$. By 1990, Afghanistan's foreign debt was estimated at $\$ 5$ billion, the bulk of it owed to the Soviet Union, and all but a marginal amount on concessional terms (although no foreign debt has been serviced or repaid since then).

Since the withdrawal of Soviet troops and given inter-factional fighting, the continuation of international vested interests (although largely in a different form since the end of the Cold War), a devastated economy and the collapse of the formal tax system (the last official taxes were levied under Daoud, some 20 years ago), the ability of governing bodies across Afghanistan to finance improvements in their areas of control became further limited. Locally held foreign reserves had all essentially been liquidated and access to gold reserves abroad proved limited. Disbursement of any loans by the IMF, meanwhile, required tacit recognition of the receiver, and given general reluctance to recognise any group other than the Northern Alliance, and that only within limits, this too proved difficult.

The Talêban, then, were all the more constrained to turn towards groups in Pakistan, the United States and Saudi Arabia, for financial and other assistance. While the availability to them (as to the Afghan State before), of internationally supplied money, weapons and training enabled the Talêban to become stronger, it also effectively increased their autonomy with respect to the society under its rule. Arms were to be had without industrialisation, revenue without capital accumulation, growth of the ruling body without bargaining between rulers and ruled. Talêban autonomy combined with a

\footnotetext{
${ }^{82}$ Christensen, A.; 1995; Aiding Afghanistan: the Background and Prospects for Reconstruction in a Fragmented Society; NIAS Reports, No.26; p.15.

${ }^{83}$ Christensen, A.; 1995; Aiding Afghanistan: the Background and Prospects for Reconstruction in a Fragmemed Society; NIAS Reports, No.26; p.35
} 
high level of capacity, but without mechanisms of accountability, has essentially enabled them to carry out social transformations and enforce its interpretation of 'order' in the manner best suited to it - the Ministry of the Prohibition of Vice and Promotion of Virtue included ${ }^{84}$.

While such autonomy may be a source of strength in the installation phase, in the institutionalisation phase it may well be a source of weakness, since the state elite is not sustained by constituencies in civil society and therefore, almost exclusively dependent upon its own internal unity and coercive powers - which can lead to fragility ${ }^{85}$. Any weakening of external support may exacerbate this. Thus, the Talêban were initially welcomed for neutralising and disbanding many of the violent and mercenary militias they encountered during their drive northwards and eastwards from Kandahar. However, their repressive interpretation of Islam, as well as their often indiscriminate violence against civilians, have done much to erode their popularity - even among the Sunni Pashtun majority to which they belong. Moreover, after recent events in Pakistan, the ability of the Pakistani State to continue its support to the Talêban may be being called into question. Unrest among the various communities of Afghanistan may also be set to continue - and history may
well repeat itself.

\section{COMMUNITY PATTERNS OF ORGANISATION, IDENTITY AND SOCIAL CONTROL:}

Patterns of community organisation in Afghanistan have all been premised upon the different and interacting systems of identity existent, whether these be articulated around Islam, ethnicity and tribalism, feudalism or the Nation-State (not yet a reality). Each one has and still does form the basis for competing allegiances defining and distributing resources such as ownership of land, flocks and cash, family connections, and foreign relations. Each one has and still does form the basis for abilities to control the various populations and encourage collective action.

\footnotetext{
${ }^{84}$ This Ministry of Vice and Virtue was set up with a view to ensuring that all conform to the edicts governing both public and private spheres of life (the latter having become something of an extension of the former). This involves punishing men for failure to grow a beard sufficiently long by Talêban standards, or punishing women not wearing, or not 'properly' wearing the chadri, a form of all-embracing, all covering veil with a small grid over the eyes.

${ }^{85}$ Rubin, B.R.; 1995; The Fragmentation of Afghanistan: State Formation and Collapse in the International System; Yale University Press; pp. 12/3.
} 


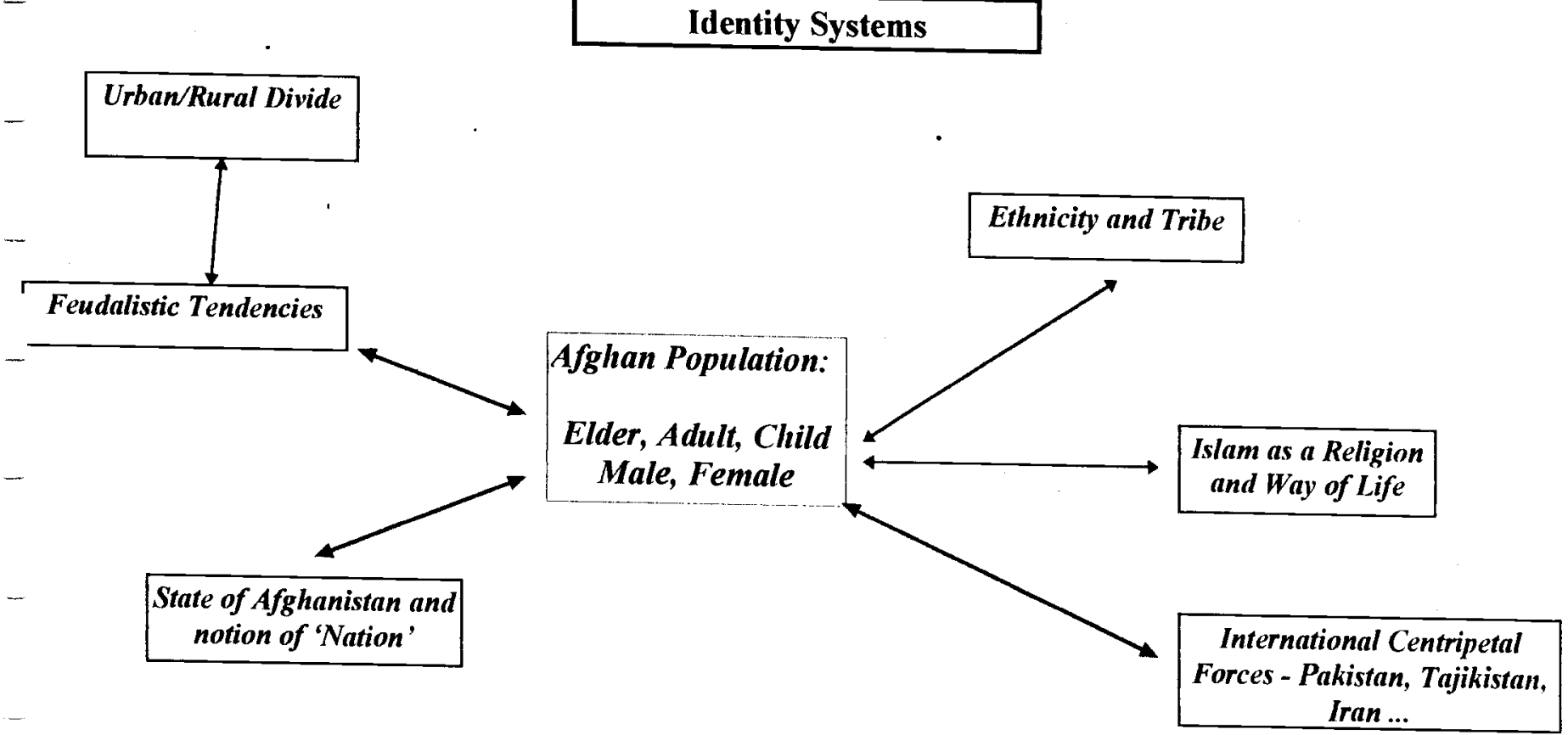


Islam has long been the dominant religion in Afghanistan (although prior to its advent, Buddhism prevailed), with membership of the community of Islam, the ummah, having been as a result, a central unifying force in the country - allowing a number of other fissures to be papered over at one time or another. The Islamic religion then, has constantly provided an important means of conciliating feuding groups or forging broader political coalitions for raid or conquest. Hence, the underlying Islamic tone in the political mobilisation of the Kabul students (1965-71), and in the war against the communist regimes and the Soviet invasion (1978-89). Indeed, the advent of communism largely transformed existing Islamic militants into leaders of the resistance, so strengthening their base. However, even after the withdrawal of the Soviets, all politico-military groups propounded an 'Islamic' Afghanistan - although not all had the backing of Pakistan.

The basic profession of Islamic faith is articulated around five pillars: the profession of faith, regular prayer, fasting, almsgiving and pilgrimage to Mecca. The faith is a monotheistic one, in which God, or Allah, is believed to have created and ruled both heaven and earth, and revealed his message to humanity through prophets such as Adam, Noah, Abraham, Moses, Jesus and finally, Mohammed, who received the final revelation of the Holy Qu'ran. The latter effectively constitutes the basis of all guidance required by Muslims in both the private and the public, the individual and the communal spheres - in this, blurring the distinction between the secular and the religious, between state and society.

Muslims believe that the Qu'ran, the traditions (sunnah), and sayings (hadith), of Mohammed together with the deeds of the early Islamic community, define Muslim behaviour - a behaviour which can, in principle, be interpreted and rendered current by individual political intervention without the existence of an intermediary between the individual and God. This said, schools of thought and interpretation by jurists (ulema, or mawlauwis), have, throughout Islamic history, increasingly come to dominate, being their judgements becoming part of Islamic law, or the shari' $a$.

These schools of thought have tended to be subsumed under the broader categories of Sunni and Shi' a Islam - a fissure itself rooted in conflict over Mohammed's legitimate successor.

Interestingly enough, in the Sunni branch of Islam, independent reasoning, or ijtihad, once integral in the interpretation of the norms and values to govern Muslim life, gradually became restricted to a certain form of analogical reasoning (qiyas), as opposed to the Shi'a branch in which independent reasoning continued to be an important source of law. The closing of the bab al-ijtihad (door of independent reasoning), essentially left the Sunni Islamic community with laws that were drawn up in the 8th and 9th centuries.

The Talêban then, are Sunni Muslims of the Hannifin legal school of thought with strong Deobandi influence (a Muslim college based in India). Most of them, however, are also of rustic Pashtun origin, with only a limited training in Islamic law gained in the madresseh, or religious schools, of Pakistan. It was through these schools, that Pakistan was instrumental in encouraging a conservative form of Islam still based on Hannifin legal thought, but further linked to Islamic scholar Maudoudi, himself having had significant influence over the Muslim Brotherhood societies of Egypt, Syria and Algeria. The latter, somewhat like the Talêban (although obviously without the Pashtun influence to which the latter have been subject), are all advocates of the application of a shari 'a, based on the principle of punishment as being indispensable to social discipline, while also revealing significant hostility towards the so-called 'West' ${ }^{86}$.

\footnotetext{
${ }^{86}$ Barry, M.; 1996/7; Afghanistan: Les Séminaristes de la Guerre; Politique Internationale (Hiver).
} 
Given that in Islam, spiritual knowledge tends to lead to religious authority, as embodied in the religious scholar, trained in law and theology (the most prominent graduates being known as maulawi, followed by the more ordinary mullah), the religious education gained by the Talêban has left them with a sense of duty and empowerment in the war effort and in establishing relations with the rest of society ${ }^{87}$. The various influences to which they have been exposed, also at least partly explains the particular form of Islam practised by them.

The majority of Hazaras, meanwhile, are - like the Iranian population - Shi'a Muslims, pledging allegiance to Ali, the son-in-law of the Prophet Mohammed, and Ali's descendants. As such, they are somewhat despised by the Sunni Talêban, not recognised as true followers of the faith and so vulnerable to discrimination. Most Hazaras are Jafari Shiites having strong links with Iran, while a small number are Ismaelis led by the Aga Khan. An even smaller number are Sunnis. In both cases, the result has been the forging of links with groups outside the nominal State - something that has no doubt played an important role in the international orientation of the country in general.

\section{Ethnicity and Tribalism:}

Ethnicity tends to be articulated around a collective name and a common myth of descent, based upon a shared history (often expressed in association with a specific territory), and a distinctive shared culture, with language and religion often providing the major parameters of the latter. In this and viewed historically over time - the groups and the ethnic identities in question tend to be neither given nor constant, but rather influenced by other social factors and processes. Nevertheless, ethnicity - as recent events around the world have shown - draws upon, and helps to reinforce, a certain sense of solidarity, rooted in the construction of social boundaries vis-à-vis other groups ${ }^{88}$.

Tribalism might be seen as something of a sub-set within this, giving primacy to ties of kinship and patrilineal descent. A tribe then, can be envisaged as a local mutual aid association whose members jointly help maintain order internally and defend the unit externally. It is more distinctively marked by norms of reciprocity than ethnicity ${ }^{89}$, and tends not to have any over-riding central authority - such that blood feud tends to be the main institution for the enforcement of justice and clientelism (based on superior personal qualities and material advantages, such as the control of tenants - perhaps through milita groups - gifts, hospitality - with guest-houses a key to this gallantry in war and conflict), the main mechanism by which to build leadership ${ }^{90}$.

Given that the territory of Afghanistan spreads over many geographical and ecological zones, its peoples and communities are correspondingly quite distinct. Nestled within the Hindu Kush mountain valleys are the minority groups like the Shi'a Hazaras and Tajiks, while the surrounding foothills and plains tend to be dominated by Sunni Pashtuns, Tajiks and Uzbeks.

The Pastuns, who are Persian-speaking, are the largest ethnic group in the country, and constitute about $40-50 \%$ of the population, approximately 6-7million persons. The main Pashtun 'homeland' stretches in an arch from the southern foothills of the Hindu Kush towards Herat in the west, with minority groups settled in the north - although, as mentioned elsewhere, contiguous groups can be

\footnotetext{
${ }^{87}$ This said, religious status is also gained by descent from the Prophet's family, descendants usually being called sayiid. Their customary role has been that of mediators in local conflicts and magico-religious leaders. In Hazarastan, the mullah and the sayid are often one.

${ }_{88}$ Anthony Smith.

${ }^{89}$ Ernst Gellner.

${ }^{90}$ This emphasis on blood feud may help explain the recent Talêban massacre of Hazaras in Mazar-i Sharif.
} 
found in the border regions with Pakistan ${ }^{91}$. The principal nomadic (and livestock-owning) groups of Afghanistan, the Koutchis, are also Pashtun with a population estimated at 1.5 million $^{92}$.

The Pashtuns are further divided along two great lines: the Durrani and Ghilzai tribes, which then sub-divide into a number of different competing groups. Thus, within the Durrani for instance, the Muhammadzai clan has been of significant importance. Across the divisions, and an underlying influence in Pashtun culture, Hinduism has played a significant role - particularly in relation to the existence of something of a the caste system. In this, the most notable caste has been that of the warriors, the kashatriyas, followed by those of agriculture and trade ${ }^{93}$. A Pashtun code, Pashtunwali, further exists to regulate relationships, two cornerstones of which are the blood feud as a means of exacting justice and hospitality, as a means of imposing reciprocal obligations on the recipient and so building allegiances and followings. The code has been embraced in particular by the Koutchis ${ }^{94}$.

Historically, the Pashtuns have also been the dominant group throughout Afghan history, whether due to a gradual coalescence of factors or due to armed struggle, as in 1929, with members occupying a majority of State posts, particularly those relating to caste hierarchies. Having been so prevalent, this has meant that the Pashtuns have also been able to relegate disliked tasks to other ethnic groups (witness the Hazaras, who ensured most menial tasks in Kabul, for instance) - with this having often been a source of discontent and unrest. It was resistance to the Soviets that played a notable role in permitting other ethnic groups to shake the foundations of Pashtun dominance.

The second largest group is perhaps that of the Tajiks, numbering anything from 2 to 4 million. However, the term actually embraces a wide variety of people, some of whom are neither Sunni Muslims nor Persian-speaking, as are most Tajiks. Contiguous groups are to be found in Tajikistan. Other important groups having fellow ethnic in the surrounding republics of Central Asia, include the Turkmen and Uzbeks, both speakers of Turkic languages.

The Hazaras, meanwhile, speak a type of Persian called Hazaragi and are the only major group in Afghanistan that is predominantly Shi' a - although also riven by political division (witness the factions having followed Harakat-i Islami in Kandahar, and Ustat Mohammed Mohaqiq in Mazar, as opposed to Khalili's Hezb-i Wadhat, for instance). Thus, various communities have been subject to gunmen from opposing factions levying taxes, while in certain areas, notably Jaghoori and Bamiyan but also in Nawor, certain villages have been under an obligation to provide a given number of youths to join the relevant militia group holding sway (that of the Hezb-i Wadhat included), with some (according to abilities) also being requested to donate wheat and perhaps, cash to help pay army salaries ${ }^{95}$.

The Hazaras are possibly of Eastern Turkic, or Mongol descent and have frequently been the subject of discrimination. In what became a brutal Sunni-Shi'a sectarian war at the end of the last century, Amir Abdul Rahman Khan destroyed much of the Hazara's tribal institutions, and gave a large part of their land, including that in Ajarestan, to Pashtun groups (both sedentary tribes and the

\footnotetext{
${ }^{91}$ Christensen, A.; 1995; Aiding Afghanistan: the Background and Prospects for Reconstruction in a Fragmented Society; NIAS Reports, No.26.

${ }_{92}$ FAO/WFP; 1997; Crop and Food Supply Assessment Mission to Afghanistan; FAO/WFP; p.7.

${ }_{94}$ Barry, M; 1996/7; Afghanistan: Les Séminaristes de la Guerre; Politique Internationale (Hiver).

94 Rubin, B.R.; 1995; The Fragmentation of Afghanistan: State Formation and Collapse in the International System; Yale University Press; p.29.

${ }^{95}$ Under the Jihaad, there was no such formal obligation, but since it was a total war, all rallied to contribute according to their capacity and virtually all had guns with which to do so.
} 
Koutchis), while selling much of the population into slavery ${ }^{96}$. Subsequent governments pursued similar policies, striving to 'Pashtunise' the population through education policies privileging Persian and Pashtun history, and administrative reform, aiming to reduce their collective bargaining power and minimise political representation (based on the definition of a sub-province and a district together with population numbers), such that recognition and financial support was channelled rather to Pashtun settlers.

However, it might be added at this point, that consolidation and development of the State required the expansion of an educated stratum to staff it, as well as the standardisation of language, both in order to regulate the use of language in government documents and to assure communication with the country's citizens. Moreover, drives towards 'modernisation' were often seen to be premised on the destruction of non-rational links, such as those of ethnicity and tribalism. Where the latter tend to stress personal, moral and ascriptive factors in status, the State - and the notion of progress that was often associated with it - was conceived as being impersonal, recognising contract, transaction and achievement ${ }^{97}$.

Nevertheless, although a limited number of Shiites were admitted to colleges for their further education, after graduation they were generally unable to secure employment within the state bureaucracy - with the exception of a few Hazaras hired within the University of Kabul, for instance. Employment opportunities were few and the Hazaras were long relegated to the ranks of restaurant and hotel servers, porters, small stall-holders and so on (in keeping with their place out of the caste system). This however, is not deny that a relatively small number of Hazaras did come to hold positions of some commercial significance, a few also having been cabinet members - the Ministry of Industry and Mines after 1992, being one such example. However, it is often claimed that this was merely tokenism, based on compromise and trade-off. By appointing Hazaras to such positions, the Pashtun ruling class (also inter-mixed with a fair number of Tajiks in the State bureaucracy), intended to portray the state as an institution reconciling class conflicts and representative of the community as a whole ${ }^{98}$.

Together and throughout history, ethnicity and tribalism have been crucial factors in the centripetal forces tugging away at the strength of the Afghan State, reducing its ability to
consolidate.

\section{Feudalism:}

A form of feudalism has been one of the organising principles informing Afghan society, and relationships among and within the component communities. Historically, this has been manifest through the relationships defining the politico-military nexus on the one hand, and those defining the mode of agricultural production on the other - although the separation between the two may not have
been so distinct.

In the nineteenth century, Hazara and Pashtun ruling classes alike also tended to be chiefs of their tribes, each having their own fiefdom with regular armed militia groups, the functions of which were twofold. Firstly, to ensure the security of trade routes within the given territory and secondly to assist in the collection of taxes from the peasantry. Fulfilment of these two functions, together with

\footnotetext{
96 Rubin, B.R.; 1995; The Fragmentation of Afghanistan: State Formation and Collapse in the International System; Yale University Press; p.31.

97 Rubin, B.R.; 1995; The Fragmentation of Afghanistan: State Formation and Collapse in the International System; Yale University Press; p.7. 98 Emadi, H.; 1997; The Hazaras and the Role in the Process of Political Transformation in Afghanistan; Central
Asian Survey, Vol. 16(3); p.372.
} 
the volunteering of a family member to the king's armed forces in times of war, essentially enabled the Mir, the Malik, the Khan or the Sultan to maintain autonomy from the monarchy and exercise political power in the region of relevance.

Within this fiefdom, land was sometimes given to certain servants and soldiers as a reward for military services, but beyond this, rights to farm the landowners 'territory' were also distributed in exchange for a form of rent composed of the peasant's labour and most of the produce obtained with it ${ }^{99}$. These farming rights, meanwhile, tended to be passed on as part of the inheritance of that particular family. Tenants tended to be a source of status and political influence for the landowner, and as such, even relatively small-holdings which could have been cultivated by the landowner, were often partly or entirely cultivated by tenants. A certain proportion of the land was also given to be used as grazing ground by all members of the tribe $e^{100}$.

It was through such tenancy agreements and rental systems, together with loans and investments made in the local market, that dependency on a minority - the relevant chiefs - by the majority - a large segment of the rural population - was fostered, so creating a hierarchy of political power based upon contractual rights and obligations. This was often buffered by a good portion of diverted state revenues. This hierarchy was legitimised through two channels:

- The feudalisation of religious institutions, whereby secular lords would, in return for homage and allegiance, invest religious representatives, the ulama, with office (enabling them to occupy important administrative posts and preside over judicial and legal matters), land endowments, or waqf, and religious taxes;

- The distribution of wealth through patronage and the creation of public goods, no doubt including the contribution of food to communal festivals.

Again, the predominance of patronage and clientilism (where duties were fulfilled not so much for the sake of an abstract notion of the 'state' or of public service, but due to personalised and accepted links with the overlord), public authority became fragmented and decentralised, to a significant extent explaining the inability of successive Afghan governments to impose its jurisdiction beyond the capital-State. Indeed, the monetisation of tax collection in 1923, while reducing the scope for corruption, meant that small farmers often had to pledge their lands as security so facilitating land transfers and allowing rural elite to consolidate and enlarge their landholdings ${ }^{101}$.

\footnotetext{
${ }^{99}$ In many societies, this latter has been composed of the surplus produced, with the peasant receiving just enough for family survival and work and nothing more. However, to what degree this held true in Afghanistan is unknown. ${ }_{100}$ Christensen, A.; 1995; Aiding Afghanistan: the Background and Prospects for Reconstruction in a Fragmented Society; NIAS Reports, No.26; p.30 and Emadi, H.; 1997; The Hazaras and the Role in the Process of Political Transformation in Afghanistan; Central Asian Survey, Vol. 16(3); p.367.

${ }^{101}$ Christensen, A.; 1995; Aiding Afghanistan: the Background and Prospects for Reconstruction in a Fragmented Society; NIAS Reports, No.26; p. 19.
} 


\section{Afghan Feudal System}

in the $19^{\mathrm{TH}}$ Century

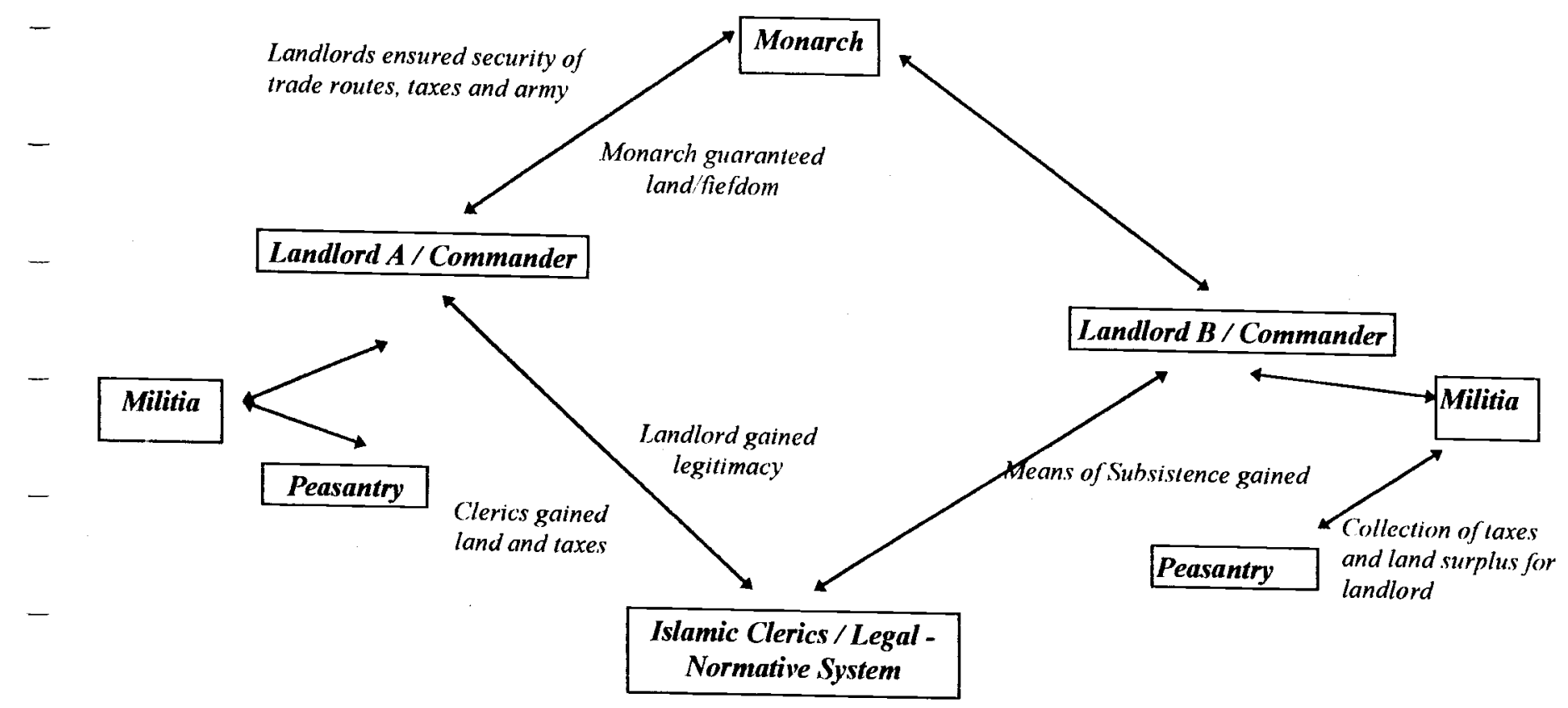


Gender:

Afghanistan remains a patrilineal society, in which membership in both family and lineage, as well as property, is inherited only by agnatic kin. Within this patrilineal society, and across all groups but particularly among the Pashtuns, the most important duty of a man is to support and protect his family. His honour, based on integrity and allegiance to moral principles and earning respect and esteem, requires him to defend and control those things collectively known as namus: zan, zar, zamin (women, gold, land) ${ }^{102}$.

Men thus see women as the repository of their honour, and any sign of sexual misconduct as a political threat to the honour and strength of the family. The punishment for such misconduct is therefore swift and harsh: death or ostracism. Thus, great stress is placed on the creation of a secure environment where the chasteness and dignity of women may be sacrosanct, something that tends to be expressed through social customs such as purdah (segregation and exclusion of women), and chadri (veiling). The extent of each varies according to ethnic group, social class and location.

\section{The Veil:}

Among the Talêban, conditioned as they are by a strong code of conduct, the Pashtunwali, constraints have been imposed to the utmost - generally in a situation where insecurity reigned - as in Kabul. Thus, women have been forced to wear the tchadri, whenever they leave the private domain or household (as well as when non-family visitors enter this latter), something which has affected the more educated strata of society who, unlike those still in a rural environment, tend to have discarded the veil. By imposing strict restraints directly on women, as the symbol of male honour, the regime would also appear to have sent out a message of intent to subordinate the personal autonomy of every individual, so strengthening the impression that it is capable of exercising control over both genders. The emphasis on punishing males for infractions committed by females also reflects the notion of male responsibility for females, and male duty to exert control over these ${ }^{103}$.

In the Hazarajat, prior to Talêban control at least, women tend to wear a scarf only, turning their heads away before any oncoming visitor (although often they will try to get a glimpse of the foreigner). This said, they tend to be considerably more constrained to the household sphere, rarely going to the bazaar, and this only when in dire need due to the absence of any male substitute. When guests are invited women will eat separately and usually last - unless the visitors are relatives.

\section{Economic Activity:}

At the same time and across ethnic divisions, women are, within a sexual division of labour, economically productive members of the household. Although usually circumscribed to the household ambit, their work in Hazarajat, at least, extends beyond child care and cooking, including elements of food processing (making yoghurt, butter and curd from milk, for instance), and vital

\footnotetext{
${ }^{102}$ Rubin, B.R.; 1995; The Fragmentation of Afghanistan: State Formation and Collapse in the International System; Yale University Press; p.24.

${ }^{103}$ Dupree, N. in Maley, W.; 1998; Fundamentalism Reborn? Afghanistan and the Talêban; Hurst \& Co.
} 
crafts such as carpet weaving and felt making ${ }^{104}$. While less evident in Pashtun Ajarestan, women are also active in agricultural tasks, helping with land preparation, weeding and harvesting. Women also take in charge animal feeding and organisation of grazing during the spring/summer period, together with any milking. As a result, they tend to play an important role in any decisions concerning milking animals, particularly cows. Women also tend to be trusted to keep any money after the sale of an animal (particularly chickens), although it will be the men who spend this - unless it is to buy small products such as matches or shampoo (otherwise they require their husband's permission). However, the animals belong to the male on divorce (as does the land).

\section{Marriage:}

In more flexible households, marriage while being arranged, may occur after the potential couple have met, talked and agreed to the person. If disagreement occurs, a new partner will be sought. It tends, however, to create networks of significant complexity, symbolising and cementing alliances (within the same ethnic group), and also affecting social standing and economic well-being, due to the practice of bride-price it can be a source of significant debt. The onus is usually upon the boy's family to provide the bulk of wedding gifts: clothes, jewellery, wedding expenses, housing and money where possible, while the girl's family may provide some foodstuffs such as wheat flour, meat, tea and sugar as well as cooking utensils and other household items to set the couple on their way to married life. Among the Koutchis, livestock forms an important part of the female's trousseau. In all cases, the village elders are usually sent to negotiate with the girl's family the amount to be exchanged.

Violence:

Violence against women appears common - whether in Pashtun societies or Hazara: beating with wood being evident due to male displeasure - and arguably having increased due to the stress and strains of war.

${ }^{104}$ Rubin, B.R.; 1995; The Fragmentation of Afghamistan: State Formation and Collapse in the International System; Yale University Press; p.24. 
Appendices for Part VI

Nutrition and Health 
Appendix I: Summary of Results - Children 6-59 months

Age/Sex

distribution

WHZ-

Score

Acute

6-29

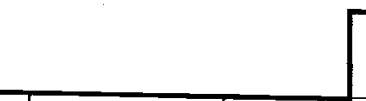

Hazarajat

894 Ajarestan

Bamiyan

Jaghoori

\begin{tabular}{c|c|}
\hline Malestan & Naw \\
\hline
\end{tabular}

\begin{tabular}{ll|l|l|l} 
Adren & 91 children 193 children & 213 children & 256 children & $141 \mathrm{chi}$
\end{tabular}

\begin{tabular}{|c|c|}
\hline \multirow[t]{2}{*}{ Boys } & $\mathrm{Nbr}$ \\
\hline & $\%$ \\
\hline \multirow[t]{2}{*}{ Girls } & $\mathrm{Nbr}$ \\
\hline & $\%$ \\
\hline
\end{tabular}

\begin{tabular}{l|l}
38 & 93
\end{tabular}

116

129

$50.9 \%$

$41.8 \%$

$48.2 \%$

$54.5 \%$

\begin{tabular}{|l|r}
\hline $50.4 \%$ & 56.0 \\
\hline
\end{tabular}

$49.1 \%$

$58.2 \%$

100

96

127

1.04

0.72

$51.8 \%$

$45.5 \%$

$49.6 \%$

44.0

\begin{tabular}{|c|c|c}
\hline \multirow{2}{*}{ Global } & Nbr & \\
\cline { 2 - 3 } & $\%$ & 8 \\
\hline Severe & Nbr &
\end{tabular}

$8.0 \%$

$7.7 \%$

8

1.20

1.02

1.2

$8.0 \%$

$6.1 \%$

15

$\frac{2}{29}$

months

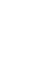

T

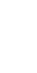

WHM

6-29

months

Glob

r

\begin{tabular}{|c|c|}
\hline$\%$ & \\
\hline $\mathrm{Nbr}$ & \\
\hline$\%$ &
\end{tabular}

$0.7 \%$

$0.0 \%$

0

$2.0 \%$

55

Severe

\begin{tabular}{|c|c|}
\hline$\%$ & $\mathbf{5 . 0} \%$ \\
\hline $\mathrm{Nbr}$ & 3 \\
\hline$\%$ & $0.3 \%$ \\
\hline
\end{tabular}

$\frac{3}{3.3 \%}$

$9.7 \%$

\begin{tabular}{|c|}
\hline 0 \\
\hline $\mathbf{0 . 0} \%$ \\
\hline 0
\end{tabular}

0

0

\begin{tabular}{|c|}
\hline 3 \\
\hline $3.3 \%$ \\
\hline
\end{tabular}

$\frac{1}{0.8 \%}$

$\frac{0}{0.09}$

\begin{tabular}{|c|r|}
\hline $0.8 \%$ & 0.0 \\
\hline 23 & 3 \\
\hline
\end{tabular}

$0.3 \%$

\begin{tabular}{|c|c|}
\hline Nbr & 21 \\
\hline$\%$ & $4.9 \%$ \\
\hline Nbr & 1 \\
\hline & $0.2 \%$ \\
\hline
\end{tabular}

$\frac{0}{0.0 \%}$

\begin{tabular}{|c|c|c|}
\hline $0.0 \%$ & 0 \\
\hline $5.0 \%$ & \\
\hline
\end{tabular}

\begin{tabular}{|c|c|}
\hline 2 & \\
\hline $\mathbf{0 . 9} \%$ & 0.4 \\
\hline 5 & 1 \\
\hline $5.1 \%$ & 9.2 \\
\hline & 1 \\
\hline
\end{tabular}

$9.0 \%$

2.1 ?

.

HAZ-

6-59

months

$<8$

7

HAM

Score

Chronic

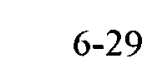

months

\begin{tabular}{|c|c|}
\hline $\mathrm{Nb}$ & 1 \\
\hline$\%$ & $0.2 \%$ \\
\hline $\mathrm{Nb}$ & 25 \\
\hline$\%$ & $2.8 \%$ \\
\hline
\end{tabular}

\begin{tabular}{|c|c|}
\hline $0.0 \%$ & $0.0 \%$ \\
\hline 0 & 5 \\
\hline $0.0 \%$ & $2.6 \%$ \\
\hline
\end{tabular}

0

\begin{tabular}{|c|c|}
\hline $0.0 \%$ & $2.6 \%$ \\
0 & 0 \\
$0.0 \%$ & $0.0 \%$ \\
\hline 21 & 71
\end{tabular}

\begin{tabular}{c|c|}
1 & 0 \\
\hline $0.1 \%$ & $0.0 \%$ \\
\hline 256 & 21
\end{tabular}

\begin{tabular}{|c|c|}
\hline 5 & \\
\hline $2.3 \%$ & \\
\hline 0 & \\
\hline $0.0 \%$ & 0 \\
\hline
\end{tabular}

\begin{tabular}{|c|r}
\hline $0.4 \%$ & 0.0 \\
\hline 11 & 0 \\
\hline
\end{tabular}

\begin{tabular}{c|r}
\hline 11 & 0 \\
\hline $9.2 \%$ & $0.0^{\circ}$ \\
\hline 1 & 0
\end{tabular}

\begin{tabular}{c|r}
1 & 0 \\
\hline $0.8 \%$ & $0.0^{\circ}$ \\
\hline 14 & 1
\end{tabular}

\begin{tabular}{c|c}
\hline 14 & 1 \\
\hline $5.5 \%$ & 0.79 \\
\hline 1 & 0
\end{tabular}

\begin{tabular}{|c|c|c|c|c|c|c|c|}
\hline \multirow[t]{2}{*}{-10} & $\mathrm{Nbr}$ & 1 & 0 & 0 & 0 & 1 & 0 \\
\hline & $\%$ & $0.1 \%$ & $0.0 \%$ & $0.0 \%$ & $0.0 \%$ & $0.4 \%$ & 0.0 \\
\hline \multirow[t]{2}{*}{ Global } & $\mathrm{Nbr}$ & 256 & 21 & 71 & 37 & 77 & 50 \\
\hline & $\%$ & $60.2 \%$ & $53.8 \%$ & $71.0 \%$ & $37.8 \%$ & $64.2 \%$ & 73.5 \\
\hline \multirow[t]{2}{*}{ Severe } & $\mathrm{Nbr}$ & 128 & 8 & 37 & 12 & 43 & \\
\hline & $\%$ & $30.1 \%$ & $20.5 \%$ & $37.0 \%$ & $12.2 \%$ & $58 \%$ & 41 \\
\hline
\end{tabular}

6-59

months

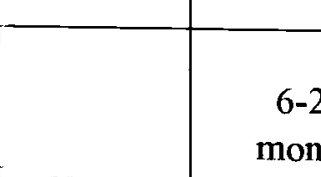

\section{$6-29$}

months

\begin{tabular}{|c|c|c|c|}
\hline & $\%$ & $301 \%$ & 20 \\
\hline \multirow[t]{2}{*}{ Global } & $\mathrm{Nbr}$ & 551 & \\
\hline & $\%$ & $61.6 \%$ & 5 \\
\hline Seve & $\mathrm{Nbr}$ & 257 & \\
\hline
\end{tabular}

$20.5 \%$

$37.0 \%$

$12.2 \%$

\begin{tabular}{|c|c|}
$\mathbf{5 1 . 6} \%$ & $\mathbf{6 9 . 9} \%$ \\
\hline 21 &
\end{tabular}

\begin{tabular}{|c|}
\hline 102 \\
\hline $47.9 \%$ \\
\hline 33
\end{tabular}

172

41.2

\begin{tabular}{c|r}
\hline 172 & 95 \\
\hline $67.2 \%$ & 67.4 \\
\hline 89 & 49 \\
\hline
\end{tabular}

$28.7 \%$

\begin{tabular}{|c|c|}
\hline 21 & 70 \\
\hline $17.6 \%$ & $\mathbf{3 6 . 3} \%$ \\
\hline 13 & 54 \\
\hline $33.3 \%$ & $54.0 \%$ \\
\hline
\end{tabular}

$15.5 \%$

$34.8 \%$

34.8

\begin{tabular}{l|c|c|c|c|c|c|r} 
& $\%$ & $\mathbf{2 8 . 7} \%$ & $\mathbf{1 7 . 6} \%$ & $\mathbf{3 6 . 3} \%$ & $\mathbf{1 5 . 5} \%$ & $\mathbf{3 4 . 8} \%$ & $\mathbf{3 4 . 8}$ \\
\hline$<.90$ & $\mathrm{Nbr}$ & 176 & 13 & 54 & 15 & 57 & 37 \\
\cline { 2 - 8 } & $\%$ & $41.4 \%$ & $33.3 \%$ & $54.0 \%$ & $15.3 \%$ & $47.5 \%$ & 54.4 \\
\hline$<80$ & $\mathrm{Nbr}$ & 2 & 0 & 1 & 0 & 1 & 0 \\
\cline { 2 - 8 } & $\%$ & $0.5 \%$ & $0.0 \%$ & $1.0 \%$ & $0.0 \%$ & $0.8 \%$ & 0.0 \\
\hline$<90$ & $\mathrm{Nbr}$ & 395 & 29 & 105 & 58 & 134 & 69
\end{tabular}

$6-59$

months

$<80$

\begin{tabular}{|c|c|c|c|c|}
\hline $\mathrm{Nbr}$ & 395 & 29 & $10 \%$ & $0.0 \%$ \\
\hline$\%$ & $44.2 \%$ & $31.9 \%$ & $54.4 \%$ & $27.2 \%$ \\
\hline $\mathrm{Nbr}$ & 6 & 0 & 2 & 0 \\
\hline
\end{tabular}

\begin{tabular}{c}
134 \\
$52.3 \%$ \\
\hline
\end{tabular}

$<110 \mathrm{~mm}$

\begin{tabular}{|c|c|}
\hline $\mathrm{H}<75 \mathrm{~cm}$ & \\
\hline $75 \mathrm{~cm} \leq \mathrm{H}<90 \mathrm{~cm}$ & \\
\hline $90 \mathrm{~cm} \leq \mathrm{H} \leq 110 \mathrm{~cm}$ & \\
\hline $\mathrm{H}<75 \mathrm{~cm}$ & \\
\hline
\end{tabular}

MUAC

$110 \leq \mathrm{MUAC}<$

$120 \mathrm{~mm}$

\begin{tabular}{|c|c|}
\hline $\mathrm{H}<75 \mathrm{~cm}$ & 57 \\
\hline $75 \mathrm{~cm} \leq \mathrm{H}<90 \mathrm{~cm}$ & 1 \\
\hline $90 \mathrm{~cm} \leq \mathrm{H} \leq 110 \mathrm{~cm}$ & \\
\hline
\end{tabular}

$\geq 120 \mathrm{~mm}$

\begin{tabular}{|c|r|}
\hline $90 \mathrm{~cm} \leq \mathrm{H} \leq 110 \mathrm{~cm}$ & 1 \\
\hline $\mathrm{H}<75 \mathrm{~cm}$ & 173 \\
\hline $75 \mathrm{~cm} \leq \mathrm{H}<90 \mathrm{~cm}$ & 410 \\
\hline
\end{tabular}

\begin{tabular}{|c|r|}
\hline $75 \mathrm{~cm} \leq \mathrm{H}<90 \mathrm{~cm}$ & 4 \\
\hline $90 \mathrm{~cm} \leq \mathrm{H} \leq 110 \mathrm{~cm}$ & 2 \\
\hline
\end{tabular}

Vaccination Status

Mortality

Rate

Card

Mother's word

$\%$ covered

Nbr

Rate

213

213

$90 / 830$

$20 \%$

$2 / 1,039$

0.64

0

\begin{tabular}{|c|c|c|c|}
\hline 2 & 0 & 3 & 1 \\
\hline $1.0 \%$ & $0.0 \%$ & $1.2 \%$ & 0.70 \\
\hline 4 & 2 & 12 & 3 \\
\hline 0 & 1 & 3 & 0 \\
\hline 0 & 0 & 0 & 0 \\
\hline 18 & 7 & 14 & 15 \\
\hline 1 & 1 & 8 & 4 \\
\hline 0 & 0 & 0 & 1 \\
\hline 40 & 38 & 52 & 25 \\
\hline 84 & 110 & 107 & 65 \\
\hline 46 & 54 & 60 & 28 \\
\hline $43 / 178$ & $7 / 195$ & $5 / 240$ & $18 / 13$ \\
\hline $30 / 178$ & $32 / 195$ & $5 / 240$ & $9 / 13$ \\
\hline $41 \%$ & $21 \%$ & $4 \%$ & $21 \%$ \\
\hline $0 / 230$ & $1 / 244$ & $0 / 297$ & $1 / 17$ \\
\hline 0 & 1.36 & 0 & 1.96 \\
\hline
\end{tabular}


AJARESTAN:

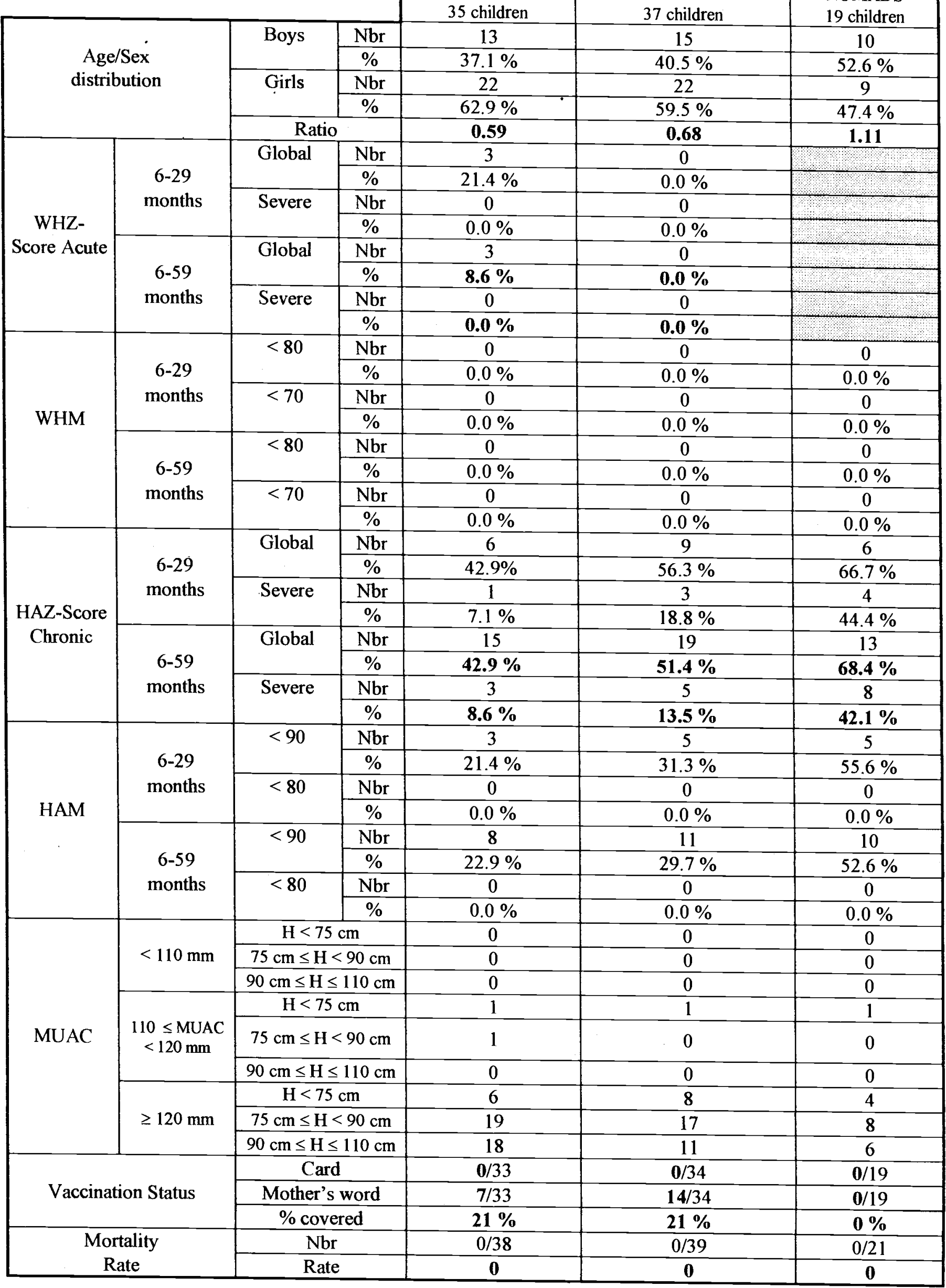




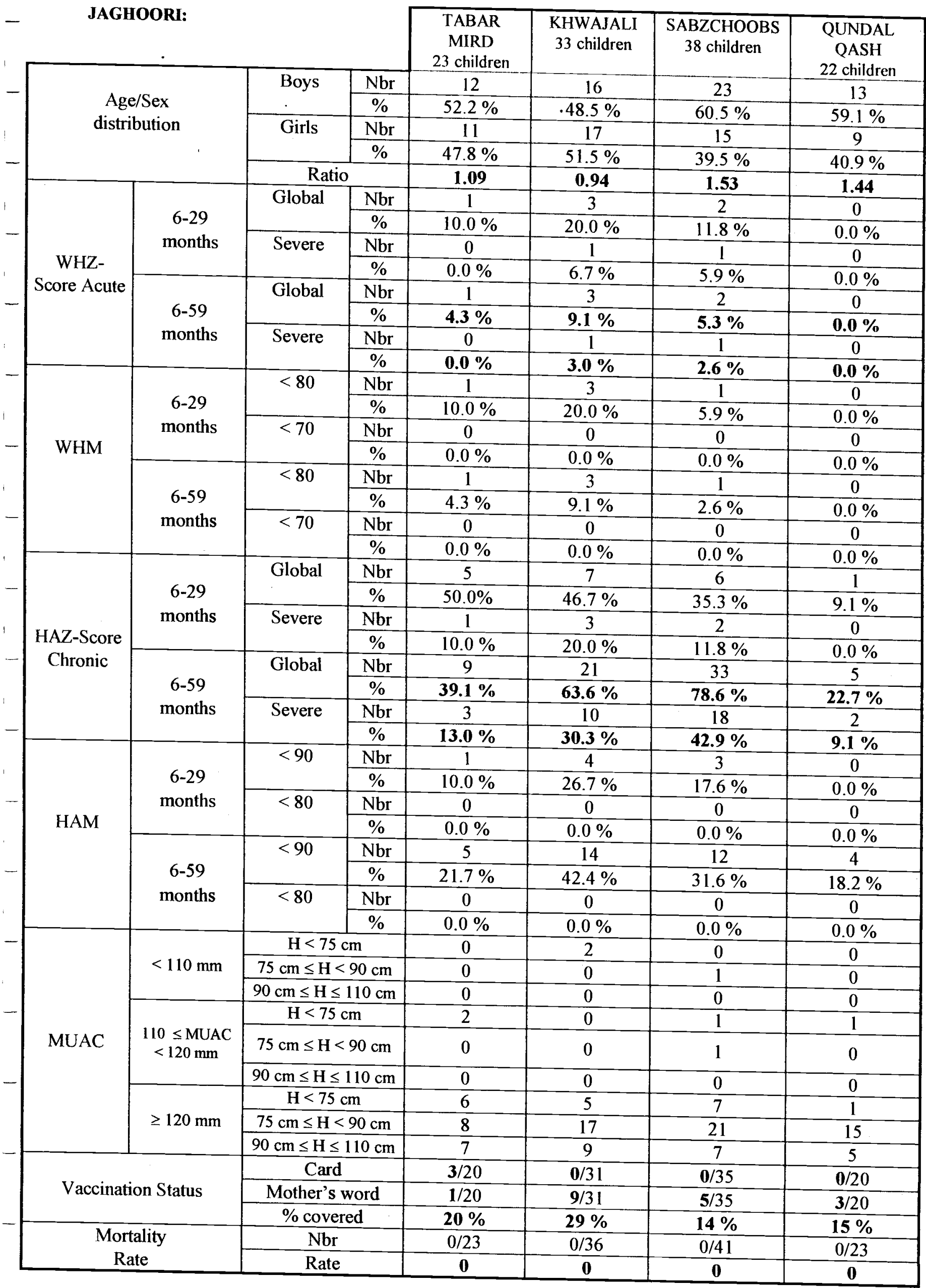




\begin{tabular}{|c|c|c|c|c|c|c|}
\hline \multicolumn{4}{|c|}{ JAGHOORI: } & $\begin{array}{l}\text { JAWDARI } \\
53 \text { children } \\
\end{array}$ & $\begin{array}{l}\text { PASHTANA } \\
16 \text { children }\end{array}$ & $\begin{array}{l}\text { AMBULLOGH } \\
28 \text { children }\end{array}$ \\
\hline \multirow{5}{*}{\multicolumn{2}{|c|}{$\begin{array}{c}\text { Age/Sex } \\
\text { distribution }\end{array}$}} & \multirow[t]{2}{*}{ Boys } & $\mathrm{Nbr}$ & 27 & 7 & 18 \\
\hline & & & $\%$ & $50.9 \%$ & $43.8 \%$ & $64.3 \%$ \\
\hline & & \multirow[t]{2}{*}{ Girls } & $\mathrm{Nbr}$ & 26 & 9 & 10 \\
\hline & & & $\%$ & $49.1 \%$ & $56.3 \%$ & $35.7 \%$ \\
\hline & & \multicolumn{2}{|c|}{ Ratio } & 1.04 & 0.78 & 1.80 \\
\hline \multirow{8}{*}{$\begin{array}{c}\text { WHZ- } \\
\text { Score Acute }\end{array}$} & \multirow{4}{*}{$\begin{array}{c}6-29 \\
\text { months }\end{array}$} & \multirow[t]{2}{*}{ Global } & $\mathrm{Nbr}$ & 0 & 0 & 0 \\
\hline & & & $\%$ & $0.0 \%$ & $0.0 \%$ & $0.0 \%$ \\
\hline & & \multirow[t]{2}{*}{ Severe } & $\mathrm{Nbr}$ & 0 & 0 & 0 \\
\hline & & & $\%$ & $0.0 \%$ & $0.0 \%$ & $0.0 \%$ \\
\hline & \multirow{4}{*}{$\begin{array}{c}6-59 \\
\text { months }\end{array}$} & \multirow[t]{2}{*}{ Global } & $\mathrm{Nbr}$ & 1 & 0 & 0 \\
\hline & & & $\%$ & $1.9 \%$ & $0.0 \%$ & $0.0 \%$ \\
\hline & & \multirow[t]{2}{*}{ Severe } & $\mathrm{Nbr}$ & 0 & 0 & 0 \\
\hline & & & $\%$ & $0.0 \%$ & $0.0 \%$ & $0.0 \%$ \\
\hline \multirow{8}{*}{ WHM } & \multirow{4}{*}{$\begin{array}{c}\text { 6-29 } \\
\text { months }\end{array}$} & \multirow[t]{2}{*}{$<80$} & Nbr & 0 & 0 & 0 \\
\hline & & & $\%$ & $0.0 \%$ & $0.0 \%$ & $0.0 \%$ \\
\hline & & \multirow[t]{2}{*}{$<70$} & $\mathrm{Nbr}$ & 0 & 0 & 0 \\
\hline & & & $\%$ & $0.0 \%$ & $0.0 \%$ & $0.0 \%$ \\
\hline & \multirow{4}{*}{$\begin{array}{c}\text { 6-59 } \\
\text { months }\end{array}$} & \multirow[t]{2}{*}{$<80$} & $\mathrm{Nbr}$ & 0 & 0 & 0 \\
\hline & & & $\%$ & $0.0 \%$ & $0.0 \%$ & $0.0 \%$ \\
\hline & & \multirow[t]{2}{*}{$<70$} & Nbr & 0 & 0 & 0 \\
\hline & & & $\%$ & $0.0 \%$ & $0.0 \%$ & $0.0 \%$ \\
\hline \multirow{8}{*}{$\begin{array}{c}\text { HAZ-Score } \\
\text { Chronic }\end{array}$} & & Global & $\mathrm{Nbr}$ & 11 & 2 & 5 \\
\hline & $6-29$ & & $\%$ & $44.0 \%$ & $25.0 \%$ & $41.7 \%$ \\
\hline & months & Severe & $\mathrm{Nbr}$ & 3 & 1 & 2 \\
\hline & & & $\%$ & $12.0 \%$ & $12.5 \%$ & $16.7 \%$ \\
\hline & & Global & Nbr & 28 & 7 & 11 \\
\hline & $6-59$ & & $\%$ & $52.8 \%$ & $43.8 \%$ & $39.3 \%$ \\
\hline & months & Severe & $\mathrm{Nbr}$ & 7 & 2 & 5 \\
\hline & & & $\%$ & $13.2 \%$ & $12.5 \%$ & $17.9 \%$ \\
\hline & & $<90$ & Nbr & 4 & 1 & 2 \\
\hline & $6-29$ & & $\%$ & $16.0 \%$ & $12.5 \%$ & $16.7 \%$ \\
\hline & months & $<80$ & $\mathrm{Nbr}$ & 0 & 0 & 0 \\
\hline HAM & & & $\%$ & $0.0 \%$ & $0.0 \%$ & $0.0 \%$ \\
\hline & & $<90$ & $\mathrm{Nbr}$ & 13 & 4 & 6 \\
\hline & $6-59$ & & $\%$ & $24.5 \%$ & $25.0 \%$ & $21.4 \%$ \\
\hline & months & $<80$ & $\mathrm{Nbr}$ & 0 & 0 & 0 \\
\hline & & & $\%$ & $0.0 \%$ & $0.0 \%$ & $0.0 \%$ \\
\hline & & $\mathrm{H}<7$ & & 0 & 0 & 0 \\
\hline & $<110 \mathrm{~mm}$ & $75 \mathrm{~cm} \leq \mathrm{H}$ & $90 \mathrm{~cm}$ & 0 & 0 & 0 \\
\hline & & $90 \mathrm{~cm} \leq \mathrm{H}$ & $110 \mathrm{~cm}$ & 0 & 0 & 0 \\
\hline & & $\mathrm{H}<7$ & & 2 & 0 & 1 \\
\hline MUAC & $\begin{array}{c}110 \leq \mathrm{MUAC} \\
<120 \mathrm{~mm}\end{array}$ & $75 \mathrm{~cm} \leq \mathrm{H}$ & $90 \mathrm{~cm}$ & 0 & 0 & 0 \\
\hline & & $90 \mathrm{~cm} \leq \mathrm{H}$ & $110 \mathrm{~cm}$ & 0 & 0 & 0 \\
\hline & & $\mathrm{H}<7$ & & 10 & 5 & 4 \\
\hline & $\geq 120 \mathrm{~mm}$ & $75 \mathrm{~cm} \leq \mathrm{H}$ & $90 \mathrm{~cm}$ & 30 & 7 & 12 \\
\hline & & $90 \mathrm{~cm} \leq \mathrm{H}$ & $110 \mathrm{~cm}$ & 11 & 4 & 11 \\
\hline & & $\mathrm{Ca}$ & & $4 / 36$ & $0 / 14$ & $\mathbf{0} / 27$ \\
\hline Vaccinat & on Status & Mother' & vord & $4 / 36$ & $0 / 14$ & $10 / 27$ \\
\hline & & $\%$ cov & & $22 \%$ & $0 \%$ & $37 \%$ \\
\hline Mor & ality & $\mathrm{Nl}$ & & $1 / 63$ & $0 / 15$ & $0 / 31$ \\
\hline $\mathbf{R}$ & & $\mathrm{Ra}$ & & 5.30 & $\mathbf{0}$ & 0 \\
\hline
\end{tabular}




\begin{tabular}{|c|c|c|c|c|c|c|c|}
\hline \multirow{2}{*}{\multicolumn{4}{|c|}{ MALESTAN: }} & & & & \\
\hline & & & & \multirow{2}{*}{$\begin{array}{c}\text { JAMBOT } \\
61 \text { children } \\
29\end{array}$} & \multirow{2}{*}{$\begin{array}{c}\begin{array}{c}\text { KORSANG } \\
4 \text { children }\end{array} \\
2\end{array}$} & $\begin{array}{l}\text { NAWDEH } \\
26 \text { children }\end{array}$ & \multirow{2}{*}{ 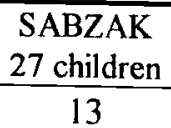 } \\
\hline \multirow{5}{*}{\multicolumn{2}{|c|}{$\begin{array}{c}\text { Age/Sex } \\
\text { distribution }\end{array}$}} & \multirow[t]{2}{*}{ Boys } & $\mathrm{Nbr}$ & & & 12 & \\
\hline & & & $\%$ & $47.5 \%$ & $50.0 \%$ & $46.2 \%$ & $48.1 \%$ \\
\hline & & \multirow[t]{2}{*}{ Girls } & $\mathrm{Nbr}$ & 32 & 2 & 14 & 14 \\
\hline & & & $\%$ & $52.5 \%$ & $50.0 \%$ & $53.8 \%$ & $51.9 \%$ \\
\hline & & \multicolumn{2}{|c|}{ Ratio } & 0.91 & 1.00 & 0.86 & 0.93 \\
\hline \multirow{8}{*}{$\begin{array}{c}\text { WHZ- } \\
\text { Score Acute }\end{array}$} & \multirow{4}{*}{$\begin{array}{c}6-29 \\
\text { months }\end{array}$} & \multirow[t]{2}{*}{ Global } & $\mathrm{Nbr}$ & 3 & 0 & 1 & 1 \\
\hline & & & $\%$ & $10.0 \%$ & $0.0 \%$ & $9.1 \%$ & $8.3 \%$ \\
\hline & & \multirow[t]{2}{*}{ Severe } & $\mathrm{Nbr}$ & 0 & 0 & 0 & 0 \\
\hline & & & $\%$ & $0.0 \%$ & $0.0 \%$ & $0.0 \%$ & $0.0 \%$ \\
\hline & \multirow{4}{*}{$\begin{array}{c}\text { 6-59 } \\
\text { months }\end{array}$} & \multirow[t]{2}{*}{ Global } & $\mathrm{Nbr}$ & 8 & 0 & 1 & 1 \\
\hline & & & $\%$ & $13.1 \%$ & $0.0 \%$ & $3.8 \%$ & $3.7 \%$ \\
\hline & & \multirow[t]{2}{*}{ Severe } & $\mathrm{Nbr}$ & 0 & 0 & 0 & 0 \\
\hline & & & $\%$ & $0.0 \%$ & $0.0 \%$ & $0.0 \%$ & $0.0 \%$ \\
\hline \multirow{8}{*}{ WHM } & \multirow{4}{*}{$\begin{array}{c}6-29 \\
\text { months }\end{array}$} & \multirow[t]{2}{*}{$<80$} & $\mathrm{Nbr}$ & 3 & 0 & 0 & 0 \\
\hline & & & $\%$ & $10.0 \%$ & $0.0 \%$ & $0.0 \%$ & $0.0 \%$ \\
\hline & & $<70$ & $\mathrm{Nbr}$ & 0 & 0 & 0 & 0 \\
\hline & & & $\%$ & $0.0 \%$ & $0.0 \%$ & $0.0 \%$ & $0.0 \%$ \\
\hline & & $<80$ & $\mathrm{Nbr}$ & 5 & 0 & 0 & 0 \\
\hline & $6-59$ & & $\%$ & $8.2 \%$ & $0.0 \%$ & $0.0 \%$ & $0.0 \%$ \\
\hline & months & $<70$ & $\mathrm{Nbr}$ & 0 & 0 & 0 & 0 \\
\hline & & & $\%$ & $0.0 \%$ & $0.0 \%$ & $0.0 \%$ & $0.0 \%$ \\
\hline & & Global & $\mathrm{Nbr}$ & 22 & 0 & 4 & 9 \\
\hline & $6-29$ & & $\%$ & $73.3 \%$ & $0.0 \%$ & $36.4 \%$ & $75.0 \%$ \\
\hline & months & Severe & $\mathrm{Nbr}$ & 15 & 0 & 2 & 4 \\
\hline HAZ-Score & & & $\%$ & $50.0 \%$ & $0.0 \%$ & $18.2 \%$ & $33.3 \%$ \\
\hline Chronic & & Global & $\mathrm{Nbr}$ & 41 & 3 & 12 & 21 \\
\hline & $6-59$ & & $\%$ & $67.2 \%$ & $75.0 \%$ & $46.2 \%$ & $77.8 \%$ \\
\hline & months & Severe & $\mathrm{Nbr}$ & 28 & 1 & 5 & 9 \\
\hline & & & $\%$ & $45.9 \%$ & $25.0 \%$ & $19.2 \%$ & $33.3 \%$ \\
\hline & & $<90$ & $\mathrm{Nbr}$ & 17 & 0 & 3 & 6 \\
\hline & $6-29$ & & $\%$ & $56.7 \%$ & $0.0 \%$ & $27.3 \%$ & $50.0 \%$ \\
\hline & months & $<80$ & $\mathrm{Nbr}$ & 0 & 0 & 0 & 0 \\
\hline HAM & & & $\%$ & $0.0 \%$ & $0.0 \%$ & $0.0 \%$ & $0.0 \%$ \\
\hline & & $<90$ & $\mathrm{Nbr}$ & 32 & 1 & 11 & 15 \\
\hline & 6-59 & & $\%$ & $52.5 \%$ & $25.0 \%$ & $42.3 \%$ & $55.6 \%$ \\
\hline & months & $<80$ & $\mathrm{Nbr}$ & 1 & 0 & 0 & 0 \\
\hline & & & $\%$ & $1.6 \%$ & $0.0 \%$ & $0.0 \%$ & $0.0 \%$ \\
\hline & & $\mathrm{H}<\overline{7}$ & & 4 & 0 & 2 & 0 \\
\hline & $<110 \mathrm{~mm}$ & $75 \mathrm{~cm} \leq \mathrm{H}$ & & 2 & 0 & 0 & 0 \\
\hline & & $90 \mathrm{~cm} \leq \mathrm{H}$ & $10 \mathrm{~cm}$ & 0 & 0 & 0 & 0 \\
\hline & & $\mathrm{H}<7$ & & 5 & 0 & 0 & 1 \\
\hline MUAC & $\begin{array}{c}110 \leq \mathrm{MUAC} \\
<120 \mathrm{~mm}\end{array}$ & $75 \mathrm{~cm} \leq \mathrm{H}$ & $90 \mathrm{~cm}$ & 3 & 0 & 2 & 0 \\
\hline & & $90 \mathrm{~cm} \leq \mathrm{H}$ & $10 \mathrm{~cm}$ & 0 & 0 & 0 & 0 \\
\hline & & $\mathrm{H}<7$ & & 14 & 0 & 6 & 6 \\
\hline & $\geq 120 \mathrm{~mm}$ & $75 \mathrm{~cm} \leq \mathrm{H}$ & $90 \mathrm{~cm}$ & 21 & 2 & 9 & 13 \\
\hline & & $90 \mathrm{~cm} \leq \mathrm{H}$ & $10 \mathrm{~cm}$ & 12 & 2 & 7 & 7 \\
\hline & & $\mathrm{Ca}$ & & $0 / 55$ & $\mathbf{0} / 4$ & $0 / 22$ & $0 / 25$ \\
\hline Vaccinat & on Status & Mother' & ford & $7 / 55$ & $1 / 4$ & $0 / 22$ & $2 / 25$ \\
\hline & & $\% \operatorname{cov}$ & & $0 \%$ & $25 \%$ & $0 \%$ & $8 \%$ \\
\hline Mor & ality & $\mathrm{Nb}$ & & $0 / 62$ & $0 / 4$ & $0 / 21$ & $0 / 29$ \\
\hline $\mathrm{R}$ & & $\mathrm{Ra}$ & & 0 & $\mathbf{0}$ & 0 & 0 \\
\hline
\end{tabular}


MALESTAN:

\begin{tabular}{|c|c|c|c|c|c|c|c|c|}
\hline \multicolumn{4}{|c|}{ MALESTAN: } & $\begin{array}{c}\text { DAHAN-BOOM } \\
50 \text { children } \\
\end{array}$ & $\begin{array}{l}\text { QOLADAM } \\
53 \text { children }\end{array}$ & $\begin{array}{c}\text { KHARZAR } \\
3 \text { children }\end{array}$ & $\begin{array}{c}\text { WALI } \\
9 \text { children }\end{array}$ & $\begin{array}{l}\text { QOSHNAK } \\
23 \text { children } \\
\end{array}$ \\
\hline \multirow{5}{*}{\multicolumn{2}{|c|}{$\begin{array}{c}\text { Age/Sex } \\
\text { distribution }\end{array}$}} & \multirow[t]{2}{*}{ Boys } & $\mathrm{Nbr}$ & 27 & 29 & 1 & 5 & 11 \\
\hline & & & $\%$ & $54.0 \%$ & $54.7 \%$ & $53.3 \%$ & $55.6 \%$ & $47.8 \%$ \\
\hline & & \multirow[t]{2}{*}{ Gịls } & $\mathrm{Nbr}$ & 23 & 24 & 2 & 4 & 12 \\
\hline & & & $\%$ & $46.0 \%$ & $45.3 \%$ & $66.7 \%$ & $44.4 \%$ & $52.2 \%$ \\
\hline & & \multicolumn{2}{|c|}{ Ratio } & 1.17 & 1.21 & 0.50 & 1.25 & 0.92 \\
\hline \multirow{8}{*}{$\begin{array}{c}\text { WHZ- } \\
\text { Score Acute }\end{array}$} & \multirow{4}{*}{$\begin{array}{c}6-29 \\
\text { months }\end{array}$} & \multirow[t]{2}{*}{ Global } & $\mathrm{Nbr}$ & 4 & 4 & 0 & 0 & 2 \\
\hline & & & $\%$ & $16.7 \%$ & $16.0 \%$ & $0.0 \%$ & $0.0 \%$ & $18.2 \%$ \\
\hline & & \multirow[t]{2}{*}{ Severe } & $\mathrm{Nbr}$ & 1 & 0 & 0 & 0 & 0 \\
\hline & & & $\%$ & $4.2 \%$ & $0.0 \%$ & $0.0 \%$ & $0.0 \%$ & $0.0 \%$ \\
\hline & \multirow{4}{*}{$\begin{array}{c}6-59 \\
\text { months }\end{array}$} & \multirow[t]{2}{*}{ Global } & $\mathrm{Nbr}$ & 6 & 5 & 0 & 0 & 2 \\
\hline & & & $\%$ & $12.0 \%$ & $9.4 \%$ & $0.0 \%$ & $0.0 \%$ & $8.7 \%$ \\
\hline & & \multirow[t]{2}{*}{ Severe } & $\mathrm{Nbr}$ & 1 & 0 & 0 & 0 & 0 \\
\hline & & & $\%$ & $2.0 \%$ & $0.0 \%$ & $0.0 \%$ & $0.0 \%$ & $0.0 \%$ \\
\hline \multirow{8}{*}{ WHM } & \multirow{4}{*}{$\begin{array}{c}6-29 \\
\text { months }\end{array}$} & \multirow[t]{2}{*}{$<80$} & $\mathrm{Nbr}$ & 4 & 2 & 0 & 0 & 2 \\
\hline & & & $\%$ & $16.7 \%$ & $8.0 \%$ & $0.0 \%$ & $0.0 \%$ & $18.2 \%$ \\
\hline & & \multirow[t]{2}{*}{$<70$} & $\mathrm{Nbr}$ & 1 & 0 & 0 & 0 & 0 \\
\hline & & & $\%$ & $4.2 \%$ & $0.0 \%$ & $0.0 \%$ & $0.0 \%$ & $0.0 \%$ \\
\hline & \multirow{4}{*}{$\begin{array}{c}6-59 \\
\text { months }\end{array}$} & \multirow[t]{2}{*}{$<80$} & $\mathrm{Nbr}$ & 5 & 2 & 0 & 0 & 2 \\
\hline & & & $\%$ & $10.0 \%$ & $3.8 \%$ & $0.0 \%$ & $0.0 \%$ & $8.7 \%$ \\
\hline & & \multirow[t]{2}{*}{$<70$} & $\mathrm{Nbr}$ & 1 & 0 & 0 & 0 & 0 \\
\hline & & & $\%$ & $2.0 \%$ & $0.0 \%$ & $0.0 \%$ & $0.0 \%$ & $0.0 \%$ \\
\hline & & Global & $\mathrm{Nbr}$ & 12 & 18 & 0 & 3 & 8 \\
\hline & $6-29$ & & $\%$ & $50.0 \%$ & $72.0 \%$ & $0.0 \%$ & $60.0 \%$ & $72.7 \%$ \\
\hline & months & Severe & $\mathrm{Nbr}$ & 6 & 13 & 0 & 1 & 1 \\
\hline HAZ-Score & & & $\%$ & $25.0 \%$ & $52.0 \%$ & $0.0 \%$ & $20.0 \%$ & $9.1 \%$ \\
\hline Chronic & & Global & $\mathrm{Nbr}$ & 30 & 41 & 0 & 7 & 17 \\
\hline & $6-59$ & & $\%$ & $60.0 \%$ & $77.4 \%$ & $0.0 \%$ & $77.8 \%$ & $73.9 \%$ \\
\hline & months & Severe & $\mathrm{Nbr}$ & 12 & 27 & 0 & 4 & 3 \\
\hline & & & $\%$ & $24.0 \%$ & $50.9 \%$ & $0.0 \%$ & $44.4 \%$ & $13.0 \%$ \\
\hline & & $<90$ & $\mathrm{Nbr}$ & 11 & 14 & 0 & 1 & 4 \\
\hline & $6-29$ & & $\%$ & $45.8 \%$ & $56.0 \%$ & $0.0 \%$ & $20.0 \%$ & $36.4 \%$ \\
\hline & months & $<80$ & $\mathrm{Nbr}$ & 0 & 0 & 0 & $\overline{0}$ & 1 \\
\hline HAM & & & $\%$ & $0.0 \%$ & $0.0 \%$ & $0.0 \%$ & $0.0 \%$ & $9.1 \%$ \\
\hline & & $<90$ & $\mathrm{Nbr}$ & 25 & 36 & 0 & 4 & 10 \\
\hline & $6-59$ & & $\%$ & $50.0 \%$ & $67.9 \%$ & $0.0 \%$ & $44.4 \%$ & $43.5 \%$ \\
\hline & months & $<80$ & $\mathrm{Nbr}$ & 0 & 1 & 0 & 0 & 1 \\
\hline & & & $\%$ & $0.0 \%$ & $1.9 \%$ & $0.0 \%$ & $0.0 \%$ & $4.3 \%$ \\
\hline & & $\mathrm{H}<7$ & & 3 & 1 & 0 & 0 & 2 \\
\hline & $<110 \mathrm{~mm}$ & $75 \mathrm{~cm} \leq \mathrm{H}$ & $90 \mathrm{~cm}$ & 1 & 0 & 0 & 0 & 0 \\
\hline & & $90 \mathrm{~cm} \leq \mathrm{H}$ & $10 \mathrm{~cm}$ & 0 & 0 & 0 & 0 & 0 \\
\hline & & $\mathrm{H}<7$ & & 1 & 7 & 0 & 0 & 0 \\
\hline MUAC & $\begin{array}{c}110 \leq \mathrm{MUAC} \\
<120 \mathrm{~mm}\end{array}$ & $75 \mathrm{~cm} \leq \mathrm{H}$ & $90 \mathrm{~cm}$ & 0 & 2 & 0 & 1 & 0 \\
\hline & & $90 \mathrm{~cm} \leq \mathrm{H}$ & $10 \mathrm{~cm}$ & 0 & $\mathbf{0}$ & 0 & 0 & 0 \\
\hline & & $\mathrm{H}<7$ & & 10 & 9 & 1 & 3 & 3 \\
\hline & $\geq 120 \mathrm{~mm}$ & $75 \mathrm{~cm} \leq \mathrm{H}$ & $30 \mathrm{~cm}$ & 21 & 25 & 2 & 4 & 10 \\
\hline & & $90 \mathrm{~cm} \leq \mathrm{H}$ & $10 \mathrm{~cm}$ & 14 & 9 & 0 & 1 & 18 \\
\hline & & $\mathrm{Ca}$ & & $1 / 48$ & $3 / 51$ & $0 / 2$ & 0/9 & $1 / 23$ \\
\hline Vaccina & on Status & Mother' & ord & $0 / 48$ & $1 / 51$ & $0 / 2$ & $0 / 9$ & $1 / 23$ \\
\hline & & $\%$ co & & $2 \%$ & $7.8 \%$ & $0 \%$ & $0 \%$ & $8.7 \%$ \\
\hline Mo & ality & $\mathrm{Nt}$ & & $0 / 52$ & $0 / 56$ & $0 / 3$ & $0 / 10$ & $0 / 26$ \\
\hline & & $\mathrm{Ra}$ & & $\mathbf{0}$ & 0 & 0 & 0 & $\mathbf{0}$ \\
\hline
\end{tabular}




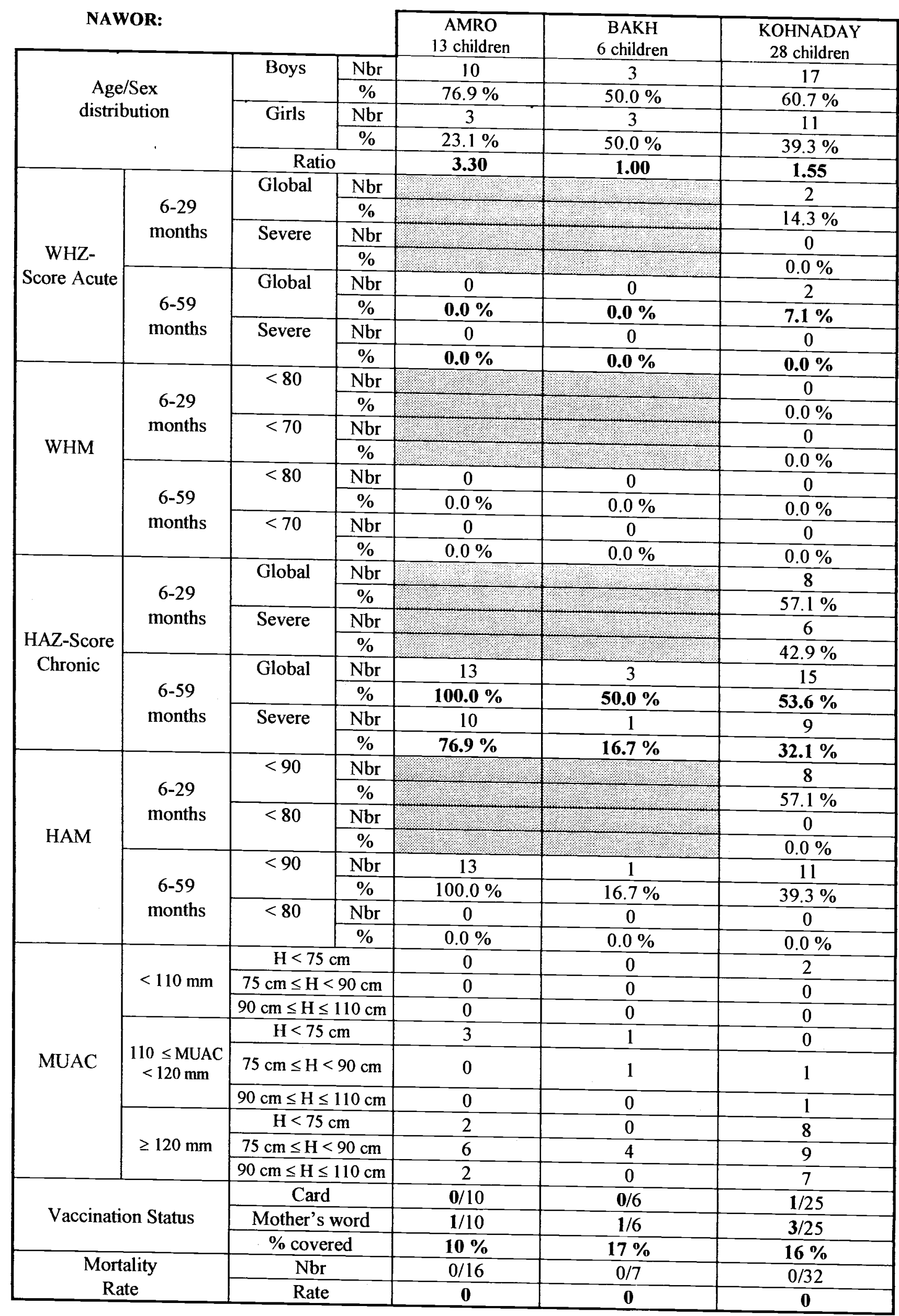




\begin{tabular}{|c|c|c|c|c|c|c|}
\hline \multicolumn{4}{|c|}{ NAWOR: } & $\begin{array}{c}\text { QARB } \\
32 \text { children }\end{array}$ & $\begin{array}{c}\text { QARC } \\
\text { 31 children }\end{array}$ & $\begin{array}{c}\text { QAB } \\
13 \text { children }\end{array}$ \\
\hline \multirow{5}{*}{\multicolumn{2}{|c|}{$\begin{array}{c}\text { Age/Sex } \\
\text { distribution }\end{array}$}} & \multirow[t]{2}{*}{ Boys } & $\mathrm{Nbr}$ & 20 & 13 & 7 \\
\hline & & & $\%$ & $62.5 \%$ & $41.9 \%$ & $53.8 \%$ \\
\hline & & \multirow[t]{2}{*}{ Girls } & $\mathrm{Nbr}$ & 12 & 18 & 6 \\
\hline & & & $\%$ & $37.5 \%$ & $58.1 \%$ & $46.2 \%$ \\
\hline & & \multicolumn{2}{|c|}{ Ratio } & 1.67 & 0.72 & 1.17 \\
\hline \multirow{8}{*}{$\begin{array}{c}\text { WHZ- } \\
\text { Score Acute }\end{array}$} & \multirow{4}{*}{$\begin{array}{c}6-29 \\
\text { months }\end{array}$} & \multirow{2}{*}{ Global } & $\mathrm{Nbr}$ & 0 & 0 & 0 \\
\hline & & & $\%$ & $0.0 \%$ & $0.0 \%$ & $0.0 \%$ \\
\hline & & \multirow[t]{2}{*}{ Severe } & $\mathrm{Nbr}$ & 0 & 0 & 0 \\
\hline & & & $\%$ & $0.0 \%$ & $0.0 \%$ & $0.0 \%$ \\
\hline & \multirow{4}{*}{$\begin{array}{c}6-59 \\
\text { months }\end{array}$} & \multirow[t]{2}{*}{ Global } & $\mathrm{Nbr}$ & 0 & 0 & 0 \\
\hline & & & $\%$ & $0.0 \%$ & $0.0 \%$ & $0.0 \%$ \\
\hline & & \multirow[t]{2}{*}{ Severe } & Nbr & 0 & 0 & 0 \\
\hline & & & $\%$ & $0.0 \%$ & $0.0 \%$ & $0.0 \%$ \\
\hline \multirow{8}{*}{ WHM } & \multirow{4}{*}{$\begin{array}{c}6-29 \\
\text { months }\end{array}$} & \multirow[t]{2}{*}{$<80$} & $\mathrm{Nbr}$ & 0 & 0 & 0 \\
\hline & & & $\%$ & $0.0 \%$ & $0.0 \%$ & $0.0 \%$ \\
\hline & & \multirow[t]{2}{*}{$<70$} & $\mathrm{Nbr}$ & 0 & 0 & 0 \\
\hline & & & $\%$ & $0.0 \%$ & $0.0 \%$ & $0.0 \%$ \\
\hline & \multirow{4}{*}{$\begin{array}{c}6-59 \\
\text { months }\end{array}$} & \multirow[t]{2}{*}{$<80$} & $\mathrm{Nbr}$ & 0 & 0 & 0 \\
\hline & & & $\%$ & $0.0 \%$ & $0.0 \%$ & $0.0 \%$ \\
\hline & & \multirow[t]{2}{*}{$<70$} & $\mathrm{Nbr}$ & 0 & 0 & 0 \\
\hline & & & $\%$ & $0.0 \%$ & $0.0 \%$ & $0.0 \%$ \\
\hline \multirow{8}{*}{$\begin{array}{c}\text { HAZ-Score } \\
\text { Chronic }\end{array}$} & & Global & $\mathrm{Nbr}$ & 12 & 12 & 2 \\
\hline & $6-29$ & & $\%$ & $66.7 \%$ & $92.3 \%$ & $40.0 \%$ \\
\hline & months & Severe & $\mathrm{Nbr}$ & 6 & 6 & 0 \\
\hline & & & $\%$ & $33.3 \%$ & $46.2 \%$ & $0.0 \%$ \\
\hline & & Global & $\mathrm{Nbr}$ & 18 & 27 & 5 \\
\hline & $6-59$ & & $\%$ & $56.3 \%$ & $87.1 \%$ & $38.5 \%$ \\
\hline & months & Severe & $\mathrm{Nbr}$ & 8 & 13 & 1 \\
\hline & & & $\%$ & $25.0 \%$ & $41.9 \%$ & $7.7 \%$ \\
\hline & & $<90$ & $\mathrm{Nbr}$ & 7 & 8 & 0 \\
\hline & $6-29$ & & $\%$ & $38.9 \%$ & $61.5 \%$ & $0.0 \%$ \\
\hline & months & $<80$ & $\mathrm{Nbr}$ & 0 & 0 & 0 \\
\hline HAM & & & $\%$ & $0.0 \%$ & $0.0 \%$ & $0.0 \%$ \\
\hline & & $<90$ & $\mathrm{Nbr}$ & 11 & 18 & 2 \\
\hline & $6-59$ & & $\%$ & $34.4 \%$ & $58.1 \%$ & $15.4 \%$ \\
\hline & months & $<80$ & $\mathrm{Nbr}$ & 0 & 1 & 0 \\
\hline & & & $\%$ & $0.0 \%$ & $3.2 \%$ & $0.0 \%$ \\
\hline & & $\mathrm{H}<7$ & & 1 & 0 & 0 \\
\hline & $<110 \mathrm{~mm}$ & $75 \mathrm{~cm} \leq \mathrm{H}$ & $90 \mathrm{~cm}$ & 0 & 0 & 0 \\
\hline & & $90 \mathrm{~cm} \leq \mathrm{H}$ & $10 \mathrm{~cm}$ & 0 & 0 & 0 \\
\hline & & $\mathrm{H}<7$ & & 2 & 6 & 0 \\
\hline MUAC & $\begin{array}{c}110 \leq \mathrm{MUAC} \\
<120 \mathrm{~mm}\end{array}$ & $75 \mathrm{~cm} \leq \mathrm{H}$ & $90 \mathrm{~cm}$ & 1 & 0 & 1 \\
\hline & & $90 \mathrm{~cm} \leq \mathrm{H}$ & $10 \mathrm{~cm}$ & 0 & 0 & 0 \\
\hline & & $\mathrm{H}<7$ & & 7 & 3 & 1 \\
\hline & $\geq 120 \mathrm{~mm}$ & $75 \mathrm{~cm} \leq \mathrm{H}$ & $90 \mathrm{~cm}$ & 16 & 13 & 8 \\
\hline & & $90 \mathrm{~cm} \leq \mathrm{H}$ & $10 \mathrm{~cm}$ & 5 & 9 & 3 \\
\hline & & $\mathrm{Ca}$ & & $15 / 29$ & $2 / 30$ & $0 / 13$ \\
\hline Vaccinat & on Status & Mother' & ord & $0 / 29$ & $1 / 30$ & $1 / 13$ \\
\hline & & $\% \operatorname{cov}$ & & $52 \%$ & $10 \%$ & $8 \%$ \\
\hline Mor & ality & $\mathrm{Nb}$ & & $1 / 41$ & $0 / 32$ & $0 / 13$ \\
\hline $\mathbf{R}$ & & $\mathrm{Ra}$ & & 8.0 & $\mathbf{0}$ & $\mathbf{0}$ \\
\hline
\end{tabular}


BAMIYAN:

\begin{tabular}{|c|c|c|c|c|c|c|c|}
\hline \multirow{2}{*}{\multicolumn{4}{|c|}{ BAMIYAN: }} & \multirow{3}{*}{$\begin{array}{c}\text { JAWKAR } \\
41 \text { children } \\
17 \\
\end{array}$} & & & \\
\hline & & & & & \multirow{2}{*}{$\begin{array}{c}\text { KAMA } \\
60 \text { children } \\
34\end{array}$} & \multirow{2}{*}{$\begin{array}{c}\text { QAB } \\
50 \text { children } \\
25\end{array}$} & \multirow{2}{*}{$\begin{array}{c}\text { SYAL } \\
42 \text { children } \\
\frac{17}{17}\end{array}$} \\
\hline \multirow{5}{*}{\multicolumn{2}{|c|}{$\begin{array}{c}\text { Age/Sex } \\
\text { distribution }\end{array}$}} & \multirow[t]{2}{*}{ Boys } & $\mathrm{Nbr}$ & & & & \\
\hline & & & $\%$ & $41.5 \%$ & $56.7 \%$ & $50.0 \%$ & $40.5 \%$ \\
\hline & & \multirow[t]{2}{*}{ Girls } & $\mathrm{Nbr}$ & 24 & 26 & 25 & 25 \\
\hline & & & $\%$ & $58.5 \%$ & $43.3 \%$ & $50.0 \%$ & $59.5 \%$ \\
\hline & & \multicolumn{2}{|c|}{ Ratio } & 0.71 & 1.31 & 1.00 & 0.68 \\
\hline \multirow{8}{*}{$\begin{array}{c}\text { WHZ- } \\
\text { Score Acute }\end{array}$} & \multirow{4}{*}{$\begin{array}{c}6-29 \\
\text { months }\end{array}$} & \multirow[t]{2}{*}{ Global } & $\mathrm{Nbr}$ & 1 & 2 & 5 & 0 \\
\hline & & & $\%$ & $4.5 \%$ & $6.7 \%$ & $17.9 \%$ & $0.0 \%$ \\
\hline & & \multirow[t]{2}{*}{ Severe } & $\mathrm{Nbr}$ & 0 & 0 & 0 & 0 \\
\hline & & & $\%$ & $0.0 \%$ & $0.0 \%$ & $0.0 \%$ & $0.0 \%$ \\
\hline & \multirow{4}{*}{$\begin{array}{c}6-59 \\
\text { months }\end{array}$} & \multirow[t]{2}{*}{ Global } & $\mathrm{Nbr}$ & 1 & 2 & 6 & 0 \\
\hline & & & $\%$ & $2.4 \%$ & $3.3 \%$ & $12.0 \%$ & $0.0 \%$ \\
\hline & & \multirow[t]{2}{*}{ Severe } & $\mathrm{Nbr}$ & 0 & 0 & 0 & 0 \\
\hline & & & $\%$ & $0.0 \%$ & $0.0 \%$ & $0.0 \%$ & $0.0 \%$ \\
\hline \multirow{8}{*}{ WHM } & \multirow{4}{*}{$\begin{array}{c}6-29 \\
\text { months }\end{array}$} & \multirow[t]{2}{*}{$<80$} & $\mathrm{Nbr}$ & 0 & 2 & 3 & 0 \\
\hline & & & $\%$ & $0.0 \%$ & $6.7 \%$ & $10.7 \%$ & $0.0 \%$ \\
\hline & & $<70$ & $\mathrm{Nbr}$ & 0 & 0 & 0 & 0 \\
\hline & & & $\%$ & $0.0 \%$ & $0.0 \%$ & $0.0 \%$ & $0.0 \%$ \\
\hline & & $<80$ & $\mathrm{Nbr}$ & 0 & 2 & 3 & 0 \\
\hline & $6-59$ & & $\%$ & $0.0 \%$ & $3.3 \%$ & $6.0 \%$ & $0.0 \%$ \\
\hline & months & $<70$ & $\mathrm{Nbr}$ & 0 & 0 & 0 & 0 \\
\hline & & & $\%$ & $0.0 \%$ & $0.0 \%$ & $0.0 \%$ & $0.0 \%$ \\
\hline & & Global & $\mathrm{Nbr}$ & 13 & 19 & 23 & 16 \\
\hline & $6-29$ & & $\%$ & $59.1 \%$ & $63.3 \%$ & $82.1 \%$ & $80.0 \%$ \\
\hline & months & Severe & $\mathrm{Nbr}$ & 8 & 8 & 12 & 9 \\
\hline HAZ-Score & & & $\%$ & $36.4 \%$ & $26.7 \%$ & $42.9 \%$ & $45.0 \%$ \\
\hline Chronic & & Global & $\mathrm{Nbr}$ & 22 & 41 & 39 & 33 \\
\hline & $6-59$ & & $\%$ & $53.7 \%$ & $68.3 \%$ & $78.0 \%$ & $78.6 \%$ \\
\hline & months & Severe & $\mathrm{Nbr}$ & 12 & 18 & 22 & 18 \\
\hline & & & $\%$ & $29.3 \%$ & $30.0 \%$ & $44.0 \%$ & $42.9 \%$ \\
\hline & & $<90$ & $\mathrm{Nbr}$ & 10 & 15 & 18 & 11 \\
\hline & $6-29$ & & $\%$ & $45.5 \%$ & $50.0 \%$ & $64.3 \%$ & $55.0 \%$ \\
\hline & months & $<80$ & $\mathrm{Nbr}$ & 0 & 1 & 0 & 0 \\
\hline HAM & & & $\%$ & $0.0 \%$ & $3.3 \%$ & $0.0 \%$ & $0.0 \%$ \\
\hline & & $<90$ & $\mathrm{Nbr}$ & 17 & 33 & 33 & 22 \\
\hline & $6-59$ & & $\%$ & $41.5 \%$ & $55.0 \%$ & $66.0 \%$ & $52.4 \%$ \\
\hline & months & $<80$ & $\mathrm{Nbr}$ & 0 & 2 & 0 & 0 \\
\hline & & & $\%$ & $0.0 \%$ & $3.3 \%$ & $0.0 \%$ & $0.0 \%$ \\
\hline & & $\mathrm{H}<7$ & & 1 & 0 & 2 & 1 \\
\hline & $<110 \mathrm{~mm}$ & $75 \mathrm{~cm} \leq \mathrm{H}$ & & 0 & 0 & 0 & 0 \\
\hline & & $90 \mathrm{~cm} \leq \mathrm{H}$ & $10 \mathrm{~cm}$ & 0 & 0 & 0 & 0 \\
\hline & & $\mathrm{H}<7$ & & 6 & 4 & 5 & 3 \\
\hline MUAC & $\begin{array}{c}110 \leq \mathrm{MUAC} \\
<120 \mathrm{~mm}\end{array}$ & $75 \mathrm{~cm} \leq \mathrm{H}$ & $90 \mathrm{~cm}$ & 0 & 0 & 1 & 0 \\
\hline & & $90 \mathrm{~cm} \leq \mathrm{H}$ & $10 \mathrm{~cm}$ & 0 & 0 & 0 & 0 \\
\hline & & $\mathrm{H}<7$ & & 6 & 12 & 13 & 9 \\
\hline & $\geq 120 \mathrm{~mm}$ & $75 \mathrm{~cm} \leq \mathrm{H}$ & $90 \mathrm{~cm}$ & 18 & 29 & 20 & 17 \\
\hline & & $90 \mathrm{~cm} \leq \mathrm{H}$ & $10 \mathrm{~cm}$ & 10 & 15 & 9 & 12 \\
\hline & & $\mathrm{Ca}$ & & $12 / 37$ & $2 / 54$ & $11 / 47$ & $18 / 40$ \\
\hline Vaccina & on Status & Mother' & Ford & $2 / 37$ & $8 / 54$ & $18 / 47$ & $2 / 40$ \\
\hline & & $\% \operatorname{cov}$ & & $38 \%$ & $19 \%$ & $62 \%$ & $50 \%$ \\
\hline Mo & ality & $\mathrm{Nk}$ & & $0 / 43$ & $0 / 68$ & $0 / 55$ & $0 / 44$ \\
\hline & & $\mathrm{Ra}$ & & o & 0 & 0 & 0 \\
\hline
\end{tabular}


Summary of Results - Babies - 0-5 months

\begin{tabular}{|c|c|c|c|c|c|c|c|}
\hline \multirow{2}{*}{ AREA } & \multicolumn{4}{|c|}{ WHZ-Score } & \multicolumn{3}{c|}{ MUAC $(\mathrm{H}<75 \mathrm{~cm})$} \\
\cline { 2 - 8 } & \multicolumn{2}{|c|}{ Global } & \multicolumn{2}{c|}{ Severe } & $<110 \mathrm{~mm}$ & $\begin{array}{c}110 \leq \mathrm{MUAC} \\
<120 \mathrm{~mm}\end{array}$ & $\geq 120 \mathrm{~mm}$ \\
\cline { 2 - 8 } & $\mathrm{Nbr}$ & $\%$ & $\mathrm{Nbr}$ & $\%$ & & 24 & 31 \\
\hline $\begin{array}{c}\text { HAZARAJAT } \\
75 \text { babies }\end{array}$ & 1 & $1.3 \%$ & 0 & $0.0 \%$ & 20 & 7 & 8 \\
\hline $\begin{array}{c}\text { BAMIYAN } \\
20 \text { babies }\end{array}$ & 1 & $5.0 \%$ & 0 & $0.0 \%$ & 5 & 3 & 13 \\
\hline $\begin{array}{c}\text { JAGHOORI } \\
17 \text { babies }\end{array}$ & 0 & $0.0 \%$ & 0 & $0.0 \%$ & 1 & 11 & 7 \\
\hline $\begin{array}{c}\text { MALESTAN } \\
25 \text { babies }\end{array}$ & 0 & $0.0 \%$ & 0 & $0.0 \%$ & 7 & 3 & 3 \\
\hline $\begin{array}{c}\text { NAWOR } \\
13 \text { babies }\end{array}$ & 0 & $0.0 \%$ & 0 & $0.0 \%$ & 7 & & 3 \\
\hline
\end{tabular}




\section{WEIGHT-FOR-HEIGHT INDEX DISTRIBUTION:}

Distribution of weight-for-height index, children aged 6-59 months, Ajarestan, July 1998

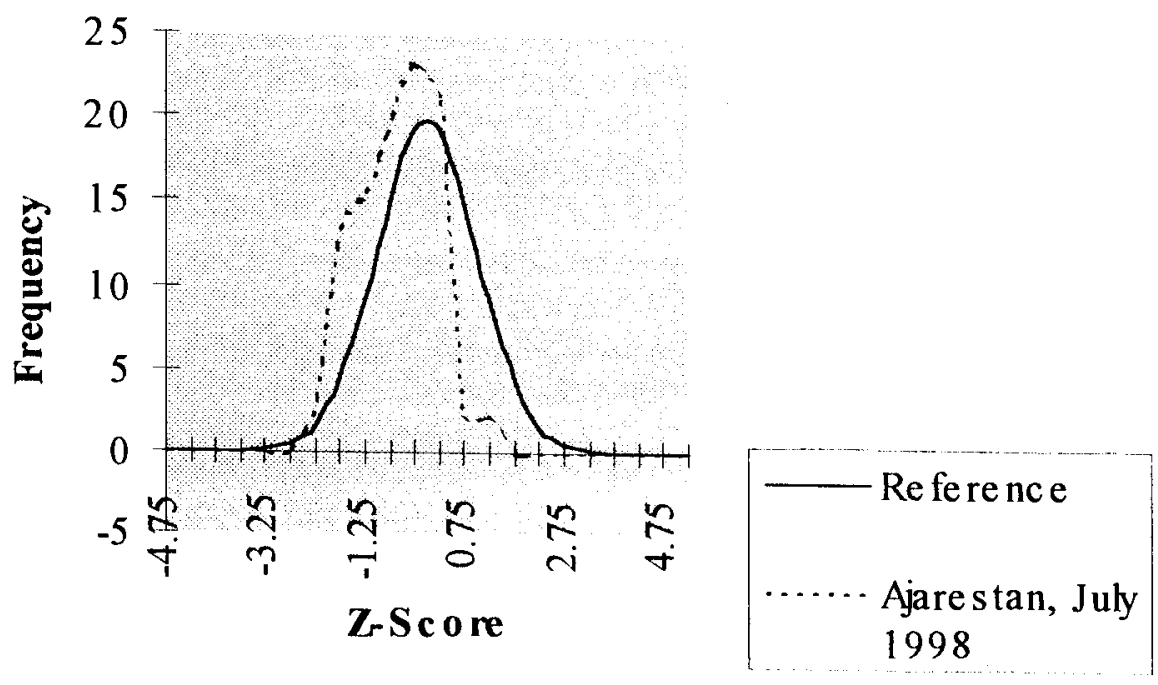

The distribution of weight-for-height expressed as a Z-Score, compared with the reference population, shows a shift to the left. This indicates that children to the left, not overlapping the curve, have a low weight in proportion to their height. The curve has a higher peak indicating a larger number of children having a medium weight in proportion to their height.

Distribution of weight-for-height index, children aged 6-59 months, Bamiyan, June 1998
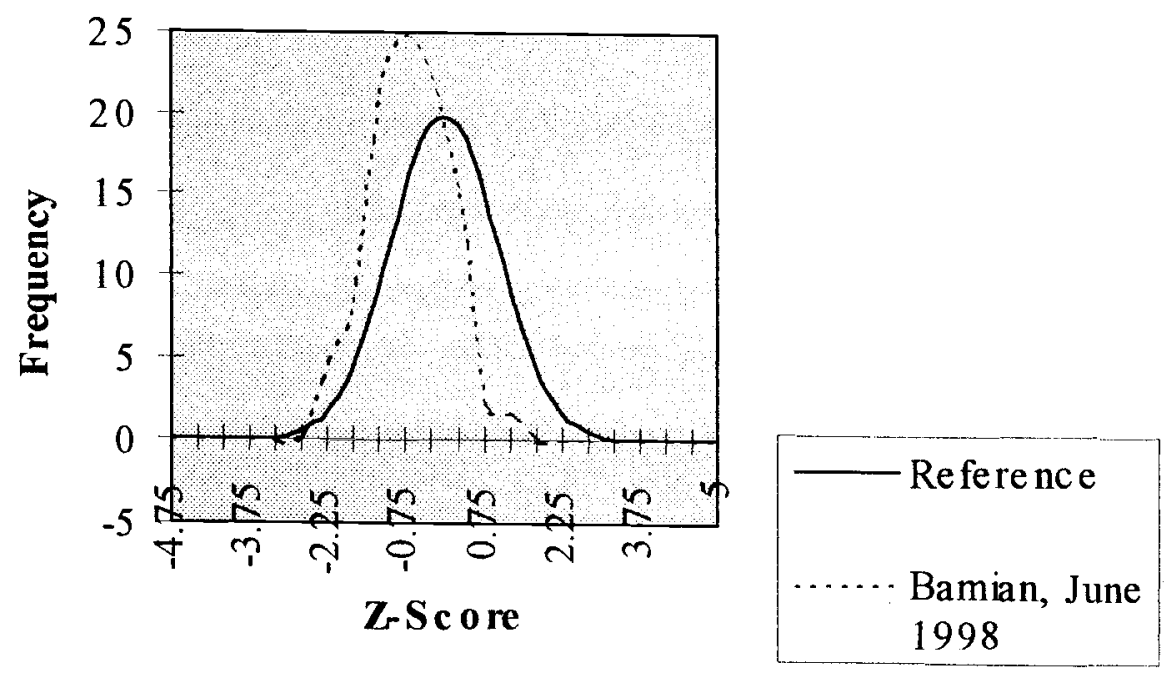

The distribution of weight-for-height expressed as a Z-Score, compared with the reference population, shows a shift to the left. This indicates that children to the left, not overlapping the curve, have a low weight in proportion to their height. The curve has a higher peak indicating a larger number of children having a medium weight in proportion to their height. 
Distribution of weight-for-height index, children aged 0-5 months, Bamiyan, June 1998

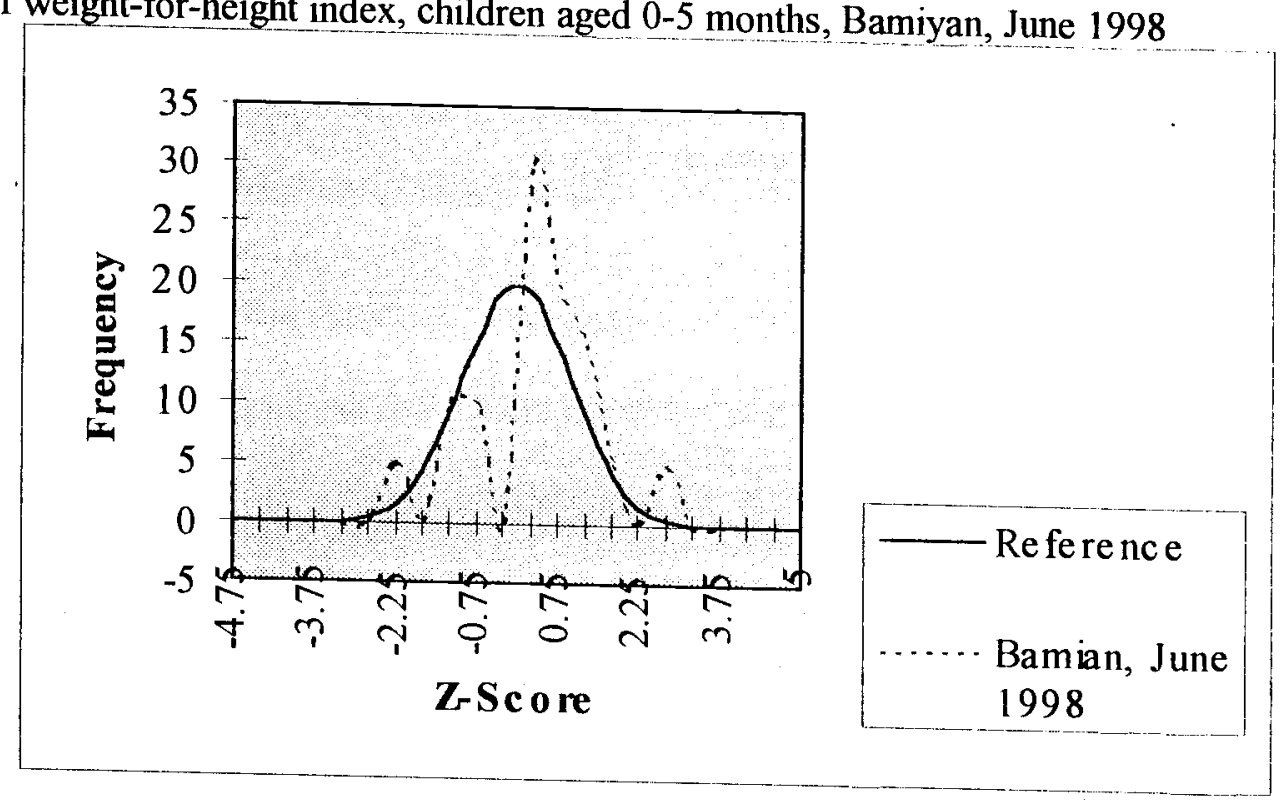

The distribution of weight-for-height expressed as a Z-Score, compared with the reference population, shows a variation across the whole of the reference curve. The curve has a higher peak indicating a larger number of children having a medium weight in proportion to their height.

Distribution of weight-for-height index, children aged 6-59 months, Jaghoori, July 1998

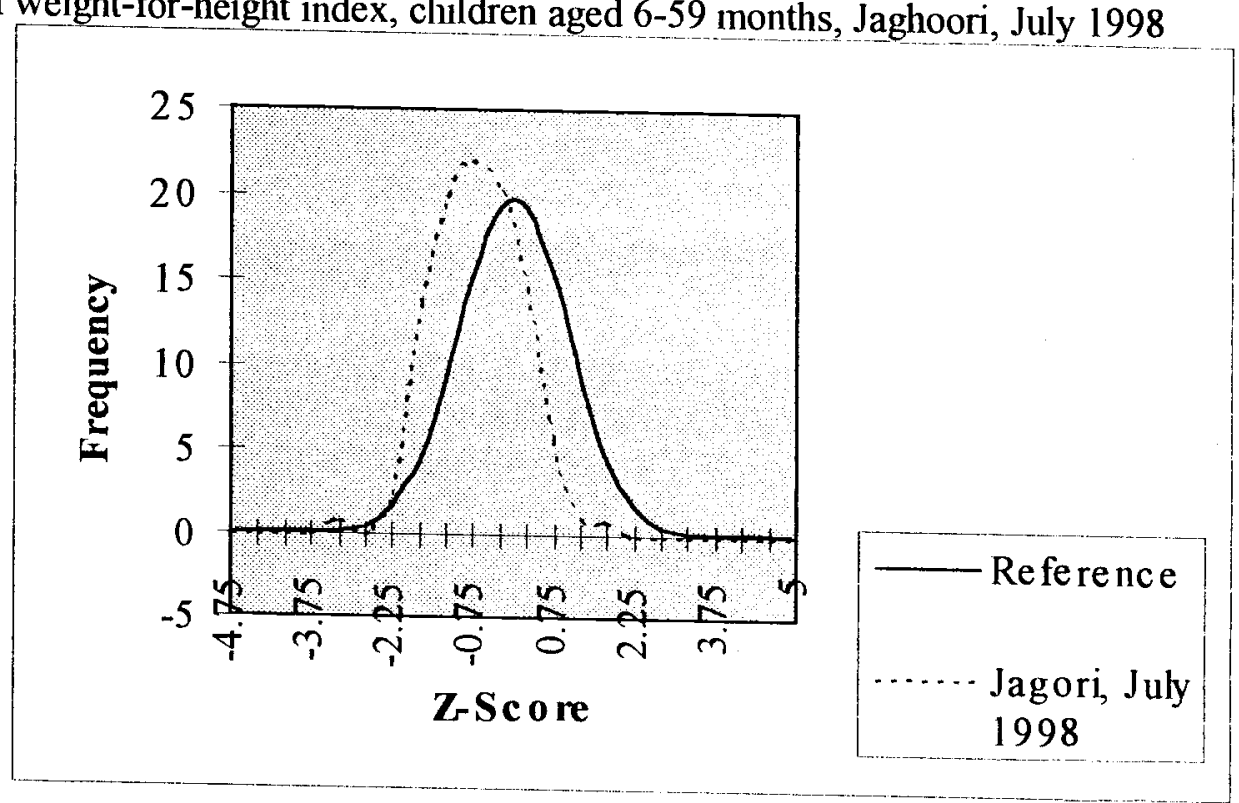

The distribution of weight-for-height expressed as a Z-Score, compared with the reference population, shows a shift to the left. This indicates that children to the left, not overlapping the curve, have a low weight in proportion to their height. The curve has a higher peak indicating a larger number of children having a medium weight in proportion to their height. 
Distribution of weight-for-height index, children aged 0-5 months, Jaghoori, July 1998
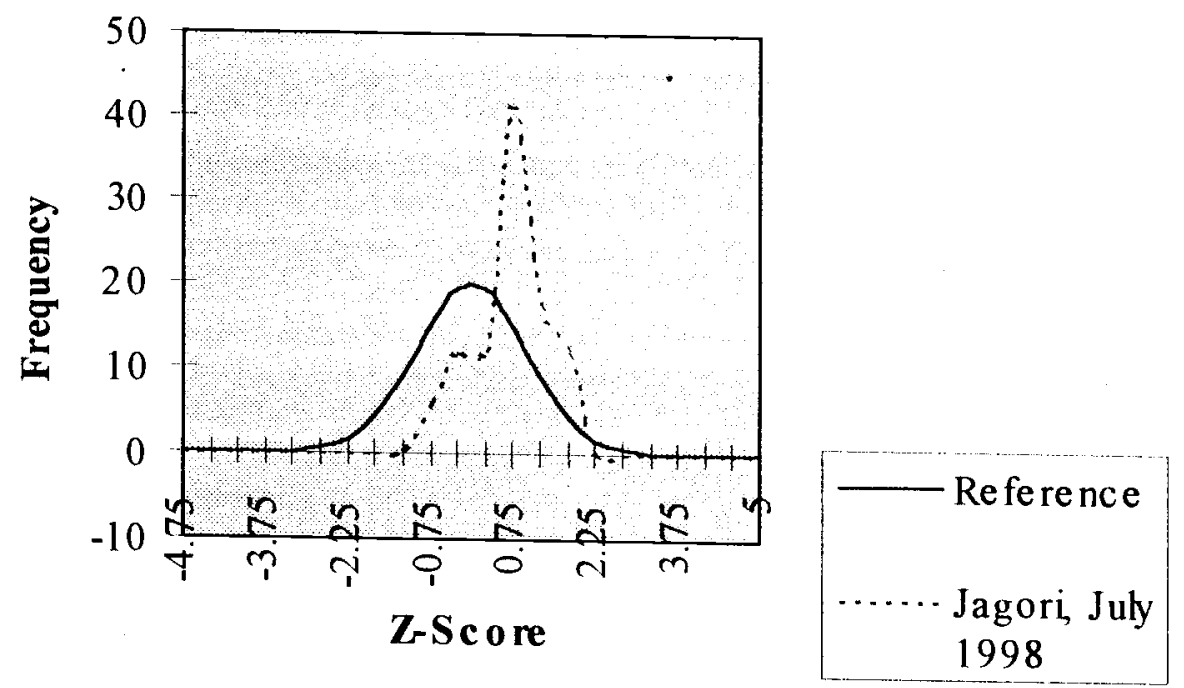

The distribution of weight-for-height expressed as a Z-Score, compared with the reference population, shows a shift to the right. This indicates that children to the right, not overlapping the curve, have a higher weight in proportion to their height The curve has a higher peak indicating a larger number of children having a medium weight in proportion to their height.

Distribution of weight-for-height index, children aged 6-59 months, Malestan, July 1998
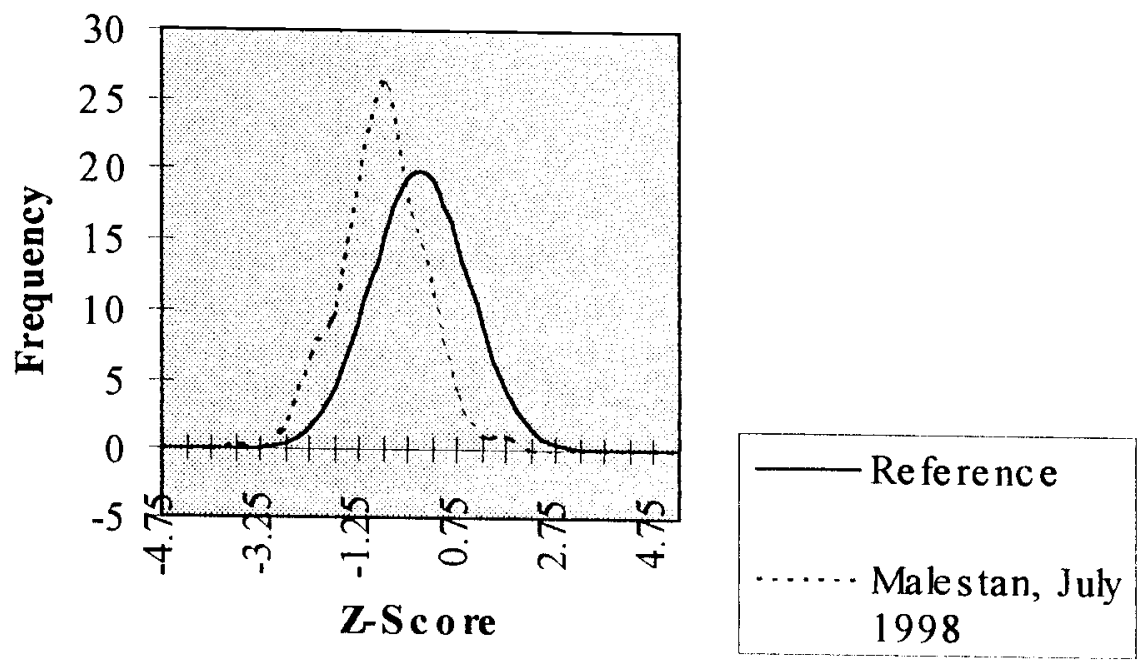

The distribution of weight-for-height expressed as a Z-Score, compared with the reference population, shows a shift to the left. This indicates that children to the left, not overlapping the curve, have a low weight in proportion to their height. The curve has a considerably higher and sharper peak indicating a larger number of children having a medium weight in proportion to their height and centred around one point. 
Distribution of weight-for-height index, children aged 0-5 months, Malestan, July 1998

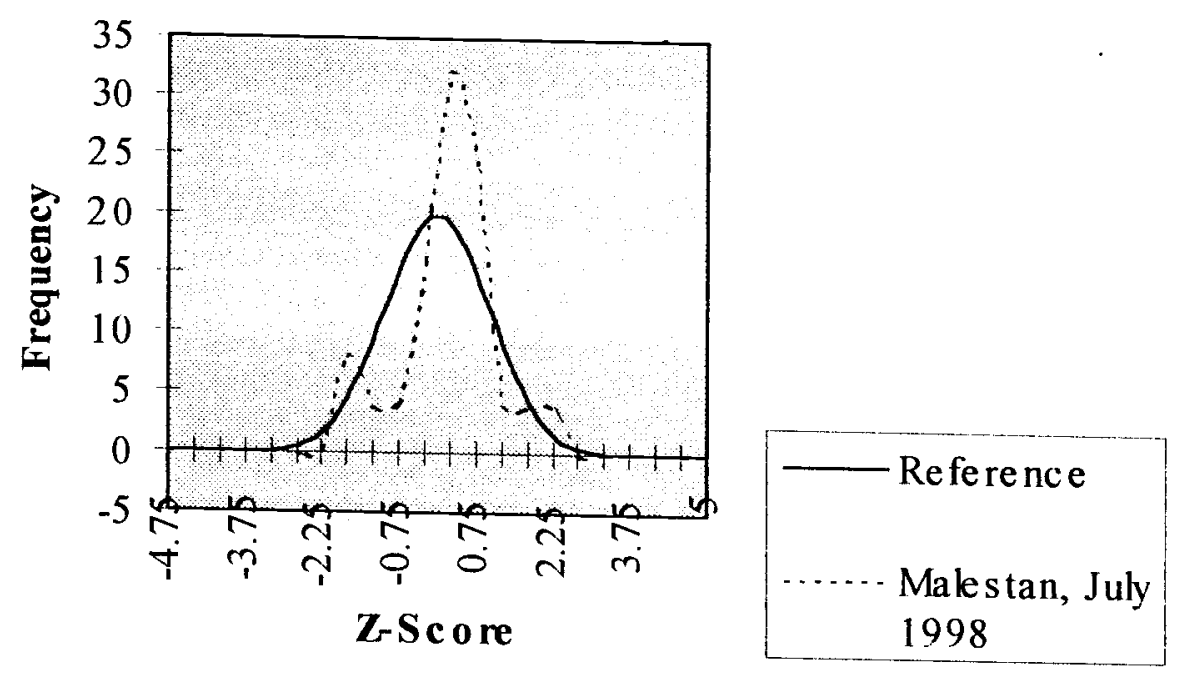

The distribution of weight-for-height expressed as a Z-Score, compared with the reference population, shows a variation across the whole of the reference curve. The curve has a higher peak indicating a larger number of children having a medium weight in proportion to their height.

Distribution of weight-for-height index, children aged 6-59 months, Nawor, July 1998
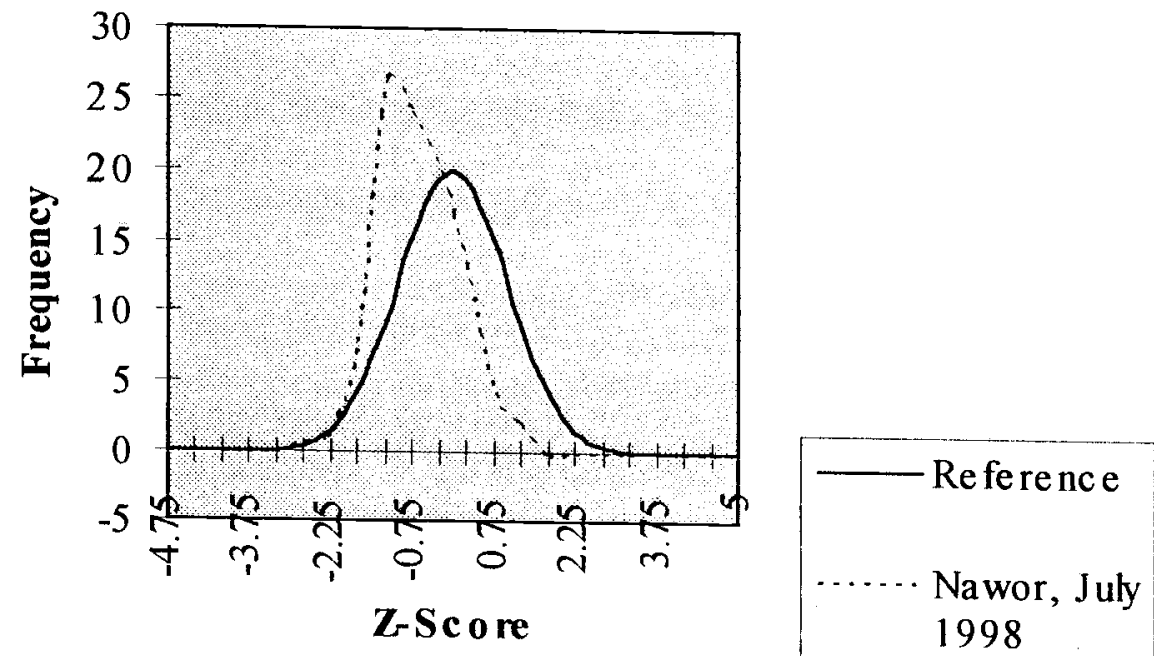

The distribution of weight-for-height expressed as a Z-Score, compared with the reference population, shows a shift to the left, but also leans to the left. This indicates that children to the left, not overlapping the curve, have a low weight in proportion to their height. The curve has a considerably higher and thinner peak indicating a larger number of children having a medium weight in proportion to their height, particularly around one point. 
Distribution of weight-for-height index, children aged 0-5 months, Nawor, July 1998

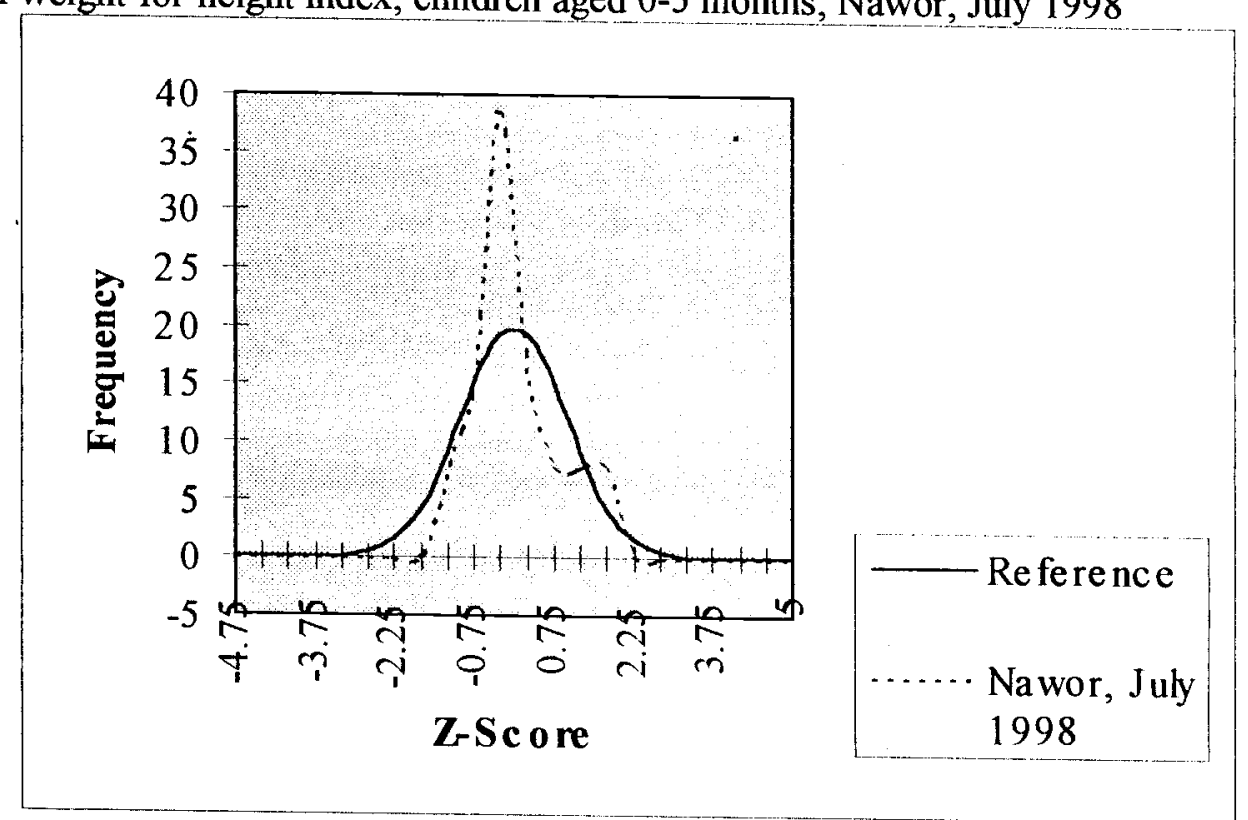

The distribution of weight-for-height expressed as a Z-Score, compared with the reference population, shows a concentration within the reference curve range, but with a much defined peak, indicating a larger number of children having a medium weight in proportion to their height. 
Table 47: Acute malnutrition versus sex, 6-59 months, Ajarestan, July 1998

\begin{tabular}{|c|c|c|c|c|c|}
\hline \multirow{2}{*}{$\begin{array}{c}\text { AGE } \\
\text { in months }\end{array}$} & \multicolumn{2}{|c|}{ WH $Z<-2 S D$} & \multicolumn{2}{|c|}{$W H Z \geq-2 S D$} & \multirow{2}{*}{$\begin{array}{c}\text { TOTAL } \\
\text { Nbr }\end{array}$} \\
\hline & $\mathrm{Nbr}$ & $\%$ & $\mathrm{Nbr}$ & $\%$ & \\
\hline Males & 3 & $7.9 \%$ & 35 & $92.1 \%$ & 38 \\
\hline Females & 0 & $0.0 \%$ & 53 & $100.0 \%$ & 53 \\
\hline TOTAL & 3 & $3.3 \%$ & 88 & $96.7 \%$ & 91 \\
\hline
\end{tabular}

There were no children aged 0-5 months screened in this area.

Table 48: Acute malnutrition versus sex, 6-59 months, Bamiyan, June 1998

\begin{tabular}{ccccc|c}
\hline AGE & \multicolumn{2}{c}{ WH Z $\mathbf{Z}-\mathbf{2 S D}$} & \multicolumn{2}{c}{ WHZ $\geq-2$ 2SD } & TOTAL \\
in months & $\mathrm{Nbr}$ & $\%$ & $\mathrm{Nbr}$ & $\%$ & Nbr \\
\hline Males & 6 & $6.5 \%$ & $8 \mathrm{e}$ & $93.5 \%$ & 93 \\
Females & 3 & $3.0 \%$ & 97 & $97.0 \%$ & 100 \\
\hline TOTAL & $\mathbf{9}$ & $\mathbf{4 . 7} \%$ & $\mathbf{1 8 4}$ & $\mathbf{9 5 . 3} \%$ & $\mathbf{1 9 3}$ \\
\hline
\end{tabular}

Table 49: Acute malnutrition versus sex, 0-5 months, Bamiyan, June 1998

\begin{tabular}{ccccc|c} 
AGE & \multicolumn{2}{c}{ WH Z $<-2$ - 2SD } & \multicolumn{2}{c|}{ WHZ $\geq-2 S D$} & TOTAL \\
in months & $\mathrm{Nbr}$ & $\%$ & $\mathrm{Nbr}$ & $\%$ & $\mathrm{Nbr}$ \\
\hline Males & 1 & $11.1 \%$ & 8 & $88.9 \%$ & 9 \\
Females & 0 & $0.0 \%$ & 11 & $100.0 \%$ & 11 \\
\hline TOTAL & 1 & $\mathbf{5 . 0} \%$ & 19 & $\mathbf{9 5 . 0} \%$ & $\mathbf{2 0}$ \\
\hline
\end{tabular}

Table 50: Acute malnutrition versus sex, 6-59 months, Jaghoori, July 1998

\begin{tabular}{ccccc|c}
\hline AGE & \multicolumn{2}{c}{ WH Z $<-2$ - 2SD } & \multicolumn{2}{c}{ WHZ $\geq-2 S D$} & TOTAL \\
in months & Nbr & $\%$ & Nbr & $\%$ & Nbr \\
\hline Males & 3 & $2.6 \%$ & 113 & $97.4 \%$ & 116 \\
Females & 4 & $4.1 \%$ & 93 & $95.9 \%$ & 97 \\
\hline TOTAL & 7 & $\mathbf{3 . 3} \%$ & $\mathbf{2 0 6}$ & $\mathbf{9 6 . 7} \%$ & $\mathbf{2 1 3}$ \\
\hline
\end{tabular}


Table 5I: Acute malnutrition versus sex, 0-5 months, Jaghoori, June 1998

\begin{tabular}{ccccc|c}
\hline $\begin{array}{c}\text { AGE } \\
\text { in months }\end{array}$ & \multicolumn{2}{c}{ WH Z Z - 2SD } & \multicolumn{2}{c|}{ WHZ $\geq-2 S D$} & TOTAL \\
\hline Males & 0 & $0.0 \%$ & -7 & $100.0 \%$ & Nbr \\
\hline Females & 0 & $0.0 \%$ & 10 & $100.0 \%$ & 10 \\
\hline TOTAL & 0 & $0.0 \%$ & 17 & $100.0 \%$ & 17 \\
\hline
\end{tabular}

Table 52: Acute malnutrition versus sex, 6-59 months, Malestan, July 1998

\begin{tabular}{ccccc|c}
\hline AGE & \multicolumn{2}{c}{ WH Z $<-2$ 2SD } & \multicolumn{2}{c|}{ WHZ $\geq-2 S D$} & TOTAL \\
in months & Nbr & $\%$ & Nbr & $\%$ & Nbr \\
\hline Males & 14 & $10.9 \%$ & 115 & $89.1 \%$ & 129 \\
Females & 9 & $7.1 \%$ & 118 & $92.9 \%$ & 127 \\
\hline TOTAL & $\mathbf{2 3}$ & $\mathbf{9 . 0} \%$ & $\mathbf{2 3 3}$ & $\mathbf{9 1 . 0} \%$ & $\mathbf{2 5 6}$ \\
\hline
\end{tabular}

Table 53: Acute malnutrition versus sex, 0-5 months, Malestan, June 1998

\begin{tabular}{|c|c|c|c|c|c|}
\hline \multirow{2}{*}{$\begin{array}{c}\text { AGE } \\
\text { in months }\end{array}$} & \multicolumn{2}{|c|}{ WH $Z<-2 S D$} & \multicolumn{2}{|c|}{$\overline{W H Z} \geq-\overline{2 S D}$} & \multirow{2}{*}{$\begin{array}{c}\text { TOTAL } \\
\text { Nbr }\end{array}$} \\
\hline & $\mathrm{Nbr}$ & $\%$ & $\mathrm{Nbr}$ & $\%$ & \\
\hline Males & 0 & $0.0 \%$ & 15 & $100.0 \%$ & 15 \\
\hline Females & 0 & $0.0 \%$ & 10 & $100.0 \%$ & 10 \\
\hline TOTAL & 0 & $0.0 \%$ & 25 & $100.0 \%$ & 25 \\
\hline
\end{tabular}

Table 54: Acute malnutrition versus sex, 6-59 months, Nawor, July 1998

\begin{tabular}{|c|c|c|c|c|c|}
\hline \multirow{2}{*}{$\begin{array}{c}\text { AGE } \\
\text { in months }\end{array}$} & \multicolumn{2}{|c|}{ WH $\overline{Z<-2 S D}$} & \multicolumn{2}{|c|}{ WHZ $\geq-2 S D$} & \multirow{2}{*}{$\begin{array}{c}\text { TOTAL } \\
\mathrm{Nbr}\end{array}$} \\
\hline & $\mathrm{Nbr}$ & $\%$ & $\mathrm{Nbr}$ & $\%$ & \\
\hline Males & 2 & $2.5 \%$ & 77 & $97.5 \%$ & 79 \\
\hline Females & 1 & $1.6 \%$ & 61 & $98.4 \%$ & 62 \\
\hline TOTAL & 3 & $2.1 \%$ & 138 & $97.9 \%$ & 141 \\
\hline
\end{tabular}

Table 55: Acute malnutrition versus sex, 0-5 months, Nawor, July 1998

\begin{tabular}{ccccc|c}
\hline $\begin{array}{c}\text { AGE } \\
\text { in months }\end{array}$ & \multicolumn{2}{c}{ WH Z $<-2$ - 2SD } & \multicolumn{2}{c|}{ WHZ $\geq-$ 2SD } & TOTAL \\
\hline Males & 0 & $0.0 \%$ & 5 & $100.0 \%$ & Nbr \\
\hline Females & 0 & $0.0 \%$ & 8 & $100.0 \%$ & 8 \\
\hline TOTAL & 0 & $\mathbf{0 . 0} \%$ & 13 & $\mathbf{1 0 0 . 0} \%$ & $\mathbf{1 3}$ \\
\hline
\end{tabular}




\section{HEIGHT-FOR-AGE INDEX DISTRIBUTION}

Distribution of the height-for-age index in Z-Score, Ajarestan, July 1998

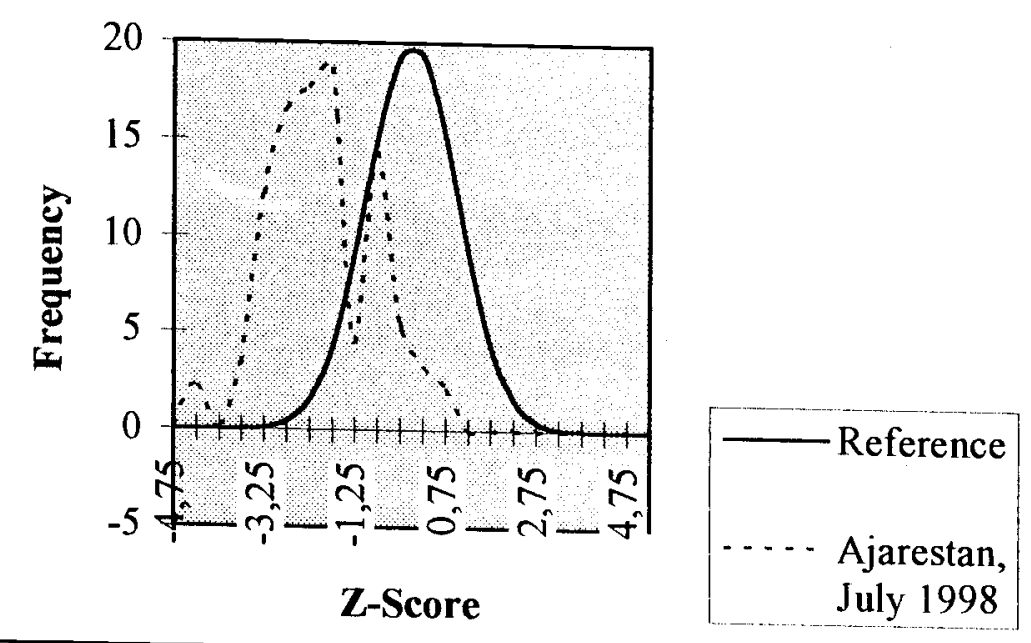

The curve shows a great shift to the left, showing a short height in proportion to age.

Distribution of the height-for-age index in Z-Score, Bamiyan, June 1998

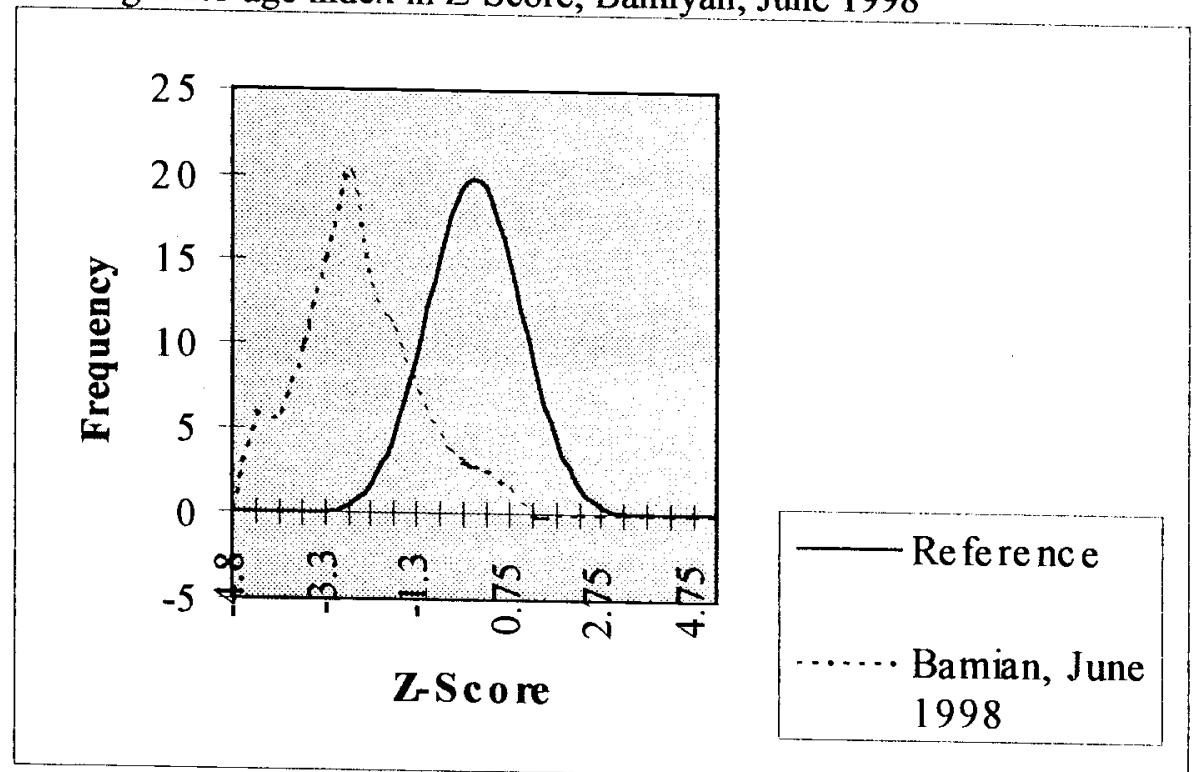

The curve shows a great shift to the left, showing a short height in proportion to age. 
- Distribution of the height-for-age index in Z-Score, Jaghoori, July 1998

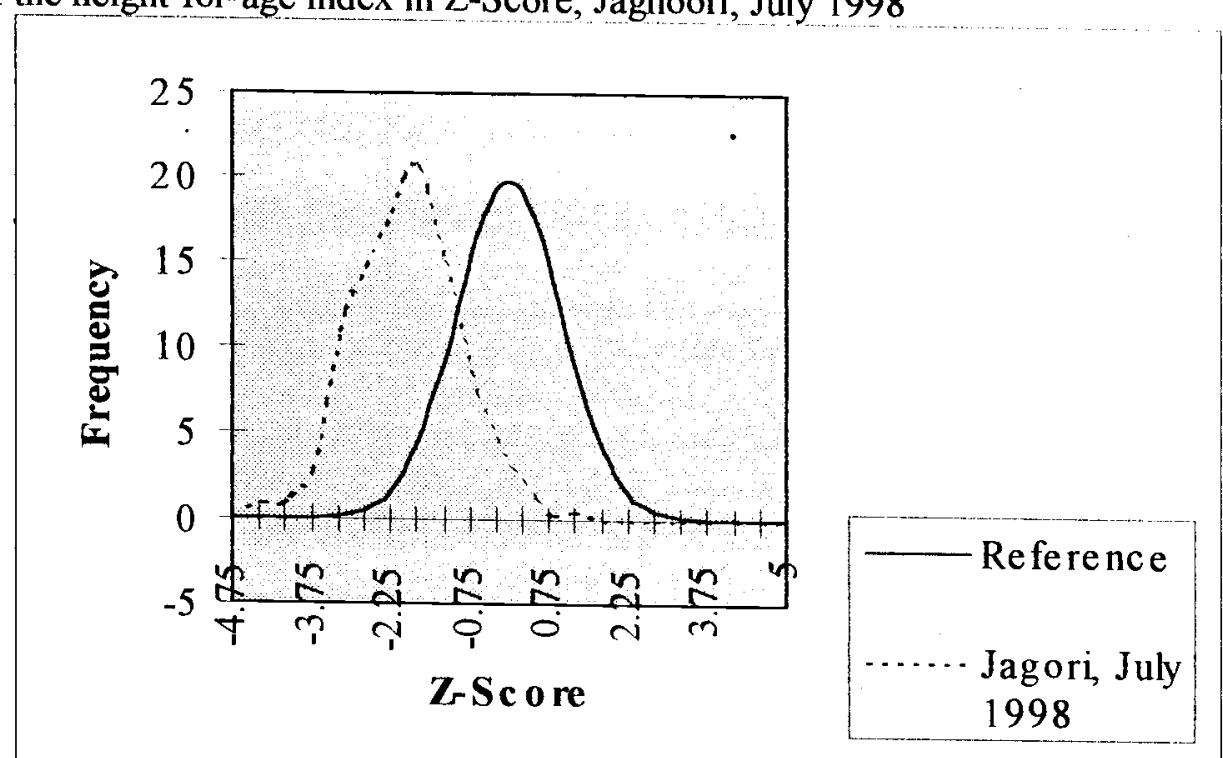

The curve shows a great shift to the left, showing a short height in proportion to age.

Distribution of the height-for-age index in Z-Score, Malestan, July 1998

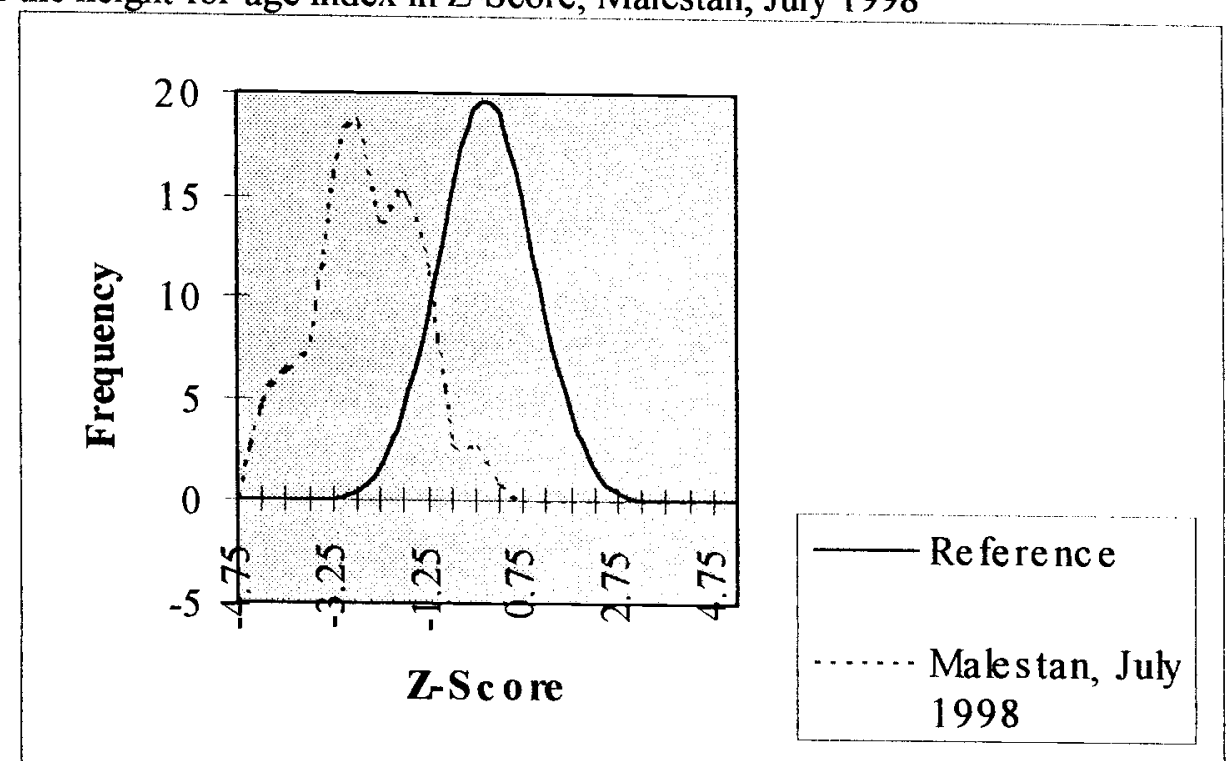

The curve shows a great shift to the left, showing a short height in proportion to age. 
Distribution of the height-for-age index in Z-Score, Nawor, July 1998

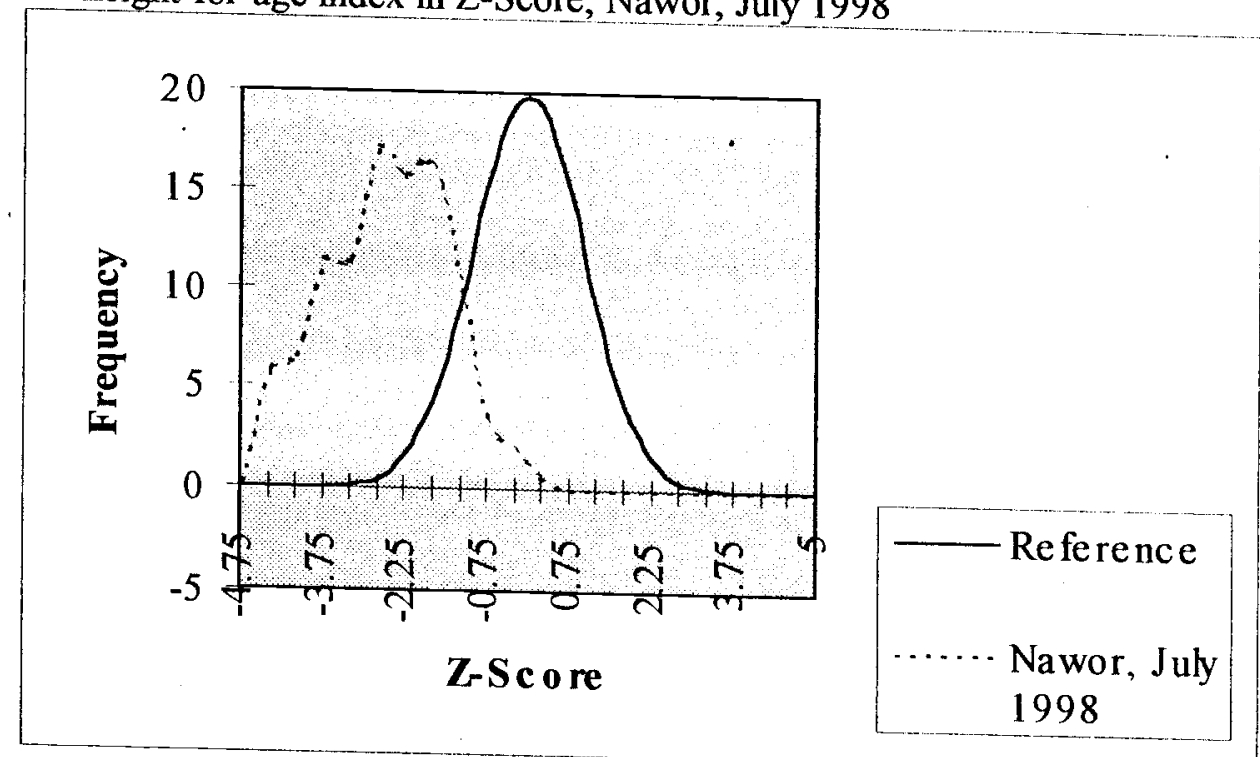

The curve shows a great shift to the left, showing a short height in proportion to age. 


\section{Appendix V: Stunting versus Wasting}

\section{STUNTING VERSUS WASTING:}

index.

Using the Z-Score expression, the height-for-age index can be compared to the weight-for-height

Table 56: Stunting versus wasting, Ajarestan, July 1998

\begin{tabular}{|c|c|c|c|c|}
\hline $\begin{array}{c}\text { AGE } \\
\text { in months }\end{array}$ & $\begin{array}{c}\text { HAZ }<- \text { 3SD } \\
\text { Severe stunting }\end{array}$ & $\begin{array}{c}-\mathbf{3 S D} \leq \mathbf{H A Z}<-\mathbf{2 S D} \\
\text { Moderate stunting }\end{array}$ & $\begin{array}{l}\text { HAZ } \geq- \text { 2SD } \\
\text { Normal height }\end{array}$ & TOTAL \\
\hline $\begin{array}{l}\text { WHZ }<- \text { 3SD } \\
\text { Severe wasting }\end{array}$ & 0 & 0 & 0 & $\begin{array}{c}\mathbf{0} \\
(0.0 \%)\end{array}$ \\
\hline $\begin{array}{c}-\mathbf{3 S D} \leq \mathbf{W H Z}<-\mathbf{2 S D} \\
\text { Moderate wasting }\end{array}$ & 1 & 0 & 2 & $\begin{array}{c}3 \\
(3.3 \%)\end{array}$ \\
\hline $\begin{array}{c}\text { HAZ } \geq-\mathbf{2 S D} \\
\text { Normal weight } \\
\end{array}$ & 15 & 31 & 42 & $\begin{array}{c}88 \\
(96.7 \%) \\
\end{array}$ \\
\hline TOTAL & $\begin{array}{c}16 \\
(17.6 \%) \\
\end{array}$ & $\begin{array}{c}31 \\
(34.1 \%) \\
\end{array}$ & $\begin{array}{c}44 \\
(48.3 \%) \\
\end{array}$ & 91 \\
\hline
\end{tabular}

Amongst the children who have a normal weight for their height $52.3 \%$ are stunted, which may be due to a poor nutritional history, a poor estimation of age, or the fact that the Hazaras are of Mongol descent and may be prone to a shorter height average genetically, than the reference population. $33.3 \%$ of wasted children were also stunted. This could be an indication of a poor diet (see diet section) over a long period of time, resulting in growth retardation, which may have become worse in the weeks proceeding the survey, causing wasting. The survey was carried out during the Hunger Gap of this region. $47.7 \%$ of the children were neither stunted nor wasted.

Table 57: Stunting versus wasting, Bamiyan, June 1998

\begin{tabular}{|c|c|c|c|c|}
\hline $\begin{array}{c}\text { AGE } \\
\text { in months }\end{array}$ & $\begin{array}{c}\text { HAZ }<- \text { 3SD } \\
\text { Severe stunting }\end{array}$ & $\begin{array}{c}-\mathbf{3 S D} \leq \mathbf{H A Z}<-\mathbf{2 S D} \\
\text { Moderate stunting }\end{array}$ & $\begin{array}{l}\text { HAZ } \geq-\mathbf{2 S D} \\
\text { Normal height }\end{array}$ & TOTAL \\
\hline $\begin{array}{l}\text { WHZ }<-3 \text { SD } \\
\text { Severe wasting }\end{array}$ & 0 & 0 & 0 & $\begin{array}{c}\mathbf{0} \\
(0.0 \%)\end{array}$ \\
\hline $\begin{array}{c}-\mathbf{3 S D} \leq \mathbf{W H Z}<-\mathbf{2 S D} \\
\text { Moderate wasting }\end{array}$ & 1 & 8 & 0 & $\begin{array}{c}9 \\
(4.6 \%)\end{array}$ \\
\hline $\begin{array}{l}\text { HAZ } \geq-2 \text { SD } \\
\text { Normal weight }\end{array}$ & 69 & 57 & 58 & $\begin{array}{c}184 \\
(95.4 \%) \\
\end{array}$ \\
\hline TOTAL & $\begin{array}{c}70 \\
(36.3 \%) \\
\end{array}$ & $\begin{array}{c}65 \\
(33.7 \%) \\
\end{array}$ & $\begin{array}{c}\mathbf{5 8} \\
(30.0 \%) \\
\end{array}$ & 91 \\
\hline
\end{tabular}

Amongst the children who have a normal weight for their height $68.5 \%$ are stunted, which may be due to a poor nutritional history, a poor estimation of age, or the fact that the Hazaras are of Mongol descent and may be prone to a shorter height average genetically, than the reference population. $100 \%$ of wasted children were also stunted. This could be an indication of a poor diet (see Diet section) over a long period of time, resulting in growth retardation, which may have become worse in the weeks proceeding the survey, causing wasting. The survey was carried out during the Hunger Gap of this region. $30.1 \%$ of the children were neither stunted nor wasted. 
Table 58: Stunting versus wasting, Jaghoori, July 1998

\begin{tabular}{|c|c|c|c|c|}
\hline $\begin{array}{c}\text { AGE } \\
\text { in months }\end{array}$ & $\begin{array}{c}\text { HAZ }<-3 \text { 3SD } \\
\text { Severe stunting }\end{array}$ & $\begin{array}{c}-3 \text { SDD } \leq \mathbf{H A Z}<-\mathbf{2 S D} \\
\text { Moderate stunting }\end{array}$ & $\begin{array}{l}\text { HAZ } \geq-2 \text { SD } \\
\text { Normal height }\end{array}$ & TOTAL \\
\hline $\begin{array}{l}\text { WHZ }<-3 \text { SSD } \\
\text { Severe wasting }\end{array}$ & 0 & 0 & 2 & 2 \\
\hline $\begin{array}{c}-\mathbf{3 S D} \leq \mathbf{W H Z}<-\mathbf{2 S D} \\
\text { Moderate wasting }\end{array}$ & 2 & 1 & 2 & $\begin{array}{l}(0.9 \%) \\
\mathbf{5} \\
(2.3 \%)\end{array}$ \\
\hline $\begin{array}{c}H A Z \geq-2 S D \\
\text { Normal weight }\end{array}$ & 31 & 68 & 107 & $\begin{array}{c}206 \\
(96.7 \%)\end{array}$ \\
\hline TOTAL & $\begin{array}{c}33 \\
(15.5 \%) \\
\end{array}$ & $\begin{array}{c}69 \\
(32.4 \%) \\
\end{array}$ & $\begin{array}{c}111 \\
(52.1 \%)\end{array}$ & 213 \\
\hline
\end{tabular}

Amongst the children who have a normal weight for their height $48.1 \%$ are stunted, which may be due to a poor nutritional history, a poor estimation of age, or the fact that the Hazaras are of Mongol descent and may be prone to a shorter height average genetically, than the reference population. $60.0 \%$ of wasted children were also stunted. This could be an indication of a poor diet (see diet section) over a long period of time, resulting in growth retardation, which may have become worse in the weeks proceeding the survey, causing wasting. The survey was carried out during the Hunger Gap of this region. $50.2 \%$ of the children were neither stunted nor wasted

Table 59: Stunting versus wasting, Malestan, July 1998

\begin{tabular}{|c|c|c|c|c|}
\hline $\begin{array}{c}\text { AGE } \\
\text { in months } \\
\end{array}$ & $\begin{array}{l}\text { HAZ }<-3 \text { 3SD } \\
\text { Severe stunting }\end{array}$ & $\begin{array}{c}-\mathbf{3 S D} \leq \mathbf{H A Z}<-\mathbf{2 S D} \\
\text { Moderate stunting }\end{array}$ & $\begin{array}{l}\text { HAZ } \geq- \text { 2SD } \\
\text { Nornal height }\end{array}$ & TOTAL \\
\hline $\begin{array}{l}\text { WHZ }<- \text { 3SD } \\
\text { Severe wasting }\end{array}$ & 0 & 0 & 1 & $\begin{array}{c}1 \\
(0.4 \%)\end{array}$ \\
\hline $\begin{array}{c}-\mathbf{3 S D} \leq \mathbf{W H Z}<-\mathbf{2 S D} \\
\text { Moderate wasting }\end{array}$ & 6 & 11 & 5 & $\begin{array}{c}22 \\
(8.6 \%)\end{array}$ \\
\hline $\begin{array}{c}\text { HAZ } \geq-2 \text { SD } \\
\text { Normal weight }\end{array}$ & 83 & 72 & 78 & $\begin{array}{c}233 \\
(91.0 \%) \\
\end{array}$ \\
\hline TOTAL & $\begin{array}{c}89 \\
(34.8 \%) \\
\end{array}$ & $\begin{array}{c}83 \\
(32.4 \%) \\
\end{array}$ & $\begin{array}{c}84 \\
(32.8 \%) \\
\end{array}$ & 256 \\
\hline
\end{tabular}

Amongst the children who have a normal weight for their height $66.5 \%$ are stunted, which may be due to a poor nutritional history, a poor estimation of age, or the fact that the Hazaras are of Mongol descent and may be prone to a shorter height average genetically, than the reference population. $77.3 \%$ of wasted children were also stunted. This could be an indication of a poor diet (see diet section) over a long period of time, resulting in growth retardation, which may have become worse in the weeks proceeding the survey, causing wasting. The survey was carried out during the Hunger Gap of this region. $30.5 \%$ of the children were neither stunted nor wasted

Table 60: Stunting versus wasting, Nawor, July 1998

\begin{tabular}{|c|c|c|c|c|}
\hline $\begin{array}{c}\text { AGE } \\
\text { in months } \\
\end{array}$ & $\begin{array}{l}\text { HAZ }<- \text { 3SD } \\
\text { Severe stunting } \\
\end{array}$ & $\begin{array}{c}-\mathbf{3 S D} \leq \mathrm{HAZ}<-\mathbf{2 S D} \\
\text { Moderate stunting }\end{array}$ & $\begin{array}{l}\text { HAZ } \geq-\mathbf{2 S D} \\
\text { Normal height }\end{array}$ & TOTAL \\
\hline $\begin{array}{l}\text { WHZ }<-3 \text { SD } \\
\text { Severe wasting }\end{array}$ & 0 & 0 & 0 & $\begin{array}{c}\mathbf{0} \\
(0.0 \%)\end{array}$ \\
\hline $\begin{array}{c}-\mathbf{3 S D} \leq \mathbf{W H Z}<-\mathbf{2 S D} \\
\text { Moderate wasting }\end{array}$ & 1 & 1 & 1 & $\begin{array}{l}3 \\
(2.1 \%)\end{array}$ \\
\hline $\begin{array}{c}\text { HAZ } \geq-2 \text { SD } \\
\text { Normal weight } \\
\end{array}$ & 48 & 45 & 45 & $\begin{array}{c}138 \\
(97.9 \%) \\
\end{array}$ \\
\hline TOTAL & $\begin{array}{c}49 \\
(34.8 \%) \\
\end{array}$ & $\begin{array}{c}46 \\
(32.6 \%) \\
\end{array}$ & $\begin{array}{c}46 \\
(32.6 \%) \\
\end{array}$ & 141 \\
\hline
\end{tabular}


Amongst the children who have a normal weight for their height $67.4 \%$ are stunted, which may be due to a poor nutritional history, a poor estimation of age, or the fact that the Hazaras are of Mongol descent and may be prone to a shorter height average genetically, than the reference population. $66.6 \%$ of wasted children were also stunted. This could be an indication of a poor diet (see diet section) over a long period of time, resulting in growth retardation, which may have become worse in the weeks proceeding the survey, causing wasting. The survey was carried out during the Hunger Gap of this region. $31.9 \%$ of the children were neither stunted nor wasted. 


\section{DISTRIBUTION OF WHZ VERSUS MUAC:}

Table 61: Distribution of WHZ versus $M U A C$ in children with a height of $\geq 75 \mathrm{~cm}$, Ajarestan, July, 1998

\begin{tabular}{|c|c|c|c|c|c|}
\hline \multirow[t]{2}{*}{ MUAC (in mm) } & \multicolumn{2}{|c|}{ MUAC $<120$} & \multicolumn{2}{|c|}{$120 \leq \mathrm{MUAC}$} & \multirow{2}{*}{$\begin{array}{c}\text { TOTAL } \\
\mathrm{Nbr} \\
\end{array}$} \\
\hline & $\mathrm{Nbr}$ & $\%$ & $\mathrm{Nbr}$ & $\%$ & \\
\hline WHZ $<-2$ SD & 0 & $0.0 \%$ & 2 & $2.9 \%$ & 2 \\
\hline WHZ $\geq-2 S D$ & 1 & $100.0 \%$ & 67 & $97.1 \%$ & 68 \\
\hline TOTAL & 1 & $1.4 \%$ & 69 & $98.6 \%$ & 70 \\
\hline
\end{tabular}

Amongst the children $\geq 75 \mathrm{~cm}$, no cases were suffering from severe acute malnutrition, combining a risk of mortality with wasting. None of the children who have a normal weight for their height in Z-Score, have a high risk of mortality with a MUAC $<110 \mathrm{~mm} .2 .9 \%$ of the children with a low risk of mortality were found to be malnourished according to their weight-for-height index. This may mean that although these children have wasted somewhat, they have not reached the stage of catabolising muscle tissue to cover their basic metabolic needs.

Table 62: Distribution of WHZ versus $M U A C$ in children with a height of $\geq 75 \mathrm{~cm}$, Bamiyan, June, 1998

\begin{tabular}{ccccc|c}
\hline MUAC (in mm) & \multicolumn{2}{c}{ MUAC $<\mathbf{1 2 0}$} & \multicolumn{2}{c}{$\mathbf{1 2 0} \leq$ MUAC } & TOTAL \\
& Nbr & $\%$ & Nbr & $\%$ & Nbr \\
\hline WHZ < - 2SD & 0 & $0.0 \%$ & 4 & $3.1 \%$ & 4 \\
WHZ $\geq$ - 2SD & 1 & $100.0 \%$ & 126 & $96.9 \%$ & 127 \\
\hline TOTAL & $\mathbf{1}$ & $\mathbf{0 . 8} \%$ & $\mathbf{1 3 0}$ & $\mathbf{9 9 . 2} \%$ & $\mathbf{1 3 1}$ \\
\hline
\end{tabular}

Amongst the children $\geq 75 \mathrm{~cm}$, no cases were suffering from severe acute malnutrition, combining a risk of mortality with wasting. None of the children who have a normal weight for their height in Z-Score, have a high risk of mortality with a MUAC $<110 \mathrm{~mm} .3 .1 \%$ of the children with a low risk of mortality were found to be malnourished according to their weight-for-height index. This may mean that although these children have wasted somewhat, they have not reached the stage of catabolising muscle tissue to cover their basic metabolic needs.

Table 63: Distribution of WHZ versus MUAC in children with a height of $\geq 75 \mathrm{~cm}$, Jaghoori, July, 1998

\begin{tabular}{ccccc|c}
\hline MUAC (in mm) & \multicolumn{2}{c}{ MUAC $<\mathbf{1 2 0}$} & \multicolumn{2}{c}{$\mathbf{1 2 0} \leq$ MUAC } & TOTAL \\
& $\mathrm{Nbr}$ & $\%$ & $\mathrm{Nbr}$ & $\%$ & Nbr \\
\hline WHZ $<-$ 2SD & 1 & $50.0 \%$ & 4 & $2.4 \%$ & $\mathbf{5}$ \\
WHZ $\geq$ - 2SD & 1 & $50.0 \%$ & 160 & $97.6 \%$ & $\mathbf{1 6 1}$ \\
\hline TOTAL & $\mathbf{2}$ & $\mathbf{1 . 2 \%}$ & $\mathbf{1 6 4}$ & $\mathbf{9 8 . 8} \%$ & $\mathbf{1 6 6}$ \\
\hline
\end{tabular}

Amongst the children $\geq 75 \mathrm{~cm}, 1$ case is suffering from severe acute malnutrition, combining a risk of mortality with wasting. None of the children who have a normal weight for their height in $\mathrm{Z}$ Score, have a high risk of mortality with a MUAC $<110 \mathrm{~mm} .2 .4 \%$ of the children with a low risk of mortality were found to be malnourished according to their weight-for-height index. This may 
mean that although these children have wasted somewhat, they have not reached the stage of catabolising muscle tissue to cover their basic metabolic needs.

Table 64: Distribution of WHZ versus MUAC in children with a height of $\geq 75 \mathrm{~cm}$, Malestan, June, 1998

\begin{tabular}{ccccc|c}
\hline MUAC (in mm) & \multicolumn{2}{c}{ MUAC $<\mathbf{1 2 0}$} & \multicolumn{2}{c}{$\mathbf{1 2 0} \leq$ MUAC } & TOTAL \\
& $\mathrm{Nbr}$ & $\mathbf{\%}$ & $\mathrm{Nbr}$ & $\%$ & Nbr \\
\hline WHZ $<-\mathbf{2 S D}$ & 8 & $72.7 \%$ & 8 & $4.8 \%$ & $\mathbf{1 6}$ \\
WHZ $\geq-$ 2SD & 3 & $27.3 \%$ & 159 & $95.2 \%$ & $\mathbf{1 6 2}$ \\
\hline TOTAL & $\mathbf{1 1}$ & $\mathbf{6 . 2 \%}$ & $\mathbf{1 6 7}$ & $\mathbf{9 3 . 8} \%$ & $\mathbf{1 7 8}$ \\
\hline
\end{tabular}

Amongst the children $\geq 75 \mathrm{~cm}$, no cases were suffering from severe acute malnutrition, combining a risk of mortality with wasting. None of the children who have a normal weight for their height in Z-Score, have a high risk of mortality with a MUAC $<110 \mathrm{~mm} .4 .8 \%$ of the children with a low risk of mortality were found to be malnourished according to their weight-for-height index. This may mean that although these children have wasted somewhat, they have not reached the stage of catabolising muscle tissue to cover their basic metabolic needs.

\begin{tabular}{|c|c|c|c|c|c|}
\hline \multirow[t]{2}{*}{ MUAC (in mm) } & \multicolumn{2}{|c|}{ MUAC $<120$} & \multicolumn{2}{|c|}{$120 \leq$ MUAC } & \multirow{2}{*}{$\begin{array}{c}\text { TOTAL } \\
\mathrm{Nbr}\end{array}$} \\
\hline & $\mathrm{Nbr}$ & $\%$ & $\mathrm{Nbr}$ & $\%$ & \\
\hline WHZ $<-2 \mathrm{SD}$ & 0 & $0.0 \%$ & 1 & $1.1 \%$ & 1 \\
\hline WHZ $\geq-2 S D$ & 5 & $100.0 \%$ & 92 & $98.9 \%$ & 97 \\
\hline TOTAL & 5 & $5.1 \%$ & 93 & $94.9 \%$ & 98 \\
\hline
\end{tabular}

Amongst the children $\geq 75 \mathrm{~cm}$, no cases were suffering from severe acute malnutrition, combining a risk of mortality with wasting. None of the children who have a normal weight for their height in Z-Score, have a high risk of mortality with a MUAC $<110 \mathrm{~mm} .1 .1 \%$ of the children with a low risk of mortality were found to be malnourished according to their weight-for-height index. This may mean that although these children have wasted somewhat, they have not reached the stage of catabolising muscle tissue to cover their basic metabolic needs. 
Appendices for Part VII

Food Security 


\section{Appendix I: Technical Calendars}

\section{Irrigated Spring Wheat}

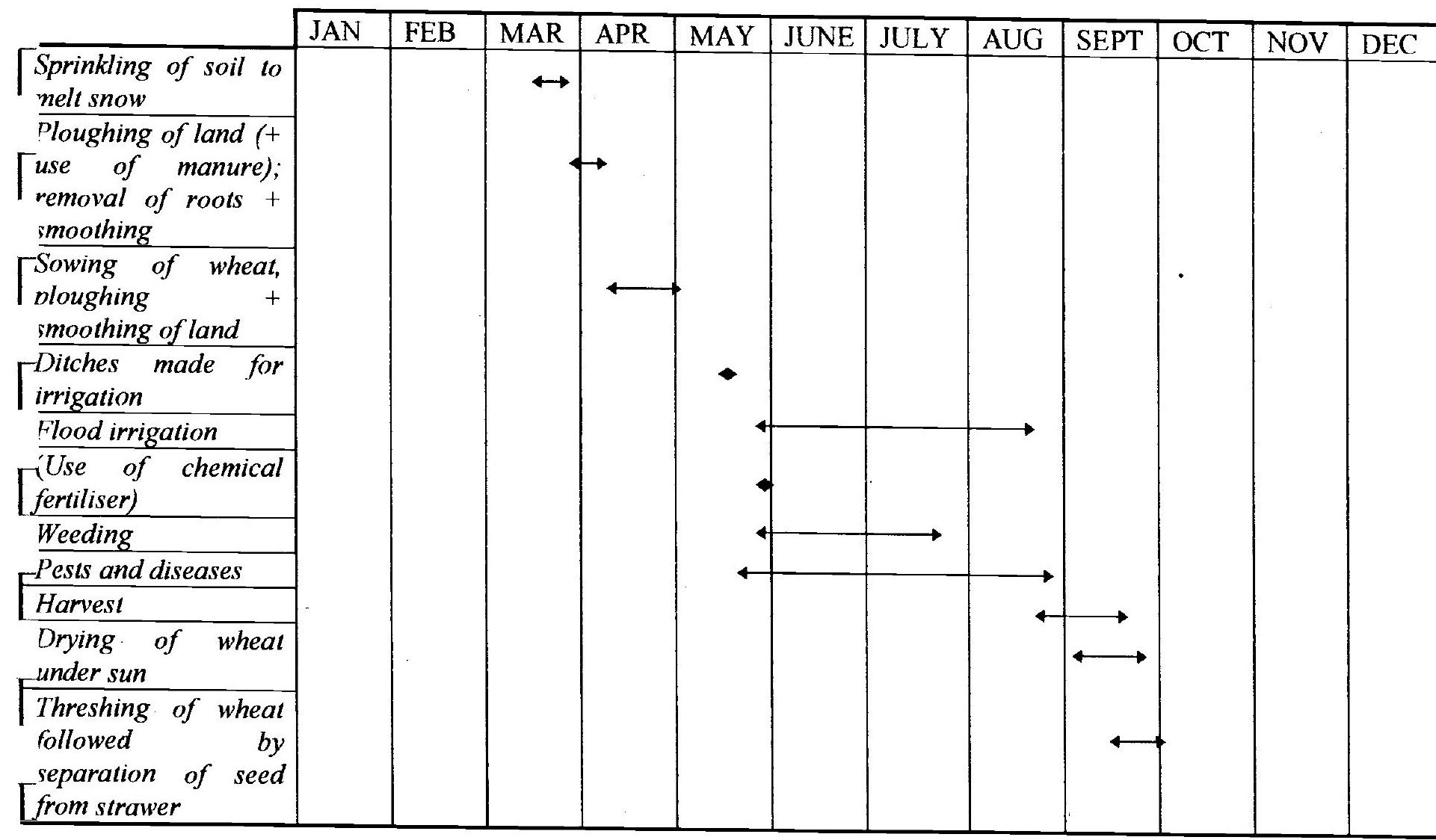

In Nawor High Plateau especially as well as parts of Bamiyan Upper Valley, the growing season begins and ends a week to two weeks later than elsewhere due to the colder temperatures to which subjected (taken into account in the above). Conversely, the calendar needs to be shifted to the left by perhaps 1 to 2 weeks for Bamiyan Lower Valley.

Before ploughing the land, soil - and sometimes ashes - are sprinkled on the land to make the snow melt. Around 2.8 tons of a mixture of manure and soil may be used (with a ratio of between $1: 4$ to $1: 2$ depending on the possibilities of the household), between ploughing. Ploughing is undertaken by men only, although women (excluding in Ajarestan), will usually take out any roots, before the land is smoothed and sown (the seeds are broadcast by hand). For those lacking oxen (particularly household type $\mathrm{C}$ and those in Jaghoori), the land is smoothed using a shovel and khalan, rather than a molla.

The germination period for wex is approximately 8-15 days; the colder the temperature, the longer it takes - as in Bamiyan Upper Valley and Nawor, for instance. Flood irrigation occurs 9 times, or every 10-12 days, in Bamiyan Lower Valley and 6-7 times, or every 15 days, in Bamiyan Upper Valley - depending upon the amount of rain (which may cause the irrigation to be delayed). In Malestan, this occurs every 10 days in sandy soil due to the higher temperatures. In all cases the field is flooded to a depth of about $4 \mathrm{~cm}$. 
If chemical fertiliser is used, it tends to be used twice and directly followed by an irrigation. Approximately $14 \mathrm{~kg}$ of urea can be used for 0.2 hectares. Around $35 \mathrm{~kg}$ of nitrogen and $21 \mathrm{~kg}$ of phosphorous could also be used - but is not done so in Bamiyan Lower and Upper Valleys due to inaccessibility.

Weeding effectively occurs in two cycles and throughout the Hazarajat, except in Ajarestan, it is carried out mainly by women by hand, who will then give the grass to any livestock, or sell it.

As from the last week of May, there may be problems of grasshoppers until around mid-August. From June to July, cutworms may damage the cluster (and around $5 \%$ of the yield), and as from the last week of July the threat of rust comes into play ${ }^{105}$. Early cold as from the third week of August is also a hazard, as are birds from around the same time until harvest in mid-September. Nawor High Plateau also suffers from problems of smut as from the end of August. Both men and women may be involved in reaping, and then later, in the separation of the seed from the straw - with the exception of Ajarestan, again.

\section{Irrigated Winter Wheat}

\begin{tabular}{|c|c|c|c|c|c|c|c|c|c|c|c|c|}
\hline & JAN & FEB & MAR & APR & MAY & JUNE & JULY & $\mathrm{AUG}$ & SEPT & OCT & NOV & DEC \\
\hline $\begin{array}{l}\text { Ploughing of land, } \\
\text { smoothing and } \\
\text { making of irrigation } \\
\text { channels }\end{array}$ & & & & & & & & & & & & \\
\hline Irrigation & & & & & & & & $\rightarrow$ & $\bullet$ & & & \\
\hline $\begin{array}{l}\text { Sowing of wheat } \\
\text { (together with any } \\
\text { DAP), followed by } \\
\text { ploughing and } \\
\text { smoothing }\end{array}$ & & & & & & & & & & & & \\
\hline $\begin{array}{l}\text { Scattering of ash and } \\
\text { soil on snow to melt }\end{array}$ & & & & $\rightarrow$ & & & & & & & & \\
\hline Weeding & & & & & & $\longrightarrow$ & & & & & & \\
\hline $\begin{array}{l}\text { (Use of white }+ \text { black } \\
\text { chemical fertiliser) }\end{array}$ & & & & & $\bullet$ & & & & & & & \\
\hline Pests and diseases & & & & $\leftarrow$ & & & & $\rightarrow$ & & & & \\
\hline Harvest & & & & & & & & & & & & \\
\hline
\end{tabular}

For Ajarestan, the technical calendar could be forwarded by 1-2 weeks due to the higher temperatures found there.

Germination occurs 5-10 days after sowing, depending upon the temperature. In Ajarestan irrigation may occur as few as 5/6 times, whilst in Malestan, in sandy loam soil, irrigation takes place 10-12 times during the growing season, but perhaps only 4-5 times in alluvial soil. In Jaghoori, irrigation may take place up to 20 times during the season due to the warmer temperature. In all cases, rainfall obviously reduces the number of irrigation.

\footnotetext{
${ }^{105}$ In order to stop the rust in a number of villages in Bamiyan, the blood of a sacrificial sheep may be poured into the irrigation network - in the name of God.
} 
Tendril weeds can cause problems, thus, weeding takes place more or less continuously as from the end of April until the end of June, during which time problems of cutworm and rust may arise once the ear/cluster begins to form. After harvest which begins 1 to 2 weeks earlier in Jaghoori compared to Malestan, the yield will only be left on the field for a few days, perhaps 2-3, and then threshed. 


\begin{tabular}{|c|c|c|c|c|c|c|c|c|c|c|c|c|}
\hline & JAN & FEB & MAR & APR & MAY & JUNE. & JULY & AUG & SEPT & OCT & NOV & DEC \\
\hline $\begin{array}{l}\text { Sowing of wheat, } \\
\text { ploughing } \\
\text { smoothing of land }\end{array}$ & . & & & $\leftrightarrow$ & & & & & & & & \\
\hline $\begin{array}{l}\text { Potential problems } \\
\text { smut and rust, as well } \\
\text { as of early cold } \\
\text { Harvest } \\
\end{array}$ & & & & & & 4 & & & 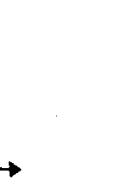 & & & \\
\hline
\end{tabular}

Sowing density is about half that of irrigated wheat, at 2-3 sers per jerib (or 14-21 kg per 0.2 hectares). With rainfed wheat, neither organic manure nor chemical fertiliser are used, due to the greater risks associated with its growth and yield. Germination takes approximately 15 days, and no weeding occurs. 
Barley

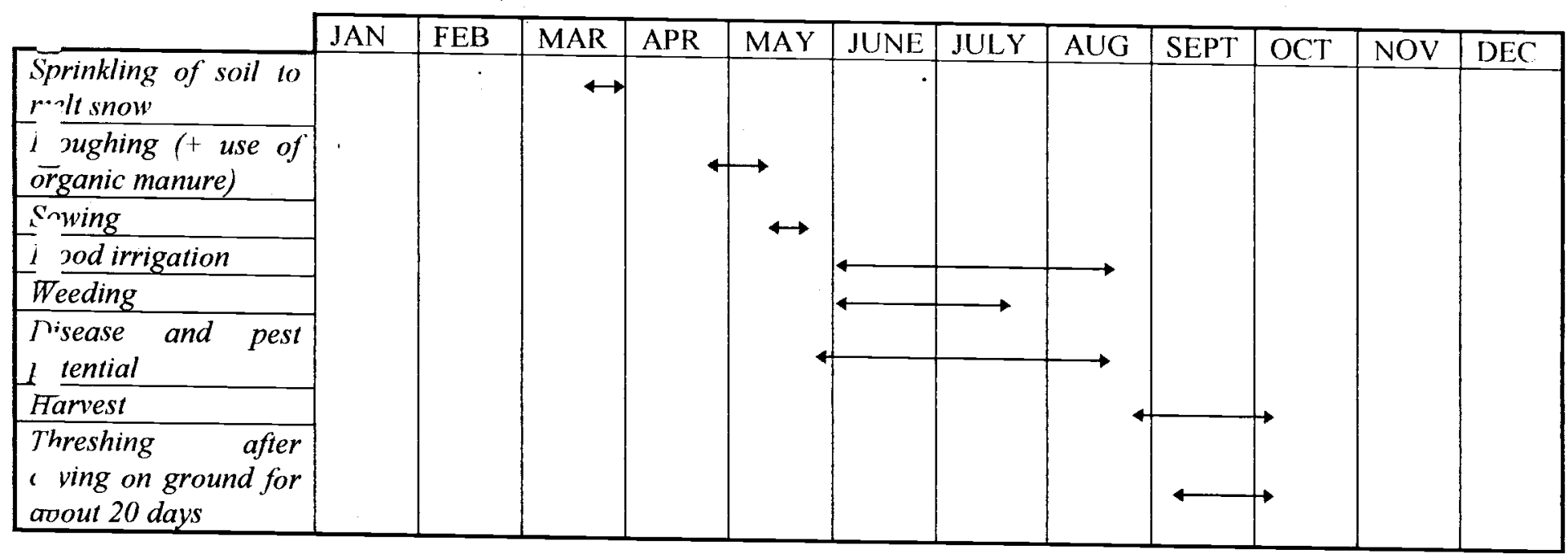

In warmer places, of higher elevation such as Ajarestan, Jaghoori and Lower Bamiyan the growing season begins perhaps 1-2 weeks earlier than that shown in the above calendar.

If organic manure is used, around 2.8 tons will be applied per jerib ( 0.2 hectares), with a ratio of manure: soil of around 1:4. The seeds are then broadcast by hand. For the caljao variety, germination takes place after 7-10 days.

In Bamiyan Upper Valley, around 6-7 irrigation take place during the growing season (every 2 weeks), to a depth of approximately $4 \mathrm{~cm}$. The last irrigation occurs the week before harvesting which may start as from the last week of August.

Weeding takes place about 2-3 times over a period of 1-2 months and is done quite constantly by women by hand. Men may sometimes help - although in Ajarestan, this is the exclusive domain of men.

As from the time of sowing, there may be problems of birds eating the seeds, as a result of which children are often required to bang metal by the fields in the morning. In some areas, scarecrows can be seen. As from the third week of June, cutworms may cause problems, and during July, grasshoppers $^{106}$. In mid-August, problems of rust may begin, just as the seeds start to form in clusters - particularly in Bamiyan Upper Valley. There may also be problems of smut (Bamiyan Upper Valley), and early cold in Bamiyan Upper Valley, Nawor reducing growth.

Barley, unlike wheat, tends to be threshed using 4 oxen, although this may be for reasons of expediency, since barley will normally be cultivated in second place, both spatially and temporally, after wheat (which has a longer growing period, requires less water and forms a more important staple).

\footnotetext{
${ }^{106}$ Grasshoppers are commonly dealt with by collecting them into big holes, burning them and then covering the hole with soil.
} 


\section{Potato}

\begin{tabular}{|c|c|c|c|c|c|c|c|c|c|c|c|c|}
\hline & JAN & FEB & MAR & APR & MAY & JUNE & JULY & AUG & SEPT & OCT & NOV & DEC \\
\hline $\begin{array}{l}\text { Sprinkling of soil to } \\
\text { melt snow }\end{array}$ & & & 4 & & & & & & & & & \\
\hline $\begin{array}{l}\text { Removal of stones for } \\
\text { ploughing ( }+ \text { use of } \\
\text { manure); smoothing } \\
\text { ofland }\end{array}$ & · & & & $\longleftrightarrow$ & & & & & & & & \\
\hline $\begin{array}{l}\text { Making of farrows in } \\
\text { one directional rows }\end{array}$ & & & & & & & & & & & & \\
\hline Potatoes planted & & & & & & & & & & & & \\
\hline Farrow irrigation & & & & & & & & & & & & \\
\hline $\begin{array}{l}\text { Weeding, followed by } \\
\text { smoothing of soil + } \\
\text { tidying of farrows }\end{array}$ & & & & & & & $\leftrightarrow$ & & & & & \\
\hline $\begin{array}{l}\text { (Second use of } \\
\text { organic manure) }\end{array}$ & & & & & & & & & & & & \\
\hline $\begin{array}{l}\text { (Use of Chemical } \\
\text { Fertiliser-2 times) }\end{array}$ & & & & & & $\bullet$ & $\bullet$ & & & & & \\
\hline $\begin{array}{l}\text { Potential problems of } \\
\text { cutworm }\end{array}$ & & & & & & & & & & & & \\
\hline $\begin{array}{l}\text { Harvesting of } \\
\text { potatoes, followed by } \\
\text { ploughing to check } \\
\text { for any remaining }\end{array}$ & & & & & & & & & & & & \\
\hline
\end{tabular}

The calendar for Lower Bamiyan Valley, Ajarestan and Jaghoori begins and ends perhaps 1-2 weeks earlier than that shown above.

If manure is used, an estimated 20 tons is used for 1 jerib ( 0.2 hectares), with a ratio of manure:soil, of 1:4.

The potatoes are planted under the soil in farrows (except in Malestan, where bounds are prevalent in alluvial soil in particular), using knives and a shovel, by both men and women. Subzgul and Safedgul have a germination period of about 20-30 days, depending on the temperature: obviously the colder it is, the longer it takes.

Farrow irrigation takes place every 7-10 days in Bamiyan Upper Valley and Nawor (perhaps 16x during the growing season), and more often in Malestan, Ajarestan, Bamiyan Lower Valley (perhaps $15 \mathrm{x}$ until September) and Jaghoori (perhaps 20x during the growing season), although this may be lessened with fertiliser use.

When chemical fertiliser is first used, around the 4th week of June, some $250 \mathrm{~kg}$ of urea are used for 1 jerib ( 0.2 hectares); about $10-20 \mathrm{~cm}$ as a sort of 'side-dressing'. The second use of urea requires only half the amount, or $250 \mathrm{~kg}$. In both instances, the fertiliser is sprinkled through a tube about $3 \mathrm{~cm}$ away towards the side of the water. Irrigation then takes place, soil added where necessary and the farrows smoothed and tidied. $35 \mathrm{~kg}$ of phosphorous, or DAP, could also be used.

During harvesting, villagers tend to help each other so that all may collect their potatoes before there is any risk of the tuber freezing. 


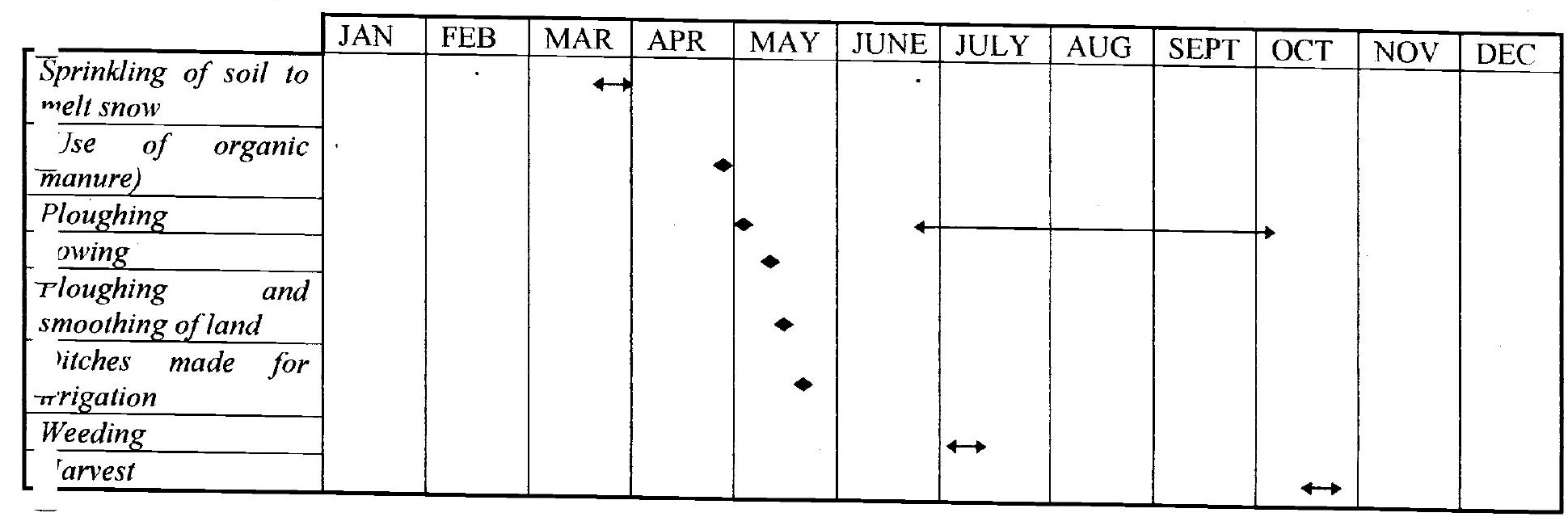

If only organic manure is used, approximately 2.45 tons may be used for $56 \mathrm{~kg}$ of seed rate, before ploughing. If, however, chemical fertiliser is also used, then this anount will be reduced. The field is then irrigated and left for around 8 days, after which time the seeds are broadcast. The field is then ploughed and smoothed/levelled, and irrigation ditches then made.

Germination occurs after about 8 days, and one month later irrigation takes place - perhaps 4 times until the end of the growing season in mid-end October. Irrigation appears to undergo a pause during weeding.

No pests or diseases were mentioned.

After harvest, the yield is left in the sunshine to dry and then threshed, with the straw later being separated from the seed by wind. 


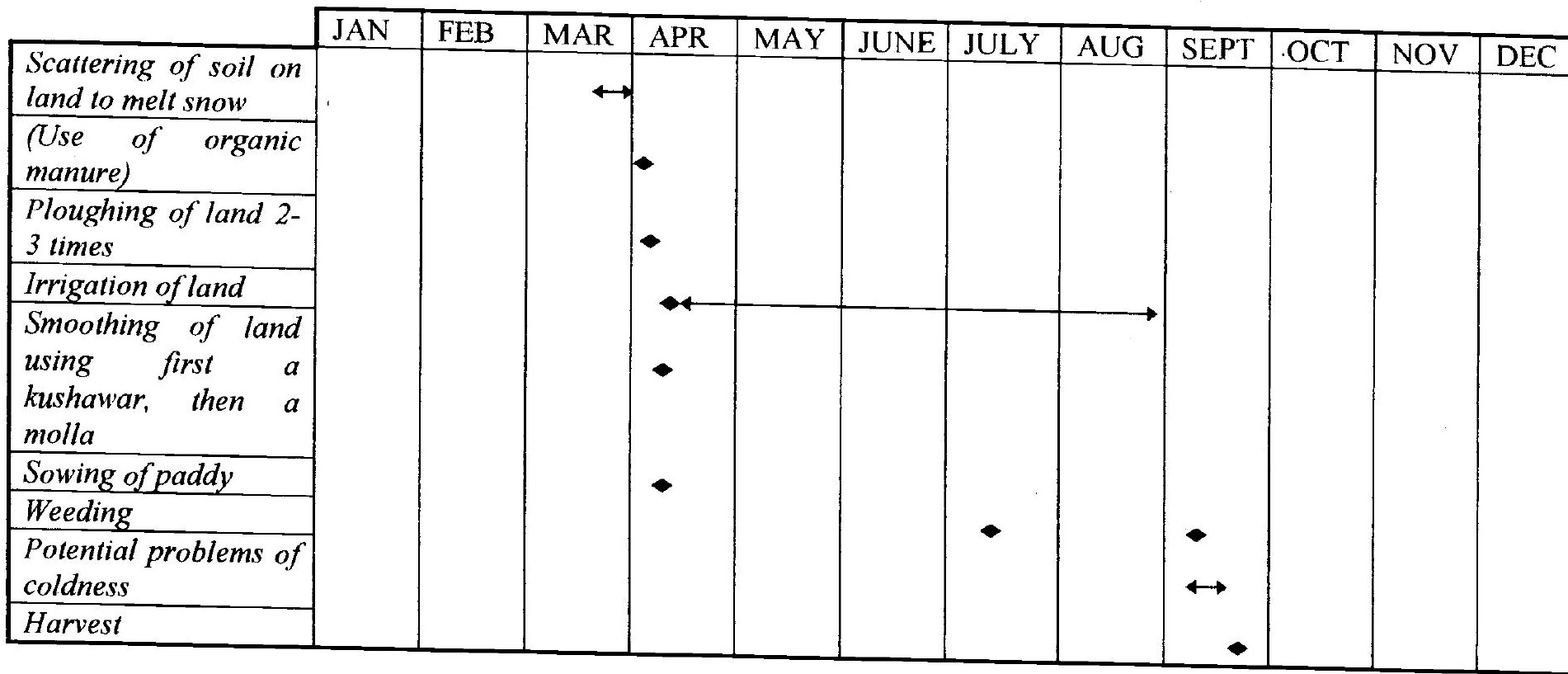

Rice tends to be planted on flat land near marshland, due to the need for water. If manure is used, approximately $700 \mathrm{~kg}$ will be used per jerib, or 0.2 hectares, in a ratio of soil:manure of 1:1 where the soil may include ashes and compost. However, some farmers avoid its use for fear of lodging (when the stem might become too long and thin to support the crop, and so collapse hindering growth). Chemical fertiliser does not appear to be used for the same reason.

Prior to sowing, the paddy is kept for 8 days in a sack in water, until germination has just begun, which takes about 1 week. The rice is then broadcast onto the irrigated land. This irrigation of the land is a constant process, which tends to be done towards the end of the day across the night until early morning so as to leave a water depth of around $20-25 \mathrm{~cm}$. This allows the water to become warm during the day (without drying up), and so facilitates the growth process. After some time, however, the water level may be reduced by around $10 \mathrm{~cm}$, with the intake being further reduced before harvest time in mid-September.

Sparrows and early coldness are the two main problems which affect rice, although the problem of sparrows is at least partially solved by constant irrigation.

After harvest (done by men only with the use of a sickle), the rice paddy is threshed and the paddy subsequently separated from the seed using a ding, a machine that rotates using water power. Before and after, wind may also be used. 


\section{Pea}

* Sowing Density: 6 sers per jerib, or $2.1 \mathrm{~kg}$ per are $(210 \mathrm{~kg}$ per hectare);

* Varieties: black and white (latter preferred due to size and taste);

* Rotation: 2-3 years with a cereal and/or another legume in Bamiyan Upper Valley and Nawor, although the likelihood in Nawor High Plateau is a 2 year rotation (due to relatively higher organic manure use);

* Neither organic manure nor chemical fertiliser are used since pea is itself nitrogen-fixing;

* Sown in the 4th week of May usually after prior irrigation of the land (followed by ploughing, smoothing and making of irrigation channels);

* Usually weeding is not done because the plant is thought to be too delicate (otherwise, this occurs in mid-June);

* Germination period: 10-15 days depending on the cold;

* Irrigation begins in the 1st/2nd week of June; 5 or 6 times during the growing season in Bamiyan Upper Valley and Nawor;

* Cutworm from June onwards and early cold and mice can cause problems;

* Harvest in 1st/2nd week September in Bamiyan Upper Valley - but perhaps 2-3 weeks later in Nawor High Plateau

\section{Lentil}

* Sowing density: 3 sers per jerib, or $1.05 \mathrm{~kg}$ per are (105 kg per hectare);

* green lentils are grown;

* sown in the 3rd or 4th week of April in Upper Bamiyan;

* neither organic manure nor chemical fertiliser are used due to the crop's own nitrogen-fixing properties;

* irrigation begins in mid-June and occurs 4 to 5 times in Upper Bamiyan during the growing season (every 15-20 days);

* germination occurs after 15-20 days at higher altitudes;

* weeding takes place once and may begin in the 3 rd week of June;

* early cold can affect the crop as from mid-July at higher altitudes;

* harvest begins in the $1 \mathrm{st} / 2$ nd week of September at higher altitudes

\section{Broad Bean}

* Sowing density: 7.5 sers per jerib, or $2.625 \mathrm{~kg}$ per are (262.5 $\mathrm{kg}$ per hectare);

* Varieties: safedak (white - preferred); siadak (black);

* Rotation: 2-3 years with a cereal and then potentially another intervening legume;

* No organic manure or chemical fertiliser used due to own nitrogen-fixing properties;

* Sown 2nd week April to 1st week of May (followed by ploughing, smoothing and making of irrigation channels);

* germination occurs 7-10 days later;

* 1st irrigation in 4th week May/1st week June; 7 to 12 times depending on the climate during the growing season;

* Weeding begins in June and continues until the 3rd week of August;

* Problems of cutworm and aphid may arise;

* Harvest begins 1 st/2nd week September 


\section{Vetch}

* Sowing density: 6 sers per jerib, or $2.1 \mathrm{~kg}$ per are (210 kg per hectare);

* Rotation: 2-3 years in Bamiyan Upper Valley with a cereal and possibly another legume, but more likely to be 2 years in Nawor High Plateau due to higher soil fertility due to higher use levels of organic manure;

* No organic manure or chemical fertiliser used due to nitrogen-fixing properties; * Sown last week of May usually after prior irrigation of land followed by ploughing, smoothing
and making of irrigation channels;

* Germination period of 10 days;

* In Malestan, irrigation may begin at the end of April taking place every 15 days (perhaps 6 to 7 times during the growing season); in Bamiyan Upper Valley irrigation begins 3rd week of June and occurs 5 to 6 times throughout the growing season until harvest;

* No weeding takes place;

* Potential problems of cutworm as from mid-July and early cold as from August;

* Harvest begins at the end of July/beginning August in Malestan but from the 3rd week of August to $\mathrm{mid} / \mathrm{end}$ September in Upper Bamiyan

\section{Clover}

* sowing density: $2.25 \mathrm{~kg}$ per jerib or $0.1125 \mathrm{~kg}$ per are (11.25 kg per hectare);

* 2 years rotation with a cereal;

* no organic manure or chemical fertiliser is used due to the nitrogen-fixing properties of the crop;

* sowing in Malestan occurs after the harvest of wheat around the beginning of September;

* germination takes around 4-7 days depending on the temperature;

* a first irrigation takes place after sowing, and then resumes after the winter period (once soil and ash have been scattered to help melt the snow), at the end of March/beginning of April, occurring at least 12 to 15 times during the growing season;

* no weeding takes place;

* in Malestan, the 1st cut occurs around the 1st week of May: 3 cuts may be possible until September

\section{Alfalfa}

* sowing density: $2.25 \mathrm{~kg}$ per jerib or $0.1125 \mathrm{~kg}$ per are (11.25 $\mathrm{kg}$ per hectare);

* rotation: with wheat and/or potato - but after 5-8 years depending;

* neither organic manure nor chemical fertiliser tend to be used due to the plant's own nitrogenfixing properties (although use of organic manure was found in Bamiyan Lower Valley);

* in Upper Bamiyan, sown in the 3rd week of April; in Jaghoori, sown after harvesting the previous crop in August or September, and then raked by hand or ploughed;

* germination occurs after 1 month in Lower Bamiyan Valley;

* 1st irrigation occurs immediately after sowing and continues in spring with around 10-12 irrigation during the growing season;

* no weeding takes place;

* 1st cut occurs mid-June in Jaghoori, with the 2nd cut around the 2nd week of July and the 3rd cut towards mid-October; in Upper Bamiyan the alfalfa is cut (only once) little by little according to needs as from the 3 rd week of July after which time (around the 1 st week of October) the livestock are left to graze on the land;

* lasts from 5-6 years at lower altitudes and 7-8 years at higher altitudes 


\section{Lathyrus}

* sowing density: 6 sers per jerib, or $2.1 \mathrm{~kg}$ perare $(210 \mathrm{~kg}$ per hectare);

* sown at the end of May in more humid areas where possible;

* no organic manure or chemical fertiliser is used due to the plant's own nitrogen-fixing properties;

* irrigated 6 times in Upper Bamiyan;

* harvest begins in the 1st week of September in Upper Bamiyan

\section{Spinach}

* a 2-year process;

* sowing density: $50 \mathrm{~g}$ for $2.5 \mathrm{~m}^{2}$;

* the land is manured and ploughed by hand before sowing;

* germination takes approximately 5 days;

* irrigation occurs 10 times;

* weeding begins in the 3 rd week of May

\section{Leak}

* sown in rows by hand at the end of March (3-4 seeds in a bond) and then covered with mud and manure;

* irrigation occurs perhaps 2 days afterwards and may take place up to 20 times in Bamiyan Lower Valley during the growing season;

* germination takes place after 15 days;

* harvest begins at the end of June and then again 2 weeks later;

* lasts for 2 years

\section{Onion}

* sowing density: $100 \mathrm{~g}$ for $20 \mathrm{~m}^{2}$;

* land is ploughed by hand using a shovel, smoothed and then irrigated in mid-April (organic manure may be used at this time);

* seeds are then broadcast;

* germination takes place after 15 days;

* irrigation occurs up to 16 times in Lower Bamiyan Valley (but slightly less at higher altitudes) until September but is reduced once the bulb starts to form;

* weeding takes place twice as from mid-June;

* no pests or diseases were cited;

* harvest begins as of end-July until end-September

\section{Radish}

* sown during the 1 st week of April;

* germination occurs after 6-7 days;

* weeding may then begin and organic fertiliser used;

* harvest begins in the $2 \mathrm{nd} / 3$ rd week of May in Lower Bamiyan? 


\section{Carrot}

* sowing density: $100 \mathrm{~g}$ for $10 \mathrm{~m}^{2}$;

* land ploughed using a shovel and organic manure added at the end of March/beginning of April in Lower Bamiyan (two weeks later in Upper Bamiyan);

* seeds broadcast in the 1st week of April and mixed with soil (2 weeks later in Upper Bamiyan);

* irrigation begins after sowing perhaps 20 times in Lower Bamiyan, perhaps 15 times in Upper Bamiyan, until harvest;

* germination takes place about 20 days later;

* weeding starts in the 1 st week of May;

* worms can be a potential problem as from the end of July;

* harvest begins in mid-September until mid-October

\section{Turnip}

* sowing density: $100 \mathrm{~g}$ for $3 \mathrm{~m}^{2}$;

* sown any time between the 1st and 3rd weeks of April - in areas where sun is likely to be less strong after hand-ploughing the land and smoothing;

* germination takes place after 5-15 days depending on the altitude and temperature;

* irrigation begins immediately after germination at the end of April occurring perhaps 10 times in cooler areas and 20 times where it is warmer during the growing season;

* weeding begins in the $1 \mathrm{st} / 2 \mathrm{nd}$ week of June;

* worms can be a problem as from the end of July at higher altitudes;

* harvest starts around mid-September at higher altitudes

\section{Cucumber}

* organic fertiliser may be used on the land in the 2nd week of April;

* the seeds will then be sown in the 3rd week of April;

* germination takes place approximately 3-4 weeks later;

* if chemical fertiliser is used it is done so at the beginning of June;

* irrigation takes place every 8 days, or 10 times during the season;

* weeding takes place 3 times;

* problems of cutworm may be manifest as from June;

* harvest begins towards the end of July until the 3rd week of September;

\section{Apple and Apricot}

* trees tend to be watered every 2 days (Malestan) or weekly (Bamiyan Lower Valley) as from the end of April until mid-October;

* for those who have access, organic manure and/or chemical fertiliser are used;

* potential worm problems exist as from the end of April/beginning of May - particularly in apricots;

* harvest for apricots begins around July/August and for apples around end-September/beginning October;

* in both instances, trees begin to produce after $5 / 6$ years of planting 


\section{Appendix II: Crop Yields}

\section{A. WHEAT YIELDS BY ZONE:}

Sowing Density: irrigated: 4-5 sers per jerib, or 1.4-1.75 kg per are

(across all zones)

rainfed: $\quad 2-3$ sers per jerib, or $0.7-1.05 \mathrm{~kg}$ per are

\section{Ajarestan: Winter Wheat}

Variety: garma;

2-year rotation with a legume (vetch, laterus or lentil, for instance)

\begin{tabular}{|l|c|c|c|c|c|c|}
\hline Land Type & $\begin{array}{c}\text { With No } \\
\text { Fertiliser }\end{array}$ & $\begin{array}{c}\text { With } \\
\text { Organic } \\
\text { Manure } \\
\text { Soil }\end{array}$ & $\begin{array}{c}\text { With Organic } \\
+ \text { Chemical } \\
\text { Fertiliser }\end{array}$ & $\begin{array}{c}\text { Good } \\
\text { Year }\end{array}$ & $\begin{array}{c}\text { Standard } \\
\text { Year }\end{array}$ & Bad Year \\
\hline Ajarestan & $\checkmark$ & & $350 \mathrm{~kg}$ & $245 \mathrm{~kg}$ & $35 \mathrm{~kg}$ \\
\hline $\begin{array}{l}\text { Irrigated, flat, } \\
\text { south-facing }\end{array}$ & & $\checkmark$ & $\checkmark$ & $280 \mathrm{~kg}$ & & \\
\hline $\begin{array}{l}\text { Irrigated, flat, } \\
\text { north-facing }\end{array}$ & & & & $\begin{array}{c}245- \\
262.5 \mathrm{~kg}\end{array}$ & & \\
\hline Irrigated & $\checkmark$ & & & &
\end{tabular}

\section{Bamiyan Lower Valley: Spring Wheat}

Soil Type: Sandy Loam

\begin{tabular}{|l|c|c|c|c|c|c|}
\hline Land Type & $\begin{array}{c}\text { Without } \\
\text { Organic } \\
\text { Manure }\end{array}$ & $\begin{array}{c}\text { With } \\
\text { Organic } \\
\text { Manure }+ \\
\text { Soil }\end{array}$ & $\begin{array}{c}\text { With Chemical } \\
\text { Fertiliser } \\
\text { Organic } \\
\text { Manure }\end{array}$ & $\begin{array}{c}\text { Good } \\
\text { Year }\end{array}$ & $\begin{array}{c}\text { Standard } \\
\text { Year }\end{array}$ & Bad Year \\
\hline $\begin{array}{l}\text { Irrigated, flat, } \\
\text { south-facing }\end{array}$ & & $\checkmark$ & & $840 \mathrm{~kg}$ & $590 \mathrm{~kg}$ & $350 \mathrm{~kg}$ \\
\hline $\begin{array}{l}\text { Irrigated, flat, } \\
\text { south-facing }\end{array}$ & & $\checkmark$ & & $560 \mathrm{~kg}$ & $350 \mathrm{~kg}$ & \\
\hline $\begin{array}{l}\text { Irrigated,fflat, } \\
\text { south-facing }\end{array}$ & $\checkmark$ & & & $280 \mathrm{~kg}$ & & \\
\hline $\begin{array}{l}\text { Irrigated, flat, } \\
\text { north-facing }\end{array}$ & $\checkmark$ & & & $210 \mathrm{~kg}$ & & \\
\hline
\end{tabular}




\section{Bamiyan Upper Valley: Spring Wheat}

* Irrigated varieties: wex (the preferred variety since seen as more productive in irrigated land and resistant against disease and pests), calhosha (reputed to have a longer growing period and less weeds), sufedcha (for rainfed), and watani safedak (a local variety with greater resistance to water shortages);

* Rainfed varieties: surkhosha, safedjosha

* Soil Type: Sandy Loam;

* 2-3 year rotation with barley and potato, or lentil, vetch and faba bean: 2 years cereal; 1 year
legume

\begin{tabular}{|c|c|c|c|c|c|c|}
\hline Land Type & $\begin{array}{c}\text { Without } \\
\text { Any } \\
\text { Fertiliser }\end{array}$ & $\begin{array}{c}\text { With } \\
\text { Organic } \\
\text { Manure }+ \\
\text { Soil } \\
\end{array}$ & $\begin{array}{c}\text { With Chemical } \\
\text { Fertiliser }+ \\
\text { Organic } \\
\text { Manure } \\
\end{array}$ & $\begin{array}{l}\text { Good } \\
\text { Year }\end{array}$ & $\begin{array}{c}\text { Standard } \\
\text { Year }\end{array}$ & Bad Year \\
\hline $\begin{array}{l}\text { Irrigated, flat, } \\
\text { south-facing }\end{array}$ & & & $r$ & $\begin{array}{c}560-700 \\
\mathrm{~kg} \\
\end{array}$ & $350 \mathrm{~kg}$ & $\begin{array}{c}175-210 \\
\mathrm{~kg}\end{array}$ \\
\hline $\begin{array}{l}\text { Irrigated, flat, } \\
\text { south-facing }\end{array}$ & & $\checkmark$ & & $350 \mathrm{~kg}$ & $210 \mathrm{~kg}$ & $\begin{array}{c}112-140 \\
\mathrm{~kg}\end{array}$ \\
\hline $\begin{array}{l}\text { Irrigated, flat, } \\
\text { north-facing }\end{array}$ & & $\checkmark$ & & $210 \mathrm{~kg}$ & $140 \mathrm{~kg}$ & $\begin{array}{c}70-105 \\
\mathrm{~kg} \\
\end{array}$ \\
\hline Rainfed, slope & $\checkmark$ & & & $105 \mathrm{~kg}$ & $60-65 \mathrm{~kg}$ & $1+-21 \mathrm{~kg}$ \\
\hline
\end{tabular}

Jaghoori: Winter Wheat

\begin{tabular}{|l|c|c|c|c|c|c|}
\hline Land Type & $\begin{array}{c}\text { Without } \\
\text { Any } \\
\text { Fertiliser }\end{array}$ & $\begin{array}{c}\text { With } \\
\text { Organic } \\
\text { Manure }\end{array}$ & $\begin{array}{c}\text { With Chemical } \\
\text { Fertiliser Only }\end{array}$ & $\begin{array}{c}\text { Good } \\
\text { Year }\end{array}$ & $\begin{array}{c}\text { Standard } \\
\text { Year }\end{array}$ & Bad Year \\
\hline Irrigated & & & $\checkmark$ & $\begin{array}{c}280-350 \\
\mathrm{~kg}\end{array}$ & $\begin{array}{c}245-280 \\
\mathrm{~kg}\end{array}$ & $\begin{array}{c}140-175 \\
\mathrm{~kg}\end{array}$ \\
\hline
\end{tabular}

Last 10 years: 3 years good, 7 years bad

\section{Malestan: Winter Wheat}

Soil Type: alluvial or sandy loam

Varieties: jaocosha, garma

Rotation: 2-3 years: onion, wheat, barley 


\begin{tabular}{|l|c|c|c|c|c|c|c|}
\hline \multicolumn{1}{|c|}{ Land Type } & $\begin{array}{c}\text { With No } \\
\text { Fertiliser }\end{array}$ & $\begin{array}{c}\text { With } \\
\text { Organic } \\
\text { Manure } \\
+ \text { Soil }\end{array}$ & $\begin{array}{c}\text { With } \\
\text { Chemical } \\
\text { Fertiliser } \\
\text { Only }\end{array}$ & $\begin{array}{c}\text { With } \\
\text { (.hemical } \\
\text { Fertiliser } \\
+ \\
\text { Organic } \\
\text { Manure }\end{array}$ & $\begin{array}{c}\text { Good } \\
\text { Vear }\end{array}$ & $\begin{array}{c}\text { Standard } \\
\text { Year }\end{array}$ & Bad Year \\
\hline $\begin{array}{l}\text { Irrigated, flat, } \\
\text { alluvial }\end{array}$ & & & & $\checkmark$ & $700 \mathrm{~kg}$ & $350 \mathrm{~kg}$ & $350 \mathrm{~kg}$ \\
\hline $\begin{array}{l}\text { Irrigated, flat, } \\
\text { alluvial }\end{array}$ & & & $\checkmark$ & & $560 \mathrm{~kg}$ & & \\
\hline $\begin{array}{l}\text { Irrigated, flat, } \\
\text { sandy loam }\end{array}$ & & & & $\checkmark$ & $525 \mathrm{~kg}$ & & \\
\hline Irrigated, flat & & $\checkmark$ & & & $385-420$ \\
$\mathrm{~kg}$ & $290 \mathrm{~kg}$ & \\
\hline Irrigated, flat & $\checkmark$ & & & & & & $140 \mathrm{~kg}$ \\
\hline
\end{tabular}

Nawor High Plateau: Spring Wheat

\begin{tabular}{|l|c|c|c|c|c|c|}
\hline Land Type & $\begin{array}{c}\text { Without } \\
\text { Any } \\
\text { Fertiliser }\end{array}$ & $\begin{array}{c}\text { With } \\
\text { Organic } \\
\text { Manure } \\
\text { Soil }\end{array}$ & $\begin{array}{c}\text { With Chemical } \\
\text { Fertiliser } \\
\text { Organic } \\
\text { Manure }\end{array}$ & $\begin{array}{c}\text { Good } \\
\text { Year }\end{array}$ & $\begin{array}{c}\text { Standard } \\
\text { Year }\end{array}$ & Bad Year \\
\hline Irrigated & $\checkmark$ & & $466 \mathrm{~kg}$ & $300 \mathrm{~kg}$ & $140 \mathrm{~kg}$ \\
\hline Rainfed & $\checkmark$ & & & $350 \mathrm{~kg}$ & $140 \mathrm{~kg}$ & $0-105 \mathrm{~kg}$ \\
\hline
\end{tabular}

Last 10 years: 2 years good; 3 years average; 5 years bad

\section{B. BARLEY YIELDS BY ZONE:}

Sowing Density: 4-5 sers per jerib, or 1.4-1.75 kg per are

Bamiyan Lower Valley:

\begin{tabular}{|l|c|c|c|c|c|}
\hline Land Type & $\begin{array}{c}\text { With } \\
\text { Organic } \\
\text { Manure }\end{array}$ & $\begin{array}{c}\text { With Chemical } \\
\text { Fertiliser }+ \\
\text { Organic Manure }\end{array}$ & Good Year & $\begin{array}{c}\text { Standard } \\
\text { Year }\end{array}$ & Bad Year \\
\hline Irrigated & & $\checkmark$ & $700 \mathrm{~kg}$ & $400 \mathrm{~kg}$ & $105-140 \mathrm{~kg}$ \\
\hline Rainfed & $\checkmark$ & & $350-420 \mathrm{~kg}$ & $280 \mathrm{~kg}$ & $175 \mathrm{~kg}$ \\
\hline
\end{tabular}




\section{Bamiyan Upper Valley:}

* Soil Type: Sandy Loam;

* Varieties: caljao (preferred), safedjao, miyajao;

* 2-3 year rotation with 2 years cereal and then a legume: pea/faba bean, for instance

\begin{tabular}{|l|c|c|c|c|c|c|}
\hline Land Type & $\begin{array}{l}\text { Without } \\
\text { Organic } \\
\text { Manure }\end{array}$ & $\begin{array}{c}\text { With } \\
\text { Organic } \\
\text { Manure }+ \\
\text { Soil }\end{array}$ & $\begin{array}{c}\text { With Chemical } \\
\text { Fertiliser }+ \\
\text { Organic } \\
\text { Manure }\end{array}$ & $\begin{array}{c}\text { Good } \\
\text { Year }\end{array}$ & $\begin{array}{c}\text { Standard } \\
\text { Year }\end{array}$ & Bad Year \\
\hline $\begin{array}{l}\text { Irrigated, flat, } \\
\text { south-facing }\end{array}$ & & $\checkmark$ & $\checkmark$ & $525 \mathrm{~kg}$ & $441 \mathrm{~kg}$ & $350 \mathrm{~kg}$ \\
\hline $\begin{array}{l}\text { Irrigated, flat, } \\
\text { south-facing }\end{array}$ & & $\checkmark$ & & $420 \mathrm{~kg}$ & $350 \mathrm{~kg}$ & $210 \mathrm{~kg}$ \\
\hline $\begin{array}{l}\text { Irrigated, } \\
\text { slope, north- } \\
\text { facing }\end{array}$ & & & & $210 \mathrm{~kg}$ & $126 \mathrm{~kg}$ & $35 \mathrm{~kg}$ \\
\hline
\end{tabular}

\section{Nawor High Plateau:}

* Variety: jaomuya;

* 2-3 year rotation with pea/vetch (1 year) and/or another cereal (wheat essentially)

\begin{tabular}{|l|c|c|c|c|}
\hline Land Type & $\begin{array}{c}\text { With Organic } \\
\text { Manure + Soil }\end{array}$ & Good Year & Standard Year & Bad Year \\
\hline Irrigated & $\checkmark$ & $525 \mathrm{~kg}$ & $335 \mathrm{~kg}$ & $0-150 \mathrm{~kg}$ \\
\hline
\end{tabular}

\section{RICE YIELDS IN AJARESTAN:}

Sowing Density: $0.135 \mathrm{~kg}$ per are

* thick rice;

* 3-4 years rotation: legume (such as laterus), cereal (winter wheat), rice - or legume twice depending on the quality of the soil

\begin{tabular}{|l|c|c|c|c|c|}
\hline Land Type & $\begin{array}{c}\text { With No } \\
\text { Fertiliser }\end{array}$ & $\begin{array}{c}\text { With Organic } \\
\text { Manure }\end{array}$ & Good Year & $\begin{array}{c}\text { Standard } \\
\text { Year }\end{array}$ & Bad Year \\
\hline Irrigated, flat & & $\checkmark$ & $\begin{array}{c}560 \mathrm{~kg} \text { paddy; } \\
420 \mathrm{~kg} \text { rice }\end{array}$ & $402 \mathrm{~kg}$ paddy & $\begin{array}{c}210-280 \mathrm{~kg} \\
\text { paddy }\end{array}$ \\
\hline Irrigated, flat & $\checkmark$ & & $\begin{array}{c}420 \mathrm{~kg} \text { paddy; } \\
300 \mathrm{~kg} \text { rice }\end{array}$ & & \\
\hline
\end{tabular}




\section{MAIZE YIELDS IN AJARESTAN:}

* 5 years rotation: wheat, watermelon, clover, wheat then maize

\begin{tabular}{|l|c|c|c|c|}
\hline Land Type & $\begin{array}{c}\text { High Amount } \\
\text { of Organic } \\
\text { Manure }\end{array}$ & Good Year & Standard Year & Bad Year \\
\hline Irrigated, flat & $\checkmark$ & $7 \mathrm{~kg}=490-560 \mathrm{~kg}$ & & $7 \mathrm{~kg}=350-420 \mathrm{~kg}$ \\
\hline
\end{tabular}

Last 10 years: 6 years bad; 4 years good

\section{E. LEGUME YIELDS:}

\section{Broad Bean Yields:}

\begin{tabular}{|l|c|c|c|}
\hline Land Type & Good Year & Standard Year & Bad Year \\
\hline Bamiyan Lower Valley & & $280 \mathrm{~kg}$ & \\
\hline Bamiyan Upper Valley & & & \\
-irrigated, south-facing & $280-350 \mathrm{~kg}$ & $210-245 \mathrm{~kg}$ & $140-175 \mathrm{~kg}$ \\
-irrigated, north facing & $210-245 \mathrm{~kg}$ & $140 \mathrm{~kg}$ & \\
\hline
\end{tabular}

\section{Lentil Yields:}

Sowing Density: $2.4-3$ sers per jerib, or 0.8-1.05 kg per are

\begin{tabular}{|l|c|c|c|}
\hline Land Type & Good Year & Standard Year & Bad Year \\
\hline Jaghoori & $218 \mathrm{~kg}$ & $160 \mathrm{~kg}$ & $102 \mathrm{~kg}$ \\
\hline Bamiyan Upper Valley & & & \\
-irrigated, south-facing & $420 \mathrm{~kg}$ & $350 \mathrm{~kg}$ & $315 \mathrm{~kg}$ \\
-irrigated, north facing & $280 \mathrm{~kg}$ & $168 \mathrm{~kg}$ & $112-140 \mathrm{~kg}$ \\
\hline
\end{tabular}

\section{Pea Yields:}

Sowing Density: 6 sers per jerib, or $2.1 \mathrm{~kg}$ per are

\begin{tabular}{|l|c|c|c|}
\hline Land Type & Good Year & Standard Year & Bad Year \\
\hline Nawor High Plateau & $168 \mathrm{~kg}$ & $110 \mathrm{~kg}$ & $52.5 \mathrm{~kg}$ \\
\hline Bamiyan Upper Valley & & & \\
-irrigated, flat, south-facing & $350 \mathrm{~kg}$ & $245 \mathrm{~kg}$ & $140 \mathrm{~kg}$ \\
-irrigated, slope, north facing & $105 \mathrm{~kg}$ & $70 \mathrm{~kg}$ & $35 \mathrm{~kg}$ \\
\hline
\end{tabular}

1997: standard year for Bamiyan 
Vetch Yields:

Sowing Density: 2.5 or 7 sers per jerib, or $0.875 \mathrm{~kg}$ per are.

\begin{tabular}{|l|c|c|c|}
\hline Land Type & Good Year & Standard Year & Bad Year \\
\hline Malestan & $25 \mathrm{~kg}$ & & $12.5 \mathrm{~kg}$ \\
\hline Bamiyan Upper Valley & & $175 \mathrm{~kg}$ & $105 \mathrm{~kg}$ \\
\hline
\end{tabular}

Lathyrus Yields:

\begin{tabular}{|l|c|c|c|}
\hline Land Type & Good Year & Standard Year & Bad Year \\
\hline Ajarestan & $115.5 \mathrm{~kg}$ & & \\
\hline Bamiyan Upper Valley & & $70 \mathrm{~kg}$ & \\
\hline
\end{tabular}

\section{F. TUBER YIELDS:}

Planting Density: 50 sers per jerib, or $17.5 \mathrm{~kg}$ per are

\section{Bamiyan Lower Valley:}

* 2-3 year rotation with wheat/barley then a legume;

* varieties: subzgul (green flower - preferred), beghul (without flower: also preferred: keeps longer due to a harder skin), chundromukly (yellow core), kufriluker (white core) - last two varieties are of Indian origin

\begin{tabular}{|l|c|c|c|c|c|c|}
\hline Land Type & $\begin{array}{c}\text { With No } \\
\text { Fertiliser }\end{array}$ & $\begin{array}{c}\text { With } \\
\text { Chemical } \\
\text { Fertiliser } \\
\text { Only }\end{array}$ & $\begin{array}{c}\text { With Organic } \\
\text { manure } \\
\text { Chemical } \\
\text { Fertiliser }\end{array}$ & $\begin{array}{c}\text { Good } \\
\text { Year }\end{array}$ & $\begin{array}{c}\text { Standard } \\
\text { Year }\end{array}$ & Bad Year \\
\hline Irrigated, flat & & $\checkmark$ & $5,600 \mathrm{~kg}$ & $4,900 \mathrm{~kg}$ & $2,100 \mathrm{~kg}$ \\
\hline Irrigated, flat & & $\checkmark$ & & & $4,083 \mathrm{~kg}$ & \\
\hline Irrigated, flat & & $\checkmark$ & & $2,100 \mathrm{~kg}$ & & \\
\hline
\end{tabular}

1997: a very good harvest

\section{Bamiyan Upper Valley:}

* 2-3 year rotation with wheat/barley then a legume;

* varieties: subzgul (green flower - preferred), beghul (without flower: also preferred: keeps longer due to a harder skin), chundromukly (yellow core), kufriluker (white core) - last two varieties are of Indian origin 


\begin{tabular}{|l|c|c|c|c|c|c|}
\hline Land Type & $\begin{array}{c}\text { Without } \\
\text { Any } \\
\text { Fertiliser }\end{array}$ & $\begin{array}{c}\text { With } \\
\text { Organic } \\
\text { Manure } \\
\text { Soil }\end{array}$ & $\begin{array}{c}\text { With Chemical } \\
\text { Iertiliser } \\
\text { Organic } \\
\text { Manure }\end{array}$ & $\begin{array}{c}\text { Good } \\
\text { Year }\end{array}$ & $\begin{array}{c}\text { Standard } \\
\text { Year }\end{array}$ & Bad Year \\
\hline $\begin{array}{l}\text { Irrigated, flat, } \\
\text { south-facing }\end{array}$ & & $\checkmark$ & & $4,900 \mathrm{~kg}$ & $3,500 \mathrm{~kg}$ & $\begin{array}{c}1,680- \\
2,100 \mathrm{~kg}\end{array}$ \\
\hline $\begin{array}{l}\text { Irrigated, flat, } \\
\text { south-facing }\end{array}$ & & $\checkmark$ & & $2,800 \mathrm{~kg}$ & & \\
\hline $\begin{array}{l}\text { Irrigated, flat, } \\
\text { south-facing }\end{array}$ & $\checkmark$ & & & $1,750 \mathrm{~kg}$ & $1,400 \mathrm{~kg}$ & $\begin{array}{c}700-840 \\
\mathrm{~kg}\end{array}$ \\
\hline $\begin{array}{l}\text { Irrigated, flat, } \\
\text { north-facing }\end{array}$ & & $\checkmark$ & & $1,400 \mathrm{~kg}$ & & \\
\hline
\end{tabular}

Jaghoori, Malestan and Nawor High Plateau:

\begin{tabular}{|l|c|c|c|c|c|}
\hline Land Type & $\begin{array}{c}\text { With } \\
\text { Organic } \\
\text { Manure }\end{array}$ & $\begin{array}{c}\text { With Chemical } \\
\text { Fertiliser - No } \\
\text { Organic Manure }\end{array}$ & $\begin{array}{c}\text { Good } \\
\text { Year }\end{array}$ & $\begin{array}{c}\text { Standard } \\
\text { Year }\end{array}$ & Bad Year \\
\hline $\begin{array}{l}\text { Jaghoori } \\
\text { Irrigated }\end{array}$ & $\checkmark$ & $3,500 \mathrm{~kg}$ & $2,600 \mathrm{~kg}$ & $1,750 \mathrm{~kg}$ \\
\hline $\begin{array}{l}\text { Malestan (green flower } \\
\text { Subzgul } \\
\text { variety preferred); Irrigated }\end{array}$ & $\checkmark$ & & $3,500 \mathrm{~kg}$ & $2,900 \mathrm{~kg}$ & $2,100 \mathrm{~kg}$ \\
\hline $\begin{array}{l}\text { Nawor flower } \\
\text { Safedgul (white frrigated } \\
\text { varietypreferred); Irrieg }\end{array}$ & $\checkmark$ & & $2,917 \mathrm{~kg}$ & $2,042 \mathrm{~kg}$ & $1,167 \mathrm{~kg}$ \\
\hline
\end{tabular}

\section{G. CARROT YIELDS:}

Sowing Density: $100 \mathrm{~g}$ per $10 \mathrm{~m}^{2}$

\begin{tabular}{|l|c|c|c|}
\hline Land Type & Good Year & Standard Year & Bad Year \\
\hline Bamiyan Upper Valley & $70 \mathrm{~kg}$ & $60 \mathrm{~kg}$ & $49 \mathrm{~kg}$ \\
\hline
\end{tabular}

\section{H. ONION YIELDS:}

\section{Bamiyan Lower Valley:}

$20 \mathrm{~m}^{2}$ leads to $140 \mathrm{~kg}$ as good; $84 \mathrm{~kg}$ as bad

$3 \mathrm{~m}^{2}$ leads to $7 \mathrm{~kg}$

$90 \mathrm{~m}^{2}$ leads to $70 \mathrm{~kg}$ as good if chemical fertiliser is used; $14 \mathrm{~kg}$ bad 


\section{TURNIP YIELDS:}

Sewing Density: $100 \mathrm{~g}$ per $30 \mathrm{~m}^{2}$

\begin{tabular}{|l|c|c|c|}
\hline Land Type & Good Year & Standard Year & Bad Year \\
\hline Bamiyan Lower Valley & $280 \mathrm{~kg}$ & & \\
\hline Bamiyan Upper Valley & $140 \mathrm{~kg}$ & & \\
\hline
\end{tabular}

\section{J. FRUIT YIELDS:}

Apple Yields:

\begin{tabular}{|l|c|c|c|}
\cline { 2 - 4 } \multicolumn{1}{c|}{} & Good Year & Standard Year & Bad Year \\
\hline Ajarestan & $42 \mathrm{~kg}$ & & \\
\hline Jaghoori & $20 \mathrm{~kg}$ & & $0 \mathrm{~kg}$ \\
\hline Bamiyan Lower Valley & & $35 \mathrm{~kg}$ & \\
\hline Bamiyan Upper Valley & $35 \mathrm{~kg}$ & $28 \mathrm{~kg}$ & \\
\hline
\end{tabular}

Apricot Yields:

\begin{tabular}{|l|c|c|c|}
\cline { 2 - 4 } \multicolumn{1}{c|}{} & Good Year & Standard Year & Bad Year \\
\hline Jaghoori & $21 \mathrm{~kg}$ & $17 \mathrm{~kg}$ & $14 \mathrm{~kg}$ \\
\hline Bamiyan Lower Valley & $21 \mathrm{~kg}$ & & \\
\hline
\end{tabular}

Mulberry, Almond and Sour Cherry in Jaghoori:

\begin{tabular}{|l|c|c|c|}
\cline { 2 - 4 } \multicolumn{1}{c|}{} & Good Year & Standard Year & Bad Year \\
\hline Jaghoori & & & \\
Mulberry & $11-12 \mathrm{~kg}$ & $7-8 \mathrm{~kg}$ & \\
Almond & $7 \mathrm{~kg}$ & $2.5 \mathrm{~kg}$ & $0.4 \mathrm{~kg}$ \\
Sour Cherry & $14-21 \mathrm{~kg}$ & & \\
\hline
\end{tabular}




\section{Appendix III: External Interventions in Agriculture}

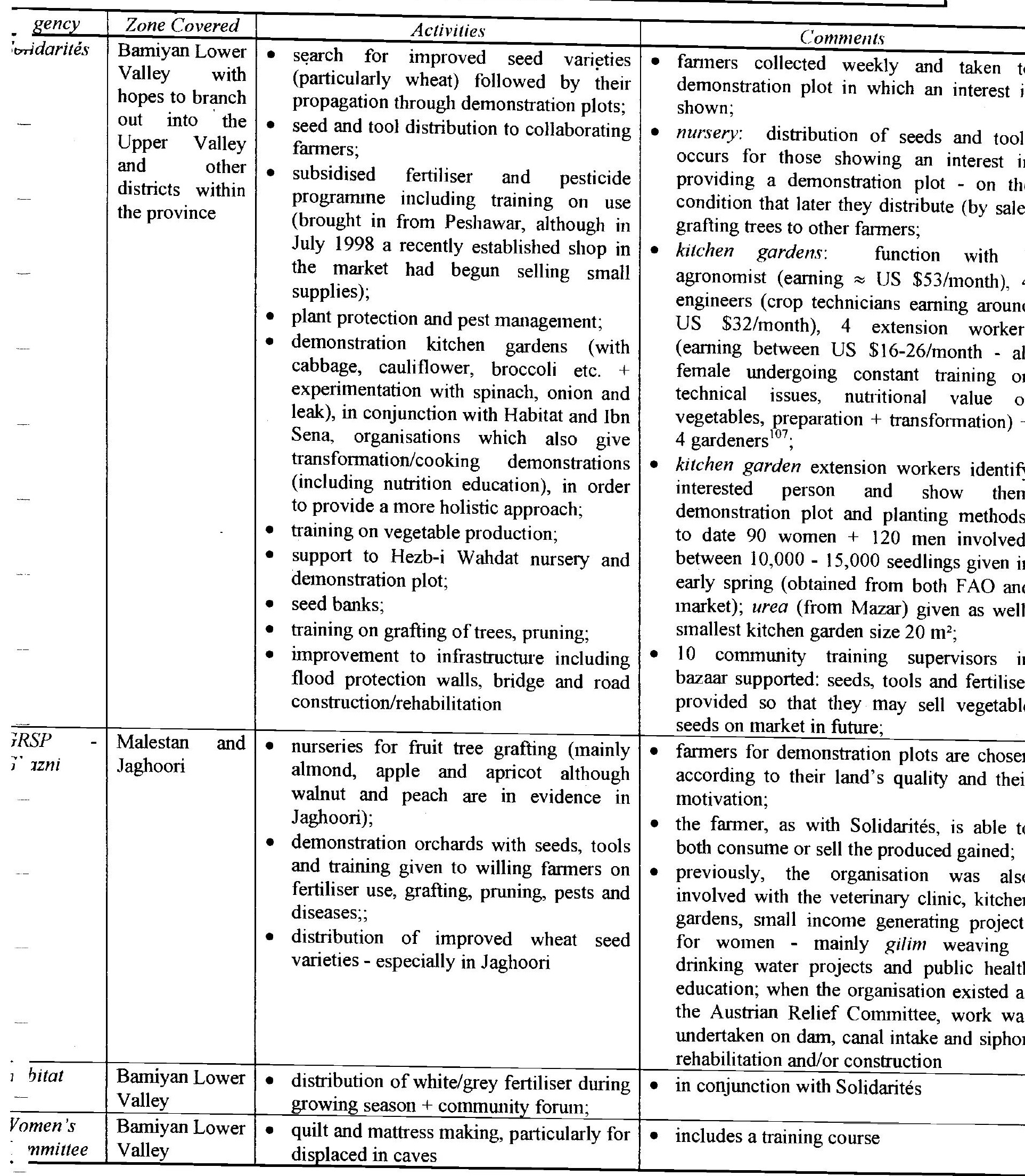

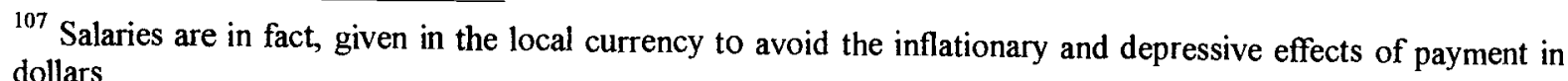


It might be noted that the Ministry of Agriculture in Kabul traditionally consisted of two deputy ministers for agriculture (for which there was a research institute, a planning section, plant protection, fertiliser and improved seed section - particularly wheat, barley and cotton - and central gene bank, among others), and for animal husbandry (responsible for forests, pastures, veterinary services and planning). The impact in most of the Hazarajat, however, is believed to have been minimal. Today, a limited among of research is carried out on improved cereals, however, most of the staff have left due to lack of payment - and may be found working for NGOs
or abroad.

External Food Distributions to Compensate for Agricultural Inadequacy

\begin{tabular}{|c|c|c|c|}
\hline Organisation & $\begin{array}{c}\text { Zone } \\
\text { Covered } \\
\end{array}$ & Activities & Comments \\
\hline ICRC & $\begin{array}{l}\text { Bamiyan } \\
\text { Lower and } \\
\text { Upper } \\
\text { Valleys } \\
\text { (particularly } \\
\text { the caves) } \\
\end{array}$ & $\begin{array}{l}\text { food distributions } \\
\text { including wheat and } \\
\text { ghee on the basis of } \\
\text { ration cards }\end{array}$ & 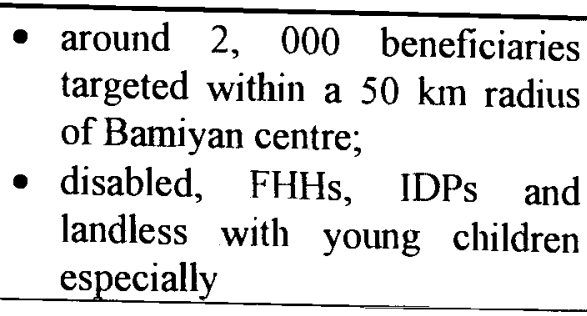 \\
\hline$W F P$ & $\begin{array}{l}\text { Hazarajat in } \\
\text { general }\end{array}$ & $\begin{array}{l}\text { - distribution of potatoes } \\
\text { in Bamiyan purchased } \\
\text { in surplus areas; } \\
\text { - distribution of wheat in } \\
\text { Nawor, Malestan and } \\
\text { Jaghoori - much of } \\
\text { which came from } \\
\text { existing stocks in } \\
\text { Termez, Uzbekistan } \\
\text { needing utilisation }\end{array}$ & $\begin{array}{l}\text { potatoes (while injecting cash } \\
\text { into economy), badly targeted, } \\
\text { with many going to those } \\
\text { already having surplus stocks; } \\
\text { - out of } 1,000 \text { kilos of wheat } \\
\text { brought from Ghazni, } 200 \text { given } \\
\text { to Talêban for right of passage; } \\
\text { however, better targeted than } \\
\text { potatoes }\end{array}$ \\
\hline
\end{tabular}




\section{Appendix IV: Agricultural Tools}

\begin{tabular}{|c|c|c|c|}
\hline Tool & Brief Description and Use & Cost \$ US & Comments \\
\hline Bale (shovel)* & $\begin{array}{l}\text { for ploughing land (particularly when no oxen } \\
\text { available), spreading manure, making farrows, } \\
\text { cleaning irrigation network and kareze }\end{array}$ & $\begin{array}{l}2.68-4.03 \\
\text { - made in } \\
\text { China } \\
\end{array}$ & $\begin{array}{l}\text { may last } \\
\text { from } 1-2 \\
\text { years } \\
\end{array}$ \\
\hline $\begin{array}{l}\text { Chorshar/Panchor } \\
\text { (fork)* }\end{array}$ & $\begin{array}{l}\text { chorshars (metal) are four-pronged, and } \\
\text { panchors (wood) five-pronged; used for } \\
\text { threshing and separating seed from straw with } \\
\text { the help of the wind }\end{array}$ & 6.71 & $\begin{array}{l}\text { may last } 2- \\
3 \text { years }\end{array}$ \\
\hline Kalan* & $\begin{array}{l}2 \text { types: single and double-sided; to help } \\
\text { smooth/level land after ploughing }\end{array}$ & $4.03-6.71$ & $\begin{array}{l}\text { may last } 2- \\
3 \text { years }\end{array}$ \\
\hline Dos (sickle)* & $\begin{array}{l}\text { for cutting grasses in mountains and } \\
\text { pastureland; for reaping harvest; men and } \\
\text { women use }\end{array}$ & $1.11-2.68$ & $\begin{array}{l}\text { may last } 2- \\
3 \text { years }\end{array}$ \\
\hline Pickaxe* & to clean and make repairs to irrigation system & $\begin{array}{l}2.68-4.01 \\
\text { - in the } \\
\text { south: from } \\
\text { Pakistan } \\
\end{array}$ & $\begin{array}{c}\text { may last } 4- \\
5 \text { years }\end{array}$ \\
\hline Hushkash (rake)* & $\begin{array}{l}\text { to mix the soil with seed after sewing - of } \\
\text { alfalfa in Jaghoori, for instance }\end{array}$ & & \\
\hline Sartor* & for cutting alfalfa & & $\begin{array}{c}\text { may last } 8- \\
10 \text { years }\end{array}$ \\
\hline Wheelbarrow & $\begin{array}{l}\text { for transferring soil, manure, turf (for those } \\
\text { without donkeys in particular) }\end{array}$ & & \\
\hline Jabal & made from iron; to remove stones from soil & 13.4 & \\
\hline $\begin{array}{l}\text { Chagall } \\
\text { /Hogbez (sieves) }\end{array}$ & $\begin{array}{l}\text { hogbez is made from cow/sheep skin, chagall } \\
\text { from metal; to remove chaff and to separate } \\
\text { good seeds from bad; women and men use }\end{array}$ & $\begin{array}{l}2.68 \text { hogbez } \\
6.71 \text { chagall }\end{array}$ & \\
\hline Hatkhash* (ruler) & to make irrigation ditches and channels & 0.27 & $\begin{array}{c}\text { may last } 2- \\
3 \text { years }\end{array}$ \\
\hline Chapa & $\begin{array}{l}\text { made from thorny bushes; to thresh wheat } \\
\text { (with } 2 \text { oxen); barley (with 4) }\end{array}$ & & \\
\hline Kushawar & $\begin{array}{l}\text { made from wood and tied to oxen; to smooth } \\
\text { land for rice after ploughing and irrigation }\end{array}$ & & $\begin{array}{l}\text { found in } \\
\text { Ajarestan } \\
\text { only }\end{array}$ \\
\hline Ding & $\begin{array}{l}\text { made essentially from wood; used to separate } \\
\text { rice from paddy through a rotation system } \\
\text { propelled by water }\end{array}$ & & $\begin{array}{l}\text { found in } \\
\text { Ajarestan } \\
\text { only }\end{array}$ \\
\hline Molla* & $\begin{array}{l}\text { to level land after ploughing; pulled by } 2 \text { oxen, } \\
\text { with } 1 / 2 \text { men }\end{array}$ & & \\
\hline Kunda & $\begin{array}{l}\text { made from wood; to make farrows for } \\
\text { potatoes, tomatoes }\end{array}$ & $\begin{array}{c}14.09 \text { or } \\
7.38 * *\end{array}$ & $\begin{array}{l}\text { may last 6- } \\
10 \text { years }\end{array}$ \\
\hline $\begin{array}{l}\text { Surgma* (plough }+ \\
\text { yoke) }\end{array}$ & $\begin{array}{l}\text { ploughing of land by tying to } 2 \text { oxen with } 1 / 2 \\
\text { men }\end{array}$ & 2.20 & $\begin{array}{l}\text { may last for } \\
5 \text { years }\end{array}$ \\
\hline
\end{tabular}

Exchange Rates used for July/August 1998

* See Diagram

** If wood is given to carpenter 


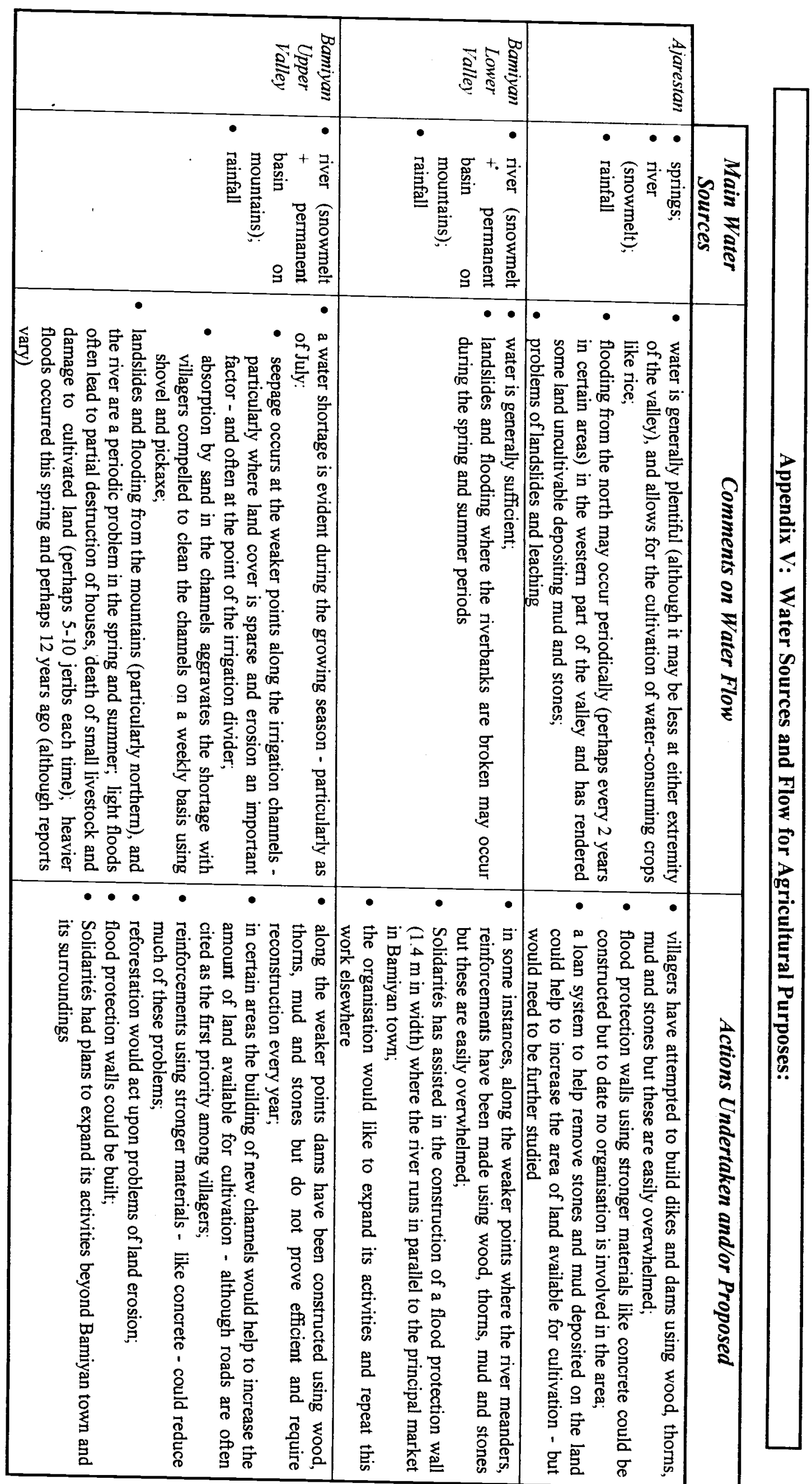




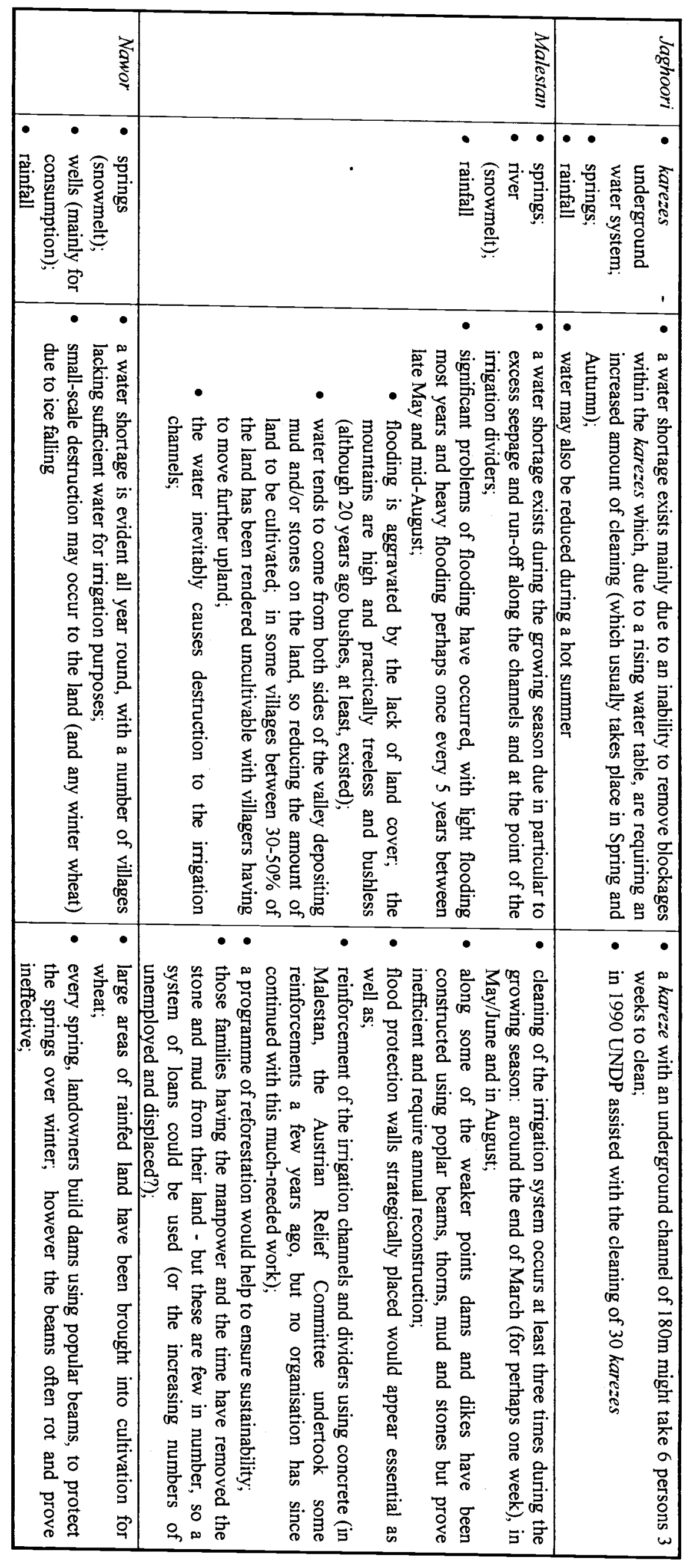




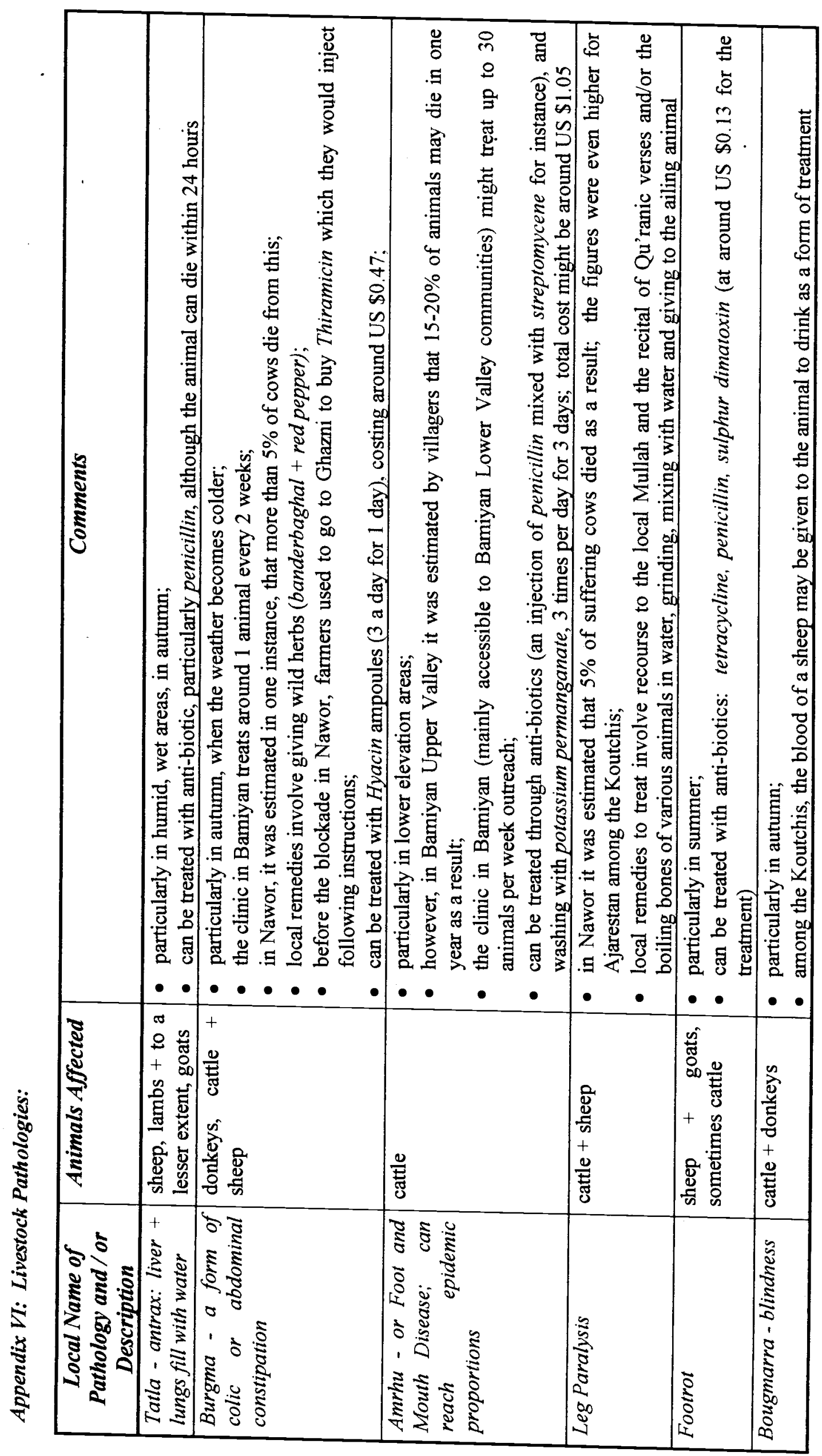




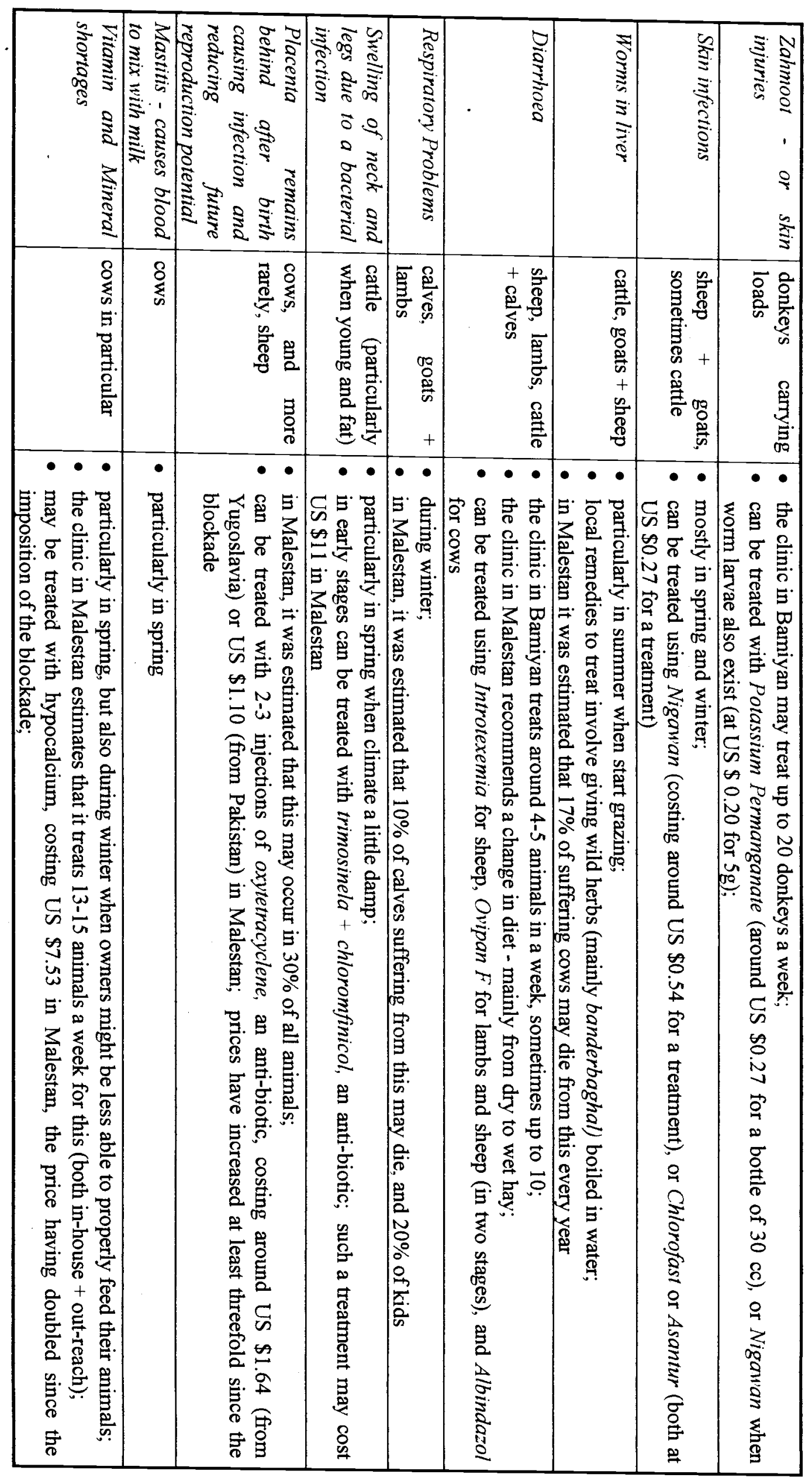




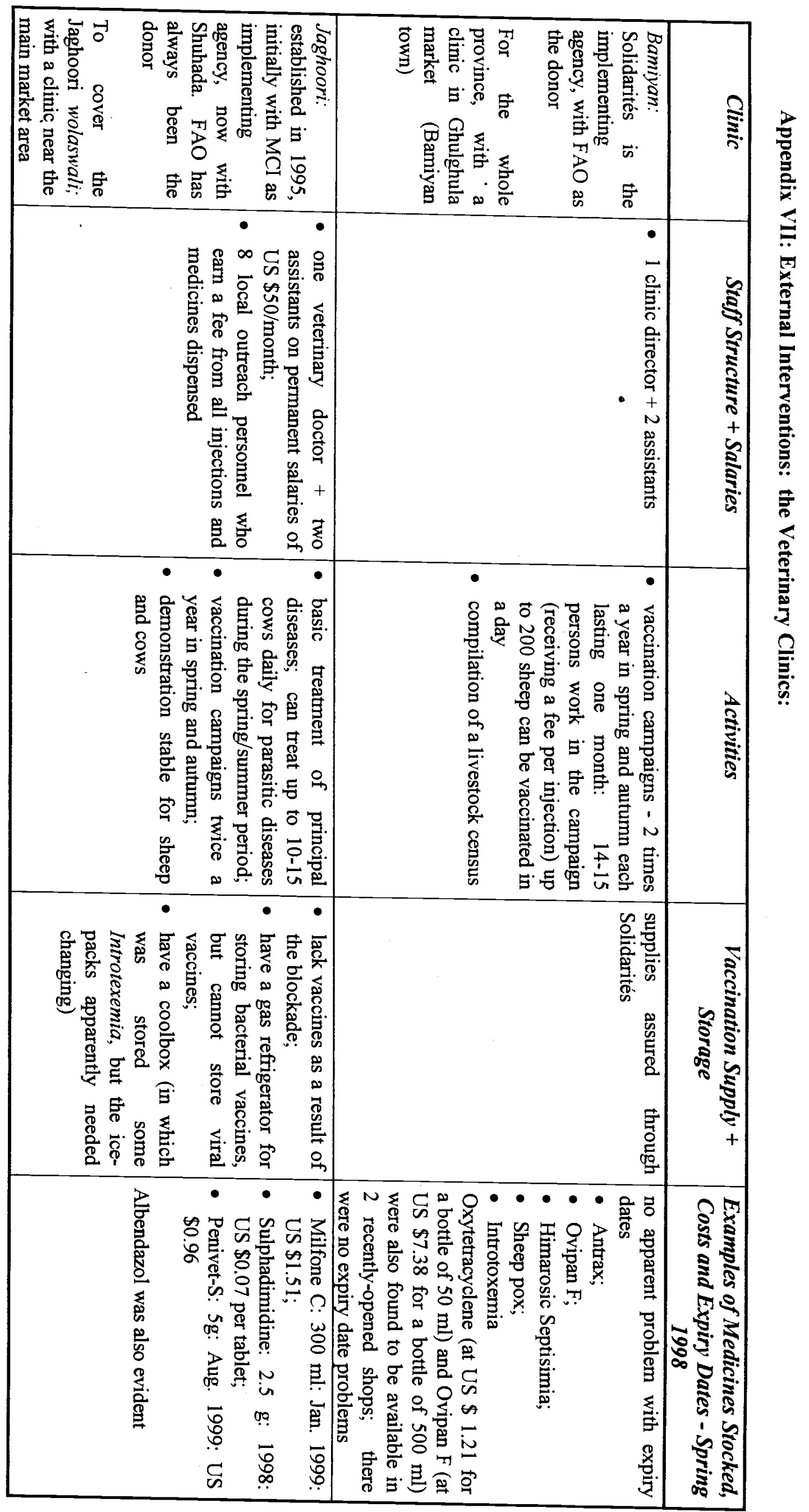




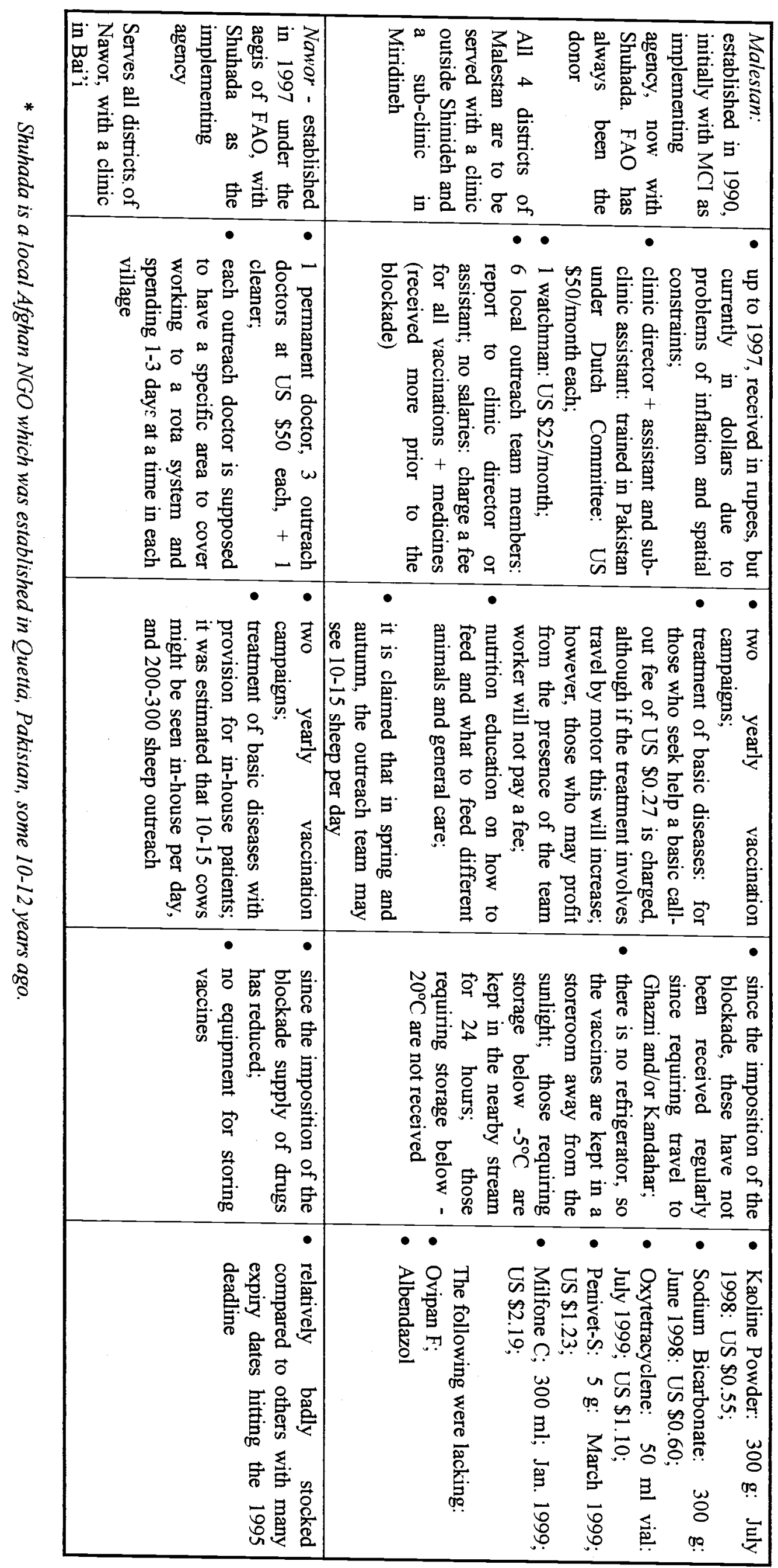




\begin{tabular}{|c|c|c|}
\hline \multicolumn{3}{|l|}{ Ajarestan: } \\
\hline . & Yield/Animal & \\
\hline Cows & $2-3$ litres/day & milked 3 times a day for 6 months (afterwards, may \\
\hline $\begin{array}{l}\text { Goats and Sheep } \\
\text { - milk } \\
\text { - wool }\end{array}$ & $\begin{array}{l}0.5 \text { litres/day } \\
0.5 \mathrm{~kg}\end{array}$ & $\begin{array}{l}\text { milked } 3 \text { times a day for } 2-3 \text { months } \\
\text { sheared once only - in late spring/early summer }\end{array}$ \\
\hline Camels & 3-4 litres/day & milked $2 / 3$ times a day for $5-6$ months \\
\hline Chickens & 5 eggs/week & for 6 months of year (spring + autumn) \\
\hline
\end{tabular}

\section{Bamiyan Lower Valley:}

\begin{tabular}{|l|l|l|}
\cline { 2 - 3 } \multicolumn{1}{c|}{} & \multicolumn{1}{c|}{ Yield/Animal } & \multicolumn{1}{c|}{ Comments } \\
\hline Cows & milk & \\
- meat & 1 litre/day & for $8-9$ months \\
\hline Goats and Sheep & $98-126 \mathrm{~kg}$ & for a cow of $8-10$ years \\
- milk & & \\
- wool & 0.5 litres/day & for $2-3$ months \\
\hline Chickens & $0.5-1.0 \mathrm{~kg}$ & sheared end of May \\
\hline
\end{tabular}

Bamiyan Upper Valley:

\begin{tabular}{|l|l|l|}
\cline { 2 - 3 } \multicolumn{1}{c|}{} & \multicolumn{1}{c|}{ Yield } & \multicolumn{1}{c|}{ Comments } \\
\hline Cows & 3 litres/day & $\begin{array}{l}\text { milked 3 times a day for around 4-5 months - assuming } \\
\text { survival of calf }\end{array}$ \\
\hline $\begin{array}{l}\text { Goats and Sheep } \\
\text { - milk }\end{array}$ & $\begin{array}{l}\text { wool } \\
\text { Chickens }\end{array}$ & $\begin{array}{l}\text { milked 3 times a day for 2-3 months } \\
\text { usually sheared twice a year }\end{array}$ \\
\hline
\end{tabular}

Jaghoori:

\begin{tabular}{|l|l|l|}
\cline { 2 - 3 } \multicolumn{1}{c|}{} & \multicolumn{1}{c|}{ Yield } & \multicolumn{1}{c|}{ Comments } \\
\hline Cows & 6 litres/day & $\begin{array}{l}\text { for } 7 \text { months (although a diminished amount might } \\
\text { follow for a few months) }\end{array}$ \\
\hline $\begin{array}{l}\text { Goats and Sheep } \\
- \text { milk } \\
- \text { wool }\end{array}$ & $\begin{array}{l}0.5-1.5 \text { litres/day } \\
0.5-1.0 \mathrm{~kg} / \text { time }\end{array}$ & $\begin{array}{l}\text { milked 3 times a day for 3 months } \\
\text { sheared twice a year (larger amounts for adults) }\end{array}$ \\
\hline Chickens & 4 eggs/week & for a period of 6 months in total \\
\hline
\end{tabular}


Malestan:

\begin{tabular}{|c|c|c|}
\hline & Yield & Comments \\
\hline $\begin{array}{l}\text { Cows } \\
\text { - milk } \\
\text { - meat } \\
\end{array}$ & $\begin{array}{l}1.5 \text { litres/day } \\
56-84 \mathrm{~kg}\end{array}$ & $\begin{array}{l}\text { milked } 3 \text { times a day for } 6-7 \text { months } \\
\text { for a cow of } 10-12 \text { years }\end{array}$ \\
\hline $\begin{array}{l}\text { Goats and Sheep } \\
\text { - milk } \\
\text { - wool }\end{array}$ & $\begin{array}{l}0.5 \text { litres/day } \\
0.5-1 \mathrm{~kg}\end{array}$ & milked 3 times for 3 months \\
\hline Chickens & $4-5$ eggs/week & $\begin{array}{l}\text { over a period of } 6 \text { months/year (spring }+ \text { autumn, } \\
\text { although may witness a reduced amount in summer) }\end{array}$ \\
\hline
\end{tabular}

\section{Nawor High Plateau:}

\begin{tabular}{|l|l|l|}
\cline { 2 - 3 } \multicolumn{1}{c|}{} & \multicolumn{1}{c|}{ Yield } & \multicolumn{1}{c|}{ Comments } \\
\hline Cows & 2 litres/day & milked 3 times a day for 6 months \\
\hline $\begin{array}{l}\text { Goats and Sheep } \\
- \text { milk } \\
- \text { wool }\end{array}$ & 1.5 litres/day & milked 2 times a day for 3 months \\
\hline
\end{tabular}

